\author{
UNIVERSIDADE DE SÃO PAULO - USP \\ INSTITUTO DE ENERGIA E AMBIENTE - IEE \\ PROGRAMA DE PÓS-GRADUAÇÃO EM ENERGIA - PPGE
}

Kauê José Felipe Novaes Cândido de Souza

Implementação de Infraestrutura Laboratorial para Análise Operacional e Capacitação em Sistemas Híbridos para Geração de Eletricidade 

Kauê José Felipe Novaes Cândido de Souza

\title{
Implementação de Infraestrutura Laboratorial para Análise Operacional e Capacitação em Sistemas Híbridos para Geração de Eletricidade
}

\begin{abstract}
Dissertação de mestrado apresentada ao Programa de Pós-Graduação em Energia do Instituto de Energia e Ambiente da Universidade de São Paulo para a obtenção do título de Mestre em Ciências.
\end{abstract}

Orientador: Prof. Dr.-Ing. João Tavares Pinho

\section{Versão Corrigida}

(Versão original disponível na Biblioteca do Instituto de Energia e Ambiente e na Biblioteca Digital de Teses e Dissertações da USP) 
AUTORIZO A DIVULGAÇÃO TOTAL OU PARCIAL DESTE TRABALHO, POR QUALQUER MEIO CONVENCIONAL OU ELETRÔNICO, PARA FINS DE ESTUDO E PESQUISA, DESDE QUE CITADA A FONTE.

FICHA CATALOGRÁFICA

Novaes, Kauê.

Implementação de Infraestrutura Laboratorial para Análise Operacional e Capacitação em Sistemas Híbridos para Geração de Eletricidade / Kauê José Felipe Novaes Cândido de Souza; orientador: João Tavares Pinho. -- São Paulo, 2018.

160: il. $30 \mathrm{~cm}$.

Dissertação (Mestrado em Ciências) - Programa de Pós-Graduação em Energia - Instituto de Energia e Ambiente da Universidade de São Paulo

1. Sistemas Híbridos. 2. Minirredes. 3. Análise operacional. 4. Capacitação. 5. Sistemas fotovoltaicos. I. Título. 
Nome: Kauê José Felipe Novaes Cândido de Souza

Título: Implementação de Infraestrutura Laboratorial para Análise Operacional e Capacitação em Sistemas Híbridos para Geração de Eletricidade.

Dissertação de mestrado apresentada ao Programa de Pós-Graduação em Energia do Instituto de Energia e Ambiente da Universidade de São Paulo para a obtenção do título de Mestre em Ciências.

Aprovado em: 24/05/2018

\section{Banca Examinadora}

Orientador: Prof. Dr.-Ing João Tavares Pinho

Prof. Dr. Roberto Zilles / Instituição: IEE USP

Prof. Dr. Wilson Negrão Macêdo / Instituição: UFPA

Dr. André Ricardo Mocelin / Instituição: IEE USP 



\section{DEDICATÓRIA}

A meus pais, Anair e Vanderlei, por me conceder esta vida, e me proporcionar a melhor educação possível, sempre apresentando os valores que devem ser seguidos.

A minhas avós, Catharina e Maria Olivia (in memoriam), a meus irmãos, Kissy e Kauãn, a meus familiares, em especial a meu tio Juvenal, tio Valnei, tia Idalina, tia Zilda, tia Edna, e a meus antepassados, que me proporcionaram uma excelente família e sempre me incentivarem a realizar meus sonhos.

À minha namorada e grande companheira, Heloisa Dandara, e sua família, por entenderem minha ausência em muitos eventos, sempre me apoiando e incentivando a buscar um futuro melhor.

À minha família do coração, Elizabeth (in memoriam), Elizangela, Rodrigo Reis, Sirles, por todo apoio e carinho ao longo de minha trajetória. 



\section{AGRADECIMENTOS}

A meu orientador, Prof. Dr.-Ing. João Tavares Pinho, pela orientação e ensinamentos transmitidos no decorrer desta dissertação.

Ao Prof. Dr. Roberto Zilles e ao Dr. André Mocelin, por me aceitarem no Laboratório de Sistemas Fotovoltaicos, desde minha iniciação cientifica e acreditarem em meu potencial.

À Prof ${ }^{a}$ MSc. Patrícia Abdalla Raimo, pelo convite para realização da iniciação cientifica no LSF.

Ao MSc. Pedro Veríssimo, pelo apoio e disponibilidade de me auxiliar no início da documentação deste trabalho.

Aos meus amigos adquiridos na vida acadêmica, Alex, Roberto Valer, Mauricio, Gilberto, Marcelo e César. Estendo estes agradecimentos também aos membros do LSF, Cristina, Teddy, Givaldo, Tadeu, Samuel e Lourival.

Ao Grupo de Estudos e Desenvolvimento de Alternativas Energéticas (GEDAE) da Universidade Federal do Pará (UFPA), pelo acolhimento durante minhas viagens a Belém.

Aos meus amigos Rodrigo Zago e Paulo, pelo apoio e grande momentos de descontração, estendo esse agradecimento aos meus amigos do Colégio Brasileiro, ETEC Aprígio Gonzaga, IFSP, por, mesmo longe, sempre cultivarem este carinho especial por mim.

A todos os professores que participaram da minha formação escolar e acadêmica, e que contribuíram para o meu desenvolvimento intelectual.

Aos amigos do IEE, por todos os gratos momentos.

À Capes e à FUSP, pelas bolsas de mestrado.

Agradeço aos funcionários do restaurante universitário da USP (Bandejão), pelas ótimas refeições servidas no decorrer deste trabalho.

Ao IEE e à USP, por terem me proporcionado o ambiente de estudo excelente.

Por fim agradeço ao Roberto Valer, por suas magníficas aulas de Forró. 



\section{RESUMO}

Novaes, Kauê. Implementação de Infraestrutura Laboratorial para Análise Operacional e Capacitação em Sistemas Híbridos para Geração de Eletricidade, 2018, 160 f. Dissertação (Mestrado em Ciências) - Programa de PósGraduação em Energia da Universidade de São Paulo, São Paulo, 2018.

Este trabalho apresenta o processo de ampliação da infraestrutura laboratorial de minirredes e sistemas híbridos do Laboratório de Sistemas Fotovoltaicos do Instituto de Energia e Ambiente da Universidade de São Paulo, (LSF-IEE/USP). O trabalho também contempla uma revisão do estado da arte de sistemas híbridos e minirredes, apresentando principalmente os aspectos técnicos, como formas de acoplamento, e interações com a rede elétrica de distribuição. Descrevem-se os sistemas híbridos presentes no LSF e a infraestrutura para sua interconexão. Posteriormente são realizados os processos de comissionamento e testes operacionais da interconexão dos sistemas híbridos entre si e com a rede elétrica. Ao final é proposto um curso de aperfeiçoamento em minirredes e sistemas híbridos utilizando a infraestrutura presente no LSF.

Palavras-chave: Sistemas híbridos, minirredes, análise operacional, capacitação, sistemas fotovoltaicos. 



\begin{abstract}
Novaes, Kauê. Implementation of Laboratory Infrastructure for Operational Analysis and Capacity Building in Hybrid Systems for Electricity Generation, 2018, 160 f . Dissertation (Msc.) - Graduate Program on Energy, University of Sao Paulo, Sao Paulo, 2018.
\end{abstract}

This work presents the expansion of the micro-grid and hybrid systems infrastructure at the Laboratory of Photovoltaic Systems of the Institute of Energy and Environment at the University of São Paulo (LSF-IEE / USP). The work also presents a review of the state of the art of hybrid systems and micro-grid, presenting mainly the technical aspects, such as types of system interconnections and interactions with the main grid. The hybrid systems existent in the LSF, as well as the infrastructure for their interconnection are described. Subsequently, the commissioning process and the operational tests with the interconnection of the hybrid systems with each other and with the main grid are performed. At the end, a capacity building course on micro-grids and hybrid systems using the existent infrastructure in the LSF is proposed.

Key words: Hybrid systems, micro-grids, operational analysis, capacity building, photovoltaic systems. 



\section{ÍNDICE DE FIGURAS}

Figura 1 - Exemplo de sistemas autônomos individuais (a) e com minirrede (b).....28

Figura 1.1 - Topologia típica de um sistema híbrido. .35

Figura 1.2 - Exemplo da interconexão de sistemas híbridos. 40

Figura 1.3 - Exemplo da transição da geração distribuída atual para a geração distribuída com $\mathrm{SH}$. .43

Figura 2.1 - Vista geral do LSF. .47

Figura 2.2 - Diagrama esquemático do sistema SMA - Trifásico. .50

Figura 2.3 - Geradores fotovoltaicos do ST1. .53

Figura 2.4 - Módulos Fotovoltaicos utilizados no ST1. .55

Figura 2.5 - Fonte c.c. .57

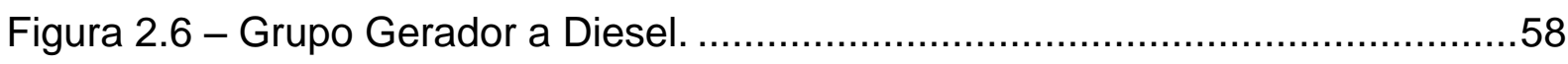

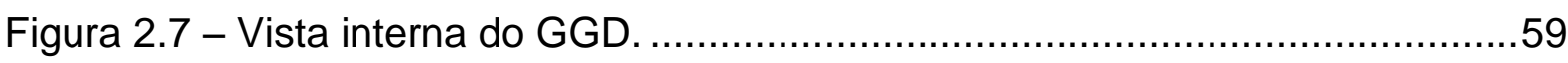

Figura 2.8 - Unidade de supervisão de corrente alternada....................................61

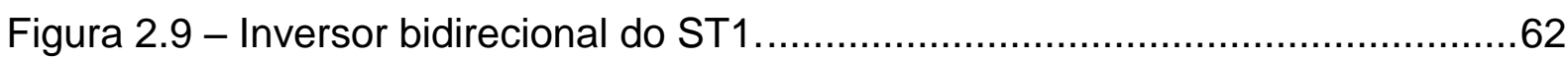

Figura 2.10 - Configuração dos inversores bidirecionais do ST1 ..........................63

Figura 2.11 - Inversores de conexão com à rede do ST1 ......................................64

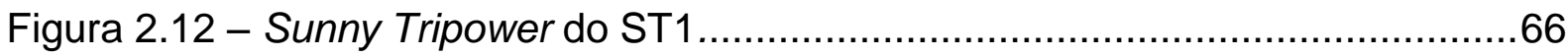

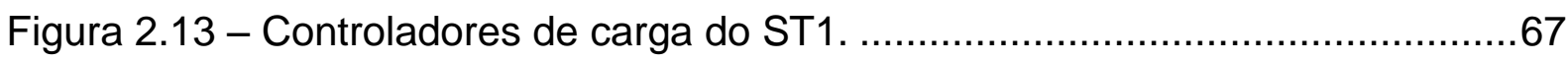

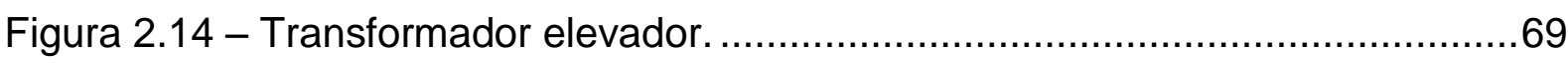

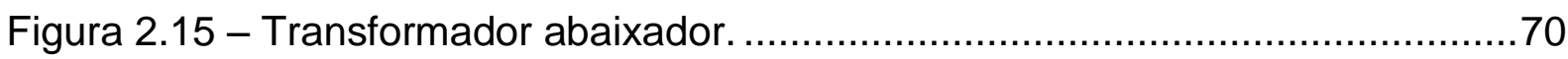

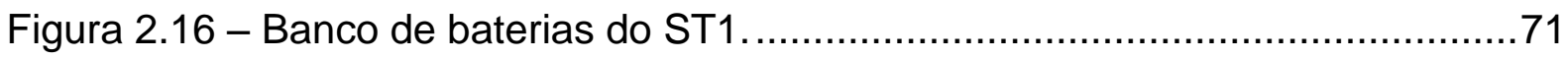

Figura 2.17 - Características construtivas da bateria do ST1 ...............................72

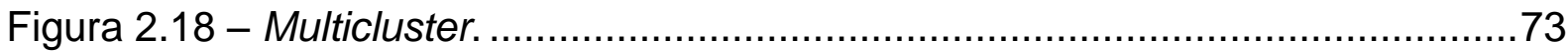

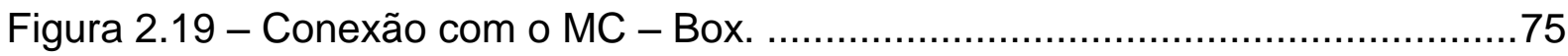

Figura 2.20 - Quadro de proteção e seccionamento. ………................................76

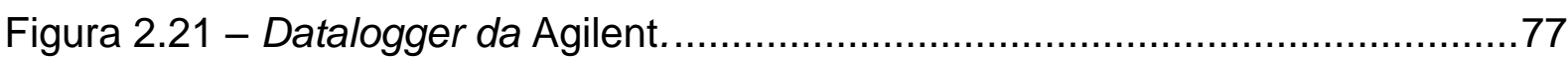

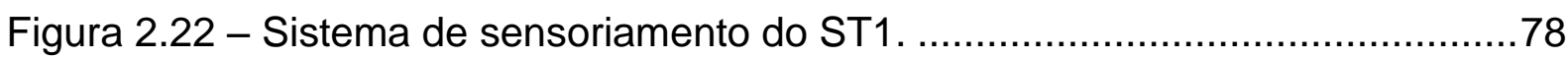

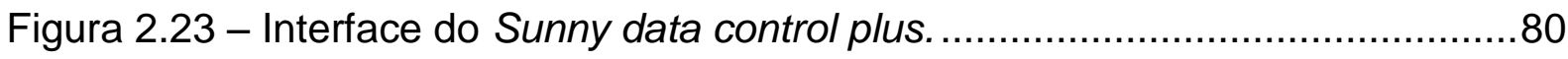

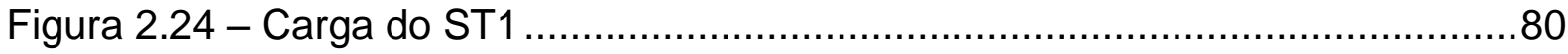

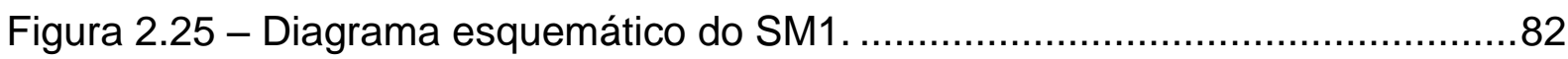

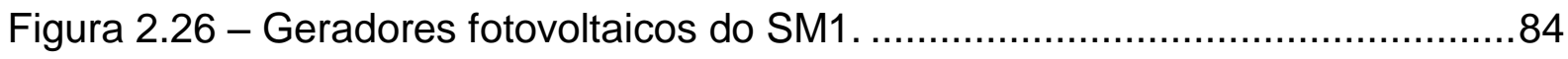




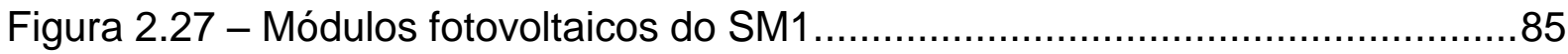

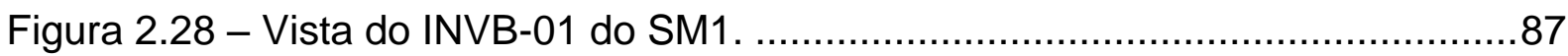

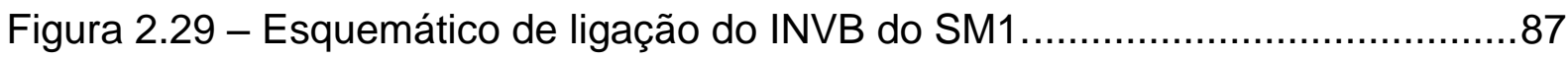

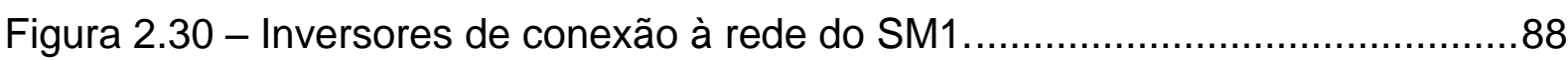

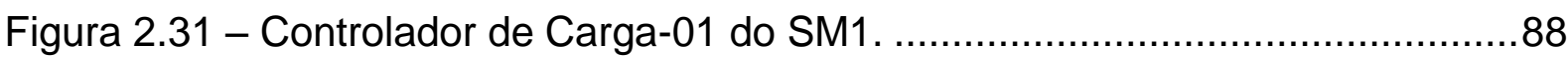

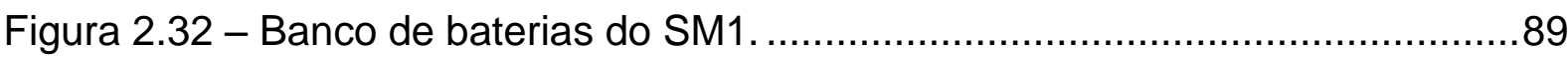

Figura 2.33 - Quadros de proteção e seccionamento SM1 . ....................................90

Figura 2.34 - Sistema de monitoramento do SM1 ..............................................

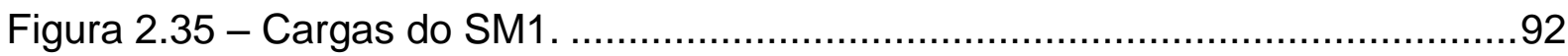

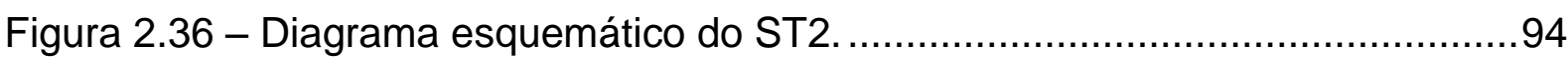

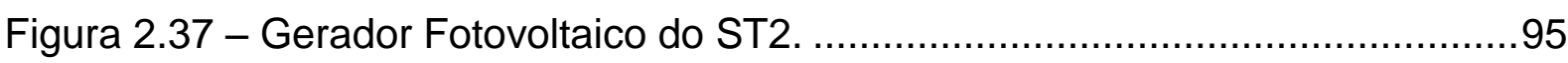

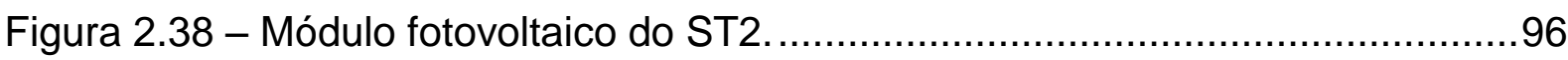

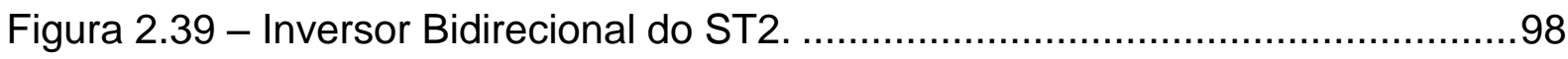

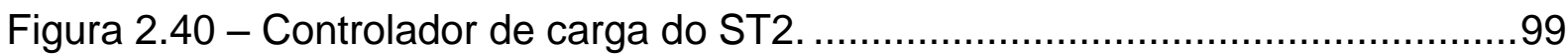

Figura 2.41 - Banco de Baterias do ST2. ..................................................... 100

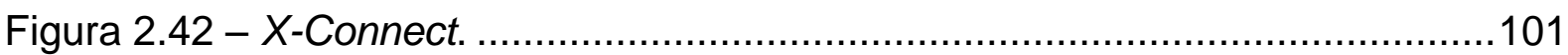

Figura 2.43 - Conexões do X-connect.........................................................102

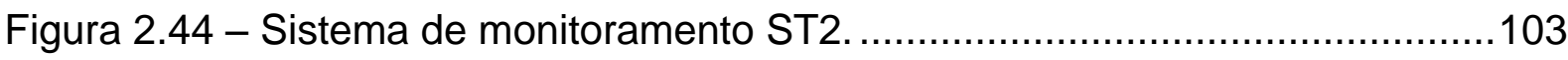

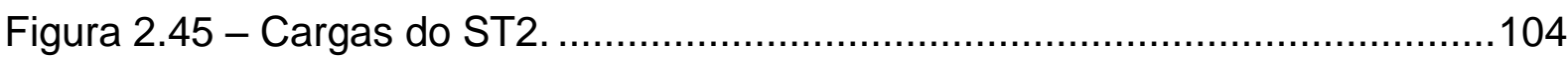

Figura 2.46 - Diagrama esquemático do SM2 .............................................106

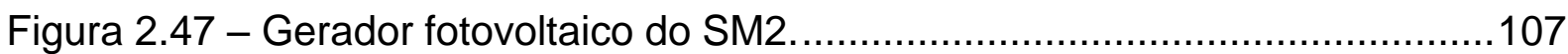

Figura 2.48 - Módulo fotovoltaico do SM2 …………...................................108

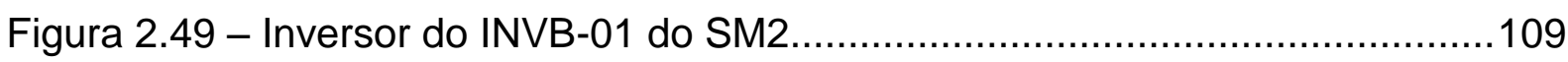

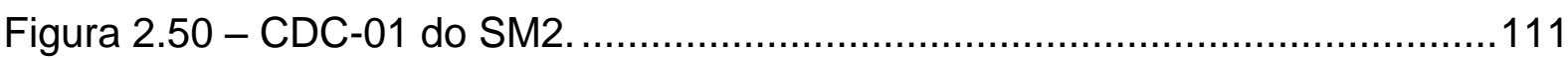

Figura 2.51 - Banco de Baterias do SM2 .........................................................112

Figura 2.52 - Vista interna do - XW Power Distribution Panel. ...............................113

Figura 2.53 - Sistema de monitoramento SM2 . ...........................................114

Figura 2.54 - Sistema de interconexão dos sistemas híbridos. ..............................116

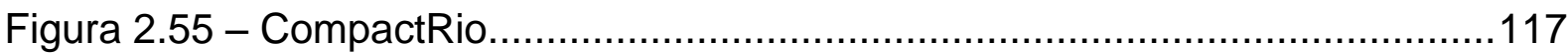

Figura 2.56 - Tela apresentando o diagrama do sistema completo de minirredes,

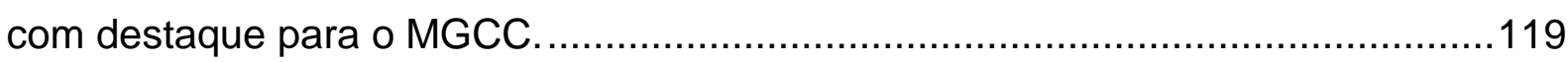

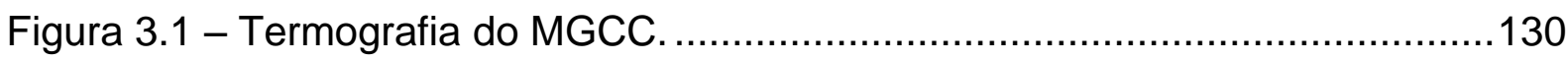

Figura 3.2 - Infraestrutura e integração dos SH..............................................131 
Figura 3.3 - Sistemas de supervisão e aquisição de dados do MGCC.

Figura 3.4 - Topologia com um único nível de hierarquia.................................135

Figura 3.5 - Topologia com dois níveis de hierarquia.....................................135

Figura 3.6 - Exemplo de controle da geração................................................137

Figura 37 - Interação com a rede elétrica....................................................138

Figura 3.8 - Topologia com um nível de hierarquia e três SH injetando potência...138

Figura 3.9 - Irradiância e frequência dos ST1 e SM1 . ......................................139

Figura 3.10 - Topologia com um nível de hierarquia e com o ST1e SM1 injetando

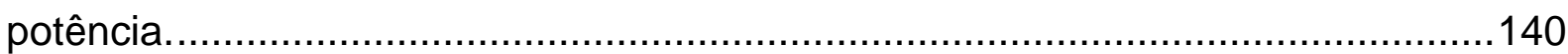

Figura 3.11 - Forma de onda da corrente no MGCC. ......................................140

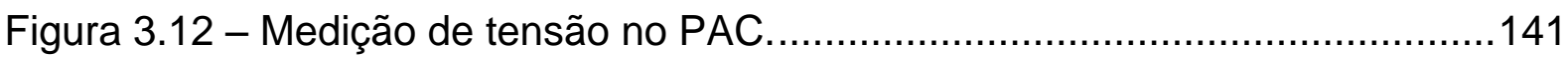

Figura 3.13 - Topologia com um nível de hierarquia e com o ST1 injetando potência.

Figura 3.14 - Injeção de potência com o aerogerador emulado. 142

Figura 3.15 - Topologia com dois níveis hierarquias e com intercâmbio de energia.

Figura 3.16 - Relação entre demanda e injeção de potência no segundo nível de hierarquia. 143

Figura 3.17 - Topologia com dois níveis de hierarquia no MGCC. ......................144

Figura 3.18 - Correntes medidas com dois níveis de hierarquia...........................145

Figura 3.19 - Desconexão pela frequência elevada. ........................................146

Figura 3.20 - Resultado de demanda e injeção de energia com as fontes externas.

Figura 4.1 - Bancada móvel de sistemas híbridos...........................................155

Figura 4.2 - Grupo gerador a diesel de 5,5 kVA. ............................................155 



\section{ÍNDICE DE TABELAS}

Tabela 2.1 - Dados dos módulos utilizados no ST1 .55

Tabela 2.2 - Especificações técnicas da fonte c.c. .57

Tabela 2.3 - Dados técnicos do GGD. .59

Tabela 2.4 - Fabricante dos componentes do GGD. 60

Tabela 2.5 - Especificações técnicas do inversor bidirecional do ST1. 62

Tabela 2.6 - Especificações técnicas do inversor de conexão à rede do ST1. .64

Tabela 2.7 - Especificações técnicas do Sunny Tripower do ST1 66

Tabela 2.8 - Especificações técnicas dos controladores de carga do ST1 .67

Tabela 2.9 - Especificações técnicas do transformador elevador 69

Tabela 2.10 - Especificações técnicas do transformador abaixador .70

Tabela 2.11 - Especificação técnica das baterias do ST1 . ...................................72

Tabela 2.12 - Especificação técnica do Multicluster Box 6.3 .................................73

Tabela 2.13 - Especificações técnicas dos módulos fotovoltaicos do SM1..............85

Tabela 2.14 - Especificações técnicas do controlador de carga-01.........................88

Tabela 2.15 - Especificações técnicas do banco de baterias do SM1 .......................89

Tabela 2.16 - Especificações Técnicas do Módulo do ST2 ...................................96

Tabela 2.17 - Especificações Técnicas do Inversor Bidirecional do ST2. ................98

Tabela 2.18 - Especificações técnicas do controlador de carga do ST2 ..................99

Tabela 2.19 - Especificações Técnicas do Módulo do SM2 ................................108

Tabela 2.20 - Especificações técnicas do INVB-01 do SM2 ................................110

Tabela 2.21 - Especificações Técnicas do CDC-01 do SM2 ..............................111

Tabela 2.22 - Especificações Técnicas do CompactRio.....................................117

Tabela 3.1 - Estratégias operacionais. ……………..................................132

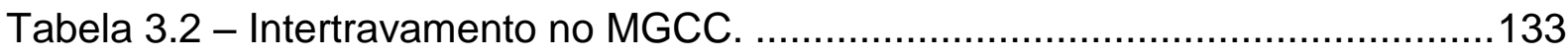

Tabela 4.1 - Lista de materiais para as aulas práticas. .......................................156 



\section{ABREVIATURAS E SIGLAS}

AGS - Automatic Generator Start

BB - Banco de Baterias

BSP - Battery Status Processor

c.a. - Corrente Alternada

c.c. - Corrente Contínua

CDC - Controlador de Carga

cRio - CompactRio

CSP - Conext System Control Panel

DPS - Dispositivo de Proteção Contra Surto

GD - Geração Distribuída

GEDAE - Grupo de Estudos e Desenvolvimento de Alternativas Energéticas

GFV - Gerador Fotovoltaico

GGD - Grupo Gerador a Diesel

IEE - Instituto de Energia e Ambiente

INVB - Inversor de Tensão Bidirecional

INVG - Inversor de Tensão Grid-Tie

Imp - Corrente de Máxima Potência

Isc - Corrente de Curto-Circuito

LSF - Laboratório de Sistemas Fotovoltaicos

MB - Medidor Bidirecional

MC - Multicluster

MGCC - Micro-Grid Central Controller

MME - Ministério de Minas e Energia

NBR - Norma Brasileira

NI - National Instruments

PAC - Ponto de Acoplamento Comum

PDP - Power Distribution Panel 
RCC-02 - Remote Control and Programming Unit

RP - Rede Principal

SB - Sunny Boy

SBC - Sunny Boy Control Plus

SCADA - Sistema de Supervisão e Aquisição de Dados

SDC - Sunny Data Control

SENAI - Serviço Nacional de Aprendizagem Industrial

SFCR - Sistemas Fotovoltaicos Conectados à Rede Elétrica

SH - Sistema Híbrido

SI - Sunny Island

SIN - Sistema Interligado Nacional

SM - Sunny Matrix

SM1 - Sistema Monofásico 1

SM2 - Sistema Monofásico 2

SSB - Sunny Sensor Box

ST1 - Sistema Trifásico 1

ST2 - Sistema Trifásico 2

SWB - Sunny Web Box

UNICAMP - Universidade Estadual de Campinas

UFPA - Universidade Federal do Pará

USCA - Unidade de Supervisão de Corrente Alternada

USP - Universidade de São Paulo

Vmp - Tensão de Máxima Potência

Voc - Tensão de Circuito Aberto 


\section{Sumário}

Introdução 25

Capítulo 1 Estado da Arte de Sistemas Híbridos e Minirredes Inteligentes ..33

1.1 Sistemas Híbridos Operando Isolados da Rede Elétrica .33

1.2 Interconexão entre Sistemas Híbridos Operando Isolados da Rede Elétrica .39

1.3 Interconexão de Sistemas Híbridos com a Rede Elétrica...........................41

1.4 Capacitação e Qualificação Profissional .................................................44

Capítulo 2 - Infraestrutura Laboratorial para Estudos de Minirredes Híbridas Inteligentes

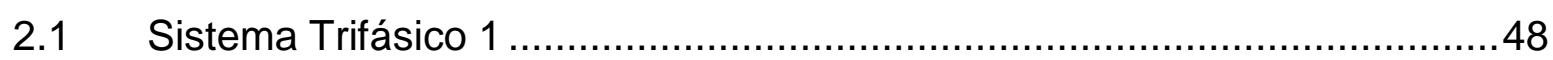

2.1.1 Sistema de Geração.............................................................

2.1.2 Sistema de Condicionamento de Potência..................................61

2.1.3 Sistema de Armazenamento ..................................................

2.1.4 Sistema de Distribuição e Comando …………………….........73

2.1.5 Sistema de Proteção ..............................................................

2.1.6 Sistema de Medição ..............................................................76

2.1.7 Sistema de Sensoriamento .................................................77

2.1.8 Sistema de Monitoramento ...................................................79

2.1.9 Sistema de Consumo de Energia...............................................8

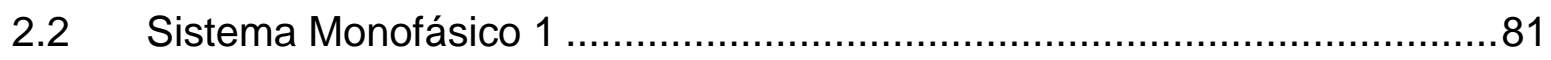

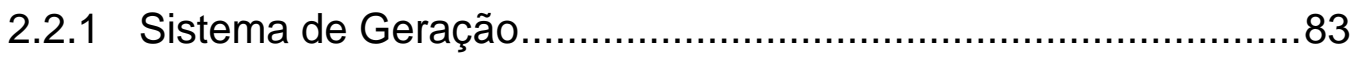

2.2.2 Sistema de Condicionamento de Potência..................................86

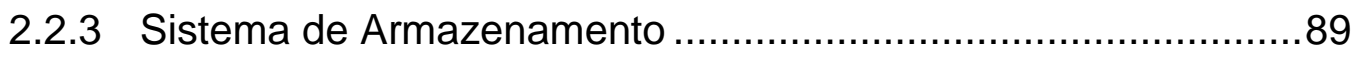

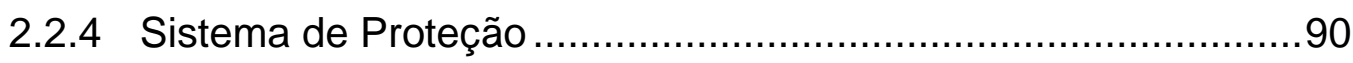

2.2.5 Sistema de Medição ...............................................................90

2.2.6 Sistema de Sensoriamento .....................................................

2.2.7 Sistema de Monitoramento .................................................... 
2.2.8 Sistema de Consumo de Energia...........................................92

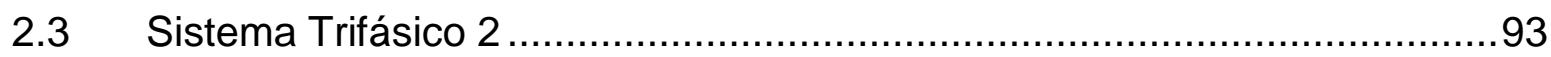

2.3.1 Sistema de Geração................................................................95

2.3.2 Sistema de Condicionamento de Potência..................................97

2.3.3 Sistema de Armazenamento ....................................................100

2.3.4 Sistema de Distribuição.........................................................101

2.3.5 Sistema de Proteção .............................................................102

2.3.6 Sistema de Medição .............................................................102

2.3.7 Sistema de Monitoramento ..................................................103

2.3.8 Sistema de Consumo de Energia............................................104

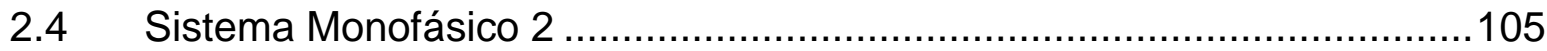

2.4.1 Sistema de Geração.............................................................107

2.4.2 Sistema de Condicionamento de Potência...............................109

2.4.3 Sistema de Armazenamento ……………………………....111

2.4.4 Sistema de Distribuição..........................................................112

2.4.5 Sistema de Proteção ...........................................................113

2.4.6 Sistema de Medição ………………………….......................113

2.4.7 Sistema de Monitoramento ....................................................114

2.1.1 Sistema de Consumo de Energia...........................................114

2.2 Sistema de Interconexão entre os Sistemas Híbridos .............................115

2.2.1 Sistema de Controle ...........................................................116

2.2.2 Sistema de Medição ……………………………………....118

2.2.3 Sistema de Monitoramento ..................................................119

2.2.4 Sistema de Proteção ...........................................................120

Capítulo 3 - Comissionamento e Ensaios Operacionais com os Sistemas Híbridos do LSF 121

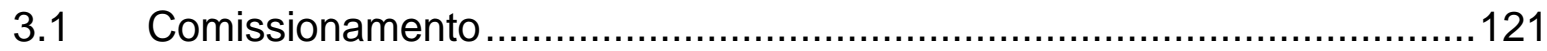




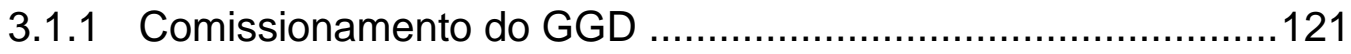

3.1.2 Comissionamento da Rede Elétrica ......................................122

3.1.3 Comissionamento dos Sistemas Híbridos …………………...123

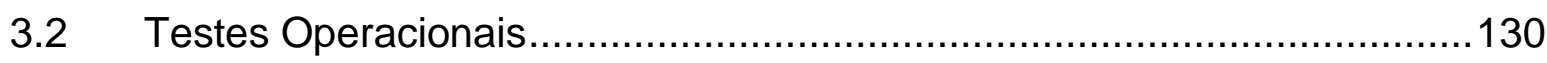

Capítulo 4 - Proposta de Curso de Aperfeiçoamento em Minirredes e Sistemas Híbridos 149

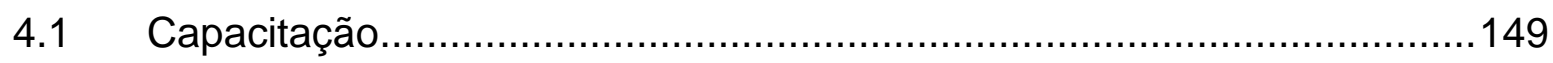

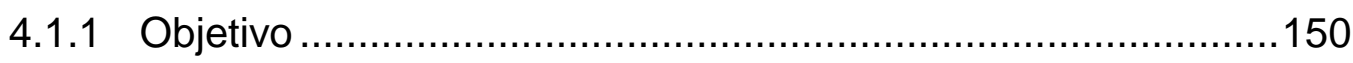

4.1.2 Pré-requisito .................................................................. 150

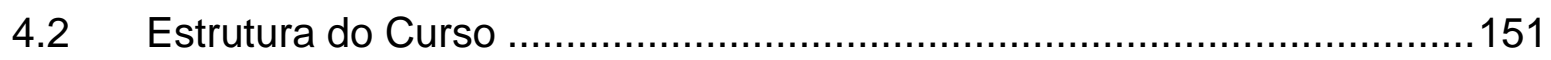

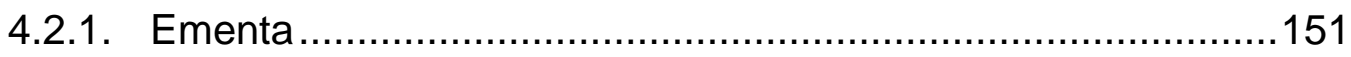

4.2.2. Conteúdo Programático Teórico.............................................151

4.2.3. Conteúdo Programático Prático …………………………....152

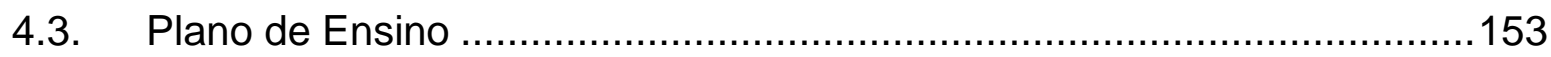

4.3.1 Plano de Ensino das Aulas Teóricas .......................................153

4.3.2 Plano de Ensino das Aulas Práticas........................................153

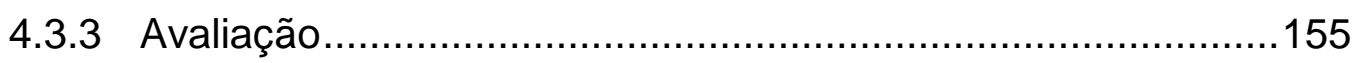

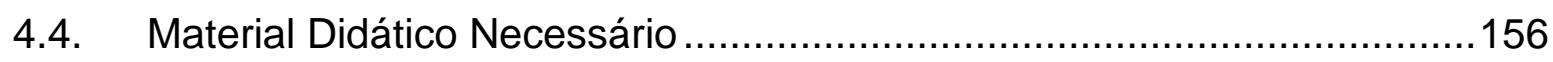

4.4.1 Material para as Aulas Teóricas .............................................156

4.4.2 Material para as Aulas Práticas...............................................156

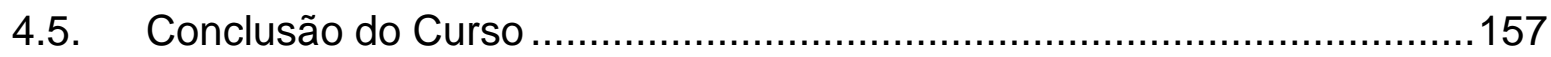

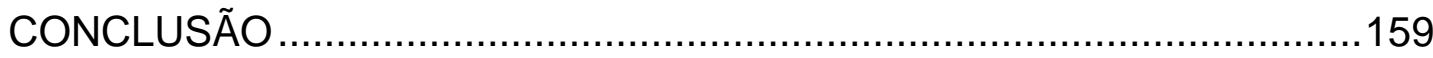

Sugestão para Trabalhos Futuros ……………………………….......160

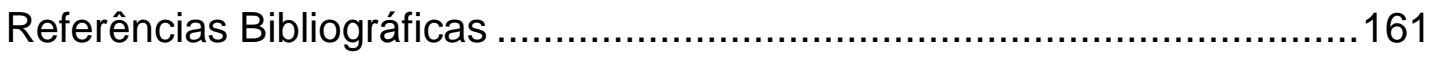

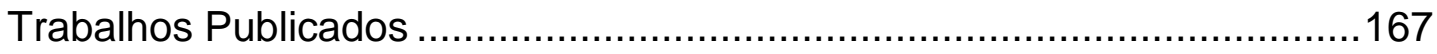





\section{INTRODUÇÃO}

A energia elétrica é, segundo a Lei 10.438, de 26 de abril de 2002, um direito de todos os cidadãos brasileiros. Contudo, no contexto brasileiro, uma significativa parcela da população não está conectada à rede elétrica, seja por barreiras técnicas, econômicas e/ou geográficas, (IBGE, 2010). Estas pessoas utilizam geralmente formas de conversão com baixa eficiência para atendimento de suas necessidades, como, por exemplo, lamparinas, velas e lanternas a pilhas, (GOLDEMBERG e LUCON, 2012). Uma alternativa inicial para fornecimento de energia para regiões isoladas foi a utilização de grupos geradores operando com combustíveis fósseis (geralmente o diesel). Contudo, a utilização de grupos geradores a diesel (GGD) apresenta elevados custos e significativos impactos ambientais, tanto na sua operação quanto no transporte do combustível.

Com o avanço tecnológico, foram desenvolvidas novas formas de suprir essas demandas de energia, que sanam problemas associados a custos e impactos ambientais e ainda possibilitam autonomia para regiões isoladas. A utilização de sistemas de geração com fontes locais, como a solar, a eólica ou a biomassa apresentou-se como uma mudança do paradigma para o suprimento de comunidades isoladas. A implementação de sistemas de geração com fontes locais pode atender a demanda de energia elétrica de modo autônomo (MOCELIN,2004). Dependendo da carga a ser atendida, pode ser instalado um pequeno sistema de geração, acumulação e condicionamento de potência por unidade consumidora, ou um sistema centralizado de geração, acumulação e condicionamento de potência, atendendo a uma minirrede de distribuição, como ilustrado na Figura 1. Para aumento da confiabilidade é possível a complementação da geração utilizando outras fontes, como os GGD. 


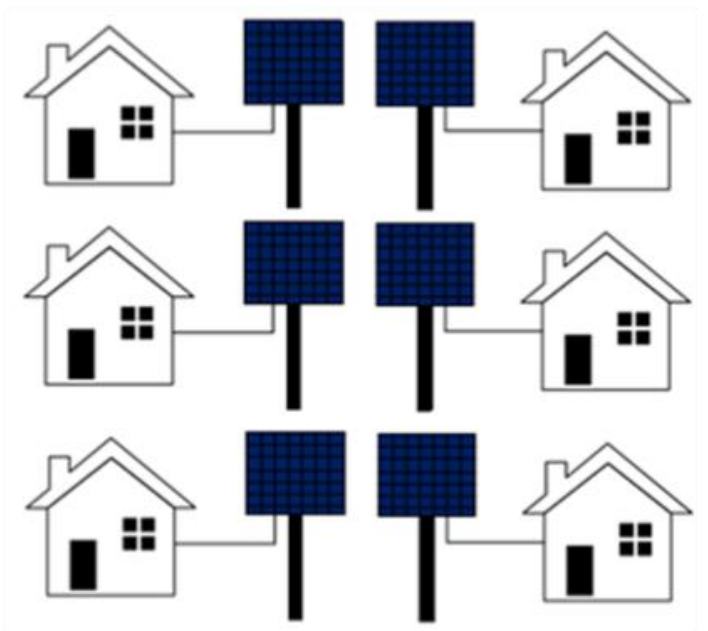

(a)

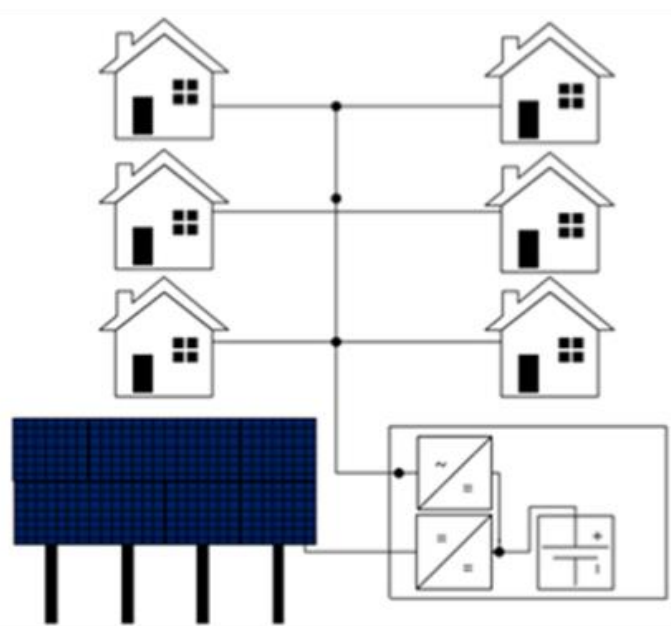

(b)

Figura 1 - Exemplo de sistemas autônomos individuais (a) e com minirrede (b).

Desta forma, as minirredes híbridas começaram a ser instaladas em locais isolados, como forma de aumentar a confiabilidade do sistema de geração (Barbosa, et al., 2016a). Porém, com o aumento da demanda de energia e a necessidade de mudança no conceito de geração centralizada, as minirredes começaram a ser conectadas à rede elétrica, possibilitando vantagens para o sistema de distribuição, como a diminuição da demanda de energia no horário de ponta do sistema, aliviando o sistema de geração e transmissão.

Contudo, existem gargalos técnicos e operacionais a serem investigados neste segmento. Neste sentido o Laboratório de Sistemas Fotovoltaicos (LSF), do Instituto de Energia e Ambiente (IEE), da Universidade de São Paulo (USP) e o Grupo de Estudos e Desenvolvimento de Alternativas Energéticas (GEDAE), da Universidade Federal do Pará (UFPA) possuem infraestrutura e experiência para investigação da implementação de sistemas híbridos de geração, conectados ou não à rede elétrica, e do estudo de possíveis estratégias operacionais e suas aplicações, (BARBOSA, 2004), (BARBOSA, et al., 2016b), (BARBOSA, et al., 2016c), (BLASQUES e PINHO, 2012), (HAUSCHILD e ZILLES, 2005), (HAUSCHILD e ZILLES, 2006), (MOCELIN, 2014), (MOCELIN e ZILLES, 2012), (PINHO, 2008), (RAMOS, 2014) e (VERÍSSIMO, 2014).

Embora existam diversos trabalhos publicados sobre minirredes híbridas, ainda existem muitos estudos a serem desenvolvidos. Entre estes, qual seria a 
melhor estratégia operacional para a integração de diversos sistemas híbridos com configurações distintas na forma de uma minirrede inteligente e como seria o comportamento desses sistemas interligados, com possibilidade de gerenciamento de demanda e geração.

\section{JUSTIFICATIVA}

Atualmente as minirredes de energia são consideradas pontos chaves para melhorar a confiabilidade e a qualidade da energia, aumentar a eficiência do sistema elétrico como um todo, possibilitar aos consumidores finais certa independência da rede principal, já que as minirredes podem operar nos modos conectado ou isolado, e também a eventual prestação de serviços ancilares.

Para a utilização prática e eficiente dessas minirredes, é necessário o emprego de tecnologia da informação, de sensoriamento remoto, automação, monitoração e controle remotos, e de medição eletrônica, que possibilitem o aumento da quantidade e da qualidade das informações relativas ao desempenho da rede, norteando a tomada de decisões nos diferentes setores do sistema elétrico, inclusive dos consumidores finais. O uso dessas tecnologias introduz o conceito de Smart Grid, ou Rede Inteligente, o que no presente caso pode ser denominado de Minirrede Inteligente.

No Brasil, são poucos os locais contendo a expertise e uma infraestrutura mínima adequada para pesquisas em minirredes inteligentes, principalmente em termos da operação das mesmas. A criação de locais apropriados para o desenvolvimento de estudos teóricos e práticos sobre minirredes inteligentes, tendo como base várias instituições envolvidas com o tema, visa ampliar a capacidade nacional no desenvolvimento e aplicação de novas tecnologias que atendam às necessidades das minirredes inteligentes, bem como a capacitação de pessoal.

A presente dissertação de mestrado foi desenvolvida em cooperação com duas instituições de pesquisa, e visou à criação e ao desenvolvimento de competências locais e infraestruturas laboratoriais capazes de possibilitar estudos teóricos e práticos, que possam representar as condições normais e críticas de 
funcionamento de minirredes isoladas e interconectadas, permitindo a investigação das questões que envolvem a operação de minirredes inteligentes, tais como o uso e a contribuição da geração distribuída, a previsão de curto prazo da geração com fontes intermitentes, a controlabilidade do despacho de energia, o sistema de armazenamento de energia, a qualidade da energia, o gerenciamento da oferta e da demanda, dentre outros fatores ligados à operação das minirredes inteligentes.

\section{OBJETIVO}

A presente dissertação de mestrado teve por objetivo desenvolver uma estrutura laboratorial de sistemas híbridos de geração de eletricidade, utilizando preferencialmente as fontes solar fotovoltaica e diesel, que permite a realização de pesquisa e desenvolvimento no tema de minirredes inteligentes, bem como a capacitação de recursos humanos nos níveis técnico e superior.

\section{ESTRUTURA DA DISSERTAÇÃO}

A dissertação está dividida em quatro capítulos e a conclusão, como descrito a seguir.

Capítulo I - Estado da Arte de Sistemas Híbridos e Minirredes Inteligentes.

Este capítulo apresenta o estado da arte de minirredes e sistemas híbridos, através da realização de pesquisa bibliográfica, focando principalmente nos aspectos técnicos, como formas de acoplamento e interações com a rede elétrica de distribuição.

Capítulo II - Infraestrutura Laboratorial para Estudos de Minirredes Híbridas Inteligentes.

Este capítulo descreve os dois sistemas híbridos pré-existentes no LSF, bem como a sua ampliação através dos dois sistemas híbridos que foram instalados no decorrer deste trabalho. Destacam-se os componentes utilizados, suas especificações técnicas, diagramas, etc. Neste capitulo também é apresentada a integração dos quatro sistemas híbridos, descrevendo a composição do quadro de 
controle, os dispositivos utilizados, e as possibilidades de interação entre os sistemas.

Capítulo III - Comissionamento e Ensaios Operacionais com os Sistemas Híbridos do LSF.

Este capítulo descreve o comissionamento dos sistemas instalados e a realização de ensaios operacionais, incluindo as análises de fluxo de potência, gestão de geração, gestão da carga e despacho de energia.

Capítulo IV - Proposta de Curso de Aperfeiçoamento em Minirredes e Sistemas Híbridos.

Este capítulo apresenta uma proposta de curso de aperfeiçoamento em minirredes e sistemas híbridos utilizando a infraestrutura existente no LSF.

Ao final são apresentadas as conclusões e sugestões para continuação do trabalho. 



\section{Capítulo 1 Estado da Arte de Sistemas Híbridos e Minirredes Inteligentes}

Este capítulo apresenta uma breve revisão do estado da arte de minirredes e sistemas híbridos, através de pesquisa bibliográfica, focando principalmente nos aspectos técnicos, como formas de acoplamento e interações com a rede elétrica de distribuição.

Esta revisão do estado da arte está dividida em quatro partes. Inicialmente é apresentada uma breve história dos sistemas híbridos e definições sobre as diferenças entre sistemas híbridos e minirredes. Também são apresentadas as formas de classificação de sistemas híbridos e algumas referências sobre esses tipos de sistemas operando isolados da rede elétrica. A segunda parte apresenta uma análise sobre as possibilidades e desafios associados à integração de sistemas híbridos. Na terceira parte são apresentados conceitos sobre a conexão de sistemas híbridos com a rede elétrica e são apresentados fatores que potencializam e entravam sua utilização. Na quarta parte é contextualizada a questão da capacitação e qualificação profissional em sistemas com fontes renováveis.

\subsection{Sistemas Híbridos Operando Isolados da Rede Elétrica}

O fornecimento de energia para uma parcela da população brasileira que está localizada distante do Sistema Interligado Nacional (SIN) ainda apresenta desafios. Na atualidade, segundo o Ministério de Minas e Energia (MME, 2017), a principal forma de atender os sistemas isolados ainda é utilizando os GGD, mesmo esta forma de geração apresentando todos os problemas associados a custos de operação, manutenção e logística e impactos ambientais em seu ciclo de vida. Neste contexto, a utilização de sistemas individuais e autônomos de geração, ou de minirredes e/ou sistemas híbridos se apresenta como soluções para este impasse de atendimento de energia para comunidades isoladas.

O emprego do termo sistemas híbridos e minirredes tangenciam o mesmo conceito, porém não realizam a mesma função, podendo em alguns casos até 
mesmo serem empregados de forma complementar. Haja vista esta dualidade, são definidos os conceitos sobre sistemas híbridos e minirredes, para melhor compreensão e emprego destes termos. Define-se como sistema híbrido (SH) aquele que utiliza duas ou mais fontes de energia (BARBOSA, 2006). Define-se como minirrede um sistema de energia que possui limitações regionais, ou seja, uma parcela da rede de distribuição, podendo possuir sistema de geração distribuída, ou geração centralizada, com armazenamento ou não, e consumidores, ou seja, cargas, podendo atuar de forma autônoma à concessionária de energia ou de forma conectada, (BERRY et al., 2010).

A utilização de duas ou mais fontes de geração em sistemas híbridos, representa maior robustez e confiabilidade para o sistema como um todo. Segundo PINHO et al. (2008b), os principais geradores utilizados de forma concomitante são o fotovoltaico e o eólico, em conjunto com um grupo gerador a diesel, como apresentado na Figura 1.1. Desta forma algumas possibilidades de sistemas híbridos são:

- Sistema híbrido eólico - diesel;

- Sistema híbrido fotovoltaico - diesel;

- Sistema híbrido fotovoltaico - eólico - diesel;

- Sistema híbrido fotovoltaico - eólico.

A Figura 1.1 representa uma das topologias mais usuais de sistemas híbridos, onde os sistemas de geração (fotovoltaico, eólico e GGD) podem ser conectados tanto no barramento c.c. quanto no barramento c.a., o sistema de acumulação (banco de baterias) é conectado no barramento c.c., e o fluxo de energia entre os barramentos e os sistemas de armazenamento e geração ocorre por meio do sistema de condicionamento de potência (inversor de conexão com a rede, inversor bidirecional e retificador). $O$ fornecimento de energia nos sistemas híbridos pode ocorrer em corrente contínua ou em corrente alternada. 


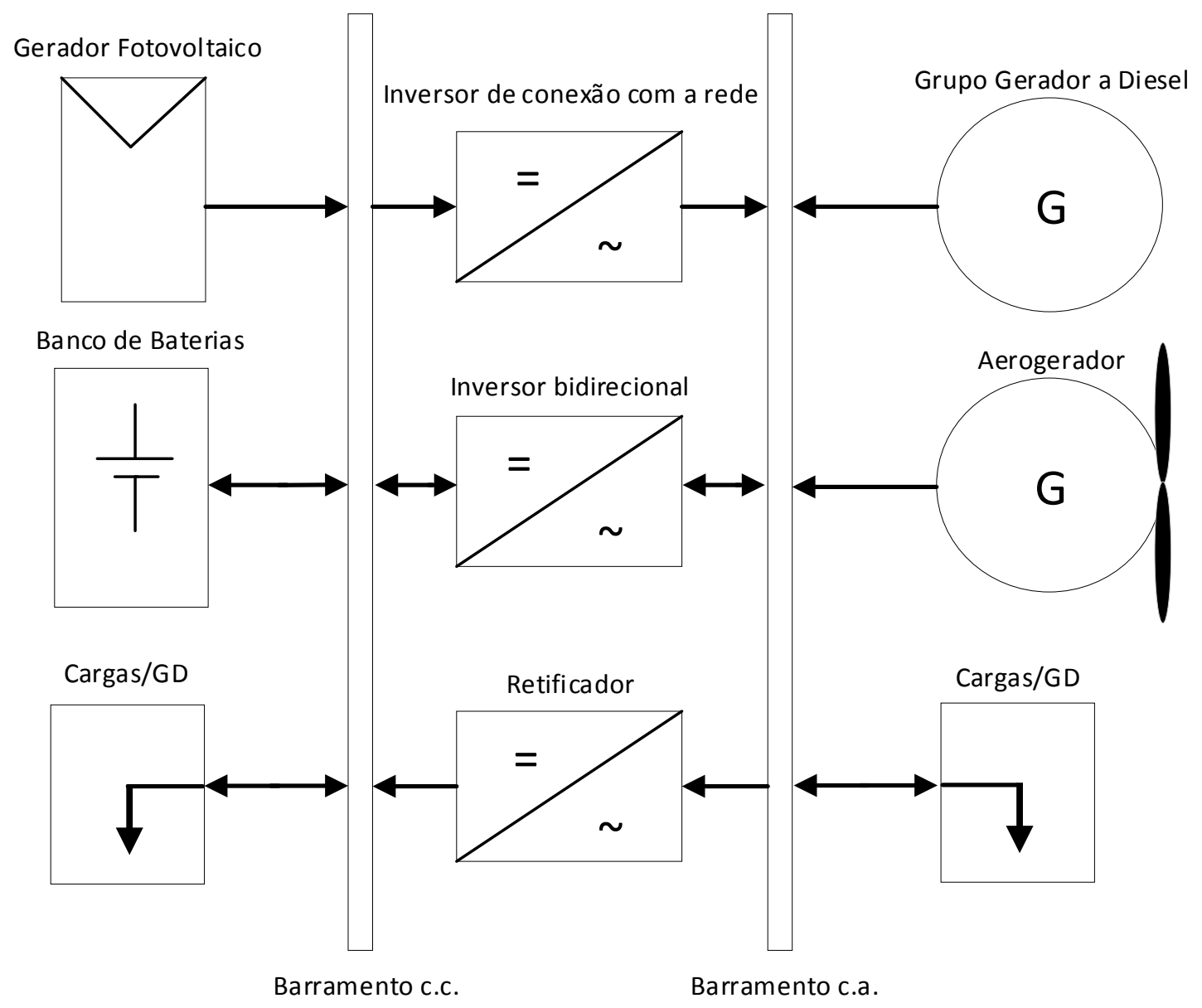

Figura 1.1 - Topologia típica de um sistema híbrido.

Fonte: Adaptado de (BARBOSA, 2006)

Segundo PINHO et al., (2008b), os sistemas híbridos podem ser classificados de diversas formas distintas; contudo, as mais relevantes e que estão inseridas nesta dissertação são: classificação quanto à interligação com a rede elétrica convencional; classificação quanto à prioridade de uso das fontes de energia; classificação quanto à forma de acoplamento dos sistemas de geração; e classificação quanto ao porte.

A classificação quanto à interligação com a rede elétrica convencional refere-se ao SH estar operando conectado à rede elétrica ou isolado da mesma.

A classificação quanto à prioridade de uso das fontes de energia baseia-se na utilização prioritária ou não das fontes renováveis. Os sistemas podem ser classificados como: sistemas baseados no recurso não renovável ou sistemas baseados no recurso renovável. 
A classificação quanto à forma de acoplamento dos sistemas de geração refere-se ao local de acoplamento em que os sistemas de geração estão conectados ao sistema híbrido. Esta classificação pode ser realizada de três formas: com o acoplamento dos geradores no barramento c.c., com o acoplamento dos geradores no barramento c.a., e com o acoplamento dos geradores de forma mista (barramentos c.c. e c.a.).

A classificação quanto ao porte é baseada na capacidade nominal instalada dos sistemas híbridos e é realizada da seguinte maneira:

A. Sistema híbrido de micro porte - Capacidades $<5 \mathrm{~kW}$ (faixa de potência utilizada para o atendimento de pequenas cargas individuais);

B. Sistema híbrido de pequeno porte $-5 \mathrm{~kW} \leq$ Capacidade $<100 \mathrm{~kW}$ (faixa de potência mais utilizada);

C. Sistema híbrido de médio porte $-100 \mathrm{~kW} \leq$ Capacidade $<1.000 \mathrm{~kW}$ (faixa de potência tipicamente constituída por grandes capacidades relativas ao subsistema de geração diesel-elétrico);

D. Sistema híbrido de grande porte - Capacidade $>1.000 \mathrm{~kW}$.

Contudo, quando o sistema híbrido é conectado à rede elétrica, o mesmo segue os critérios da Resolução Normativa ANEEL 482/2012, com a atualização pela RN 687/2015, do seguinte modo:
A. Microgeração < $75 \mathrm{~kW}$;
B. Minigeração. $75 \leq$ Capacidade $<5 \mathrm{MW}$.

Os sistemas utilizados no LSF podem ou não ser conectados à rede elétrica, são baseados na utilização do recurso renovável, e são de pequeno porte. Todos os sistemas híbridos analisados possuem acoplamento c.c. e/ou misto.

Os conceitos apresentados anteriormente introduzem as definições de sistemas híbridos e de minirredes. As pesquisas sobre sistemas híbridos aplicados à eletrificação rural é um tema bem relevante e com diversos trabalhos publicados. Alguns destes trabalhos foram utilizados como referências para a elaboração desta dissertação. 
BARBOSA (2006) realiza uma avaliação da implementação de sistemas híbridos fotovoltaico-eólico-diesel na região Norte, realizando uma revisão do estado da arte dos sistemas híbridos, caracterizando sua evolução histórica, os principais tipos e classificações, as suas composições básicas e aspectos positivos e negativos da eletrificação usando SH. Também são analisadas as características técnicas, operacionais, econômicas e de gerenciamento, que servem como base para as proposições de modelos para $\mathrm{SH}$, que influenciam diretamente sobre a estratégia de operação e gestão dos $\mathrm{SH}$ regionais.

HAUSCHILD (2006) faz uma avaliação de estratégias de operação de SH fotovoltaico-eólico-diesel utilizados para eletrificação rural descentralizada, aplicada a dois estudos de caso. A análise tem por objetivo a otimização da utilização do grupo gerador a diesel, determinando como o GGD deveria ser conectado ao $\mathrm{SH}$ e qual seria o melhor momento para fornecimento de energia para $\circ \mathrm{SH}$. São apresentados os princípios fundamentais de $\mathrm{SH}$ e uma técnica de dimensionamento de SH. A avaliação das estratégias de operação é feita por meio de simulações que utilizam dados coletados nas próprias localidades, como o perfil de consumo de energia elétrica e os potenciais solar e eólico. Com esses dados são efetuadas simulações com diferentes estratégias de operação e diferentes graus de participação das energias renováveis na energia total produzida pelo sistema, a fim de se obterem resultados da operação do sistema, como consumo de óleo diesel e profundidade de descarga média do banco de baterias. A partir dos resultados das simulações faz uma análise econômica, a fim de determinar qual das estratégias é a mais adequada para a operação de SH de fornecimento de energia elétrica.

LAU et al. (2010) realizam simulações computacionais para avaliar os potenciais beneficios ambientais, energéticos e econômicos da implementação de um sistema híbrido fotovoltaico-diesel substituindo sistemas de geração puramente a diesel em comunidades isoladas da Malásia. A diminuição da dependência de combustiveis fósseis, a maior inserção de fontes renováveis, o aumento da oferta de energia, e a diminuição dos impactos ambientais foram os fatores que incentivaram a realização da pesquisa. A investigação demonstrou o impacto da penetração da geração fotovoltaica no custo da energia, e na diminuição das horas de funcionamento dos GGD para as configurações híbridas consideradas. Com os 
resultados das simulações foi possivel verificar que há elevado potencial para a implementação, atualização e/ou substituição dos sistemas isolados com geração a diesel por sistemas hibridos fotovoltaico-diesel.

BLASQUES (2014) apresenta propostas de otimização para as etapas de dimensionamento, operação e gestão de SH de geração de eletricidade atendendo minirredes de distribuição de eletricidade. É realizada uma revisão bibliográfica sobre as estratégias de operação, tarifação e gestão da energia, e proposta uma estratégia de operação que visa otimizar o despacho de energia do sistema, identificando a melhor relação, sob aspectos técnicos e econômicos, entre o atendimento da carga exclusivamente via fontes renováveis e banco de baterias (BB), ou exclusivamente pelo GGD. Duas formas de carregamento foram analisadas, uma com o BB sendo carregado exclusivamente pelo sistema fotovoltaico e outra com o BB também podendo ser carregado pelo GGD. É proposto um modelo de gestão do sistema, considerando formas de tarifação e sistemas de controle de carga, cujo objetivo é garantir uma relação adequada entre a disponibilidade energética do sistema de geração e a carga demandada. O modelo de gestão do sistema propõe o estabelecimento de limites de consumo e demanda adequados à realidade de comunidades isoladas atendidas por sistemas com fontes renováveis que, se corretamente empregados, podem ajudar a garantir a sustentabilidade dos sistemas.

VERÍSSIMO (2014) apresenta o processo de montagem, instalação, comissionamento e ensaios operacionais do Laboratório de Estudos de $\mathrm{SH}$ e Minirredes do GEDAE/UFPA. Nesse trabalho são apresentados: definição, histórico, composição, tipos, classificações, vantagens, desvantagens e exemplos de aplicações desses sistemas e também é feita uma abordagem sobre minirredes no contexto mundial e nacional. Posteriormente, são definidos e especificados todos os equipamentos que compõem o laboratório e são apresentados os processos de montagem, instalação e comissionamento de tais equipamentos. Por fim, são apresentados resultados de ensaios operacionais, que comprovam a efetividade de funcionamento do sistema.

Os trabalhos apresentados anteriormente comprovam 0 elevado conhecimento na aplicação de SH operando isolados da rede elétrica, com relação 
às suas funcionalidades, topologias, estratégias operacionais, e formas de acoplamento dos geradores. Contudo, a evolução da tecnologia permitiu a aplicação dos SH de formas distintas às formas mais habituais. STRAUSS (2003), nesta vertente, exemplifica a interconexão entre $\mathrm{SH}$ operando isolados da rede elétrica, bem como a conexão de $\mathrm{SH}$ com a rede elétrica aplicando novas estratégias de controle.

\subsection{Interconexão entre Sistemas Híbridos Operando Isolados da Rede}

\section{Elétrica}

A interconexão entre SH se apresenta como uma potencial solução para adversidades, tanto em sistemas isolados quanto em sistemas conectados à rede elétrica. A integração permite maior flexibilidade e modularidade, características importantes para melhorar a robustez geral dos sistemas e enfrentar potenciais problemas imprevistos.

A interconexão entre minirredes isoladas, formando uma minirrede híbrida, possibilita 0 intercâmbio de energia entre os consumidores/produtores (prosumidores) e a existência de múltiplos prosumidores permite um melhor gerenciamento dos sistemas de geração e armazenamento, possibilitando uma nova perspectiva para os processos de dimensionamento dos mesmos, e ainda atendendo aos eventuais eventos de elevada demanda. O intercâmbio de energia entre os prosumidores representa uma elevação das possibilidades de estratégias operacionais, permitindo fluxo de energia em momentos de excesso de geração ou elevação da demanda (PEÇAS LOPES et al., 2006). A integração de unidades de geração e armazenamento em um cluster permite flexibilidade de despacho entre os sistemas, aumenta o valor da energia produzida, contribui para a qualidade da energia e resulta em um sistema de energia globalmente mais robusto.

A formação de uma minirrede híbrida possibilita um conjunto de estratégias operacionais, sendo essas: coletiva, atendendo a todos os sistemas, priorizando o intercâmbio de energia entre os sistemas, em vez da utilização da uma fonte central de energia; ou individual, sendo que cada SH possui seu sistema de geração, condicionamento de potência, armazenamento e cargas, existindo, desta forma, a 
possibilidade de realizar uma autogestão e diminuir a dependência de sistemas externos (PALIZBAN et al., 2014). A Figura 1.2 ilustra uma configuração deste tipo.

$\mathrm{Na}$ atualidade, os $\mathrm{SH}$ conseguem fazer conversões c.c./c.a. bem como o processo inverso, por conta da utilização de inversores bidirecionais. A utilização desta topologia ocasiona uma diminuição da dependência de um sistema central de geração, e a energia sobressalente pode ser cedida para outros sistemas que a demandem em determinado momento, possibilitando que o descasamento entre os picos de geração e demanda dos diversos sistemas seja minimizado.

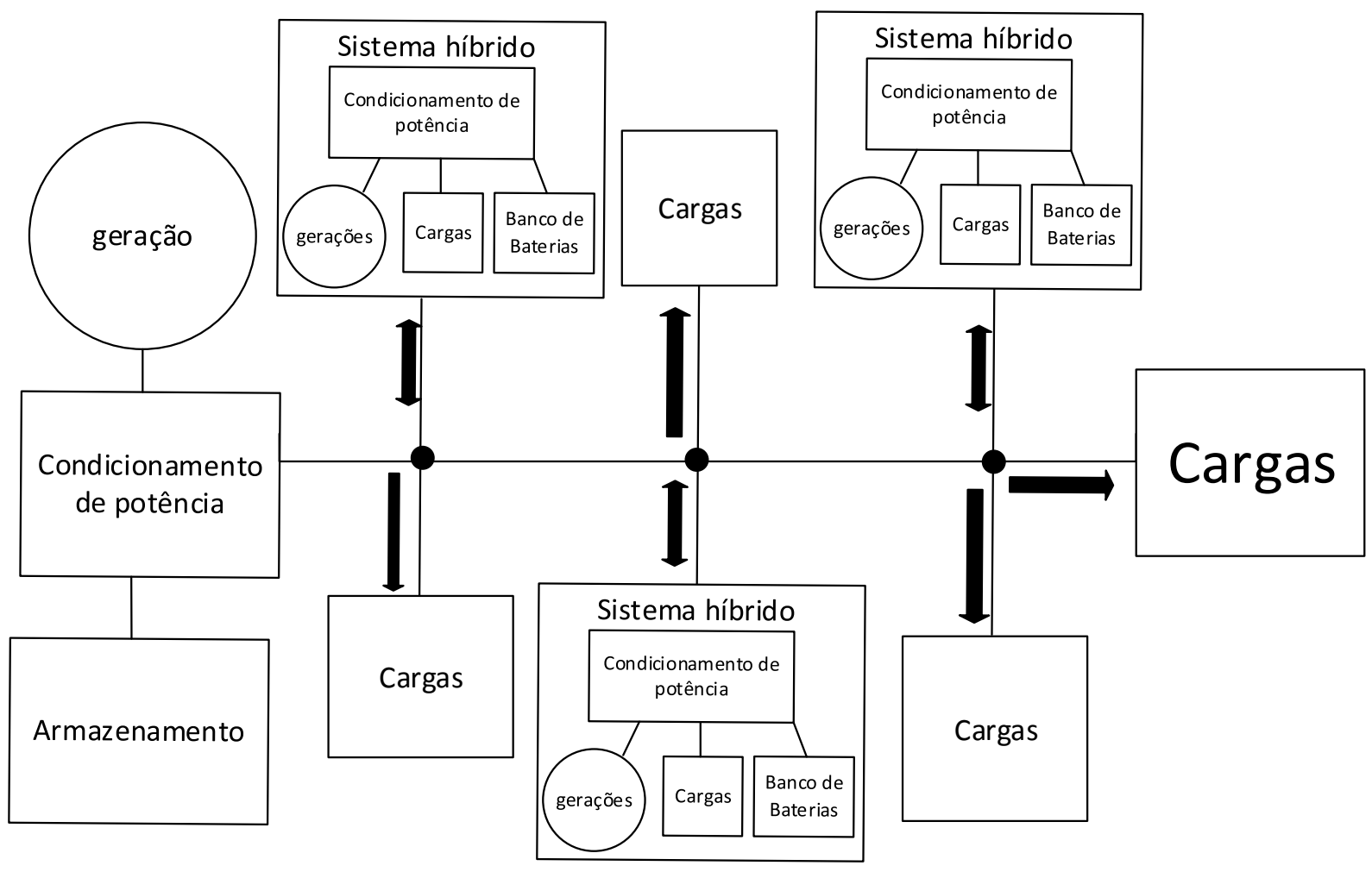

Figura 1.2 - Exemplo da interconexão de sistemas híbridos.

Entretanto, a aplicação de tais topologias ainda não superou dificuldades e barreiras, de modo que todos os benefícios possam ser apreciados. É importante mencionar que o controle de tais topologias é mais complicado, mesmo que estratégias de controle distribuídas e estratégias multi-agente sejam aplicadas. $\mathrm{O}$ sistema de condicionamento de potência precisa de uma maneira de coordenar suas operações, para gerenciar a troca de energia entre os sistemas e a operação de todos os componentes de uma maneira adequada. Além disso, a coordenação e a comunicação entre os agentes envolvidos precisam ir além do nível técnico. As 
barreiras econômicas e regulatórias também precisam ser superadas, pois podem influenciar várias partes interessadas das diferentes áreas integradas.

A integração entre $\mathrm{SH}$ adicionados a uma minirrede de distribuição vem sendo pesquisada por diversos autores. As pesquisas buscam analisar aspectos quanto a estratégias operacionais, modos de acoplamento dos prosumidores, simulações para maior penetração da geração por fontes renováveis, análises econômicas, dentre outros temas (VASILJEVSKA et al., 2012), (JIANG et al., 2013), (MARZBAND et al., 2016). Contudo, mesmo a interconexão apresentando aspectos positivos que ressaltam sua utilização, sua aplicação ainda é pouco difundida na prática.

Além das barreiras anteriormente citadas, a incerteza quando à forma ideal de interconexão, controle, comunicação, operação e estabilidade deste tipo de topologia são fatores que diminuem a atratividade para a aplicação da interconexão de SH. Neste sentido, grupos de pesquisa estão investigando estas lacunas, visando auxiliar na maior utilização de minirredes híbridas.

\subsection{Interconexão de Sistemas Híbridos com a Rede Elétrica}

No contexto brasileiro, a interconexão de $\mathrm{SH}$ com a rede elétrica ainda não é permitida, já que não há legislação para sistemas com armazenamento. 0 desconhecimento quanto à operação, potenciais benefícios ou adversidades que estas conexões podem realizar ainda é uma barreira a ser superada.

A transição da aplicação de SH operando de modo isolado para a conexão com a rede elétrica é baseada nos potenciais benefícios que sistemas de geração com fontes renováveis e com acumulação podem fornecer para o prosumidor e para o sistema elétrico. A micro e a minigeração estão regulamentadas no Brasil desde 2012; contudo, esta ocorre sem um sistema de armazenamento e os prosumidores ficam dependentes da rede elétrica. A possibilidade de gerenciamento da demanda e da geração pode trazer uma nova realidade para o setor elétrico.

Os benefícios da conexão de SH com a rede elétrica são: atenuação da rampa de demanda, fornecimento de serviços ancilares, estabilização de tensão e 
frequência, correção de fator de potência, dentre outros benefícios. Contudo, os desafios associados à interconexão de SH não se limitam aos de natureza técnica, sendo as barreiras econômicas e regulatórias mais difíceis de serem superadas (Novaes et al., 2018).

Quanto aos aspectos econômicos, a possibilidade de gestão da geração e da demanda apresenta benefícios para os prosumidores e para o sistema elétrico. Para os prosumidores, o retorno do valor da energia consumida e não demandada da rede elétrica; já para o setor elétrico, esta forma de conexão possibilita postergar investimentos no sistema de geração, transmissão e distribuição. Segundo PALIZBAN et al., (2014), a interconexão de SH com a rede elétrica representa a implantação de usinas virtuais pelos benefícios apresentados. Porém, em contrapartida, sua aplicação ocasiona a criação de um novo mercado, que ainda precisa ser regulado (SINHA et al., 2008). O gerenciamento da demanda e da geração permite a adoção de várias estratégias, possibilitando períodos de desconexão, períodos de injeção de potência, e períodos de demanda de potência, de acordo com a estratégia operacional adotada. A Figura 1.3 apresenta a transição da geração distribuída atual para a geração distribuída com adição dos $\mathrm{SH}$, com a elevação da penetração dos prosumidores, onde estes deixam de ser personagens passivos e tornam-se personagens ativos do setor elétrico, auxiliando na geração e prestação de serviços. 


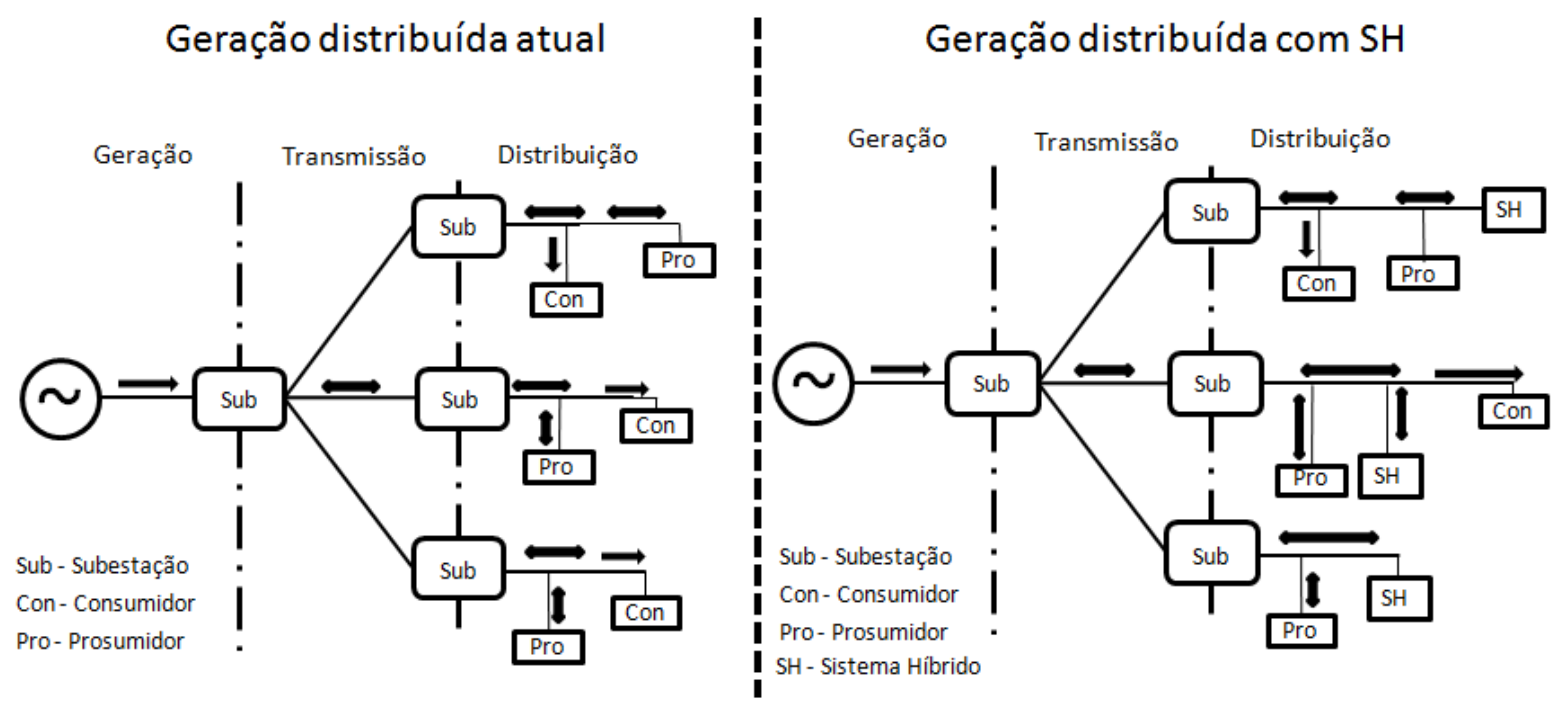

Figura 1.3 - Exemplo da transição da geração distribuída atual para a geração distribuída com SH.

$\mathrm{Na}$ conexão de $\mathrm{SH}$ com a rede elétrica também há outros problemas importantes analisados, como: a questão da precificação dos serviços ancilares prestados pelos prosumidores com armazenamento para a rede elétrica (PEÇAS LOPES et al., 2007), a quantificação dos benefícios de medidas de eficiência energética com a aplicação de sistemas de armazenamento e geração local e renovável ao longo do sistema de distribuição (DIVYA e ØSTERGAARD, 2009), a quantificação dos benefícios ambientas da elevação da utilização de fontes renováveis não poluentes, como a diminuição das emissões de gases do efeito estufa dentre outros benefícios ambientais (RAHIMI e IPAKCHI, 2010).

Os pontos positivos da possibilidade de conexão de $\mathrm{SH}$ com a rede elétrica são inúmeros; porém, a melhor forma de realizar isso ainda é uma incógnita. Alguns testes experimentais em pequena escala têm sido realizados, buscando entender 0 modo de operação, estabilidade, confiabilidade, estratégias de controle, etc. (DALI et al., 2010). Contudo, para maior penetração desta ação ainda se faz necessário realizar mais testes operacionais em condições reais, com cargas elevadas, e sistemas de geração, condicionamento de potência e armazenamento mais robustos.

A conexão de SH com a rede elétrica ainda possui fatores que diminuem sua atratividade de interconexão. Esses fatores são: 
- Os elevados custos associados ao sistema de armazenamento e condicionamento de potência, e também a vida útil relativamente curta do sistema de armazenamento;

- $\quad$ A falta de regulamentação adequada para a conexão;

- Modo de cobrança, e a possibilidade de criação de um mercado de energia paralelo. Onde a compra da energia ocorra no momento em que ela está com menor preço e sua venda quando ela estiver com maior valor.

\subsection{Capacitação e Qualificação Profissional}

A qualificação profissional ainda representa um obstáculo a ser superado na utilização de fontes renováveis de energia em geral. Atualmente, mesmo as empresas que realizam inúmeras instalações ainda necessitam adquirir mais conhecimento sobre os equipamentos utilizados (BLASQUES, 2014). Na atualidade, há apenas indicadores do aumento exponencial das instalações de micro e minigeradores, não havendo, porém, indicadores sobre a qualidade das instalações. Todavia, há esforços da academia, indústria e concessionárias para elevar a qualidade das instalações, pois a sua falta representa sérios problemas, como: custo de manutenção elevado; redução do desempenho; risco às pessoas e ao patrimônio; perda da confiabilidade na tecnologia, dentre outros.

A preocupação com a capacitação dos profissionais que possam atuar no mercado de fontes renováveis é evidente, tanto em sistemas conectados à rede elétrica quanto em sistemas isolados. Os danos causados pela ausência de medidas de segurança são inúmeros, pois, além de danos materiais, existe a possibilidade de riscos para instaladores e beneficiados da instalação, que precisam ser evitados.

A busca por alternativas que melhorem este panorama é global, ocorrendo esforços em diversas localidades do mundo. Em âmbito nacional alguns autores apontam possíveis soluções para elevação da qualificação profissional, como por exemplo (MOCELIN, 2014) e (SILVA, 2017), cujas contribuições são comentadas posteriormente. Em âmbito internacional a preocupação com a qualificação profissional também vem sendo estudada por alguns pesquisadores. TSOUTSOS et al. (2013), apresentam uma série de iniciativas e medidas de capacitação e qualificação profissional, para conseguirem atingir a meta de $20 \%$ de energias 
renováveis no consumo final de energia até 2020. A prerrogativa é fundamentada na seguinte afirmação: "A aplicação de tecnologias fotovoltaicas requer técnicos altamente qualificados para instalação, manutenção e operação. Até hoje, os mercados nacionais têm crescido mais rápido do que a capacidade que os instaladores de sistemas fotovoltaicos são capazes de satisfazer".

SOORIYAARACHCHI et al. (2015) apresentam estudos de casos na Alemanha, Espanha, Estados Unidos e na região do Oriente Médio, que demonstram a criação de empregos com a aplicação de fontes renováveis e medidas de eficiência energética. Isso evidencia a importância dos efeitos socioeconômicos associados ao desenvolvimento destas tecnologias.

Em termos gerais a qualificação profissional, que hoje representa uma barreira na difusão da tecnologia, pode ser a solução para problemas pontuais na sociedade. Ações concretas para sua aplicação possibilitam a elevação da qualidade das instalações, que por sua vez irá melhorar o desempenho dos sistemas, resultando em uma maior penetração e criação de mercado mais sólido, além de gerar empregos. 


\section{Capítulo 2 - Infraestrutura Laboratorial para Estudos de Minirredes Híbridas Inteligentes}

Este capítulo descreve os dois sistemas híbridos pré-existentes no LSF, bem como a ampliação da infraestrutura do LSF através de dois sistemas híbridos que foram instalados pela equipe técnica do LSF no decorrer deste trabalho. São destacados os componentes utilizados, suas especificações técnicas, diagramas, etc. Neste capitulo também é apresentada a integração dos quatro sistemas híbridos, descrevendo a composição do quadro de controle, os dispositivos utilizados, e as possibilidades de interação entre os sistemas.

O LSF, fundado em 1995, tem dentre seus projetos de pesquisa quatro topologias de sistemas híbridos $(\mathrm{SH})$, que consistem de um conjunto de equipamentos para representar sistemas elétricos de fornecimento de energia com configurações distintas, que podem funcionar individualmente ou conjuntamente, de forma isolada ou interligada à rede da concessionária.

A Figura 2.1 apresenta uma vista da área de testes do LSF, destacando em primeiro plano os diversos geradores fotovoltaicos utilizados nos sistemas híbridos e em outras aplicações.

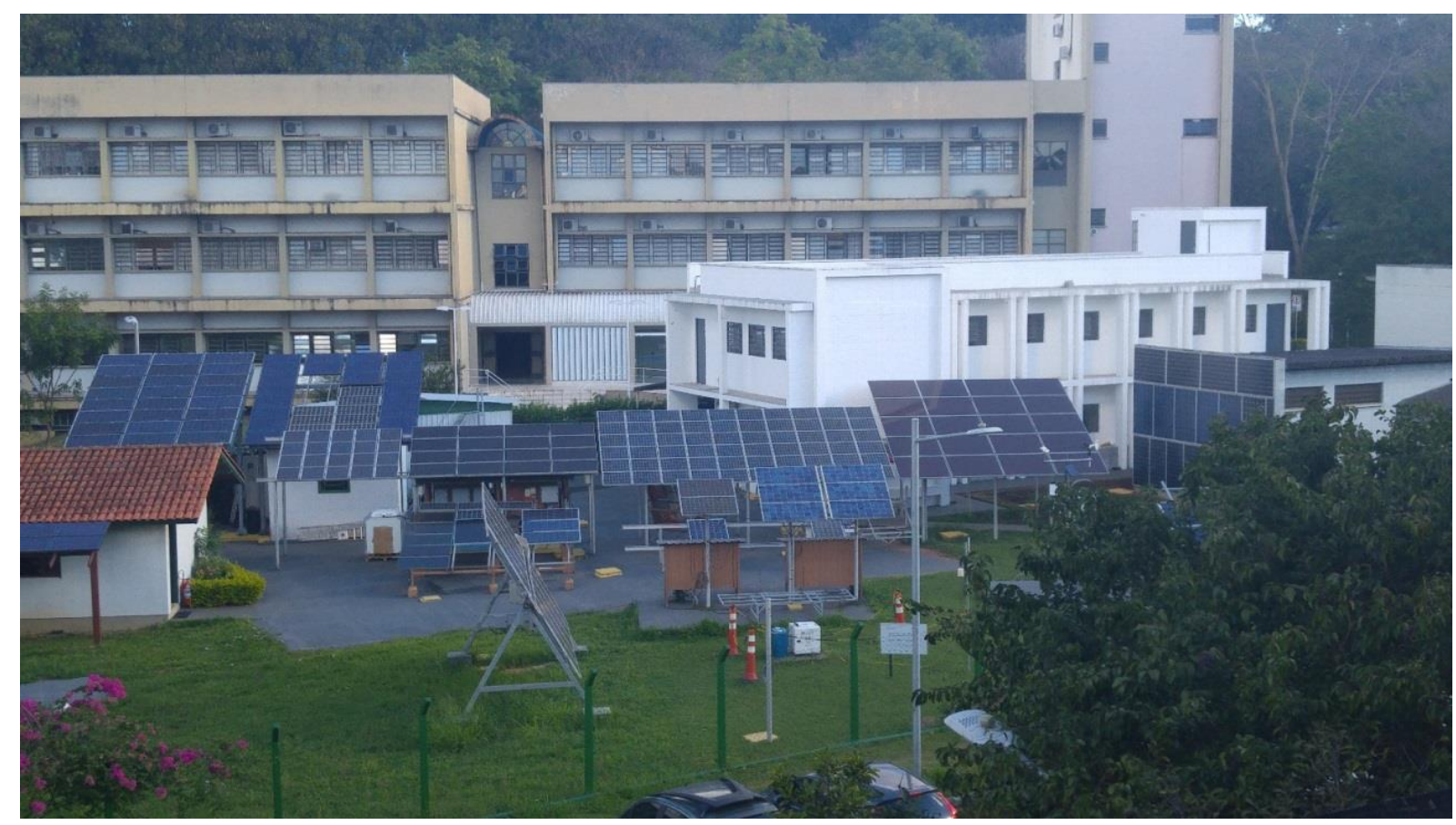

Figura 2.1 - Vista geral do LSF. 
As quatro topologias de sistemas são híbridas, por utilizarem mais de uma fonte de energia (MANWELL, 2004), (PINHO et al., 2008a), sendo elas a energia solar fotovoltaica (renovável) e a energia proveniente de um grupo gerador a diesel, e todas possuem sistemas de armazenamento eletroquímico (bancos de baterias), podendo ainda se conectar à rede elétrica convencional de distribuição. As configurações são:

- $\quad$ Sistema SMA Trifásico - ST1;

- $\quad$ Sistema Studer Trifásico - ST2;

- $\quad$ Sistema SMA Monofásico - SM1;

- $\quad$ Sistema Schneider Monofásico - SM2.

\subsection{Sistema Trifásico 1}

O sistema SMA Trifásico é composto por sistemas de geração de energia elétrica, condicionamento de potência, armazenamento, sensoriamento, comunicação, medição, proteção, consumo de energia, distribuição e comando, conforme descrito a seguir.

- Sistema de Geração:

> 8 Geradores fotovoltaicos (GFV-01, GFV-02, GFV-03, GFV-04, GFV-05, GFV-06, GFV-07 e GFV-08);

$>1$ Fonte c.c. de $10 \mathrm{~kW}$.

$>1$ Grupo gerador a diesel de 40 kVA (GGD).

- Sistema de Condicionamento de Potência:

> 7 Inversores de conexão à rede (INVG-01, INVG-02, INVG-03, INVG-04, INVG-05, INVG-06 e INVG-07);

> 3 Inversores bidirecionais de $5 \mathrm{~kW}$ cada (INVB-01, INVB-02 e INVB-03);

> 2 Controladores de carga (CDC-01 e CDC-02);

> 1 Transformador elevador 220 / 380 V, de 50 kVA;

> 1 Transformador abaixador de 380 / 220 V, 50 kVA.

- Sistema de Armazenamento:

> 1 Banco de baterias VRLA de 48 V / 490 Ah em C10.

- Sistema de Distribuição e Comando:

> 1 Multicluster box (SMA / MC-Box 6.3). 
- Sistema de Proteção e Seccionamento:

> 6 Chaves seccionadoras triplas portas fusíveis (Nh00 e NH01);

> 33 Disjuntores;

> 16 Dispositivos de proteção contra surto;

> 8 Fusíveis cilíndricos;

$>\quad 7$ Chaves contatoras.

- Sistema de Medição:

$>5$ Shunts;

> 2 Dataloggers (Agilent / 34970A);

> 4 Medidores bidirecionais (MB-01, MB-02, MB-03 e MB-04);

> 4 Transdutores de tensão.

- Sistema de Sensoriamento:

$>1$ Sensor de temperatura ambiente;

$>1$ Sensor de temperatura de costa de módulo;

$>1$ Anemômetro;

$>1$ Sunny sensor box (SSB).

- Sistema de Monitoramento:

$>1$ Sunny boy control plus (SBC);

$>\quad$ Programa de Leitura e Análise de Dados (PLA);

$>1$ Sunny Data Control (SDC);

> Programa Rainbowplus;

$>1$ Computador.

- $\quad$ Sistema de Consumo de Energia:

> 2 Quadros de distribuição;

$>$ Cargas.

A Figura 2.2 ilustra o diagrama esquemático do ST1. 


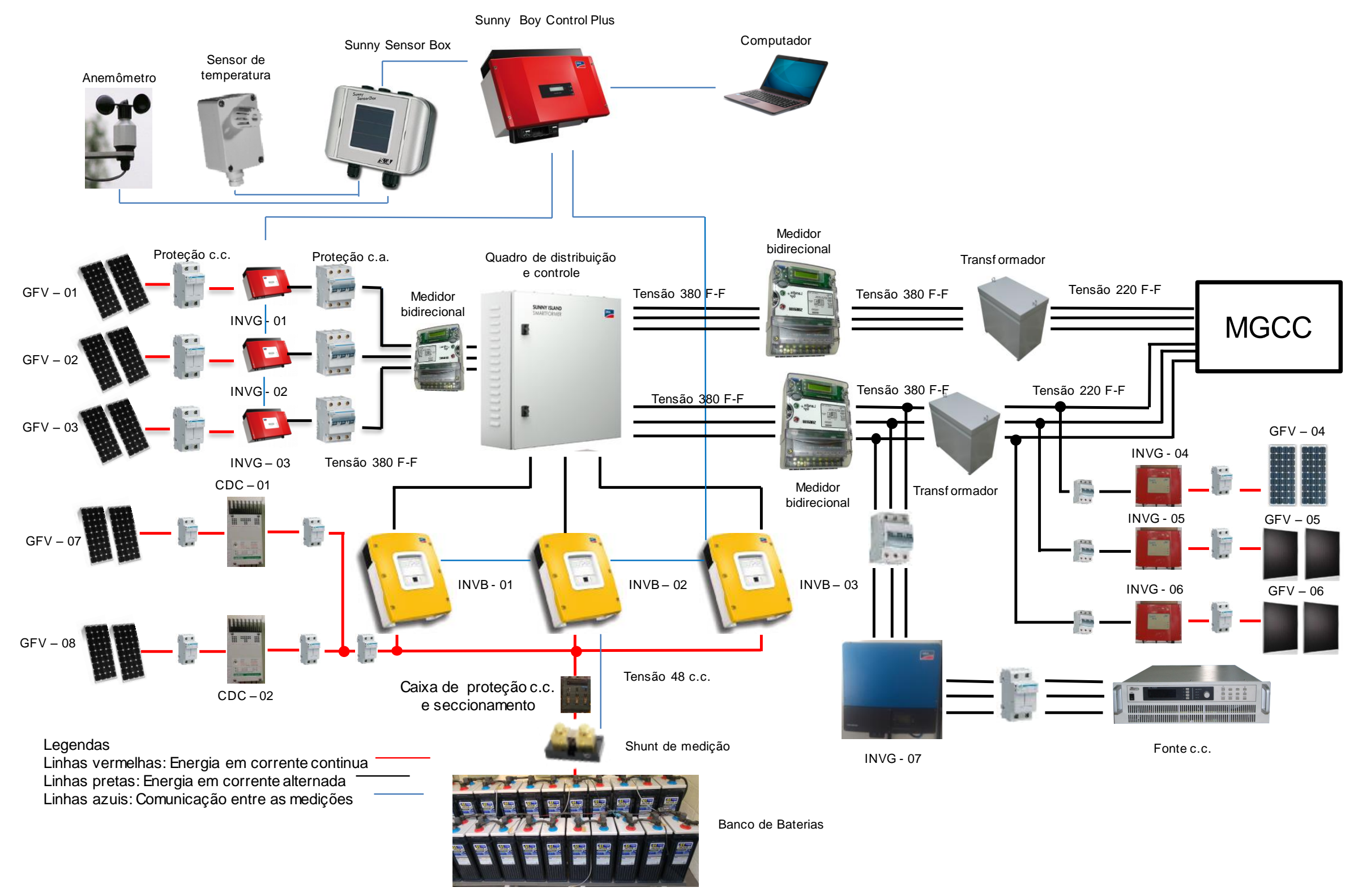

Figura 2.2 - Diagrama esquemático do sistema SMA - Trifásico. 
Assim como descrito anteriormente, o ST1 possui alguns sistemas em sua composição; contudo, são detalhados apenas os sistemas de geração de energia elétrica, condicionamento de potência, armazenamento, distribuição e comando. Os outros sistemas são brevemente apresentados, e maiores detalhes sobre os mesmos estão presentes na Descrição da Minirrede com Sistemas Híbridos do LSF, relatório técnico, que foi utilizado como referencial teórico para documentação das minirredes do laboratório. (Novaes, et al., 2018b).

\subsubsection{Sistema de Geração}

O sistema de geração é responsável pela conversão de fontes primárias em energia elétrica. O ST1 é um sistema híbrido, por utilizar mais de uma fonte de energia para a geração de eletricidade, no caso a solar, diesel, fonte c.c. e rede elétrica.

\subsubsection{Geradores Fotovoltaicos}

Neste sistema, há oito geradores fotovoltaicos, denominados de GFV01/ST1, GFV-02/ST1, GFV-03/ST1, GFV-04/ST1, GFV-05/ST1, GFV-06/ST1, GFV07/ST1 e GFV-08/ST1, conforme apresentado na Figura 2.3.

Os geradores fotovoltaicos GFV-01/ST1, GFV-02/ST1 e GFV-03/ST1 são conectados aos INVG-01/ST1, INVG-02/ST1 e INVG-03/ST1, constituindo um sistema de geração com acoplamento em corrente alternada. Os geradores GFV04/ST1, GFV-05/ST1 e GFV-06/ST1 são conectados aos INVG-04/ST1, INVG05/ST1 e INVG-06/ST1, sendo, porém, conectados no lado da carga no multicluster, realizando o fluxo reverso de potência como geração distribuída. O GFV-07/ST1 e o GFV-08/ST1 estão conectados aos CDC-01/ST1 e CDC-02/ST1, realizando, deste modo, o acoplamento em corrente contínua, junto ao banco de baterias. 


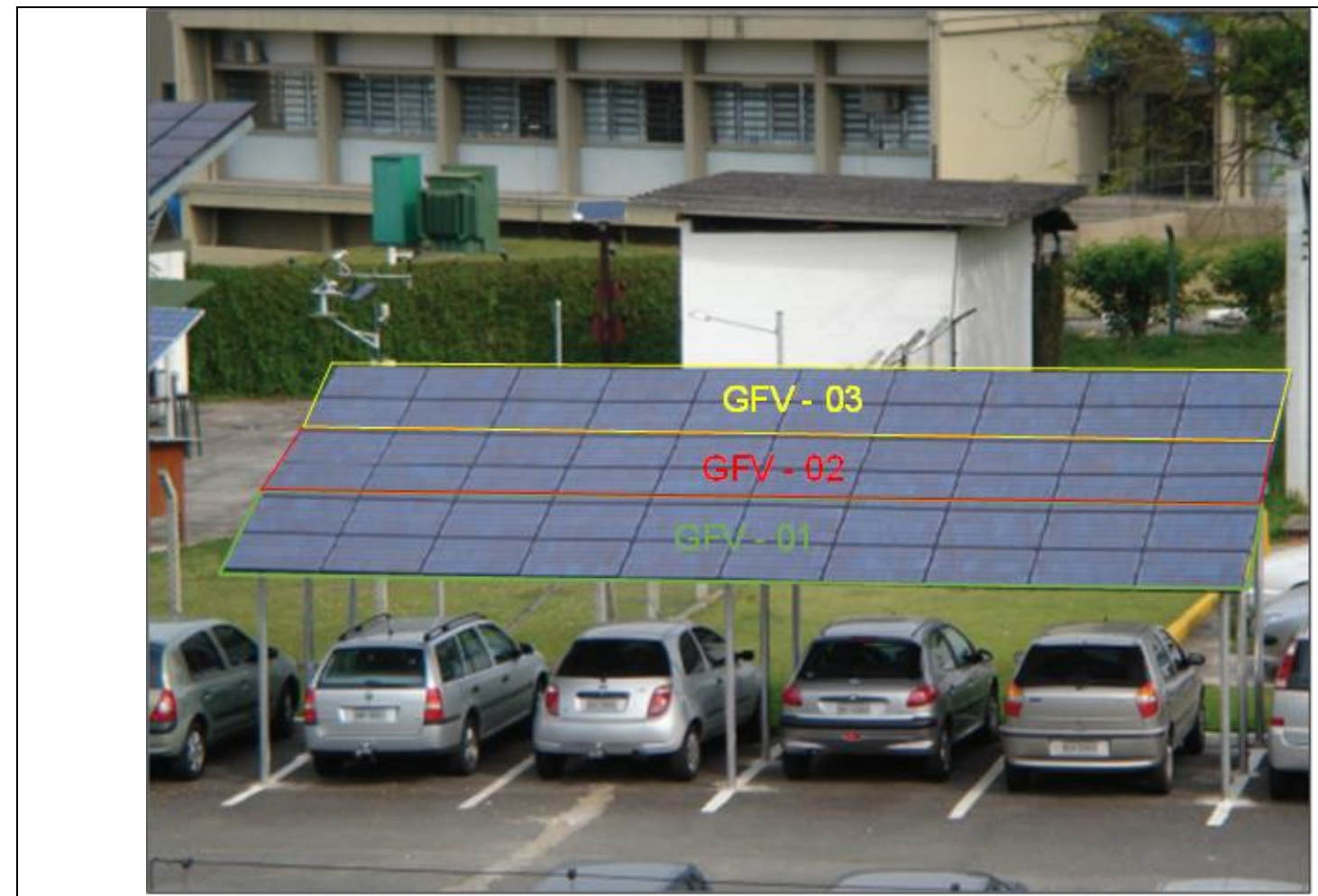

GFV-01/ST1, GFV-02/ST1 e GFV-03/ST1.

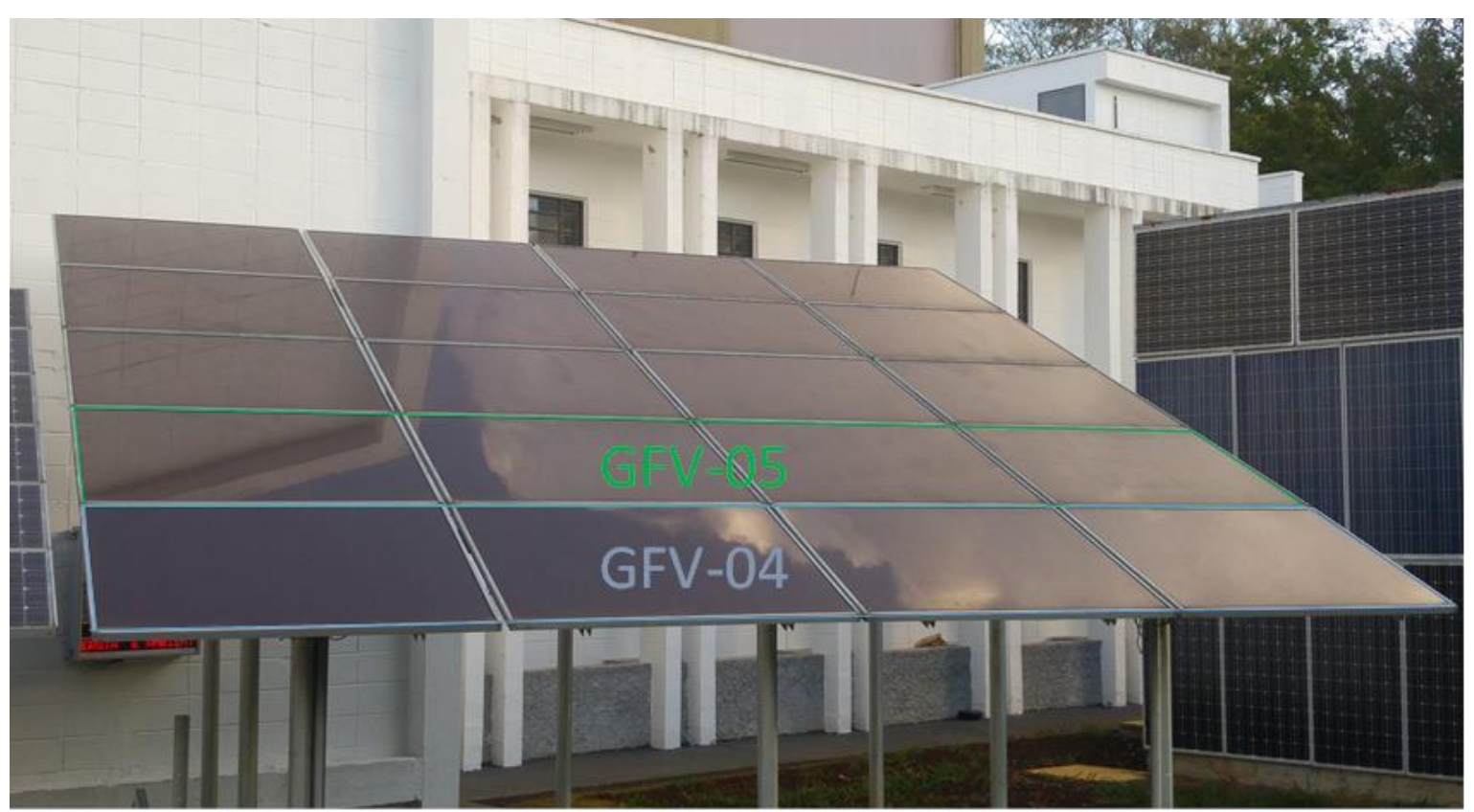

GFV-04/ST1 e GFV-05/ST1. 

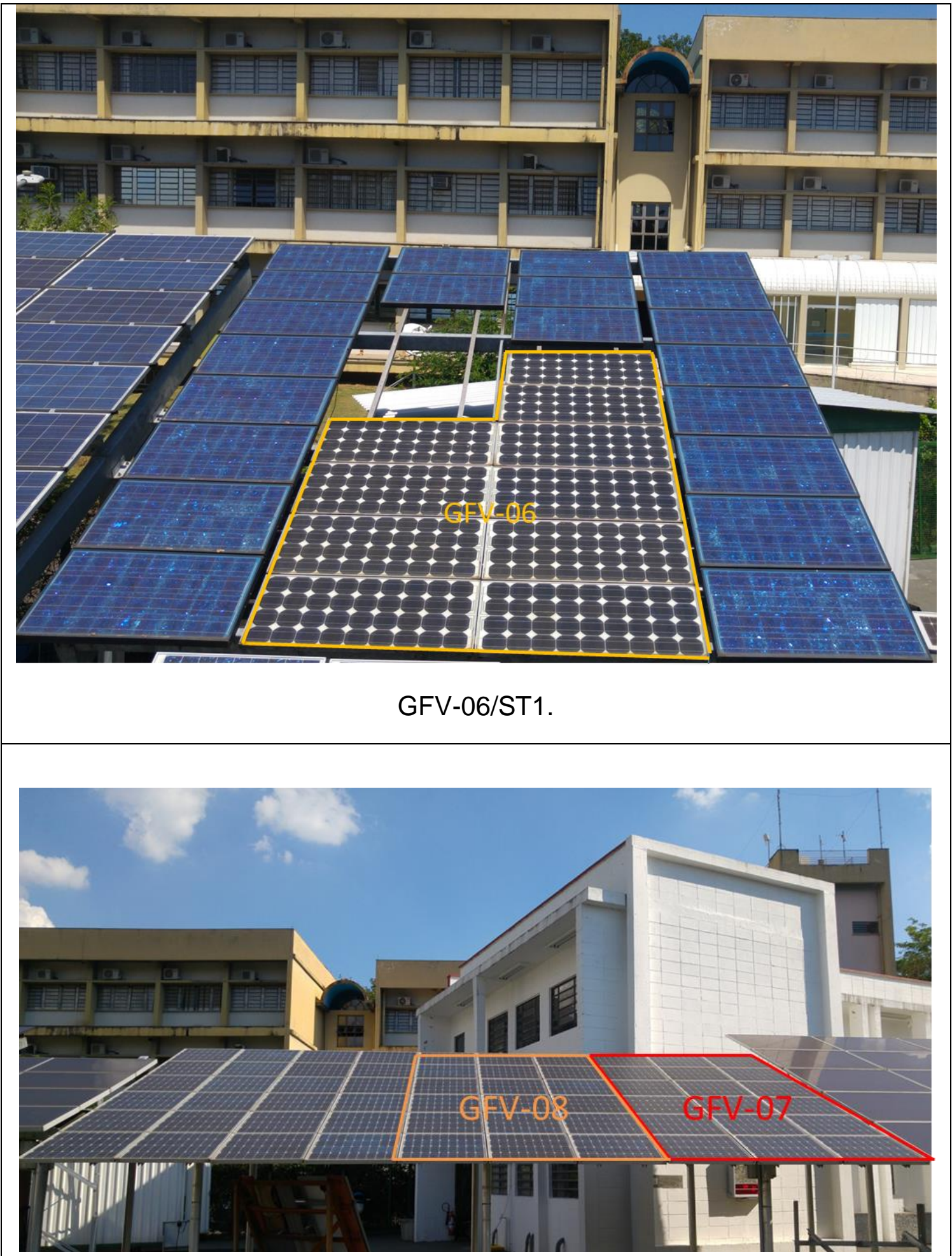

GFV-07/ST1 e GFV-08/ST1.

Figura 2.3 - Geradores fotovoltaicos do ST1. 
A Figura 2.3 apresenta os geradores fotovoltaicos; porém, o número de módulos apresentados na figura é maior do que o indicado, já que o arranjo fotovoltaico em que os geradores GFV-04/ST1 e GFV-05/ST1 estão ligados, também possui módulos que são utilizados em outra topologia de sistema híbrido e também para um sistema de bombeamento fotovoltaico. O mesmo fato ocorre com os arranjos em que os GFV-06/ST1, GFV-07/ST1 e GFV-08/ST1 estão conectados, que também possuem outros módulos que são utilizados para o bombeamento fotovoltaico.

Os módulos fotovoltaicos que compõem os geradores são dos seguintes fabricantes:

- GFV-01/ST1 Astropower;

- GFV-02/ST1 Astropower;

- GFV-03/ST1 Astropower;

- GFV-04/ST1 DuPont;

- GFV-05/ST1 DuPont;

- GFV-06/ST1 Atersa;

- GFV-07/ST1 Isofotón;

- GFV-08/ST1 Isofotón.

Módulos com diferentes especificações técnicas são utilizados no sistema híbrido para atenderem as especificações dos dispositivos de condicionamento de potência. Os módulos utilizados estão apresentados na Figura 2.4 e os dados de placa estão mostrados na Tabela 2.1. 


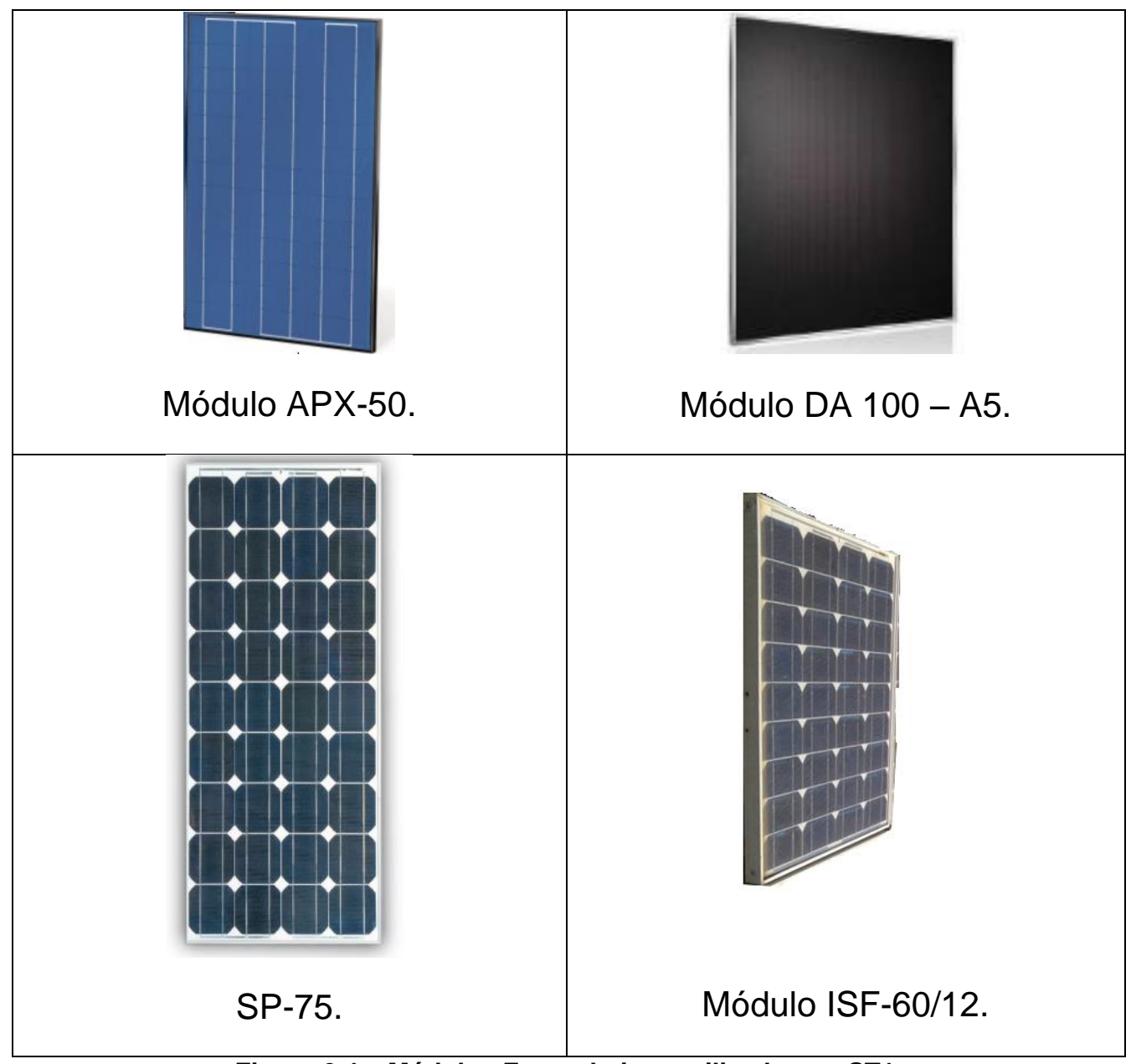

Figura 2.4 - Módulos Fotovoltaicos utilizados no ST1.

Fonte: Adaptado de Astro Power (2002), Atersa (2012), Inmetro (2013), Isofoton (2007).

Tabela 2.1 - Dados dos módulos utilizados no ST1.

\begin{tabular}{|l|l|l|l|l|}
\hline Fabricante & Astropower & DuPont & Atersa & Isofotón \\
\hline Modelo & APX-50 & $\begin{array}{l}\text { DA 100 - } \\
\text { A5 }\end{array}$ & SP-75 & ISF-60/12 \\
\hline Potência & $50 \mathrm{~W}$ & $100 \mathrm{~W}$ & $75 \mathrm{~W}$ & $60 \mathrm{~W}$ \\
\hline $\begin{array}{l}\text { Tensão de máxima potência } \\
(\text { Vmp) }\end{array}$ & $16,7 \mathrm{~V}$ & $75 \mathrm{~V}$ & $17 \mathrm{~V}$ & $17,3 \mathrm{~V}$ \\
\hline $\begin{array}{l}\text { Corrente de máxima potência } \\
\text { (Imp) }\end{array}$ & $3,0 \mathrm{~A}$ & $1,34 \mathrm{~A}$ & $4,4 \mathrm{~A}$ & $3,47 \mathrm{~A}$ \\
\hline
\end{tabular}




\begin{tabular}{|l|l|l|l|l|}
\hline Corrente de curto-circuito (Isc) & $3,6 \mathrm{~A}$ & $1,66 \mathrm{~A}$ & $4,8 \mathrm{~A}$ & $3,73 \mathrm{~A}$ \\
\hline Tensão de circuito aberto (Voc) & $21,5 \mathrm{~V}$ & $100 \mathrm{~V}$ & $21,7 \mathrm{~V}$ & $21,6 \mathrm{~V}$ \\
\hline Máxima tensão do sistema & $600 \mathrm{~V}$ & $1.000 \mathrm{~V}$ & $1.000 \mathrm{~V}$ & $760 \mathrm{~V}$ \\
\hline Tipo de célula & Poly-Si & Filme fino & Mono-Si & Poly-Si \\
\hline Número de células & 36 & -- & 36 & 36 \\
\hline
\end{tabular}

Fonte: Adaptado de Astro Power (2002), Atersa (2012), Inmetro (2013), Isofoton (2007).

A composição dos geradores fotovoltaicos é descrita a seguir:

- GFV-01: 10 módulos em série (string) (215 Voc / 167 Vmp) e dois strings em paralelo (6 Imp), totalizando 20 módulos (1,0 kWp).

- GFV-02: 10 módulos em série (string) (215 Voc / 167 Vmp) e dois strings em paralelo (6 Imp), totalizando 20 módulos (1,0 kWp).

- GFV-03: 10 módulos em série (string) (215 Voc / $167 \mathrm{Vmp}$ ) e dois strings em paralelo (6 Imp), totalizando 20 módulos (1,0 kWp).

- GFV-04: 2 módulos em série (string) (200 Voc / 150 Vmp) e dois strings em paralelo (2,68 Imp), totalizando 4 módulos $(0,4 \mathrm{kWp})$.

- $\quad$ GFV-05: 2 módulos em série (string) (200 Voc / $150 \mathrm{Vmp}$ ) e dois strings em paralelo (2,68 Imp), totalizando 4 módulos $(0,4 \mathrm{kWp})$.

- $\quad$ GFV-06: 10 módulos em série (string) (217 Voc / 170 Vmp) e um string (4,4 Imp), totalizando 10 módulos $(0,75 \mathrm{kWp})$.

- $\quad$ GFV-07: 6 módulos em série (string) (129,6 Voc / 103,8 Vmp) e três strings em paralelo (10,41 Imp), totalizando 18 módulos (1,08 kWp).

- GFV-08: 6 módulos em série (string) (129,6 Voc / 103,8 Vmp) e três strings em paralelo (10,41 Imp), totalizando 18 módulos (1,08 kWp).

\subsubsection{Fonte c.c.}

A fonte c.c., apresentada na Figura 2.5, possui potência $10 \mathrm{~kW}$, podendo fornecer energia em corrente contínua na faixa de tensão de 0 a 600 Volts, em 
diversos modos de operação. Suas especificações técnicas estão apresentadas na Tabela 2.2. A fonte c.c. é utilizada no sistema para emular a saída de potência elétrica de um aerogerador.

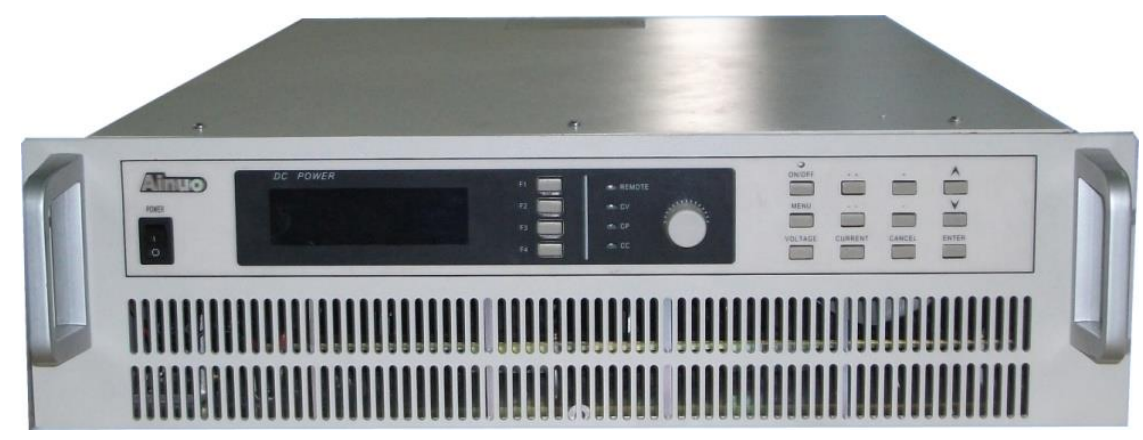

Figura 2.5 - Fonte c.c.

Tabela 2.2 - Especificações técnicas da fonte c.c.

\begin{tabular}{|c|c|c|}
\hline \multirow{6}{*}{ Entrada (c.a.) } & Fases & 3-fases + terra \\
\hline & Faixa de tensão & 380 VAC $\pm 10 \%$ \\
\hline & Frequência & $47-63 \mathrm{~Hz}$ \\
\hline & Fator de potência & $>0,78$ \\
\hline & Eficiência & $>87$ \% (Padrão de entrada c.a. em Plena carga) \\
\hline & Estabilidade & $\begin{array}{l} \pm 0,05 \% \text { do ponto de ajuste após } 8 \text { horas de } \\
\text { aquecimento, carga fixa e usando sensor de } \\
\text { temperatura }\end{array}$ \\
\hline \multicolumn{2}{|c|}{ Proteção } & $\begin{array}{l}\text { Na entrada e saída por sobretensão. } \\
\text { Superaquecimento, proteção contra curto-circuito }\end{array}$ \\
\hline \multicolumn{2}{|c|}{ Interface de Comunicação } & RS-232 \\
\hline $\begin{array}{l}\text { Controle analógico } \\
\text { remoto }\end{array}$ & Precisão & $\begin{array}{c}\text { Tensão } \pm 0,25 \% \text { F.S }(0-5 \text { V), 0,5 \% F.S }(0-10 \text { V) } \\
\text { Corrente: } \pm 0,8 \% \text { F. S }\end{array}$ \\
\hline \multirow{3}{*}{ Ambiente } & $\begin{array}{c}\text { Faixa de } \\
\text { temperatura }\end{array}$ & $-25 \sim 65^{\circ} \mathrm{C}$ \\
\hline & $\begin{array}{l}\text { Temperatura de } \\
\text { trabalho }\end{array}$ & $0 \sim 50^{\circ} \mathrm{C}$ \\
\hline & Umidade relativa & $10 \sim 95 \%$ \\
\hline
\end{tabular}




\begin{tabular}{|c|c|c|c|}
\hline & \multicolumn{3}{|c|}{$\leq 65 \mathrm{~dB}$} \\
\hline \multirow{3}{*}{ Dimensões (mm) } & Largura & \multicolumn{2}{|c|}{482} \\
\hline & Altura & \multicolumn{2}{|c|}{132} \\
\hline & Comprimento & \multicolumn{2}{|c|}{613} \\
\hline Peso & \multicolumn{3}{|c|}{$37 \mathrm{~kg}$} \\
\hline \multirow{2}{*}{$\begin{array}{c}\text { Faixa de tensão } \\
\text { de saída }\end{array}$} & Faixa de potência e corrente & \multirow{2}{*}{$\begin{array}{l}\text { Ruído } \\
\text { VPP }\end{array}$} & Ruído \\
\hline & $10 \mathrm{~kW}$ & & RMS \\
\hline $0-40 \mathrm{~V}$ & $0-250 \mathrm{~A}$ & $75 \mathrm{mV}$ & $20 \mathrm{mV}$ \\
\hline $0-600 \mathrm{~V}$ & $0-17 \mathrm{~A}$ & $350 \mathrm{mV}$ & $60 \mathrm{mV}$ \\
\hline
\end{tabular}

\subsubsection{Grupo Gerador a Diesel}

O grupo gerador a diesel (GGD), apresentado na Figura 2.6, é fabricado pela Gruger, sendo cabinado, tipo hospitalar. O GGD possui potência de $40 \mathrm{kVA}$, sendo $32 \mathrm{~kW}$ de potência ativa, tensão de $127 \mathrm{~V}$ fase-neutro, e $220 \mathrm{~V}$ fase-fase. A sua configuração de instalação foi planejada para suprir demandas eventuais, como testes, ou falta de energia da rede externa, podendo ser acionado com partida remota.

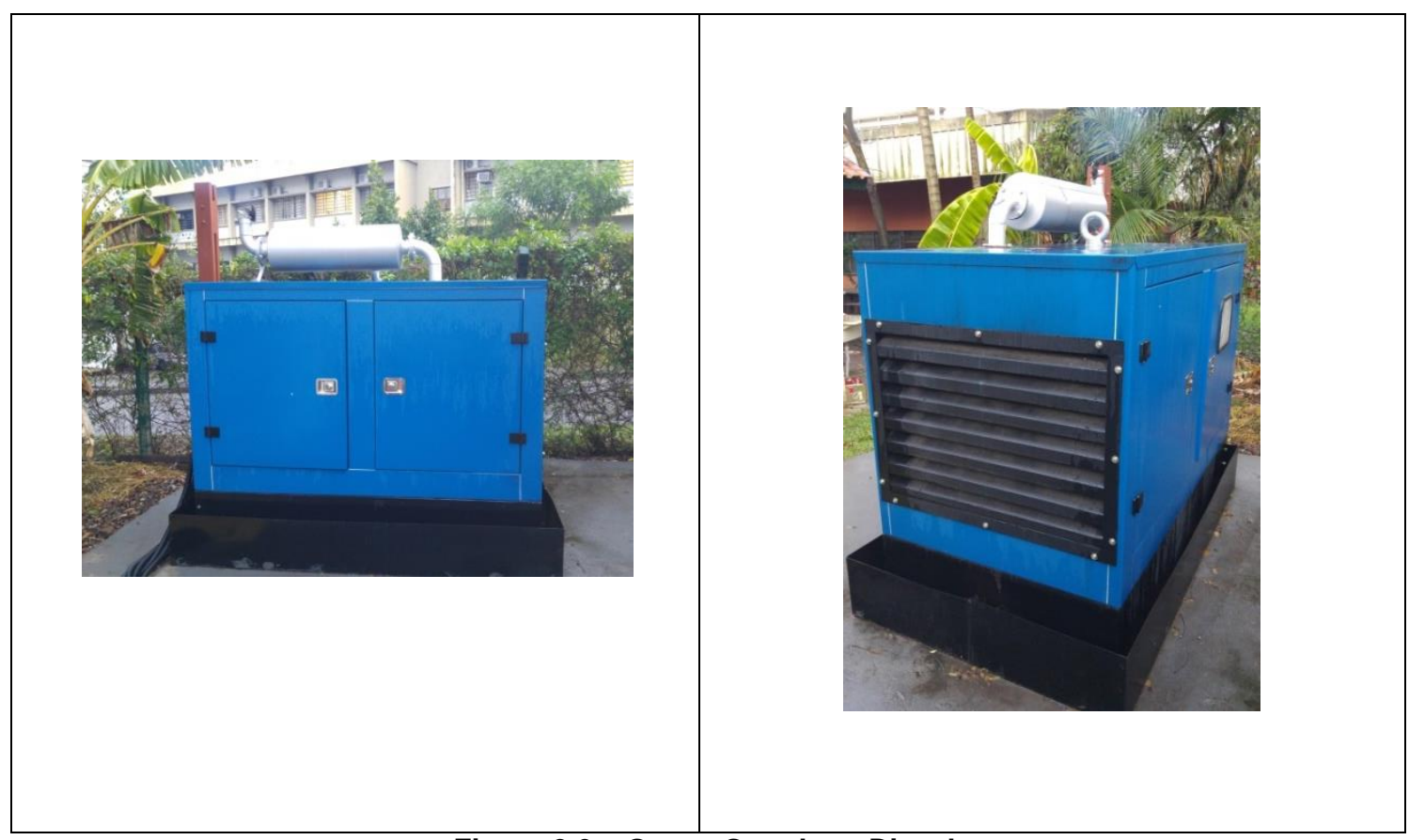

Figura 2.6 - Grupo Gerador a Diesel. 
No interior da cabine do GGD estão dispostos um tanque de combustível de 220 litros, duas baterias de 12 V/ 85 Ah associadas em paralelo, e um motor de combustão interna acoplado a um gerador síncrono (Figura 2.7). Os dados técnicos referentes ao GGD e especificações dos fabricantes são apresentados na Tabela 2.3 e na Tabela 2.4 .

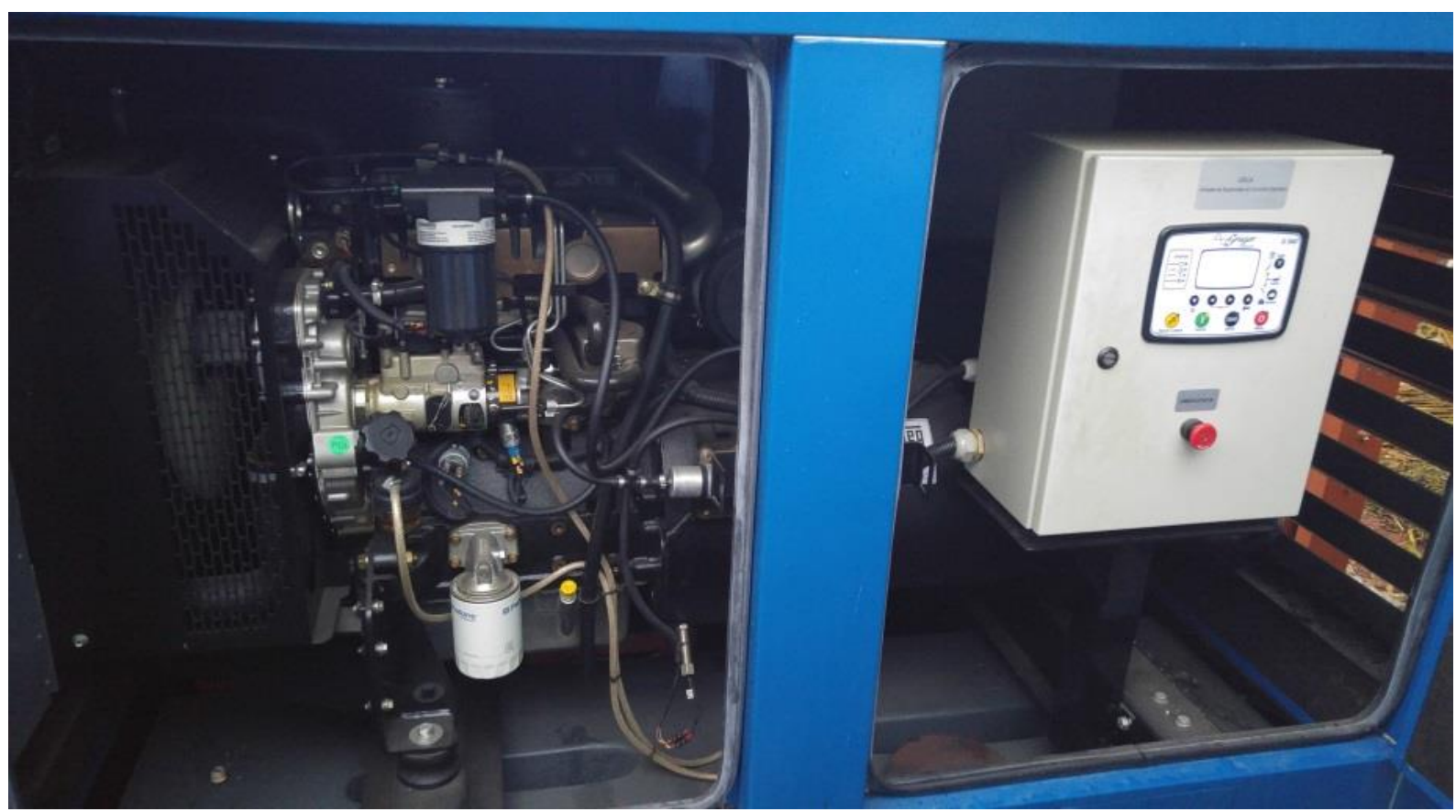

Figura 2.7 - Vista interna do GGD.

Tabela 2.3 - Dados técnicos do GGD.

\begin{tabular}{|l|l|}
\hline Fabricante & Gruger \\
\hline Regime de funcionamento & Prime \\
\hline Tensão de fornecimento & $220 / 127 \mathrm{~V}_{\text {c.a. }}$ \\
\hline Tensão da bateria & $12 \mathrm{~V}_{\text {c.c. }}$ \\
\hline Frequência & $60 \mathrm{~Hz}$ \\
\hline Potência & $40 \mathrm{kVA}$ \\
\hline
\end{tabular}




\begin{tabular}{|l|l|}
\hline Montagem & Contêiner c/ atenuação \\
\hline Quadro de comando & \\
\hline Modelo & G500 \\
\hline Painel de comando & Geminado \\
\hline Controle & Automático \\
\hline
\end{tabular}

Tabela 2.4 - Fabricante dos componentes do GGD.

\begin{tabular}{|l|l|}
\hline Fabricante do motor & Perkins \\
\hline Fabricante do gerador & Weg \\
\hline Fabricante da bomba injetora & Delphi \\
\hline Fabricante do regulador de tensão & Grameyer \\
\hline
\end{tabular}

O acionamento remoto e o controle dos parâmetros do gerador são realizados através de comunicação RS-485 com a unidade de supervisão de corrente alternada (USCA), mostrada na Figura 2.8. 


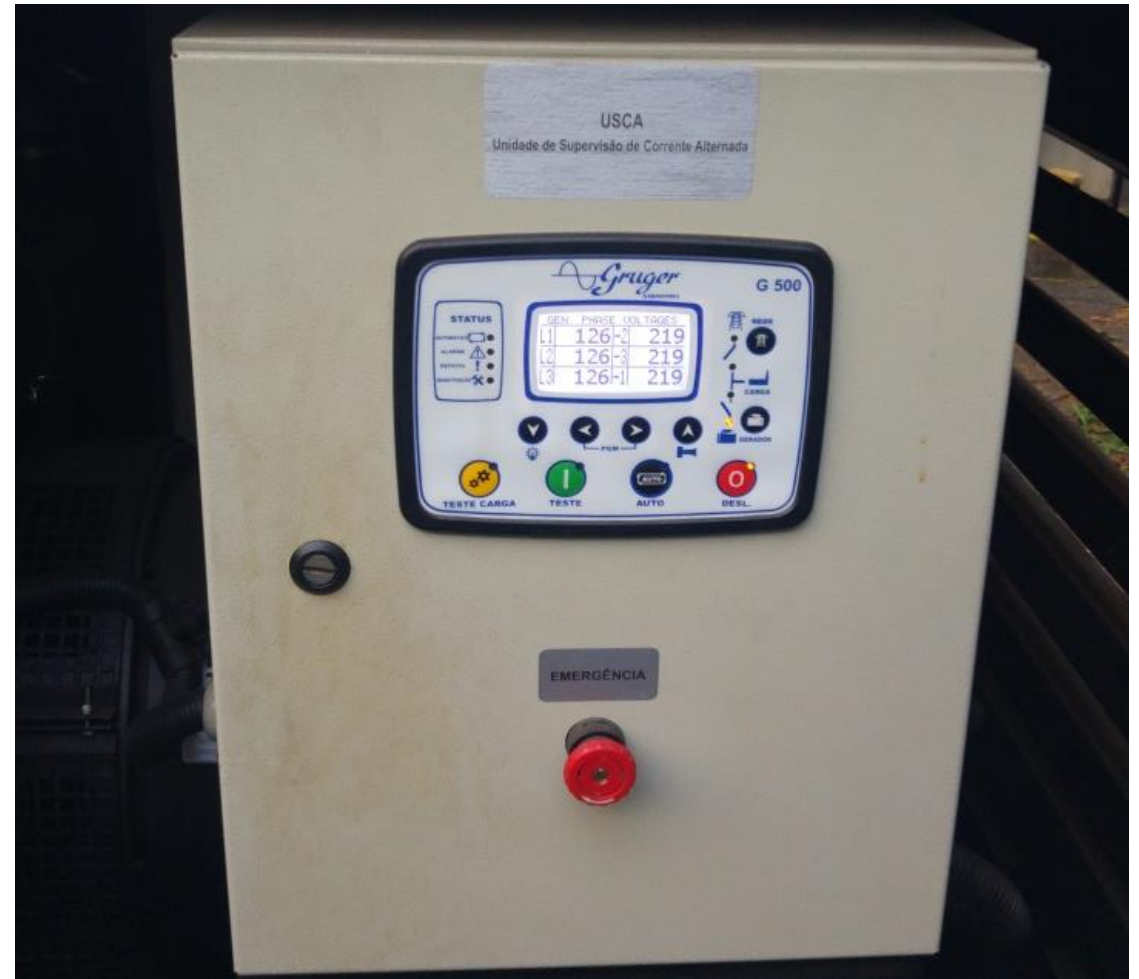

Figura 2.8 - Unidade de supervisão de corrente alternada.

\subsubsection{Rede Elétrica}

A rede elétrica pode fornecer energia para todos os sistemas híbridos $(\mathrm{SH})$, simultaneamente ou individualmente. A rede elétrica pode fornecer energia pela chave de transferência presente no GGD ou diretamente no sistema de interconexão entre todos os $\mathrm{SH}$.

\subsubsection{Sistema de Condicionamento de Potência}

O sistema de condicionamento de potência realiza a conversão de energia para padrões aceitáveis para os sistemas, sejam essas conversões c.c./c.a. ou o inverso, conversão c.c./c.c., e transformação c.a./c.a. O sistema de condicionamento de potência compreende tanto os inversores bidirecionais quanto os inversores de conexão à rede, controladores de carga e transformadores. 


\subsubsection{Inversores Bidirecionais}

Os inversores bidirecionais Sunny Island 5048 são destinados à formação da rede de distribuição de energia (Figura 2.9). Eles podem tanto inverter o sinal de tensão c.c. para c.a. (atendimento de cargas típicas), quanto retificar o sinal de tensão c.a. para c.c. (carregamento do banco de baterias). A Tabela 2.5 apresenta as principais especificações técnicas fornecidas pelo fabricante.

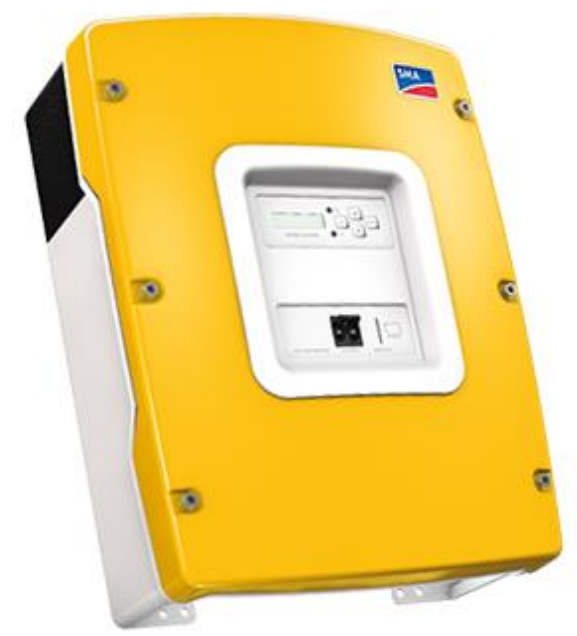

Figura 2.9 - Inversor bidirecional do ST1.

Fonte: SMA America (2011).

Tabela 2.5 - Especificações técnicas do inversor bidirecional do ST1.

\begin{tabular}{|c|c|}
\hline Fabricante & SMA \\
\hline Modelo & SI 5048 \\
\hline Saída (c.a.) & $230 \mathrm{~V}(202$ a $253 \mathrm{~V})$ \\
\hline Faixa de tensão da rede (ajustável) & 45 a $65 \mathrm{~Hz}$ \\
\hline Faixa de frequência de operação & $5.000 \mathrm{~W}$ \\
\hline Potência contínua de saída a $25^{\circ} \mathrm{C}$ & $6.500 \mathrm{~W}$ \\
\hline Potência de saída por 30 minutos a $25^{\circ} \mathrm{C}$ & $7.200 \mathrm{~W}$ \\
\hline Potência de saída por 1 minuto a 25 ${ }^{\circ} \mathrm{C}$ & $21 \mathrm{~A}$ \\
\hline Corrente nominal & $100 \mathrm{~A}$ \\
\hline Corrente de pico por 60 ms & $<3 \%$ \\
\hline Distorção harmônica de tensão & $-1 \mathrm{a}+1$ \\
\hline Fator de potência & - \\
\hline Entrada (c.a.) & \\
\hline
\end{tabular}




\begin{tabular}{|c|c|}
\hline Faixa de tensão da rede (ajustável) & $230 \mathrm{~V}(172,5$ a $250 \mathrm{~V})$ \\
\hline Frequência & $50(40 \mathrm{a} 60 \mathrm{~Hz})$ \\
\hline Corrente máxima de entrada (ajustável) & $56 \mathrm{~A}(2 \mathrm{a} 56 \mathrm{~A})$ \\
\hline Potência máxima de entrada & $12,8 \mathrm{~kW}$ \\
\hline Bateria & $48 \mathrm{~V}(41$ a $68 \mathrm{~V})$ \\
\hline Tensão da bateria & $120 \mathrm{~A}$ \\
\hline Corrente máxima de carregamento da bateria & $100 \mathrm{~A}$ \\
\hline Corrente de carregamento contínuo & $100 \mathrm{a} 1.000 \mathrm{Ah}$ \\
\hline Capacidade de bateria & VRLA/FLA/NiCd \\
\hline Tipos de bateria &
\end{tabular}

Fonte: Adaptado de SMA America (2011).

Respeitadas essas especificações, esses inversores podem ser inseridos em diversas opções de configurações, dependendo da característica da rede a ser energizada. Os três inversores bidirecionais, INVB-01/ST1, INVB-02/ST1 e INVB03/ST1, estão inseridos em uma rede trifásica, composta de 4 fios, sendo cada inversor, deste modo, responsável pela alimentação de uma fase especifica (Figura 2.10).

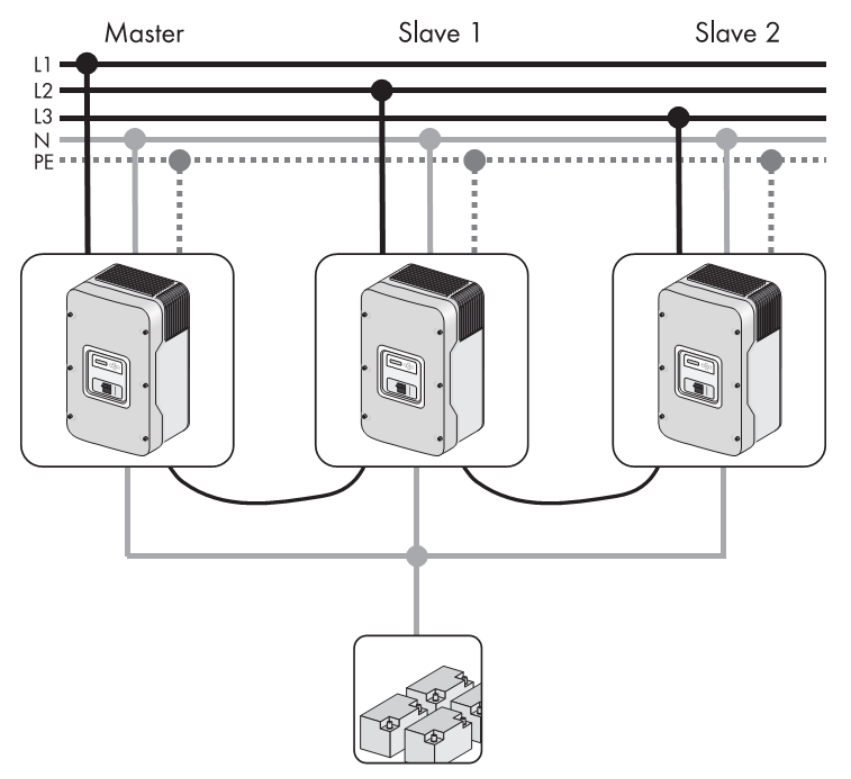

Figura 2.10 - Configuração dos inversores bidirecionais do ST1.

Fonte: SMA America (2011). 
Os três inversores estão configurados para um ser o master (INVB-01) e os outros dois serem slaves (INVB-02 e INVB-03). A parametrização é realizada no INVB-01/ST1, e as configurações são inseridas automaticamente nos outros inversores.

\subsubsection{Inversores de Conexão à Rede}

Os inversores de conexão à rede ou conversores c.c./c.a. são responsáveis pela conversão de energia em corrente contínua em energia em corrente alternada. Desta forma, os inversores adequam a energia proveniente dos módulos fotovoltaicos à rede à qual estão conectados.

Os INVG são destinados à conexão elétrica dos GFV, onde os modelos utilizados são o Sunny Boy 1200 e o Sunny Boy 1100 (Figura 2.11). As principais especificações técnicas estão descritas na Tabela 2.6, conforme fornecidas pelo fabricante.

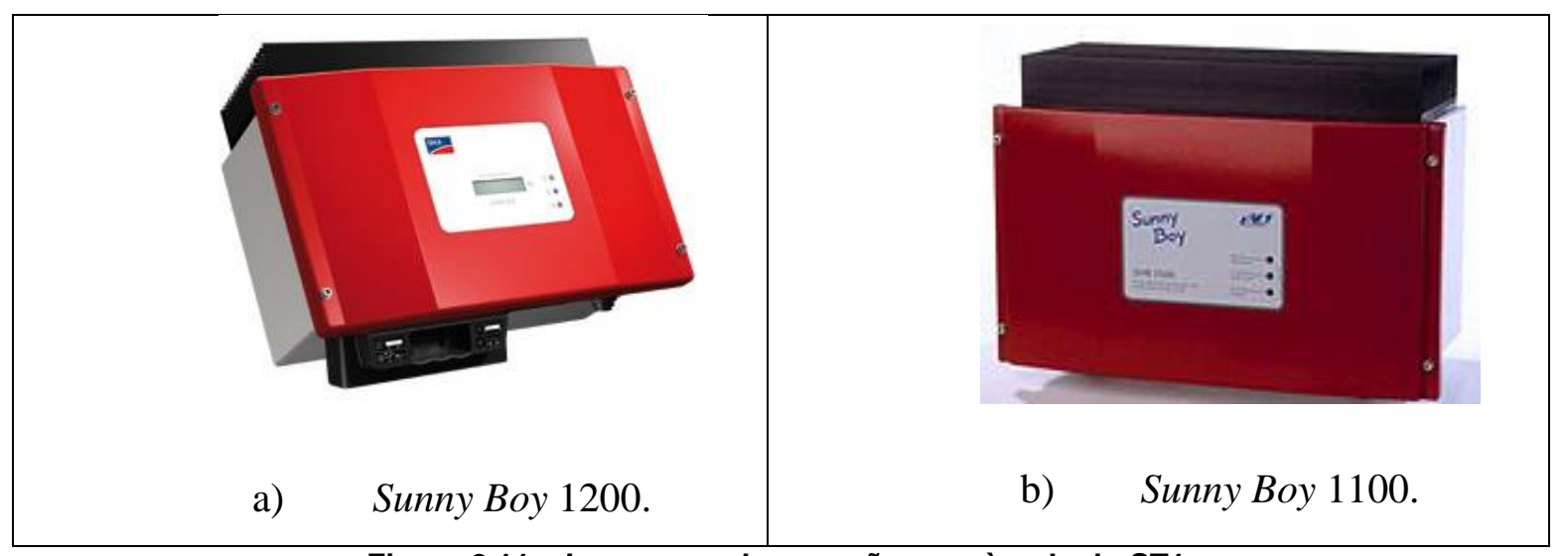

Figura 2.11 - Inversores de conexão com à rede do ST1.

Fonte: SMA AMERICA (2004), SMA AMERICA (2010).

Tabela 2.6 - Especificações técnicas do inversor de conexão à rede do ST1.

\begin{tabular}{|c|c|c|}
\hline Fabricante & SMA & SMA \\
\hline Modelo & Sunny Boy 1200 & Sunny Boy 1100 \\
\hline Entrada c.c. & - & - \\
\hline Potência máxima & $1.320 \mathrm{~W}$ & $1.100 \mathrm{~W}$ \\
\hline
\end{tabular}




\begin{tabular}{|c|c|c|}
\hline Tensão máxima & $400 \mathrm{~V}$ & $400 \mathrm{~V}$ \\
\hline Tensão no MPPT & $100 \mathrm{~V}-320 \mathrm{~V}$ & $139 \mathrm{~V}-400 \mathrm{~V}$ \\
\hline Tensão mínima de operação & $120 \mathrm{~V}$ & $120 \mathrm{~V}$ \\
\hline Corrente máxima & $12,6 \mathrm{~A}$ & $10 \mathrm{~A}$ \\
\hline Saída c.a. & - & $1.100 \mathrm{~W}$ \\
\hline Máxima potência de saída & $1.200 \mathrm{~W}$ & $1.000 \mathrm{VA}$ \\
\hline Potência de saída & $1.200 \mathrm{VA}$ & $230 \mathrm{~V}$ \\
\hline Tensão de saída (ajustável) & $180 \mathrm{~V}-265 \mathrm{~V}$ & $5,5 \mathrm{~A}$ \\
\hline Máxima corrente de saída & $6,1 \mathrm{~A}$ & $60 \mathrm{~Hz} \pm 0,2 \mathrm{~Hz}$ \\
\hline Frequência & $60 \mathrm{~Hz} \pm 4,5 \mathrm{~Hz}$ & 1 \\
\hline Fator de potência (cos $\phi)$ & 1 & $93 \%$ \\
\hline Máxima eficiência & $92,1 \%$ & \\
\hline
\end{tabular}

Fonte: Adaptado de SMA AMERICA (2004), SMA AMERICA (2010).

Os inversores INVG-01/ST1, INVG-02/ST1 e INVG-03/ST1 estão conectados entre os GFV-01/ST1, GFV-02/ST1 e GFV-03/ST1 e ao Multicluster, no barramento PV-Bus.

Os inversores INVG-04/ST1, INVG-05/ST1 e INVG-06/ST1 são utilizados para fluxo reverso de potência, formando um sistema de geração distribuída, para injetar energia pelo lado da carga no sistema de distribuição e comando.

Os inversores INVG-01 ao INVG-06 realizam o condicionamento de potência proveniente dos módulos fotovoltaicos; contudo, o ST1 possui outro inversor de 15 kW, para emulação do aerogerador. O inversor utilizado é um Sunny Tripower, apresentado na Figura 2.12. O INVG-07 está conectado entre a fonte c.c. e o barramento de $380 \mathrm{~V}$, cujas especificações técnicas estão descritas na Tabela 2.7. 


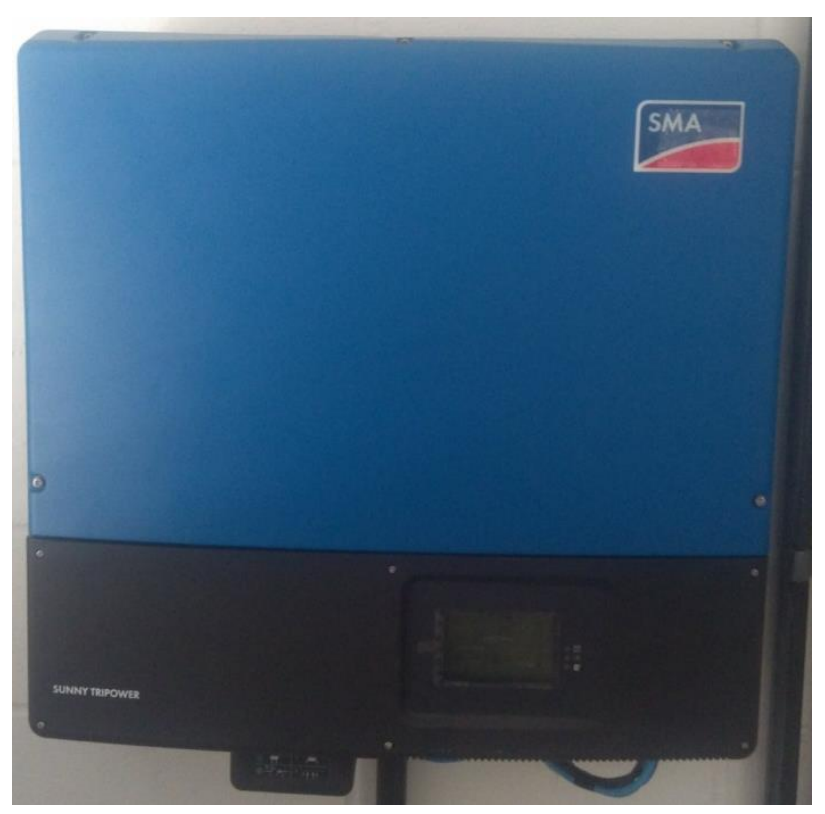

Figura 2.12 - Sunny Tripower do ST1.

Tabela 2.7 - Especificações técnicas do Sunny Tripower do ST1.

\begin{tabular}{|l|c|}
\hline Fabricante & SMA \\
\hline Modelo & Sunny Tripower 15000-TL-10 \\
\hline Entrada c.c. & $15.330 \mathrm{~W}$ \\
\hline Potência máxima & $1.000 \mathrm{~V}$ \\
\hline Tensão máxima & 240 - 800 V \\
\hline Tensão no MPPT & $150 \mathrm{~V}$ \\
\hline Tensão mínima de operação & $33 \mathrm{~A}$ \\
\hline Corrente máxima por string & $43 \mathrm{~A}$ \\
\hline Corrente máxima de curto-circuito por string & 2 \\
\hline Número de MPPT & 5 \\
\hline String por MPPT & - \\
\hline Saída c.a. & $15.000 \mathrm{~W}$ \\
\hline Máxima potência de saída & $15.000 \mathrm{VA}$ \\
\hline Potência de saída & $30 / 220 \mathrm{~F}-\mathrm{N} / 380 \mathrm{~F}-\mathrm{F}$ \\
\hline Tensão nominal de saída & $160 \mathrm{a} 280 \mathrm{~V} \mathrm{F-N}$ \\
\hline Tensão de saída (ajustável) & $24 \mathrm{~A}$ \\
\hline Máxima corrente de saída & $60 \mathrm{~Hz} / 54 \mathrm{~Hz}$ a 65 Hz \\
\hline Frequência & 1 \\
\hline Fator de potência (cos $\phi$ ) & $98,2 \%$ \\
\hline Máxima eficiência & \\
\hline Fonnte: Adaptado SMA (2016). & \\
\hline
\end{tabular}

Fonte: Adaptado SMA (2016). 


\subsubsection{Controlador de Carga}

O controlador de carga é um equipamento cuja finalidade é o controle da carga e descarga do sistema de acumulação de energia.

Os controladores Schneider e Trace utilizados neste sistema possuem somente a função de controlador de carga, isso é, eles executam somente a função de carregamento do sistema de armazenamento de energia (Figura 2.13).

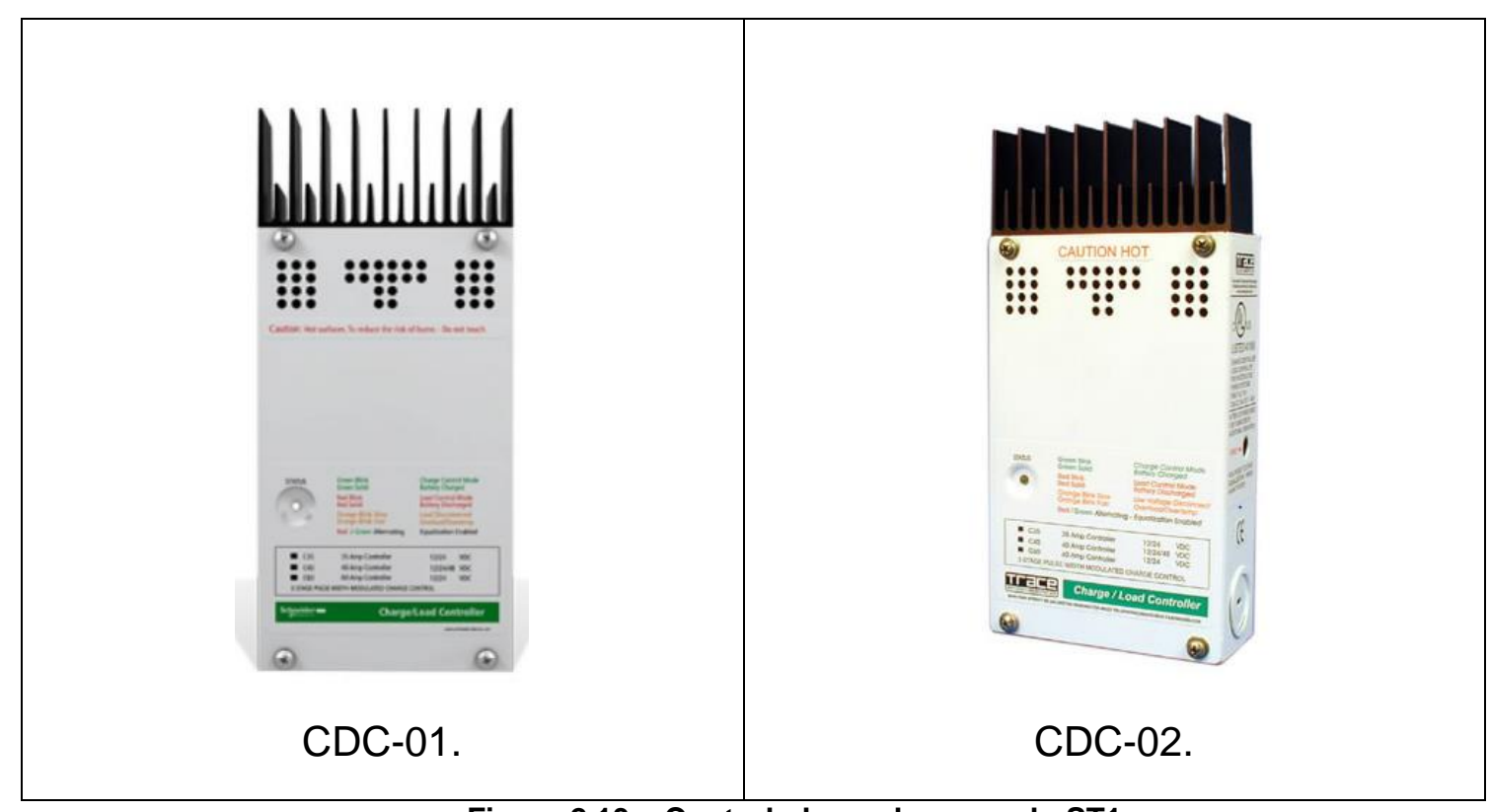

Figura 2.13 - Controladores de carga do ST1.

Fonte: XANTREX (2001) e XANTREX (2002).

Os controladores Xantrex e Trace, do fabricante Schneider, possuem as especificações técnicas apresentadas na TABELA 2.8.

Tabela 2.8 - Especificações técnicas dos controladores de carga do ST1.

\begin{tabular}{|l|c|c|}
\hline Modelo & C40 Xantrex & C40 Trace \\
\hline Configuração de tensão de saída & 12,24 e 48 Vc.c. & $\begin{array}{c}12,24 \text { e } 48 \\
\text { Vc.c. }\end{array}$ \\
\hline Máxima tensão de circuito aberto & 125 Vc.c. & 125 Vc.c. \\
\hline Máxima corrente de carga & $40 \mathrm{~A}$ & $40 \mathrm{~A}$ \\
\hline
\end{tabular}




\begin{tabular}{|l|c|c|}
\hline Corrente de curto-circuito & $85 \mathrm{~A}$ & $80 \mathrm{~A}$ \\
\hline Tensão de disparo máxima & $0,30 \mathrm{~V}$ & $0,30 \mathrm{~V}$ \\
\hline Corrente de autoconsumo & $3-15 \mathrm{~mA}$ & $3-15 \mathrm{~mA}$ \\
\hline Método de regulagem do carregamento & $\begin{array}{r}\text { PWM em 3 etapas (carga, } \\
\text { absorção e flutuação) }\end{array}$ \\
\hline
\end{tabular}

Fonte: Adaptado de XANTREX (2001) e XANTREX (2002).

Os controladores de carga, assim como descrito anteriormente, estão realizando um acoplamento c.c. diretamente no sistema de acumulação de energia. O CDC-01/ST1 adéqua a energia proveniente do GFV-07/ST1 e o CDC-02/ST1 a energia proveniente do GFV-08/ST1 ao nível de tensão compatível com o sistema de acumulação.

\subsubsection{Transformador Elevador}

O transformador elevador é um elemento para condicionamento de potência, sendo utilizado para adequação do nível de tensão dos geradores ao do sistema de condicionamento de potência. Os geradores do sistema híbrido, além dos fotovoltaicos, são o GGD e a rede elétrica, que podem ser comutados pela entrada.

O transformador utilizado é do fabricante ALDE, tipo TTF 50, conforme ilustrado na Figura 2.14. 


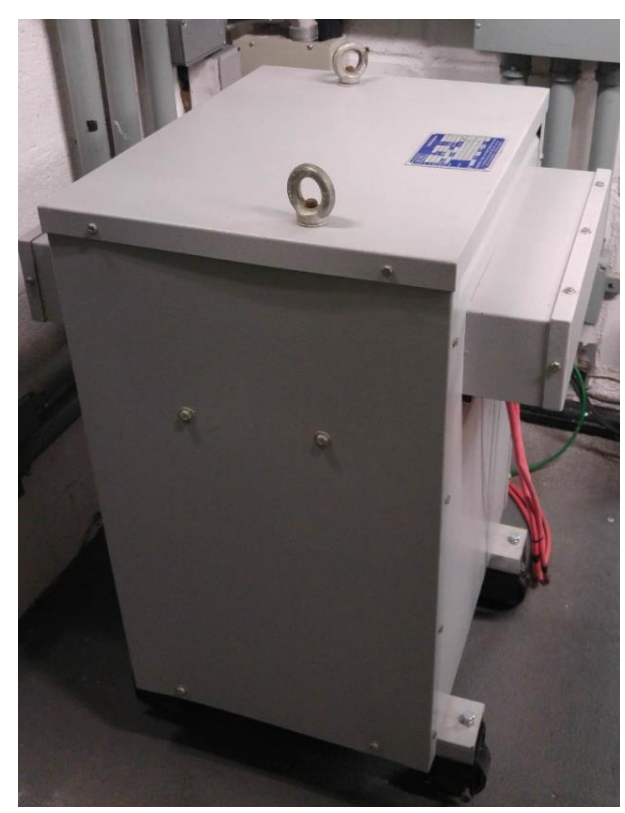

Figura 2.14 - Transformador elevador.

A conexão elétrica é feita com delta no primário e estrela não aterrada no secundário, conforme apresentado nas especificações técnicas da Tabela 2.9.

Tabela 2.9 - Especificações técnicas do transformador elevador.

\begin{tabular}{|l|c|}
\hline Fabricante & ALDE \\
\hline Tipo & TTF 50 \\
\hline Nível de Isolação & $1,2 \mathrm{kV}$ \\
\hline Número de fases & 3 Fases \\
\hline Primário & Delta \\
\hline Secundário & Estrela aterrada \\
\hline Classe Térmica & $60 \mathrm{~Hz}$ \\
\hline Frequência & $220 \mathrm{~V} \mathrm{~F}-\mathrm{F}$ \\
\hline Tensão de entrada & $380 \mathrm{~V} \mathrm{~F}-\mathrm{F}$ \\
\hline Tensão de saída & $50 \mathrm{kVA}$ \\
\hline Potência & \\
\hline
\end{tabular}

\subsubsection{Transformador Abaixador}

Assim como o transformador elevador, o transformador abaixador (Figura 2.15) tem a função de permitir a conexão elétrica entre dois circuitos com diferentes 
níveis de tensão. A conexão elétrica é feita com delta no primário e estrela aterrada no secundário, conforme apresentado nas especificações técnicas da Tabela 2.10.

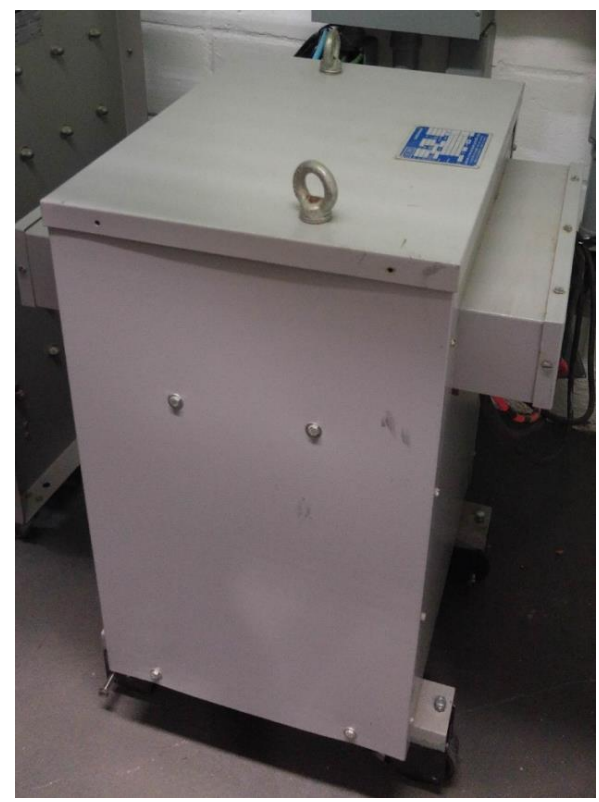

Figura 2.15 - Transformador abaixador.

Tabela 2.10 - Especificações técnicas do transformador abaixador.

\begin{tabular}{|l|c|}
\hline Fabricante & ALDE \\
\hline Tipo & TTF 50 \\
\hline Nível de Isolação & $1,2 \mathrm{kV}$ \\
\hline Número de fase & 3 Fases \\
\hline Primário & Delta \\
\hline Secundário & Estrela aterrada \\
\hline Classe Térmica & F \\
\hline Frequência & $60 \mathrm{~Hz}$ \\
\hline Tensão de entrada & $380 \mathrm{~V} \mathrm{~F}-\mathrm{F}$ \\
\hline Tensão de saída & $220 \mathrm{~V} \mathrm{~F}-\mathrm{F}$ \\
\hline Potência & $50 \mathrm{kVA}$ \\
\hline
\end{tabular}

\subsubsection{Sistema de Armazenamento}

Inicialmente, os sistemas híbridos foram projetados para suprimento da demanda de energia de cargas isoladas da rede da concessionária. A utilização de 
acumuladores de energia, ou outros sistemas de armazenamento, tornava-se necessária para suprimento de energia durante o período em que as fontes não estivessem produzindo energia, ou estivessem com produção menor do que a demanda do sistema. Deste modo, os acumuladores de energia tinham características de funcionamento ora como "carga", ora como "fonte".

O sistema de armazenamento é formado por um banco de baterias de 23,52 kWh. O banco é composto por 24 elementos, de $2 \mathrm{~V}$ e 490 Ah (regime C10) cada (Figura 2.16).

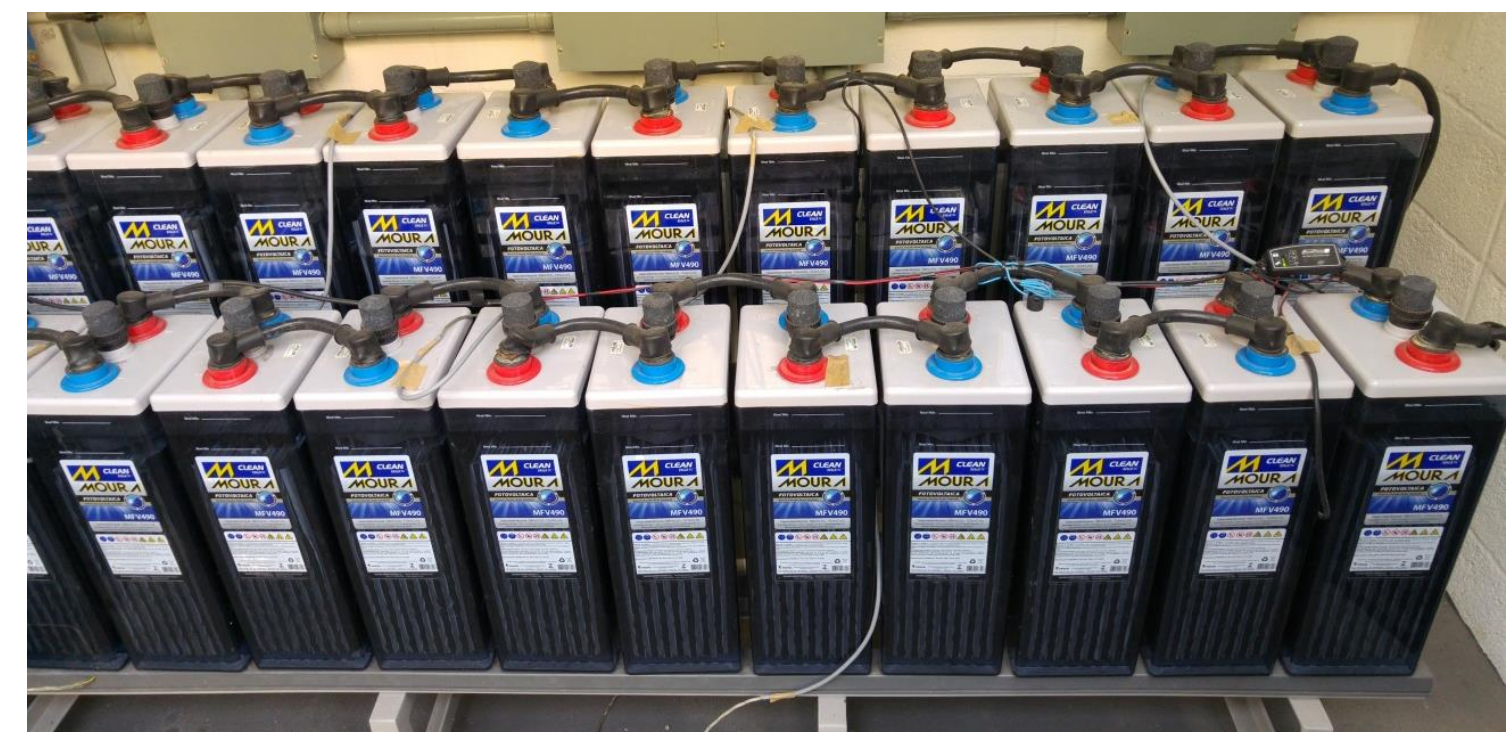

Figura 2.16 - Banco de baterias do ST1.

Os elementos utilizados para formação do banco de baterias (Figura 2.17) têm características construtivas diferentes das baterias utilizadas para outras aplicações. Estas baterias são específicas para aplicações fotovoltaicas, podendo sofrer processos de carga e descarga diários por longos períodos. As especificações técnicas estão descritas na Tabela 2.11. 


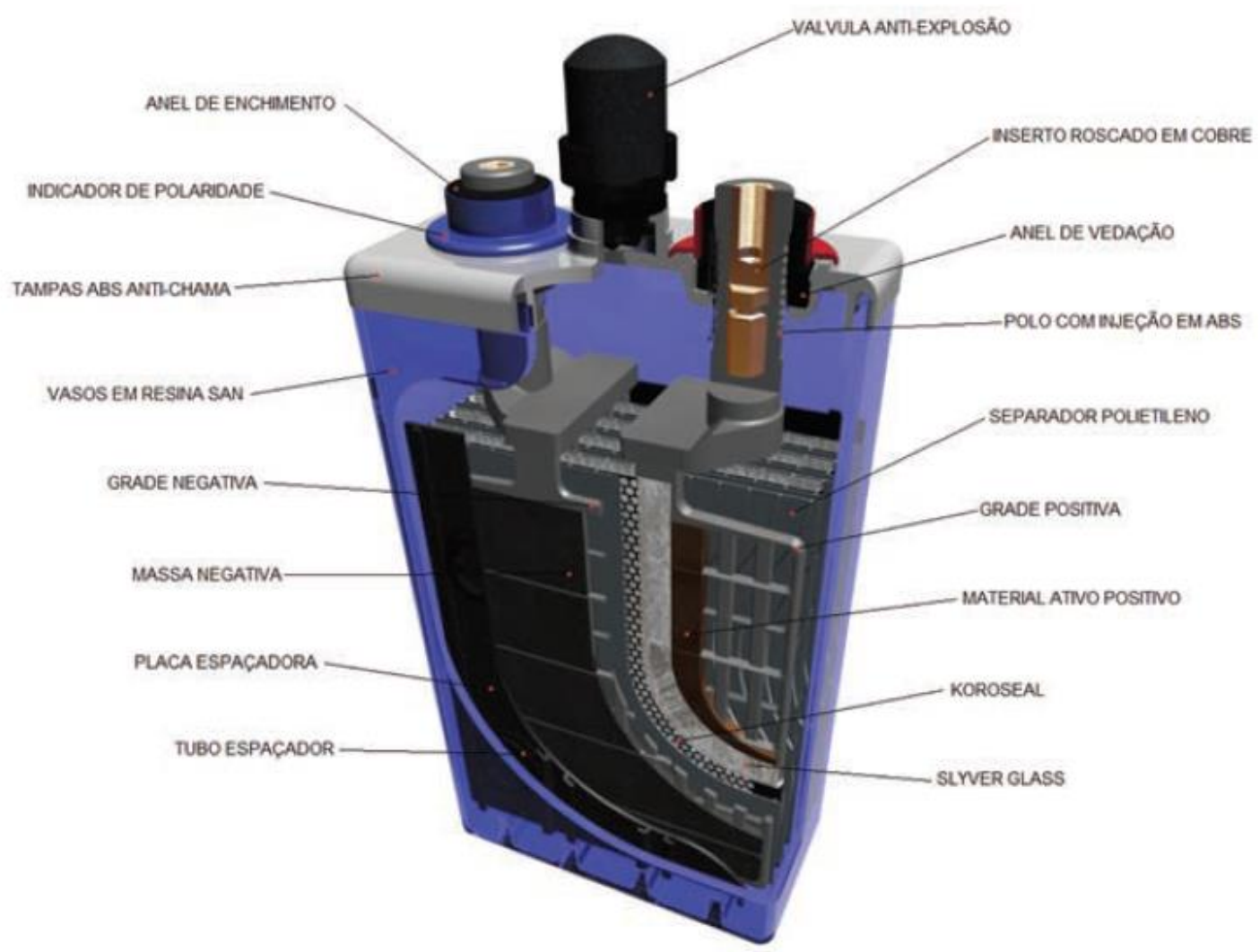

Figura 2.17 - Características construtivas da bateria do ST1.

Fonte: ACUMULADORES MOURA (2015).

Tabela 2.11 - Especificação técnica das baterias do ST1.

\begin{tabular}{|c|c|c|}
\hline Fabricante & \multicolumn{2}{|c|}{ Moura } \\
\hline Modelo & \multicolumn{2}{|c|}{ MFV 490 } \\
\hline \multirow{3}{*}{ Capacidade (Ah) } & C20 & 595 \\
\cline { 2 - 3 } & C10 & 490 \\
\cline { 2 - 3 } & C8 & 469 \\
\hline \multirow{3}{*}{ Dimensões (mm) } & Comprimento & 166 \\
\cline { 2 - 3 } & Largura & 206 \\
\cline { 2 - 3 } & \multicolumn{2}{|c|}{ Altura 41} \\
\hline Peso (kg) & \multicolumn{2}{|c|}{} \\
\hline
\end{tabular}

Fonte: Adaptado de ACUMULADORES MOURA (2015). 


\subsubsection{Sistema de Distribuição e Comando}

O Multicluster Box (Figura 2.18) é o sistema de distribuição e comando, que possibilita a conexão entre os sistemas de geração com o sistema de acumulação, 0 despacho para as cargas e o sistema de interconexão com os outros $\mathrm{SH}$. As principais especificações técnicas desse equipamento são apresentadas na Tabela 2.12 .

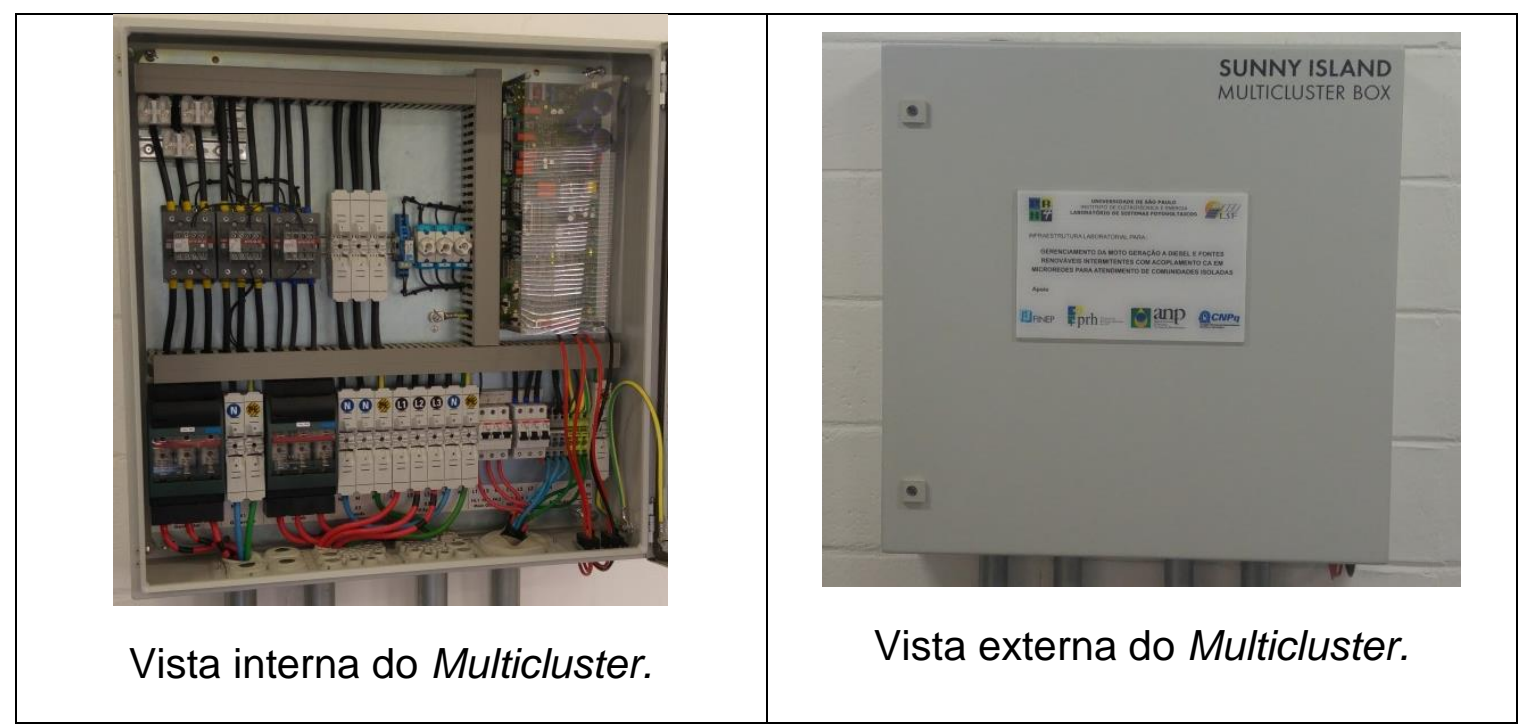

Figura 2.18 - Multicluster.

Tabela 2.12 - Especificação técnica do Multicluster Box 6.3.

\begin{tabular}{|c|c|c|}
\hline \multicolumn{2}{|c|}{ Fabricante } & SMA \\
\hline \multicolumn{2}{|c|}{ Modelo } & Multicluster Box 6.3 \\
\hline \multicolumn{3}{|c|}{ Geral } \\
\hline \multicolumn{2}{|c|}{ Número de fases } & 3 Fases \\
\hline \multicolumn{2}{|c|}{ Tensão nominal } & $230 \mathrm{~V}(\mathrm{FN}), 380 \mathrm{~V}(\mathrm{FF})$ \\
\hline \multicolumn{2}{|c|}{ Frequência } & $50 \mathrm{~Hz}(40 \mathrm{~Hz}$ a $70 \mathrm{~Hz})$ \\
\hline \multirow{3}{*}{ Dimensões (mm) } & Largura & 760 \\
\hline & Altura & 760 \\
\hline & Comprimento & 210 \\
\hline \multicolumn{2}{|c|}{ Peso $(\mathrm{kg})$} & 60 \\
\hline \multicolumn{2}{|c|}{ Conexão com Sunny Island } & \\
\hline
\end{tabular}




\begin{tabular}{|c|c|}
\hline Máximo número de equipamentos & 6 \\
\hline Potência em c.a. a $25^{\circ} \mathrm{C}$ & $30 \mathrm{~kW}$ \\
\hline Corrente c.a. a $25^{\circ} \mathrm{C}$ & $3 \times 44 \mathrm{~A}$ \\
\hline Potência em c.a. a $45^{\circ} \mathrm{C}$ & $24 \mathrm{~kW}$ \\
\hline Corrente c.a. a $45^{\circ} \mathrm{C}$ & $3 \times 35 \mathrm{~A}$ \\
\hline Potência em c.a. por 30 minutos & $40 \mathrm{~kW}$ \\
\hline Potência em c.a. por 1 minuto & $50 \mathrm{~kW}$ \\
\hline \multicolumn{2}{|l|}{ Conexão com Sistemas Fotovoltaicos } \\
\hline Quantidade & 1 (Trifásico) \\
\hline Potência em c.a. a $25^{\circ} \mathrm{C}$ & $55 \mathrm{~kW}$ \\
\hline Corrente c.a. a $25^{\circ} \mathrm{C}$ & $3 \times 80 \mathrm{~A}$ \\
\hline \multicolumn{2}{|l|}{ Conexão com as Cargas } \\
\hline Quantidade & 1 (Trifásico) \\
\hline Potência a $25^{\circ} \mathrm{C}$ & $55 \mathrm{~kW}$ \\
\hline Corrente a $25^{\circ} \mathrm{C}$ & $3 \times 80 \mathrm{~A}$ \\
\hline Fusível & $\mathrm{NH} 00$ \\
\hline \multicolumn{2}{|l|}{ Conexão com GGD } \\
\hline Quantidade & 1 (Trifásico) \\
\hline Potência em c.a. a $25^{\circ} \mathrm{C}$ & $55 \mathrm{~kW}$ \\
\hline Corrente c.a. a $25^{\circ} \mathrm{C}$ & $3 \times 80 \mathrm{~A}$ \\
\hline Fusível & $\mathrm{NHOO}$ \\
\hline \multicolumn{2}{|l|}{ Condições ambientais } \\
\hline Temperatura ambiente & $-25^{\circ} \mathrm{C}$ a $50^{\circ} \mathrm{C}$ \\
\hline Proteção & IP65 \\
\hline Umidade do ar & $0 \%$ a $100 \%$ \\
\hline
\end{tabular}

Fonte: Adaptado SMA AUSTRALIA (2010).

A Figura 2.19 apresenta a maneira como o MC-Box integra a distribuição c.a. para os inversores (Sunny Island e Sunny Boy) e GGD, mantendo conexão com a minirrede, que é vista como a própria carga. Entretanto, algumas conexões do MCBox foram alteradas e numeradas da seguinte maneira: a adaptação número 1 apresenta a conexão da rede elétrica; a conexão número dois é a geração no acoplamento em corrente contínua; e a conexão número três é a conexão da geração distribuída. 


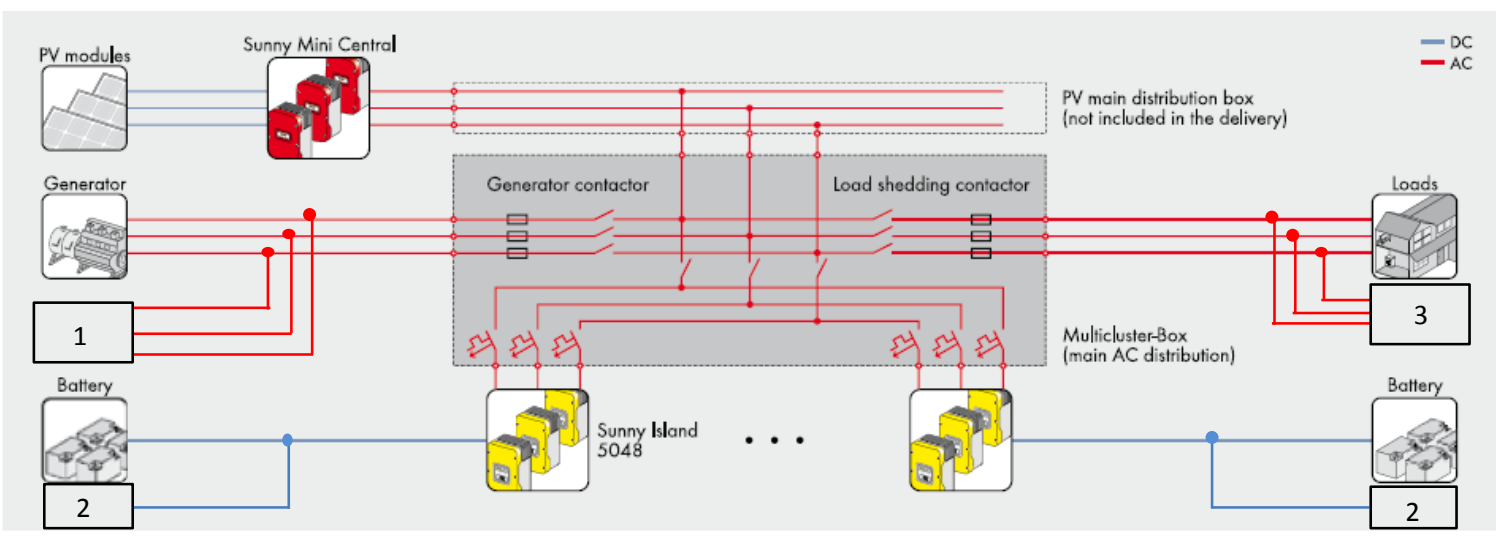

Figura 2.19 - Conexão com o MC - Box.

Fonte: SMA AUSTRALIA (2010).

O ST1 possui outros sistemas além dos já mencionados, como sistema de sensoriamento, sistema de proteção, sistema de monitoramento, sistema de medição e sistema de consumo de energia, que são brevemente apresentados a seguir.

\subsubsection{Sistema de Proteção}

O sistema de proteção realiza a proteção tanto no âmbito de corrente alternada, quanto em corrente contínua, além de realizar o seccionamento do sistema em diversas partes. Há dez quadros de proteção e seccionamento e quatro quadros de seccionamento e medição, onde estão presentes chaves seccionadoras porta-fusível, disjuntores, dispositivos de proteção contra surto, fusíveis e chaves contatoras. A Figura 2.20 apresenta um dos quadros de proteção e seccionamento presentes no LSF. 


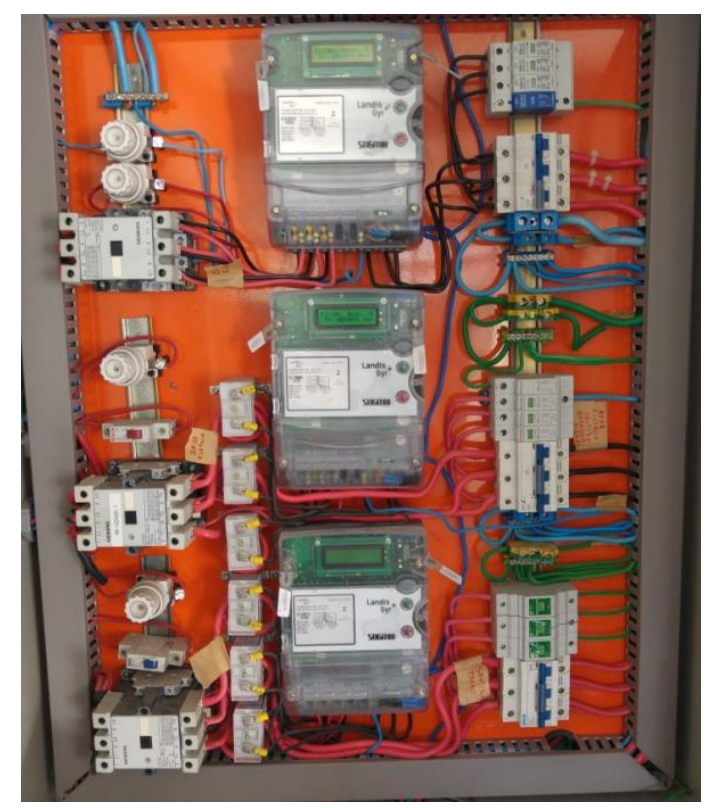

Figura 2.20 - Quadro de proteção e seccionamento.

\subsubsection{Sistema de Medição}

O sistema de medição é responsável pela medição, coleta e armazenamento das variáveis elétricas de todo o sistema. Estas são: dados de correntes, tensões, potência, entre outras variáveis. Desta forma, torna-se possível analisar o despacho de energia, além do desempenho de uma parte do sistema ou dele como um todo. $\mathrm{O}$ sistema de medição é composto por quatro quadros de medições e seccionamento, dois dataloggers do fabricante Agilent modelo 34972A e cinco shunts. Além destes equipamentos, as medições também são realizadas pelos inversores instalados no sistema.

Os quadros de proteção e seccionamento possuem em seu interior alguns equipamentos para desempenharem estas funções, como medidores, TC, contatoras, e disjuntores, assim como apresentado na Figura 2.20. Os medidores bidirecionais Saga1000 permitem a análise dos parâmetros elétricos no sentido direto e reverso, além de armazenar os valores medidos durante 45 dias, com intervalos de integração de 5 minutos.

Os dataloggers possuem as mesmas especificações técnicas, porém realizam funções distintas no sistema; um realiza as medições individuais dos 
elementos de acumulação, enquanto o outro realiza as medições da geração no acoplamento c.c.

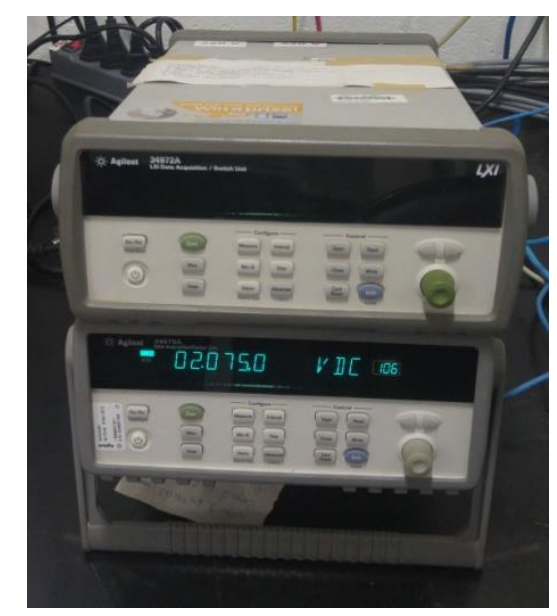

Figura 2.21 - Datalogger da Agilent.

Quatro shunts estão instalados no quadro de acoplamento em corrente contínua. Estes mensuram a corrente total que flui dos GFV-07/ST1, GFV-08/ST1, CDC-01/ST1 e CDC-02/ST1.

O shunt está instalado junto ao banco de baterias, permitindo desta forma a medição da corrente total que entra ou sai do banco. Estas medidas são analisadas pelo INVB-01, que também apresenta os dados de corrente, tensão, estado de cargas entre outros parâmetros do sistema.

\subsubsection{Sistema de Sensoriamento}

O desempenho do sistema de geração fotovoltaico é afetado por fatores externos, além da irradiação solar. A temperatura ambiente, que influencia na temperatura das células dos módulos, entre outros fatores, contribui para aumentar ou diminuir o desempenho do sistema de geração fotovoltaico. Deste modo, faz-se necessária a utilização de um sistema de sensoriamento e aquisição de dados. $\mathrm{O}$ sistema de sensoriamento é apresentado na Figura 2.22 e é composto por um anemômetro, um sensor de temperatura ambiente, um sensor de temperatura de costa de módulo e um sunny sensor Box (SSB). 


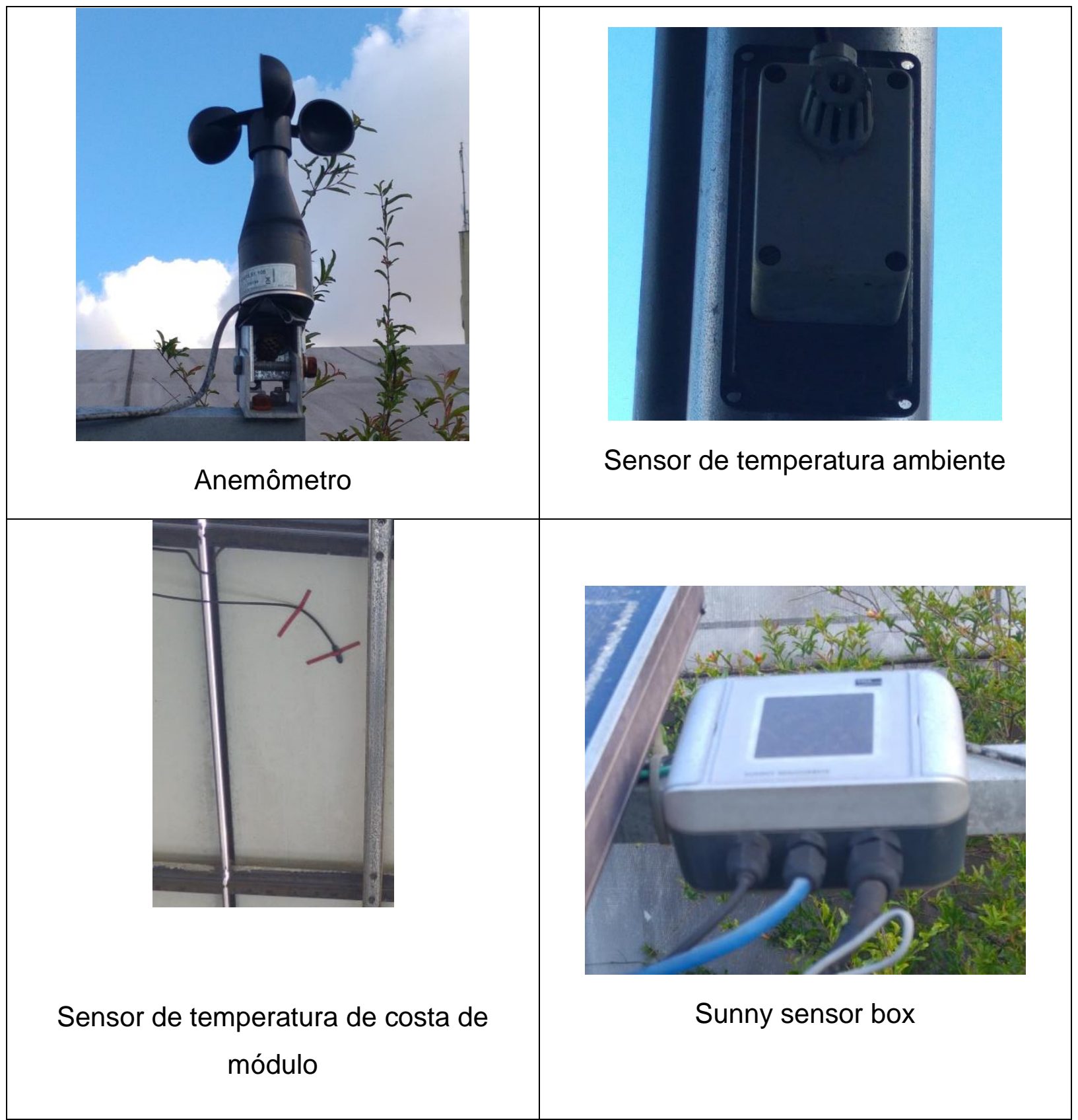

Figura 2.22 - Sistema de sensoriamento do ST1.

O anemômetro é um sensor destinado a medir a velocidade horizontal do vento. O sistema utilizado é do fabricante SMA, onde os dados coletados podem ser processados e transmitidos pelo SSB.

O sensor de temperatura ambiente consiste em resistência de medição modelo PT100, colocada em uma cobertura de plástico com IP65. O modelo instalado faz parte dos sensores fabricados pela SMA. 
O sensor de temperatura de costa de módulo possui algumas características semelhantes ao sensor de temperatura ambiente; ambos utilizam resistência de medição modelo PT100, porém este sensor possui maior faixa de abrangência, podendo atingir uma maior faixa de temperaturas.

O SSB é um dispositivo que processa os dados dos outros sensores da SMA apresentados e envia os dados para o Sunny control Plus. Este sensor também possui uma célula fotovoltaica de referência, que possibilita medir a irradiância no plano do gerador fotovoltaico.

\subsubsection{Sistema de Monitoramento}

O sistema de monitoramento é responsável pelo processamento e exibição das variáveis elétricas e ambientais de todo o ST1 O sistema de monitoramento é composto por um Sunny boy control plus (SBC); e por três softwares instalados em um computador, sunny data control (SDC), um programa de leitura e análise de dados (PLA) e Rainbowplus.

O SBC é o dispositivo que recebe os dados dos equipamentos da SMA, permitindo o monitoramento e a realização de análises de desempenho. O SBC utiliza o protocolo de comunicação próprio do fabricante. Este também se comunica com o computador, desta forma é possível adquirir os dados do sistema.

O SDC é um programa para computador da SMA, com o qual se pode realizar o armazenamento em longo prazo dos dados do sistema fotovoltaico, e também visualizá-los (Figura 2.23).

O PLA é um programa similar ao SDC, porém este pode realizar o armazenamento e exibição dos dados referentes aos medidores bidirecionais. Neste programa é possível a apresentação dos dados de energia em tempo real na forma de gráfico, ou exportação dos dados em formato de planilhas do Excel.

O Rainbowplus é um programa para computador do fabricante Gruger para apresentar as variáveis elétricas e mecânicas do GGD. Neste é possível comandar e parametrizar o GGD, isso além de obter informações do mesmo. 


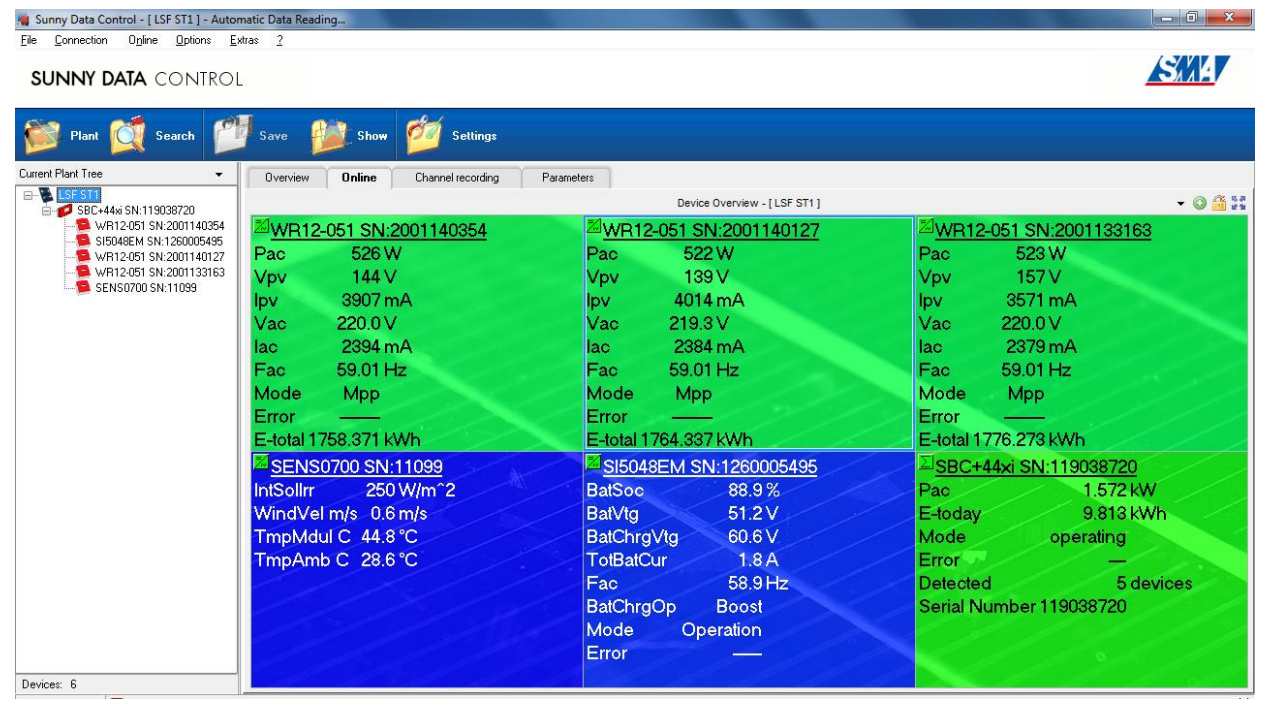

Figura 2.23 - Interface do Sunny data control plus.

\subsubsection{Sistema de Consumo de Energia}

A energia do ST1 pode ser demandada de diversas formas. Para a finalidade de pesquisa o sistema fornece a energia para parte do prédio do LSF, cargas resistivas em corrente alternada e cargas em corrente contínua (Figura 2.24).

Outra forma de demandar a energia do ST1 é a possibilidade de injeção de energia na rede elétrica, pelo fluxo reverso de potência. Os INVB-01 ao INVB-03 permitem a injeção do excesso da geração de energia proveniente dos módulos ou da fonte c.c., desde que o banco de baterias esteja com o estado de carga elevado.

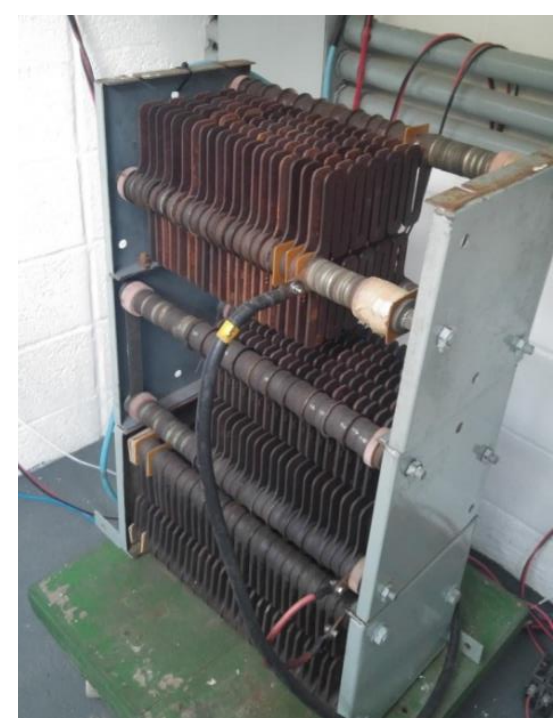

Figura 2.24 - Carga do ST1 


\subsection{Sistema Monofásico 1}

O sistema SMA Monofásico é composto por subsistemas de geração de energia elétrica, condicionamento de potência, armazenamento, sensoriamento, comunicação, medição, proteção e consumo de energia; conforme descrito a seguir.

- Sistema de Geração:

> 3 Geradores fotovoltaicos (GFV-01, GFV-02 e GFV-03);

> 1 Grupo Gerador Diesel de 40 kVA (GGD).

- Sistema de Condicionamento de Potência:

> 2 Inversores de conexão à rede (INVG-01 e INVG-02);

$>1$ Inversor bidirecional de $5 \mathrm{~kW}$ (INVB-01);

$>1$ Controlador de carga (CDC-01).

- Sistema de Armazenamento:

> 1 Banco de baterias VRLA de 48 V / 200 Ah.

- Sistema de Proteção:

$>1$ Chave seccionadora fusível (NH00);

$>18$ Disjuntores.

- Sistema de Medição:

$>1$ Shunt.

- Sistema de Sensoriamento:

> 1 Sensor de temperatura ambiente;

> 1 Sensor de temperatura de costa de módulo;

$>1$ Sunny sensor box.

- Sistema de Monitoramento:

$>1$ Sunny Web Box (SWB);

$>1$ Computador.

- Sistema de Consumo de Energia:

$>1$ Carga resistiva;

> 1 Inversor SMA modelo Hydroboy.

A Figura 2.25 ilustra o diagrama esquemático do SM1. 


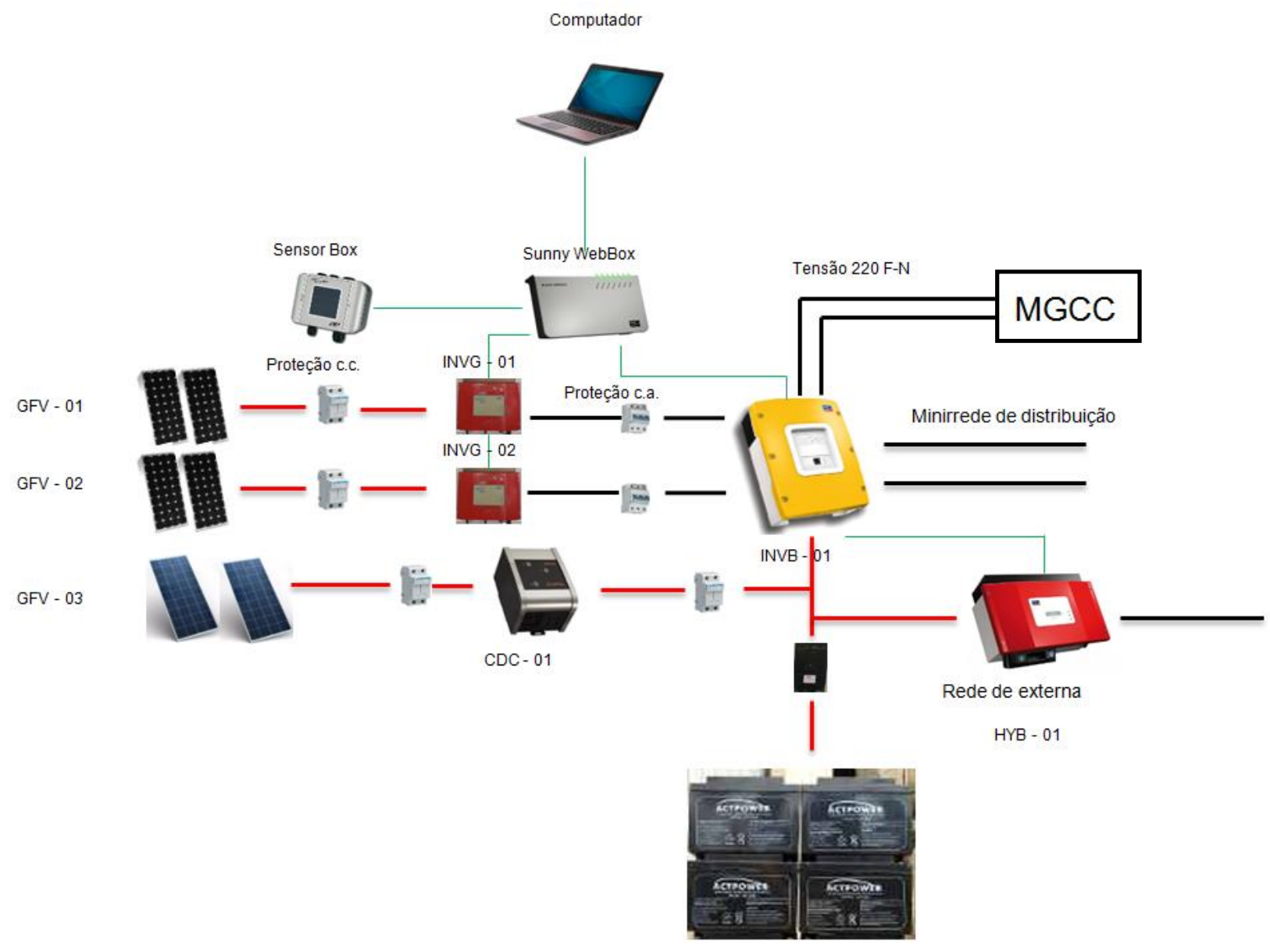

Legendas

Linhas vermelhas: Energia em corrente continua

Linhas pretas: Energia em corrente alternada

Banco de Bateria

Figura 2.25 - Diagrama esquemático do SM1. 


\subsubsection{Sistema de Geração}

A energia elétrica fornecida para o sistema pode ser proveniente de três fontes distintas, sendo estas: a geração fotovoltaica, o GGD e a rede elétrica externa.

\subsubsection{Geradores Fotovoltaicos}

O SM1 possui três geradores fotovoltaicos, sendo dois para acoplamento em corrente alternada (GFV-01/SM1 e GFV-02/SM1) e um para acoplamento em corrente contínua (GFV-03/SM1).

O GFV-01/SM1 está conectado ao INVG-01/SM1, assim como GFV-02/SM1 está conectado ao INVG-02/SM1. O GFV-03/SM1 está conectado ao CDC-01/SM1. A Figura 2.26 apresenta e destaca os geradores fotovoltaicos do SM1.

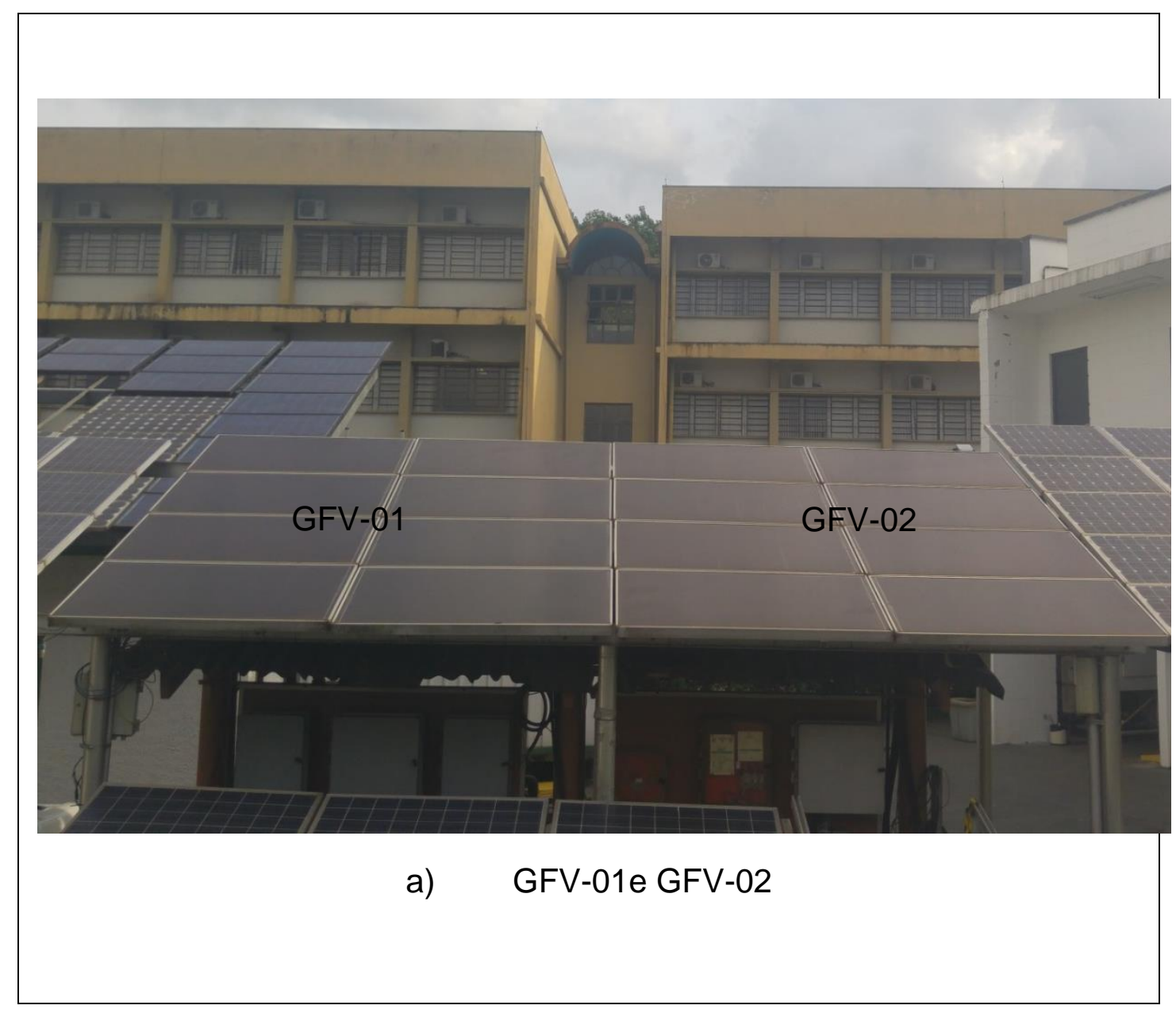




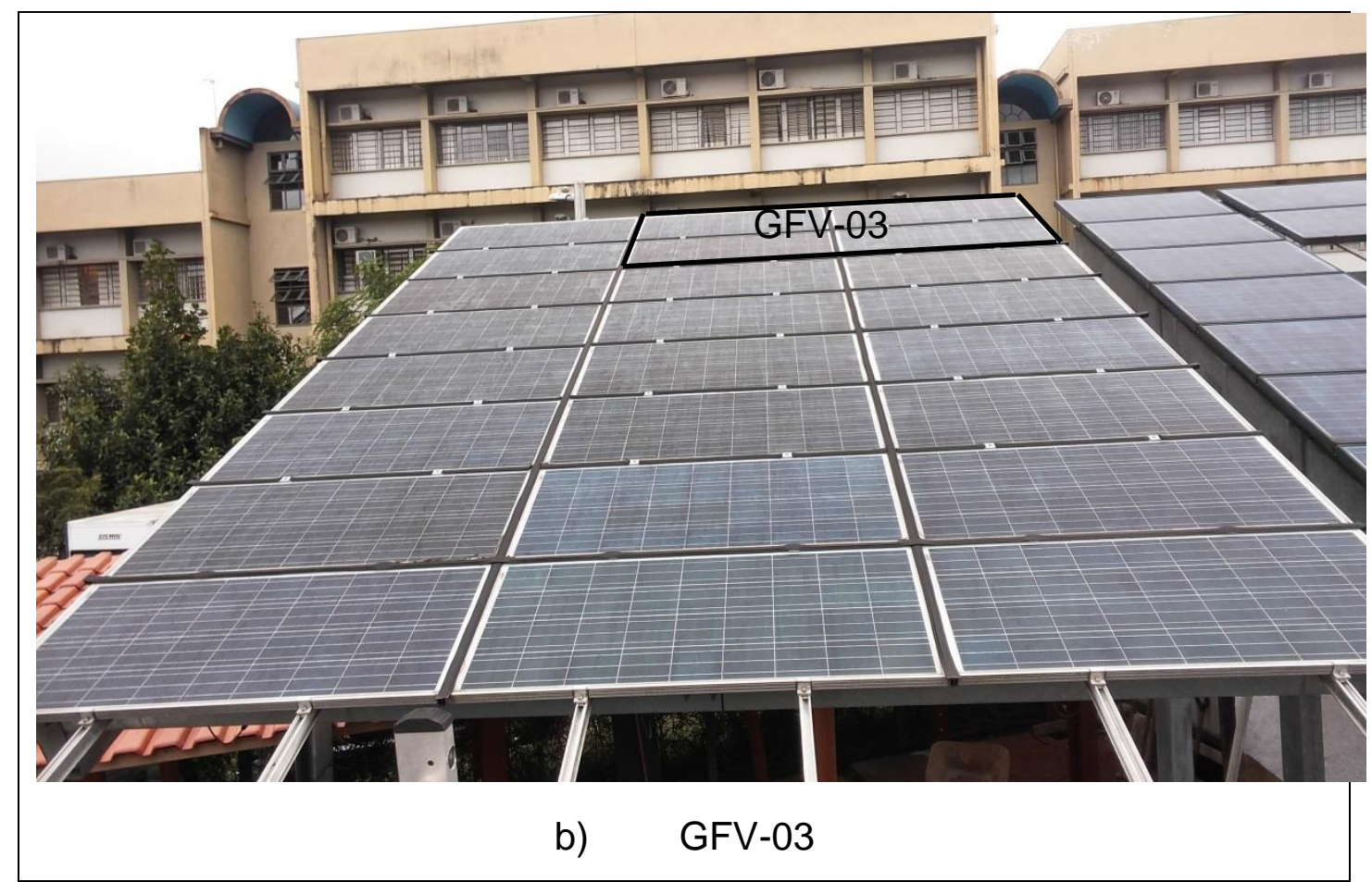

Figura 2.26 - Geradores fotovoltaicos do SM1.

Os módulos que compõem os geradores fotovoltaicos são dos seguintes fabricantes:

- GFV-01/SM1 BP Solar;

- GFV-02/SM1 BP Solar;

- GFV-03/SM1 Komaes Solar.

Os geradores fotovoltaicos utilizados no SM1 possuem especificações técnicas diferentes, para fins de pesquisa e ampliação da gama de fabricantes testados. A Figura 2.27 apresenta os módulos e a Tabela 2.13 apresenta as suas especificações técnicas. 


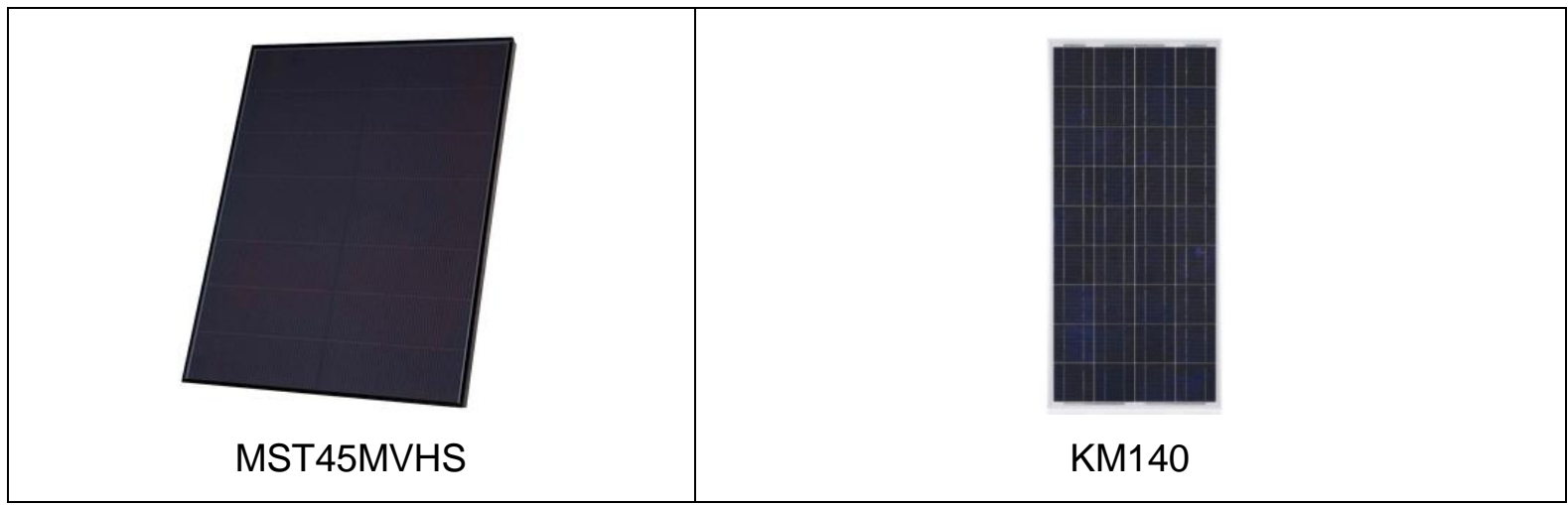

Figura 2.27 - Módulos fotovoltaicos do SM1.

Fonte: BP SOLAR (2009) e KOMAES SOLAR (2009).

Tabela 2.13 - Especificações técnicas dos módulos fotovoltaicos do SM1.

\begin{tabular}{|l|l|l|}
\hline Fabricante & BP Solar & Komaes Solar \\
\hline Modelo & MST45MVHS & Km 140 \\
\hline Potência (W) & 45 & 140 \\
\hline Tensão de máxima potência (Vmp) & $75 \mathrm{~V}$ & $18,36 \mathrm{~V}$ \\
\hline Corrente de máxima potência (Imp) & $0,6 \mathrm{~A}$ & $7,65 \mathrm{~A}$ \\
\hline Corrente de curto-circuito & $0,78 \mathrm{~A}$ & $8,17 \mathrm{~A}$ \\
\hline Tensão de circuito aberto & $100 \mathrm{~V}$ & $21,96 \mathrm{~A}$ \\
\hline Máxima tensão do sistema & $600 \mathrm{~V}$ & $1.000 \mathrm{~V}$ \\
\hline Tipo de célula & Filme fino & Poly-Si \\
\hline Número de células & --- & 36 \\
\hline
\end{tabular}

Fonte: BP SOLAR (2009) e KOMAES SOLAR (2009).

A composição dos geradores fotovoltaicos é descrita a seguir:

- $\quad$ GFV-01/SM1: 4 módulos em série (string) (404 Voc / 300 Vmp) e dois strings em paralelo (1,2 Imp), totalizando 8 módulos $(0,36 \mathrm{kWp})$; 
- $\quad$ GFV-02/SM1: 4 módulos em série (string) (404 Voc / 300 Vmp) e dois strings em paralelo (1,2 Imp), totalizando 8 módulos $(0,36 \mathrm{kWp})$;

- $\quad$ GFV-03/SM1: 4 módulos em série (string) (87,84 Voc / 73,74 Vmp) e um string (7,65 Imp), totalizando 4 módulos (0,56 kWp).

\subsubsection{Grupo Gerador a Diesel}

O GGD é o elemento comum entre todos os sistemas híbridos, e suas imagens e especificações técnicas estão apresentadas na Figura 2.6, Figura 2.7, Figura 2.8 e na Tabela 2.3 e Tabela 2.4.

\subsubsection{Rede Elétrica Externa}

Assim como mencionado anteriormente, a rede elétrica pode fornecer energia para todos os (SH) simultaneamente ou individualmente. A rede elétrica pode fornecer energia pela chave de transferência presente no GGD ou direto no sistema de interconexão entre todos os SH.

\subsubsection{Sistema de Condicionamento de Potência}

O sistema de condicionamento de potência realiza a conversão de energia para padrões aceitáveis para os sistemas, sejam essas conversões c.c./c.a. ou o inverso, conversão c.c/c.c., e transformação c.a./c.a. Os equipamentos para montagem do sistema de condicionamento são: inversor bidirecional; inversores de conexão à rede; controlador de carga e transformador.

\subsubsection{Inversor Bidirecional}

O inversor bidirecional é o responsável tanto pela conversão c.c./c.a. quanto pela conversão c.a./c.c. Como este sistema híbrido é monofásico, é utilizado um inversor bidirecional, cujas especificações técnicas são apresentadas na Tabela 2.5. A Figura 2.28 apresenta o INVB-01/SM1. 


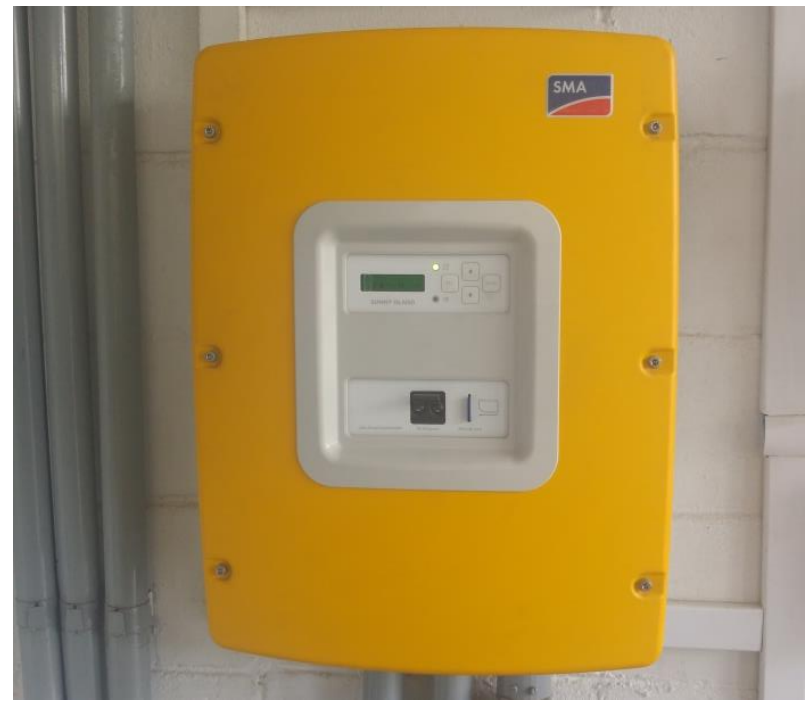

Figura 2.28 - Vista do INVB-01 do SM1.

A Figura 2.29 apresenta seu esquema de conexão à rede ou ao GGD, os INVG e as cargas atendidas. Neste sistema foi realizada uma adaptação que é a conexão da geração no acoplamento em corrente contínua, que é apresentado com o número um.

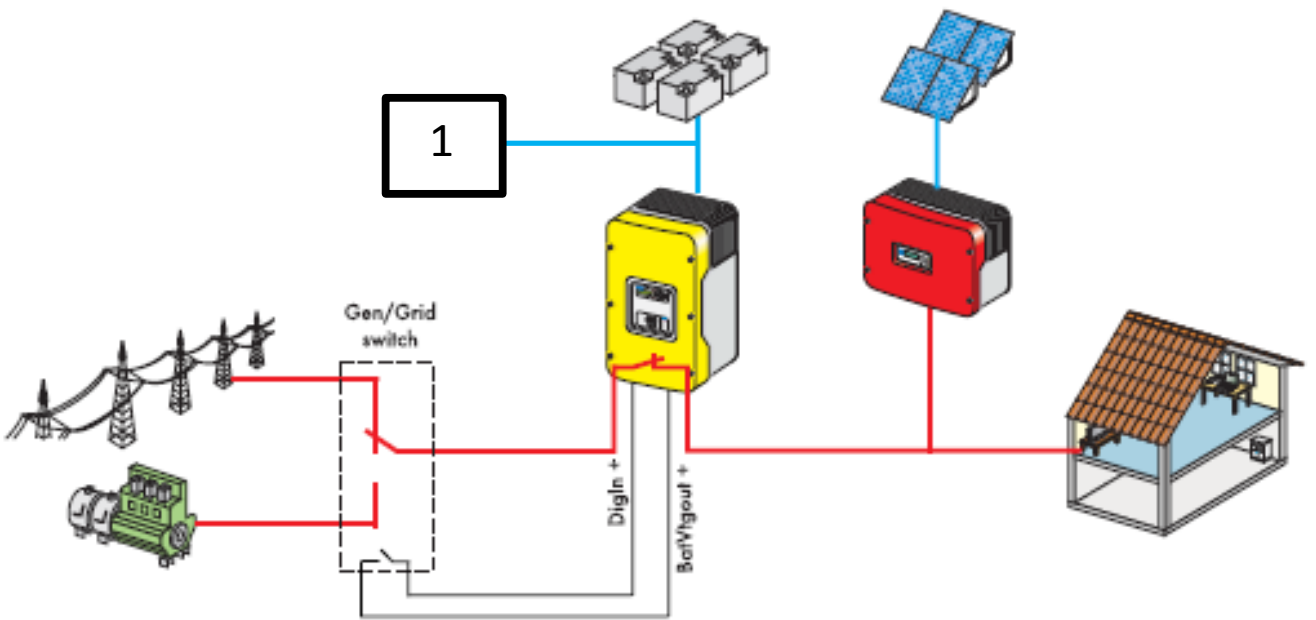

Figura 2.29 - Esquemático de ligação do INVB do SM1.

Fonte: SMA AMERICA (2011). 


\subsubsection{Inversores de Conexão à Rede}

Os inversores de conexão à rede instalados no SM1 são fontes de corrente, pois utilizam os parâmetros de tensão da rede de referência e injetam corrente no sistema híbrido. Os inversores utilizados são do modelo Sunny Boy 1100, e suas especificações técnicas são apresentadas na Tabela 2.6. A disposição dos INVG-01 e INVG-02 são apresentadas na Figura 2.30.

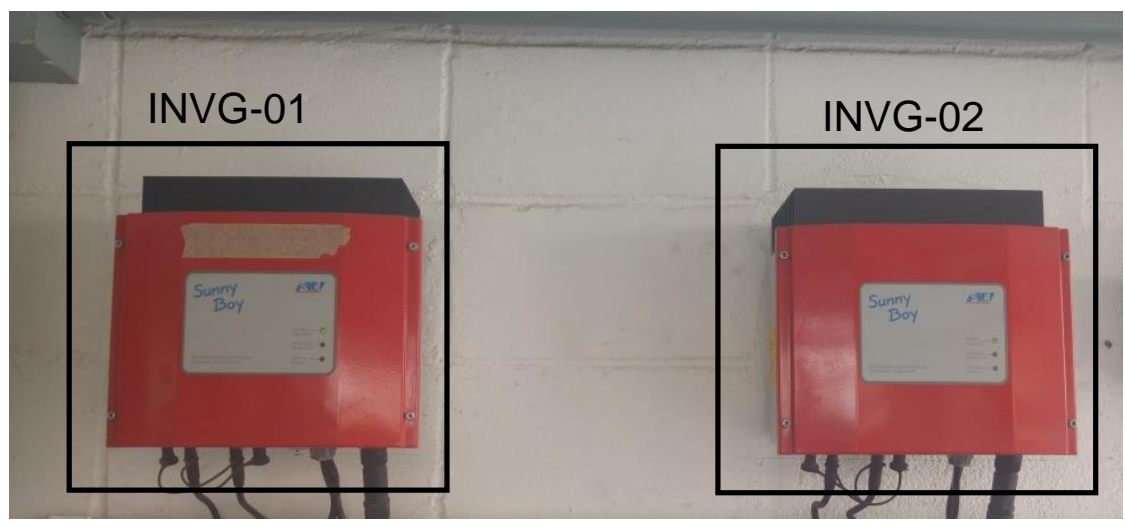

Figura 2.30 - Inversores de conexão à rede do SM1.

\subsubsection{Controlador de Carga}

O controlador de carga é responsável pela conversão c.c./c.c. e pelo carregamento da bateria no acoplamento c.c. O CDC-01 instalado no sistema é o Phocos MPS 45 (Figura 2.31), cujas especificações técnicas estão descritas na Tabela 2.14.

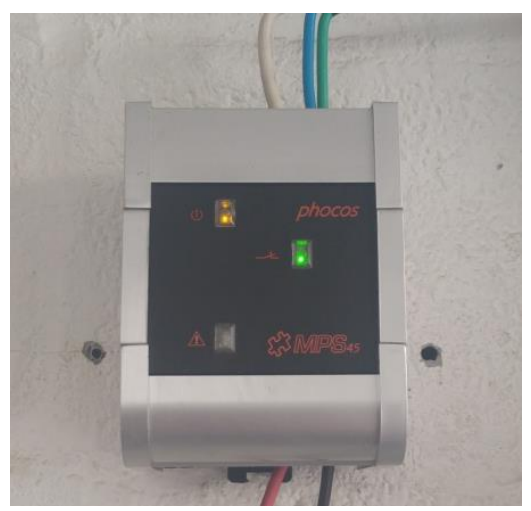

Figura 2.31 - Controlador de Carga-01 do SM1.

Tabela 2.14 - Especificações técnicas do controlador de carga-01. 


\begin{tabular}{|c|c|}
\hline Modelo & MPS 45 \\
\hline Configuração de tensão de saída & $12 / 24 / 48 \mathrm{~V}$ \\
\hline Máxima tensão de circuito aberto & $95 \mathrm{~V}$ \\
\hline Máxima corrente de carga & $45 \mathrm{~A}$ \\
\hline Corrente de autoconsumo & $<10 \mathrm{~mA}$ \\
\hline
\end{tabular}

Fonte: PHOCOS AG (2015).

\subsubsection{Sistema de Armazenamento}

O sistema de armazenamento é composto por um banco de baterias com quatro elementos associados em série. As baterias Actopower utilizadas possuem tensão de $12 \mathrm{~V}$ e capacidade nominal de $200 \mathrm{Ah}$ (regime C10), totalizando um banco de 9,6 kWh. A Figura 2.32 ilustra o banco de baterias e a Tabela 2.15 apresenta as suas especificações técnicas.
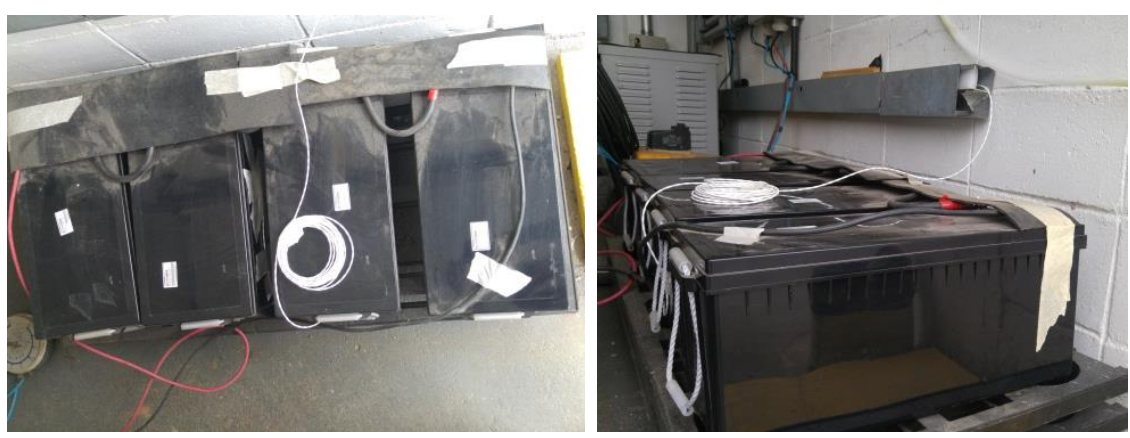

Figura 2.32 - Banco de baterias do SM1.

Tabela 2.15 - Especificações técnicas do banco de baterias do SM1.

\begin{tabular}{|c|c|c|}
\hline Fabricante & \multicolumn{2}{|c|}{ Actpower } \\
\hline Elemento & \multicolumn{2}{|c|}{ Chumbo Ácido } \\
\hline Modelo & \multicolumn{2}{|c|}{ AP12200 } \\
\hline Capacidade (Ah) & \multicolumn{2}{|c|}{200} \\
\hline \multirow{3}{*}{ Dimensões (mm) } & Comprimento & 522 \\
\hline & Largura & 240 \\
\hline & Altura & 240 \\
\hline Peso (kg) & \multicolumn{2}{|c|}{60} \\
\hline
\end{tabular}

Fonte: (ACTPOWER, 2015). 


\subsubsection{Sistema de Proteção}

O sistema de proteção é composto por dispositivos de proteção contra sobrecorrente, tanto no acoplamento em c.c. como no acoplamento em c.a. O SM1 possui quatro quadros de proteção e seccionamento, que estão localizados próximo aos geradores fotovoltaicos, condicionadores de potência e sistema de armazenamento. Deste modo é possível a desconexão de parte do sistema para manobra e possíveis manutenções. A Figura 2.33 apresenta uma parte dos quadros de proteção e seccionamento do SM1.

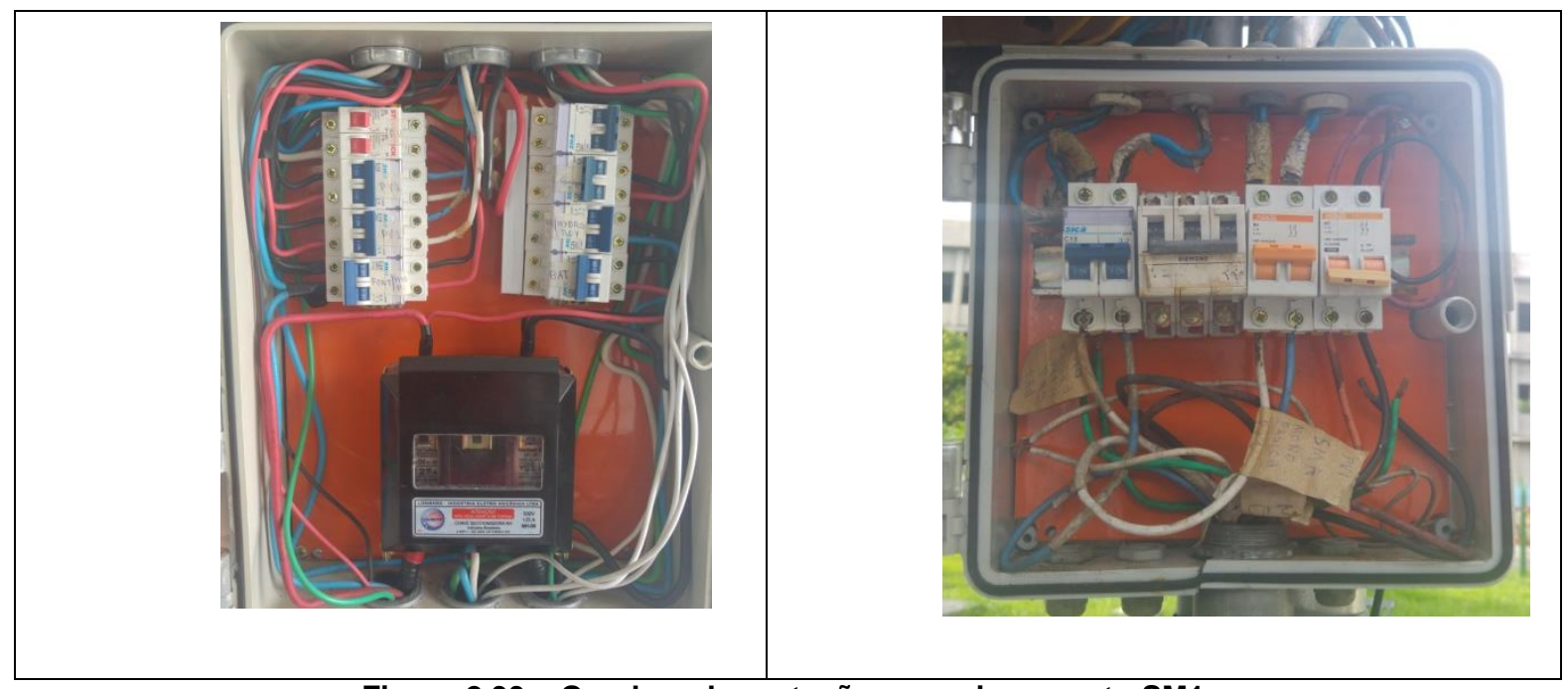

Figura 2.33 - Quadros de proteção e seccionamento SM1.

\subsubsection{Sistema de Medição}

As medições dos parâmetros elétricos do SM1 são realizadas por meio de um shunt e pelos medidores embutidos nos equipamentos do fabricante SMA. O shunt está instalado junto ao banco de baterias, possibilitando desta forma medir a corrente total que flui pelo banco de baterias. Os outros parâmetros elétricos de tensão, potência e frequência, são medidos pelo INVB-01/SM1. 


\subsubsection{Sistema de Sensoriamento}

O sistema de sensoriamento presente no SM1 possui as mesmas características do sistema utilizado pelo ST1. Os sensores utilizados neste sistema são: sensor de temperatura ambiente, um sensor de costa de módulo e SSB.

\subsubsection{Sistema de Monitoramento}

O sistema de monitoramento é responsável pelo processamento e exibição das variáveis elétricas e ambientais de todo o SM1. A Figura 2.34, apresenta parte do sistema de monitoramento, o Sunny WebBox (SWB) o Sunny Matrix (SM).

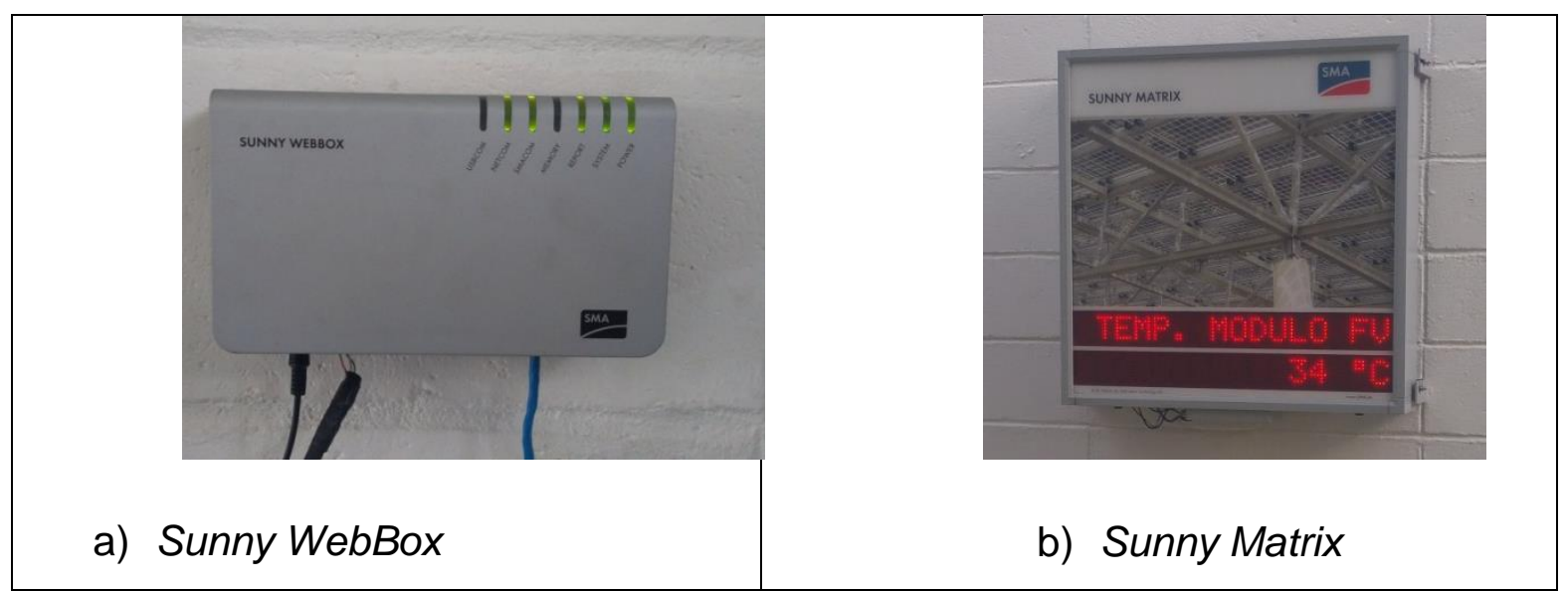

Figura 2.34 - Sistema de monitoramento do SM1.

O SWB é um equipamento que realiza a coleta e documentação dos dados dos dispositivos conectados, permitindo o monitoramento dos sistemas. O SWB fornece os dados gravados através de uma ligação à Internet, sendo os dados apresentados no website do Sunny Portal.

O SM é um dispositivo que realiza a interface gráfica dos dados adquiridos pelo sistema e processados pelo SWB. Os dados que podem ser exibidos abrangem tanto os dados de produtividade do sistema quanto os parâmetros meteorológicos locais. 


\subsubsection{Sistema de Consumo de Energia}

A Figura 2.35 apresenta a carga resistiva e o Hydro boy, que são os dispositivos que demandam a energia no SM1. O fornecimento de energia para essas cargas ocorre em corrente contínua, pois ambos estão conectados no barramento c.c. Desta forma é possível realizar processos de carga e descarga com o sistema de acumulação.

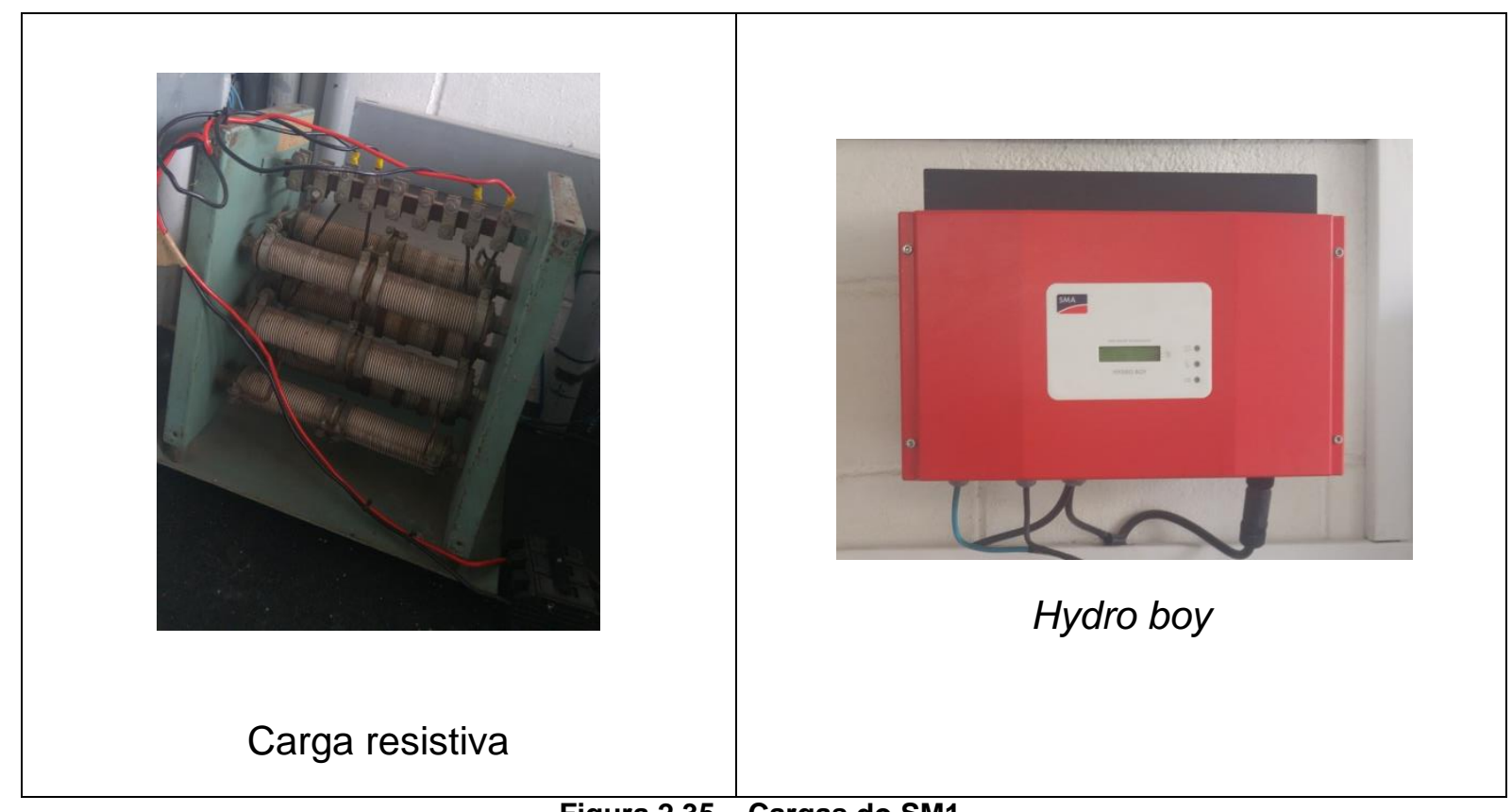

Figura 2.35 - Cargas do SM1.

O Hydro boy é um equipamento que poderia estar no sistema de condicionamento de potência, já que ele realiza a conversão c.c./c.a. Contudo, neste sistema ele realiza a função de uma carga eletrônica, onde se programa o valor de corrente que ele irá extrair do banco de baterias e injetar na rede c.a. Todavia, ele poderia ser conectado no lado da carga do SM1 e realizar o papel de uma GD.

O SM1 também apresenta a possibilidade de injeção de energia para a rede elétrica, pelo fluxo reverso de potência. O INVB-01 permite a injeção do excesso da geração de energia proveniente dos módulos, desde que o banco de baterias esteja com o estado de carga elevado. 


\subsection{Sistema Trifásico 2}

O ST2 é composto por sistemas de geração de energia elétrica, condicionamento de potência, armazenamento, sensoriamento, comunicação, medição, distribuição e comando, conforme descrito a seguir:

- Sistema de Geração:

> 1 Gerador fotovoltaico;

> 1 Grupo Gerador Diesel de 40 kVA (GGD).

- Sistema de Condicionamento de Potência:

$>\quad 3$ Inversores bidirecionais de $5 \mathrm{~kW}$ cada (INVB-01/ST2, INVB-02/ST2 e INVB-03/ST2);

> 1 Controlador de carga (CDC-01/ST2).

- Sistema de Armazenamento:

> 2 Bancos de baterias VRLA de 48 V / 200 Ah (C10).

- Sistema de Distribuição e Comando:

$>1 X$-Connect.

- Sistema de Proteção:

$>\quad 6$ Chaves seccionadoras fusíveis ( $\mathrm{NH} 00)$;

$>33$ Disjuntores;

> 6 Dispositivo de proteção contra surtos.

- Sistema de Medição:

> 3 Transformadores de corrente (TC);

$>3$ Shunts.

- $\quad$ Sistema de Monitoramento:

$>1$ Remote control and programming unit (RCC-02);

$>1$ Xcom-CAN;

$>1$ Battery Status Processor (BSP);

$>1$ Programa;

$>1$ Computador.

- Sistema de Consumo de Energia:

> 2 Quadros de distribuição:

$>1$ Carga resistiva.

A Figura 2.36 ilustra o diagrama esquemático do ST2. 


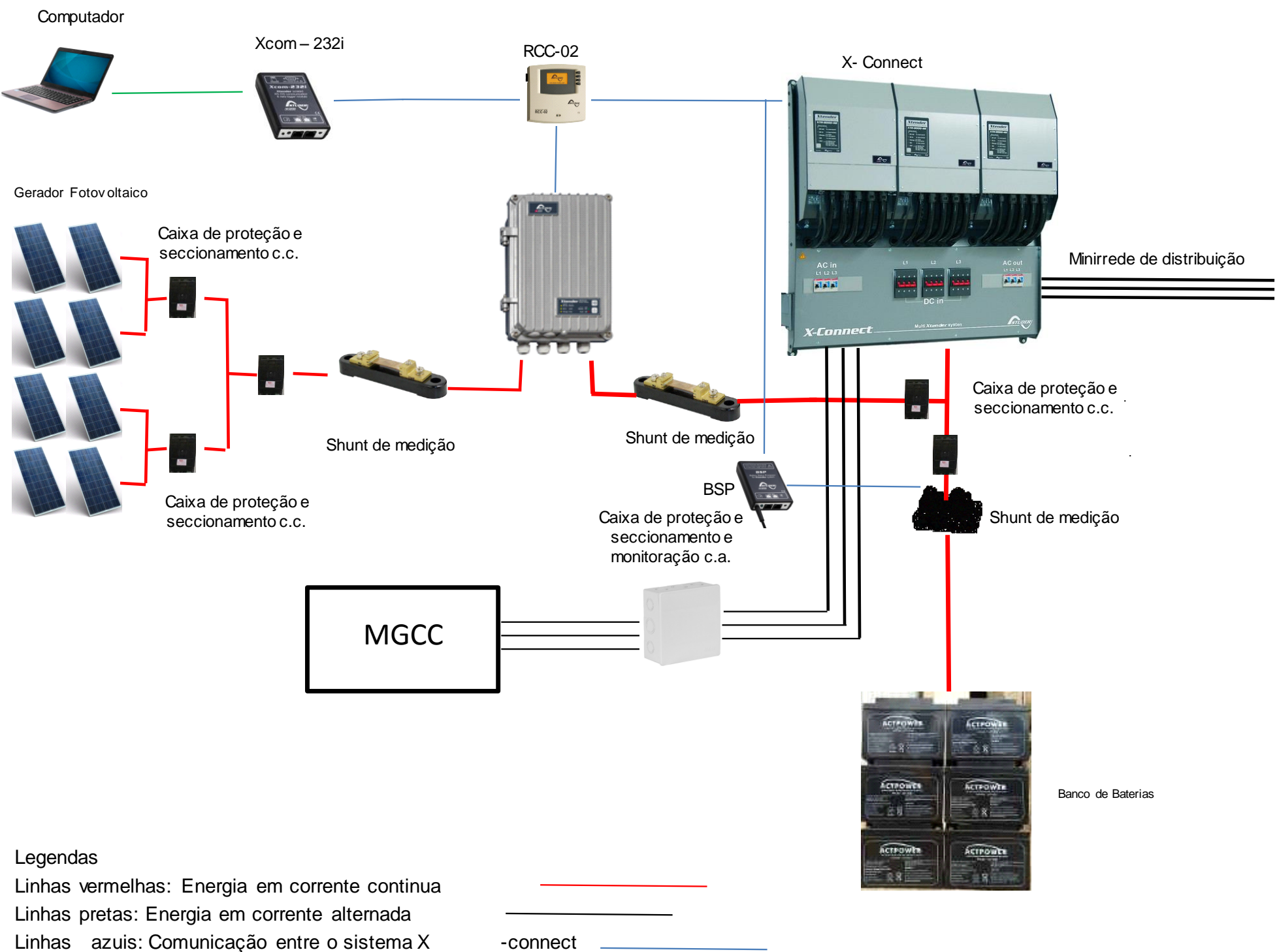

Figura 2.36 - Diagrama esquemático do ST2. 


\subsubsection{Sistema de Geração}

A energia elétrica fornecida para o ST2 pode ser proveniente de três fontes distintas, sendo estas: a geração fotovoltaica, o GGD e a rede elétrica externa.

\subsubsection{Geradores Fotovoltaicos}

O ST2 possui um gerador fotovoltaico com quatros strings associados em paralelo. Diferentemente dos sistemas ST1 e SM1, este sistema não possui acoplamento misto, sendo todo o sistema de geração fotovoltaico conectado no barramento de corrente contínua.

O GFV-01/ST2 está conectado ao CDC-01/ST2. A Figura 2.37 apresenta e destaca o gerador fotovoltaico do ST2.

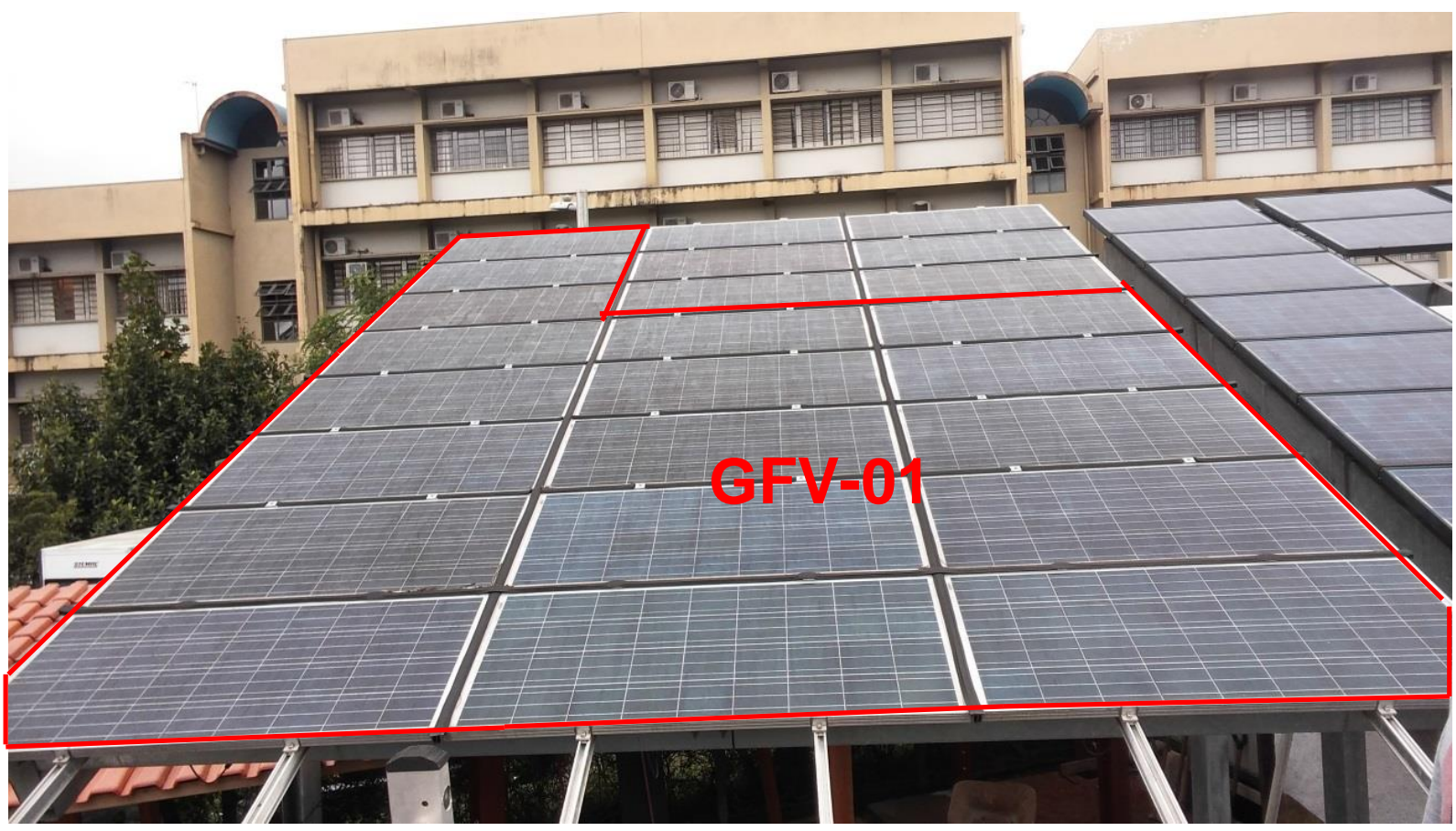

Figura 2.37 - Gerador Fotovoltaico do ST2.

Os módulos fotovoltaicos que não estão destacados na Figura 2.37 são utilizados no SM1. Os módulos fotovoltaicos que compõem os geradores fotovoltaicos são do fabricante Komaes Solar. 
O gerador fotovoltaico utilizado no ST2 possui um único fabricante. A Figura 2.38 apresenta o módulo e a Tabela 2.16 apresenta as suas especificações técnicas.

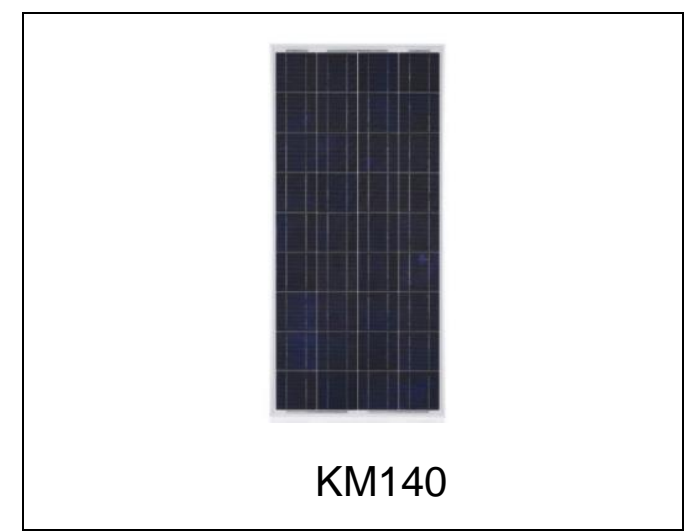

Figura 2.38 - Módulo fotovoltaico do ST2.

Fonte: (KOMAES SOLAR, 2009).

Tabela 2.16 - Especificações Técnicas do Módulo do ST2.

\begin{tabular}{|l|l|}
\hline Fabricante & Komaes Solar \\
\hline Modelo & KM 140 \\
\hline Potência W & $140 \mathrm{~W}$ \\
\hline Tensão de máxima potência $\left(\mathrm{V}_{\mathrm{mp}}\right)$ & $18,36 \mathrm{~V}$ \\
\hline Corrente de máxima potência $(\mathrm{Imp})$ & $7,65 \mathrm{~A}$ \\
\hline Corrente de curto-circuito & $8,17 \mathrm{~A}$ \\
\hline Tensão de circuito aberto & $21,96 \mathrm{~A}$ \\
\hline Máxima tensão do sistema & $1.000 \mathrm{~V}$ \\
\hline Tipo de célula & Poly-Si \\
\hline Número de células & 36 \\
\hline
\end{tabular}

Fonte: Adaptado de (KOMAES SOLAR, 2009). 
A composição do gerador fotovoltaico é descrita a seguir:

- $\quad$ GFV-01/ST2: 5 módulos em série (string) (109,8 Voc / 91,8 Vmp) e quatro strings em paralelo (30,6 Imp), totalizando 20 módulos (2,8 kWp).

\subsubsection{Grupo Gerador a Diesel}

O GGD é o elemento comum entre todos os sistemas híbridos e suas imagens e especificações técnicas estão apresentadas na Figura 2.6, Figura 2.7, Figura 2.7 e na Tabela 2.3 e Tabela 2.4.

\subsubsection{Rede Elétrica Externa}

Assim como mencionado anteriormente, a rede elétrica pode fornecer energia para todos os sistemas híbridos $(\mathrm{SH})$ simultaneamente ou individualmente. A rede elétrica pode fornecer energia pela chave de transferência presente no GGD ou direto no sistema de interconexão entre todos os SH.

\subsubsection{Sistema de Condicionamento de Potência}

O sistema de condicionamento de potência realiza a conversão de energia para padrões aceitáveis para o sistema, sejam essas conversões c.c./c.a ou o inverso, e conversão c.c/c.c. Este sistema não possui inversores de conexão à rede e seus equipamentos de condicionamento de potência são: inversor bidirecional e controlador de carga.

\subsubsection{Inversores Bidirecionais}

Os inversores bidirecionais (INVB-01/ST2, INVB-02/ST2, e INVB-03/ST2) convertem energia em corrente contínua em energia em corrente alternada e possibilitam a conexão de uma fonte externa em corrente alternada para carregar o banco de baterias, funcionando, desta forma, como retificadores de tensão.

Os INVB são instalados no $X$-connect, possibilitando conexão e comunicação entre os INVB/ST2 e a formação de uma rede trifásica. A conversão 
c.c./c.a. ocorre INVB/ST2 (Figura 2.39). A Tabela 2.17 apresenta as especificações técnicas dos inversores.

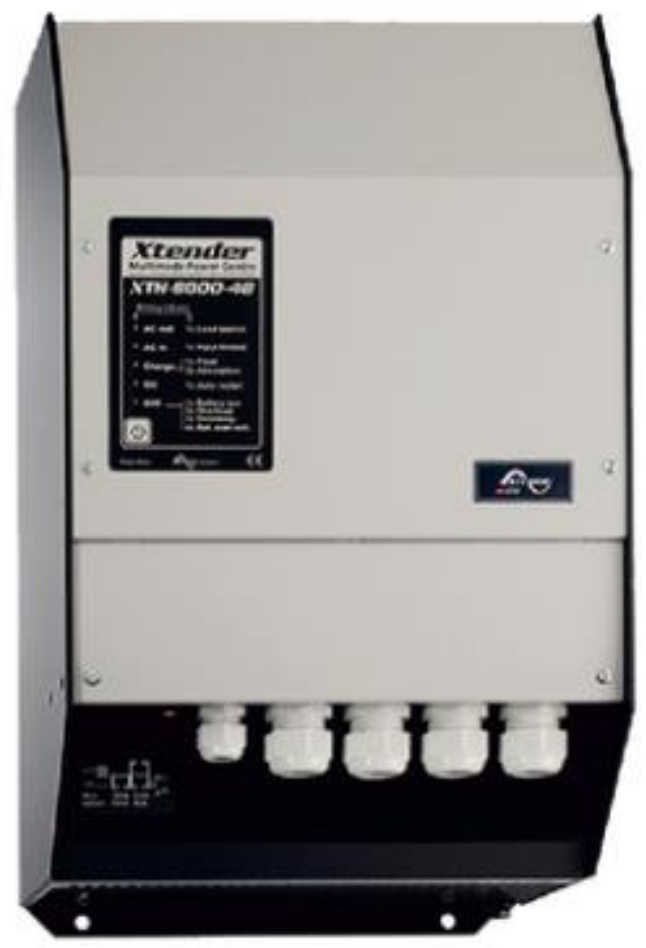

Figura 2.39 - Inversor Bidirecional do ST2.

Fonte: (STUDER INNOTEC SA, 2016).

Tabela 2.17 - Especificações Técnicas do Inversor Bidirecional do ST2.

\begin{tabular}{|c|c|}
\hline Fabricante & Studer \\
\hline Modelo & XTH 6000-48 \\
\hline Inversor & $48 \mathrm{~V}$ \\
\hline Tensão nominal da bateria & 38 a $68 \mathrm{~V}$ \\
\hline Faixa de tensão de carregamento & 45 a $65 \mathrm{~Hz}$ \\
\hline Faixa de frequência de saída & $5.000 \mathrm{VA}$ \\
\hline Potência contínua de saída a $25^{\circ} \mathrm{C}$ & $6.000 \mathrm{VA}$ \\
\hline Potência de saída por 30 minutos a $25^{\circ} \mathrm{C}$ & $15.000 \mathrm{VA}$ \\
\hline Potência máxima de saída & - \\
\hline Carregador de Bateria & $100 \mathrm{~A}$ \\
\hline Corrente máxima de carregamento & \\
\hline
\end{tabular}




\begin{tabular}{|c|c|c|}
\hline Método de regulagem do carregamento & \multicolumn{2}{|c|}{$\begin{array}{c}\text { PWM em } 3 \text { etapas (carga, absorção e } \\
\text { flutuação) }\end{array}$} \\
\hline Dados Gerais & \multicolumn{2}{|l|}{-} \\
\hline Faixa de tensão de entrada CA & \multicolumn{2}{|c|}{150 a 265 F-F / 50 a 140 F-N } \\
\hline Faixa de frequência de entrada & \multicolumn{2}{|c|}{$45 \mathrm{a} 65 \mathrm{~Hz}$} \\
\hline Corrente máxima de entrada & \multicolumn{2}{|c|}{$56 \mathrm{~A}$} \\
\hline \multirow{3}{*}{ Dimensões (mm) } & Comprimento & 300 \\
\hline & Largura & 500 \\
\hline & Altura & 230 \\
\hline Peso (kg) & \multicolumn{2}{|c|}{42} \\
\hline
\end{tabular}

Fonte: Adaptado de STUDER INNOTEC SA (2016).

\subsubsection{Controlador de Carga}

O controlador de carga instalado no sistema realiza o condicionamento da energia proveniente dos módulos para uma faixa aceitável para o banco de baterias. O controlador XTS 1400-48 está instalado entre o gerador fotovoltaico e o barramento em corrente contínua no X-Connect (Figura 2.40) e suas especificações técnicas estão apresentadas na Tabela 2.18.

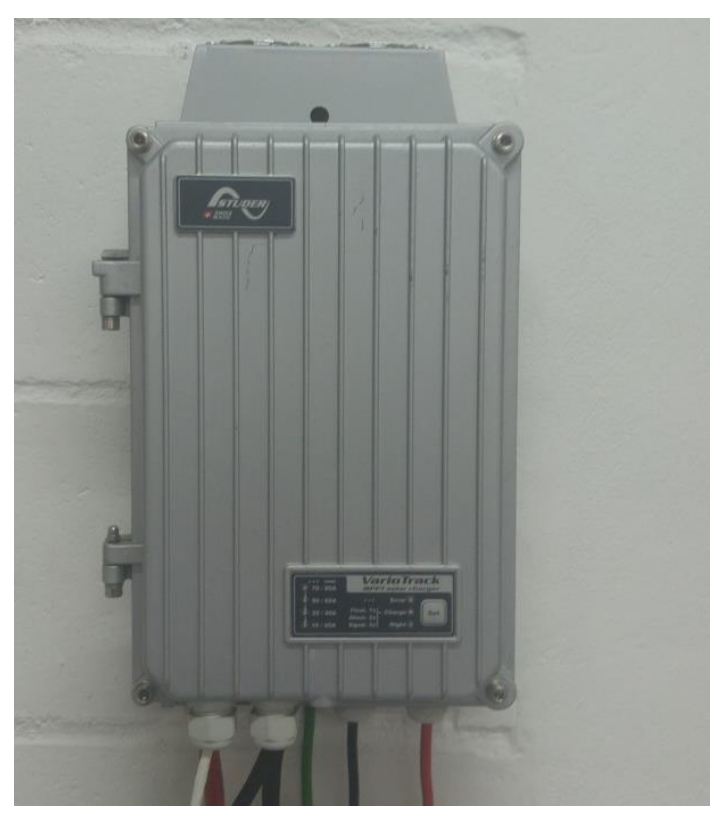

Figura 2.40 - Controlador de carga do ST2.

Tabela 2.18 - Especificações técnicas do controlador de carga do ST2. 


\begin{tabular}{|c|c|c|}
\hline Modelo & \multicolumn{2}{|c|}{ XTS 1400-48 } \\
\hline Configuração de tensão de saída & \multicolumn{2}{|c|}{$48 \mathrm{~V}$} \\
\hline Faixa de tensão de saída & \multicolumn{2}{|c|}{38 a $68 \mathrm{~V}$} \\
\hline Tensão máxima do PV & \multicolumn{2}{|c|}{$150 \mathrm{~V}$} \\
\hline Corrente máxima de carregamento & \multicolumn{2}{|c|}{$12 \mathrm{~A}$} \\
\hline Eficiência & \multicolumn{2}{|c|}{$93 \%$} \\
\hline Corrente de autoconsumo & \multicolumn{2}{|c|}{$<10 \mathrm{~mA}$} \\
\hline \multirow{3}{*}{ Dimensões $(\mathrm{mm})$} & Comprimento & 310 \\
\hline & Largura & 210 \\
\hline & Altura & 110 \\
\hline Peso $(\mathrm{kg})$ & \multicolumn{2}{|c|}{9,3} \\
\hline
\end{tabular}

Fonte: Adaptado de (STUDER INNOTEC SA, 2016).

\subsubsection{Sistema de Armazenamento}

O sistema de armazenamento é composto por dois bancos de baterias, associados em paralelo, cada um com quatro elementos associados em série. As baterias Actopower utilizadas possuem tensão de $12 \mathrm{~V}$ e capacidade nominal de 200 Ah (regime C10), totalizando um banco de 19,2 kWh. A Figura 2.41 ilustra o banco de baterias e a Tabela 2.15 apresenta as especificações técnicas das baterias.

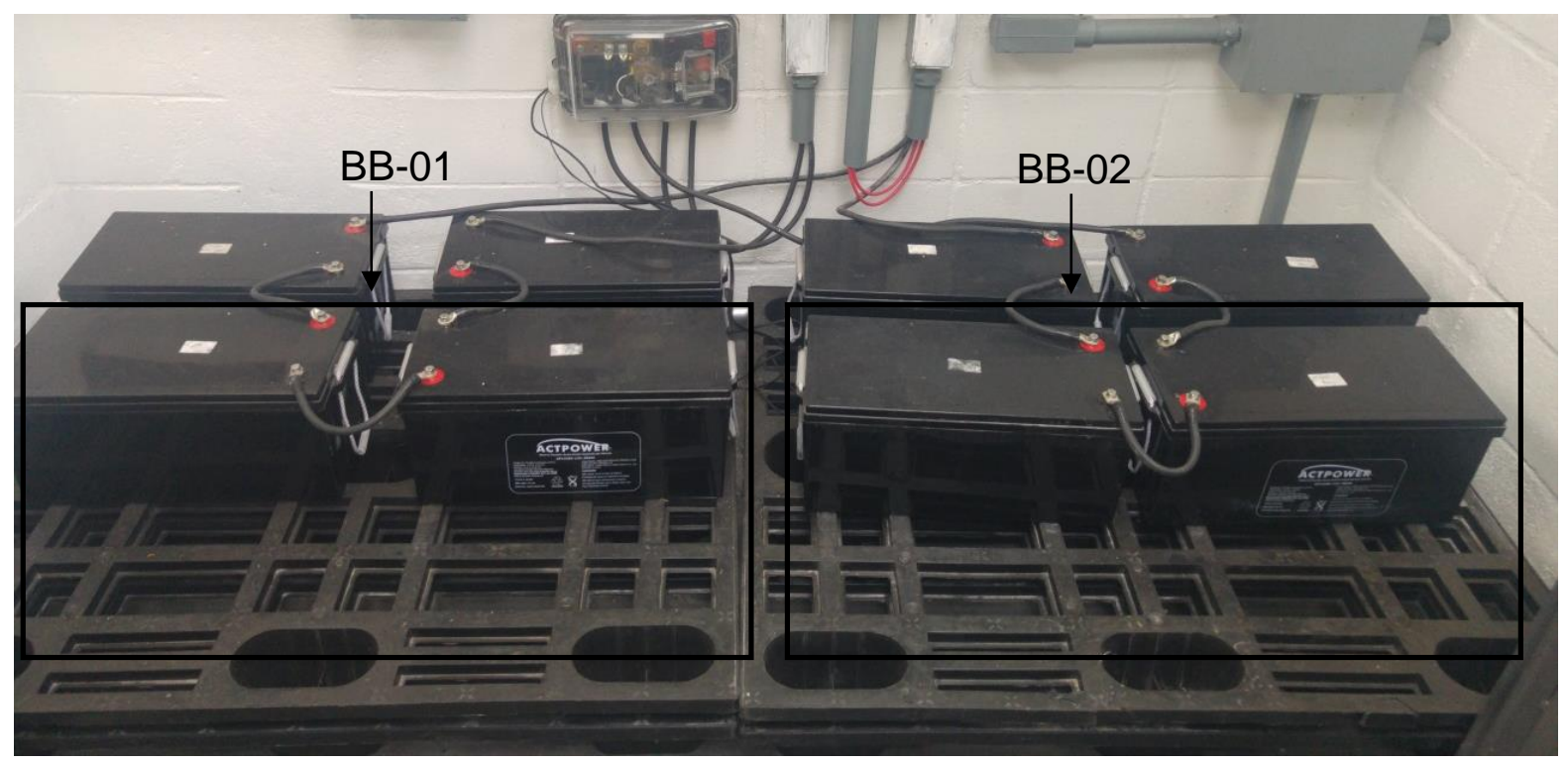

Figura 2.41 - Banco de Baterias do ST2. 


\subsubsection{Sistema de Distribuição}

O X-connect (Figura 2.42) é o dispositivo que realiza a distribuição de energia no sistema. Nele estão presentes o barramento em corrente contínua, que libera energia elétrica para o sistema de armazenamento, a entrada de energia elétrica das fontes externas provenientes do sistema de interconexão dos $\mathrm{SH}$, e a entrada de energia do sistema de geração fotovoltaica.

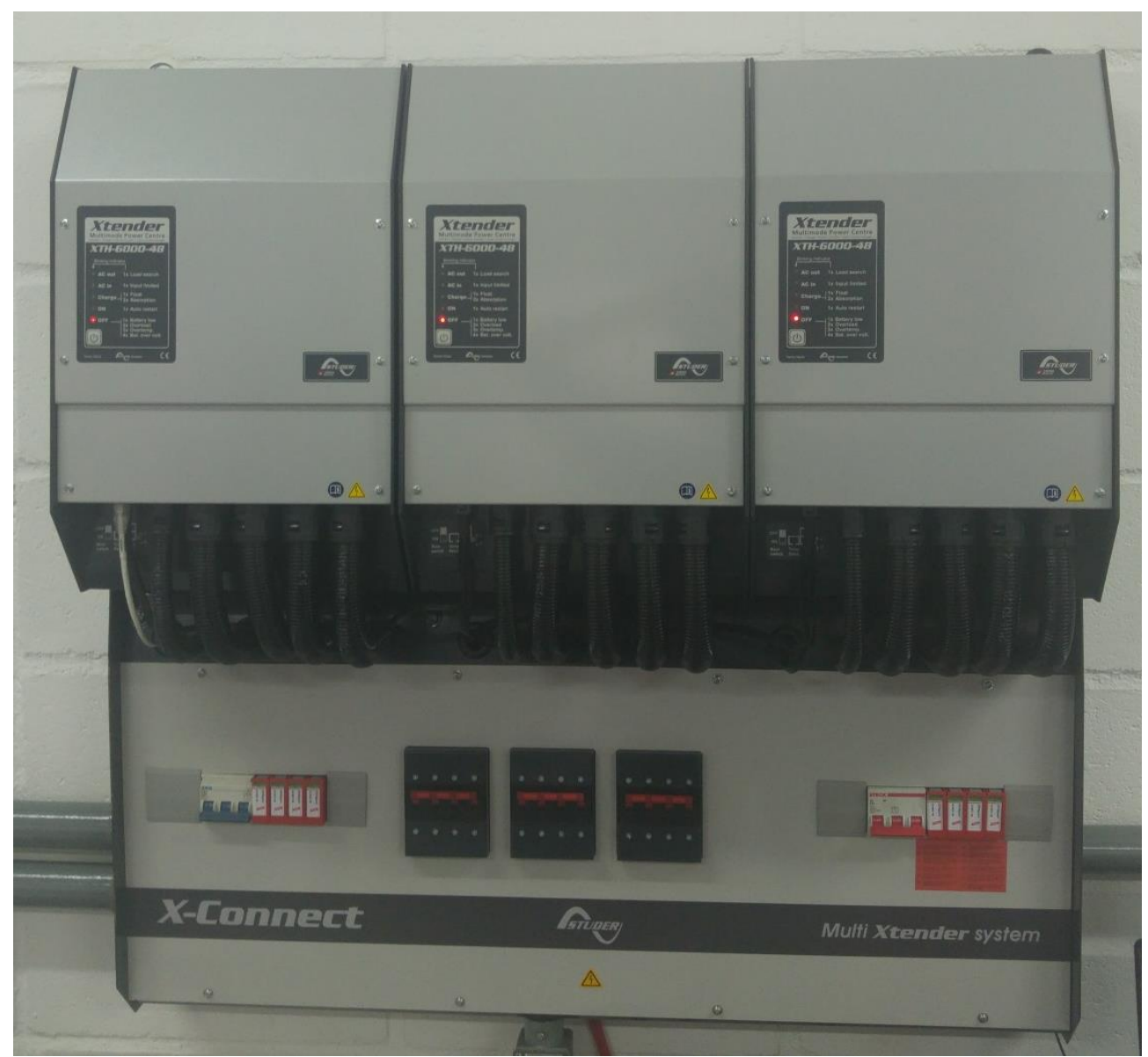

Figura 2.42 - X-Connect.

A Figura 2.43 apresenta o $X$-Connect sem sua tela de proteção, destacando os dispositivos utilizados para realizar as conexões de entrada e saída de energia em corrente alternada, e o barramento em corrente contínua, onde estão em paralelo o controlador de carga, as baterias e a entrada em corrente contínua dos inversores bidirecionais. 


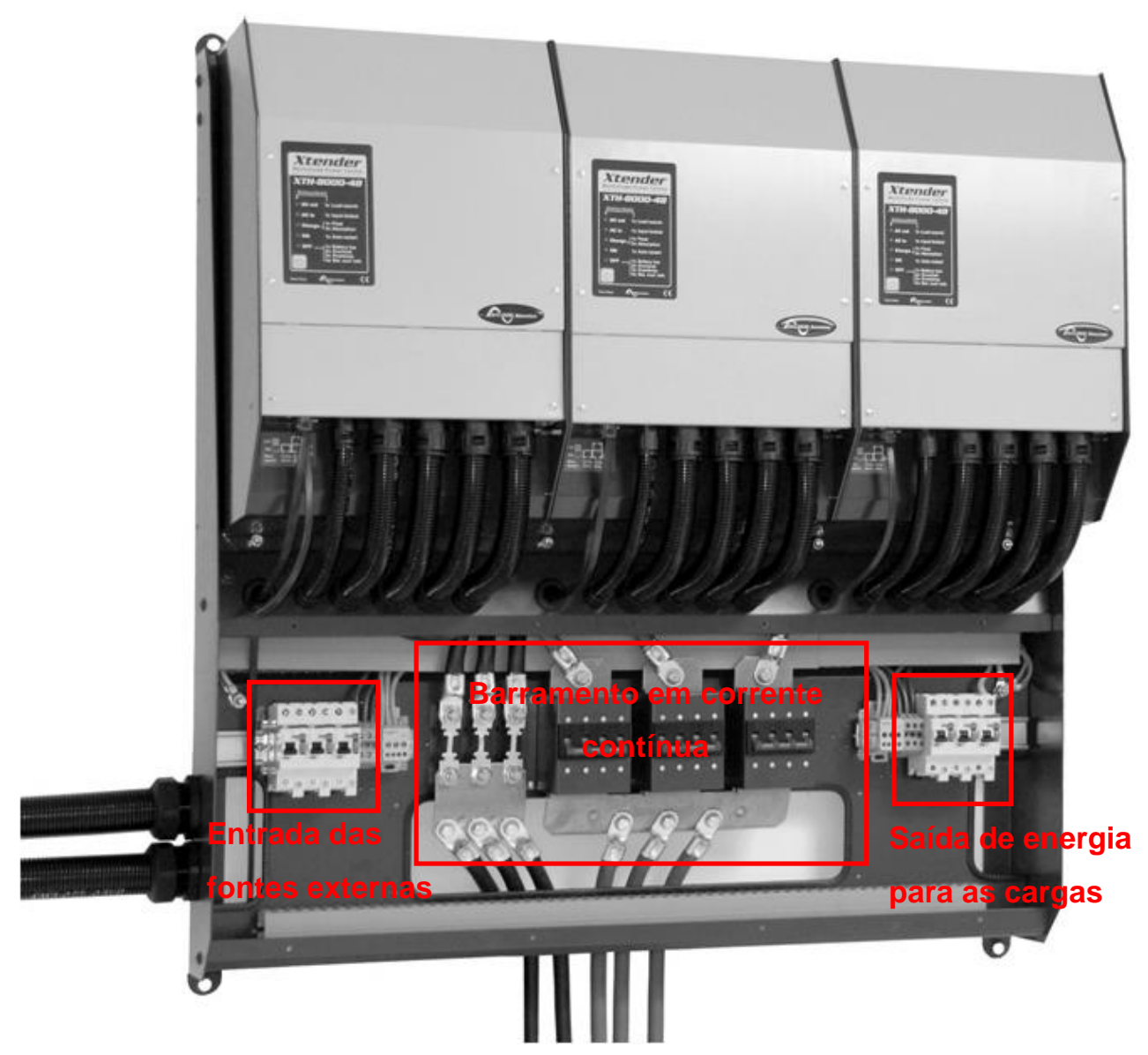

Figura 2.43 - Conexões do X-connect.

Fonte: Adaptado de STUDER INNOTEC (2008).

\subsubsection{Sistema de Proteção}

O sistema de proteção é composto por dois quadros de proteção e seccionamento, três chaves seccionadoras porta-fusível, disjuntores e DPS que estão presentes no $X$-connect. Desta forma as proteções ocorrem tanto no âmbito de corrente contínua quanto no de corrente alternada, além da possibilidade de seccionamento do sistema em pontos distintos.

\subsubsection{Sistema de Medição}

As medições de correntes, tensões, e potência, são realizadas nos três quadros de medição e seccionamento, onde estão presentes TC e shunts. Os TC são utilizados para medir as correntes no lado c.a., tanto na entrada quanto na saída de energia. As medições c.c. ocorrem no shunt, que mede a corrente total que flui no 
sistema de armazenamento, isso é, a corrente que está entrando ou saindo do banco de baterias. Os outros shunts medem as correntes dos GFV-01/ST2 e depois do CDC-01/ST2.

\subsubsection{Sistema de Monitoramento}

A Figura 2.44 apresenta o sistema de monitoramento, que é composto por três dispositivos do fabricante Studer: O Remote control and progamming unit (RCC02), o Battery Status Processor (BSP) e o Xcom-232i. Estes dispositivos realizam o monitoramento e a amostragem dos parâmetros elétricos do ST2, e a apresentação gráfica é realizada por um computador.

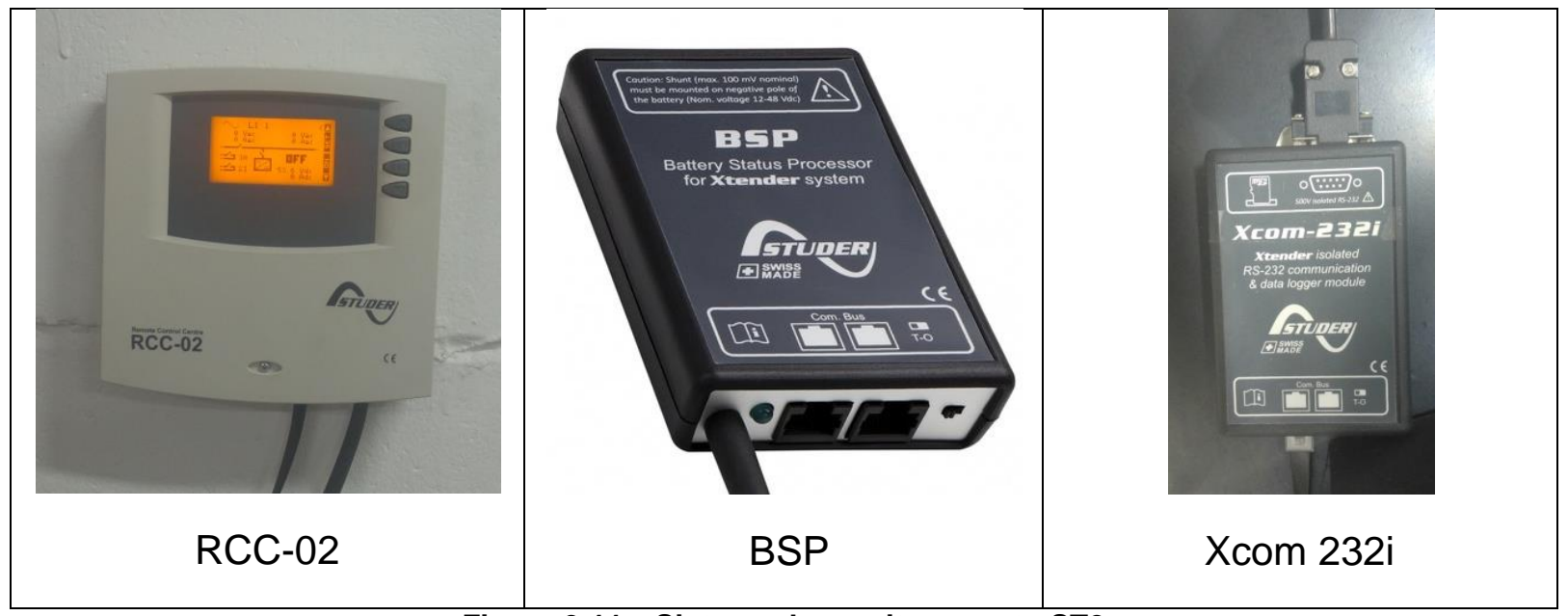

Figura 2.44 - Sistema de monitoramento ST2.

O RCC-02 é um dispositivo que programa os parâmetros do sistema, verifica os parâmetros elétricos e ajusta algumas variáveis, além de armazenamento e notificação de eventos ocorridos no sistema (STUDER INNOTEC SA, 2016).

O Xcom-232i é o módulo de comunicação que permite o acesso à maioria dos valores e configurações dos dispositivos conectados ao barramento de comunicação dos equipamentos do fabricante Studer e interliga com o computador.

O BSP é um dispositivo utilizado para monitorar o banco de baterias. Ele está interconectado com os equipamentos do sistema, para fornecer informações sobre o banco de baterias, tais como: estado de carga das baterias, tensão das baterias, temperatura além da medição de corrente com auxílio do shunt. 


\subsubsection{Sistema de Consumo de Energia}

A energia do ST2 pode ser demandada apenas em corrente alternada, e o sistema possui um quadro onde é possível ligar cargas monofásicas, bifásicas ou trifásicas, isso além da carga resistiva trifásica de $10 \mathrm{~kW}$.

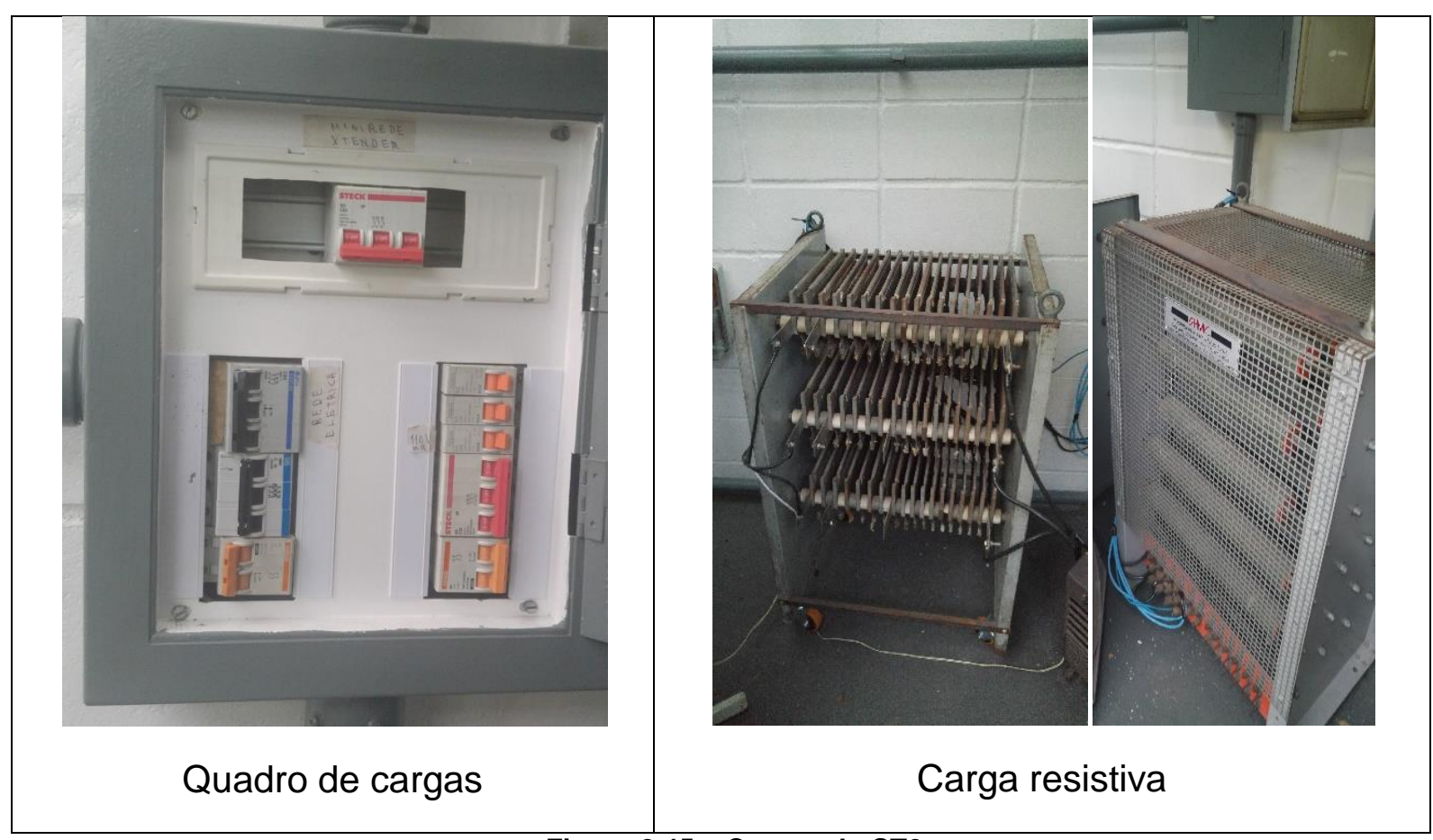

Figura 2.45 - Cargas do ST2. 


\subsection{Sistema Monofásico 2}

O SM2 é composto por sistemas de geração de energia elétrica, condicionamento de potência, armazenamento, sensoriamento, comunicação, medição, distribuição e comando, conforme descrito a seguir.

- Sistema de Geração:

$>1$ Gerador fotovoltaico (GFV-01/SM2);

> 1 Grupo gerador a diesel de 40 kVA (GGD).

- Sistema de Condicionamento de Potência:

$>1$ Inversor bidirecional de $4 \mathrm{~kW}$;

> 1 Controlador de carga (CDC-01/SM2).

- Sistema de Armazenamento:

> 1 Banco de baterias VRLA de $24 \mathrm{~V} / 200 \mathrm{Ah}$ (C10).

- Sistema de Distribuição e Comando:

> 1 XW Power Distribution Painel.

- Sistema de Proteção:

> 2 Chaves seccionadoras fusíveis (tipo do fusível);

> 9 Disjuntores;

> 2 Dispositivo de proteção contra surtos.

- Sistema de Medição:

$>3$ Shunts.

- Sistema de Monitoramento:

> 1 Conext System Control Panel;

> 1 Conext Automatic Generator Start;

$>1$ Computador.

- Sistema de Consumo de Energia:

> 1 Quadro de distribuição;

$>1$ Carga resistiva.

A Figura 2.46 ilustra o diagrama esquemático do SM2. 


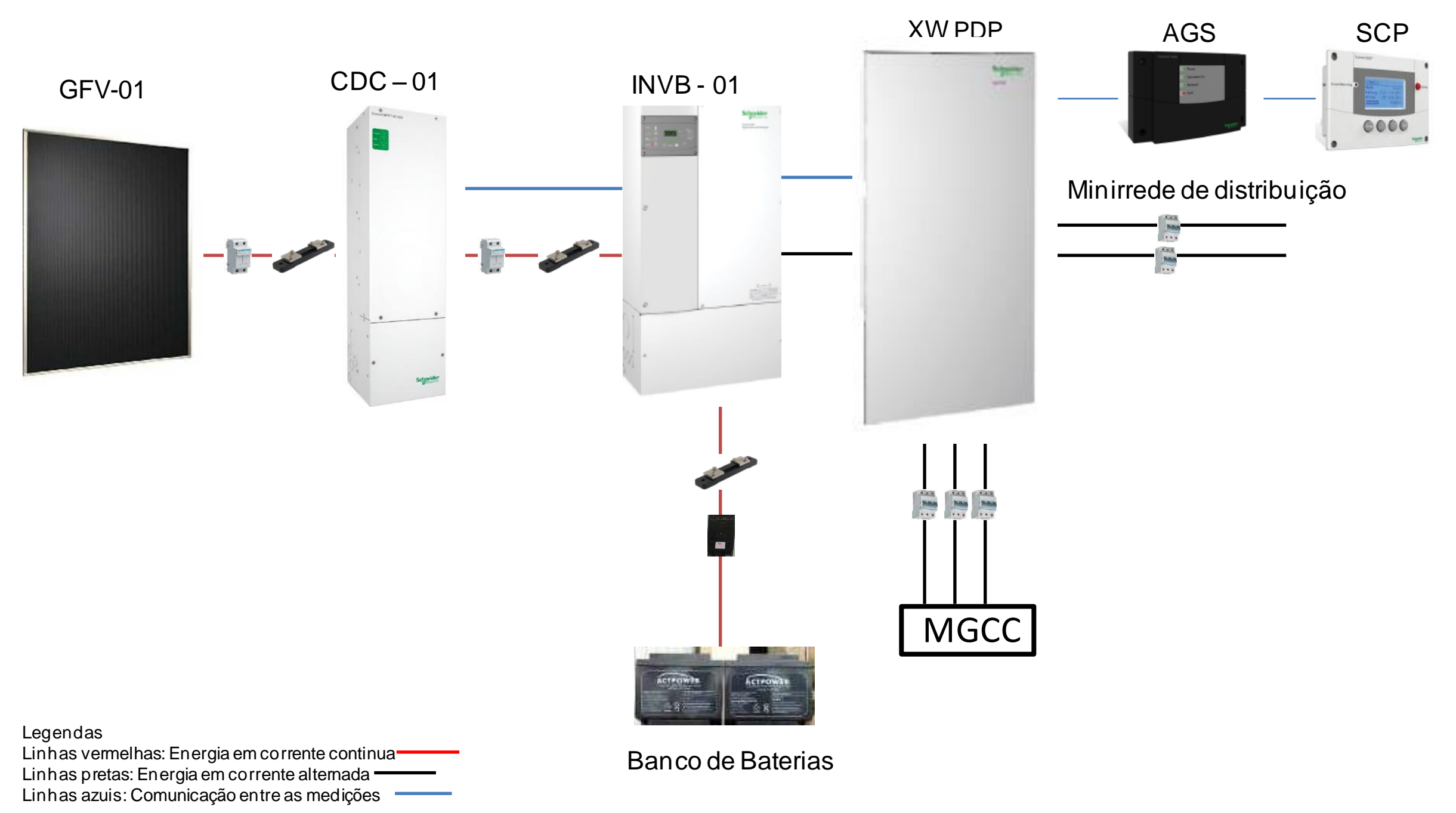

Figura 2.46 - Diagrama esquemático do SM2. 


\subsubsection{Sistema de Geração}

A energia elétrica fornecida para o SM2 pode ser proveniente de três fontes distintas, sendo estas: a geração fotovoltaica, o GGD e a rede elétrica externa.

\subsubsection{Gerador Fotovoltaico}

O SM2 possui um gerador fotovoltaico com quatros módulos associados em série. O GFV-01/SM2 está conectado ao CDC-01/SM2. A Figura 2.47 apresenta e destaca o gerador fotovoltaico do SM2.

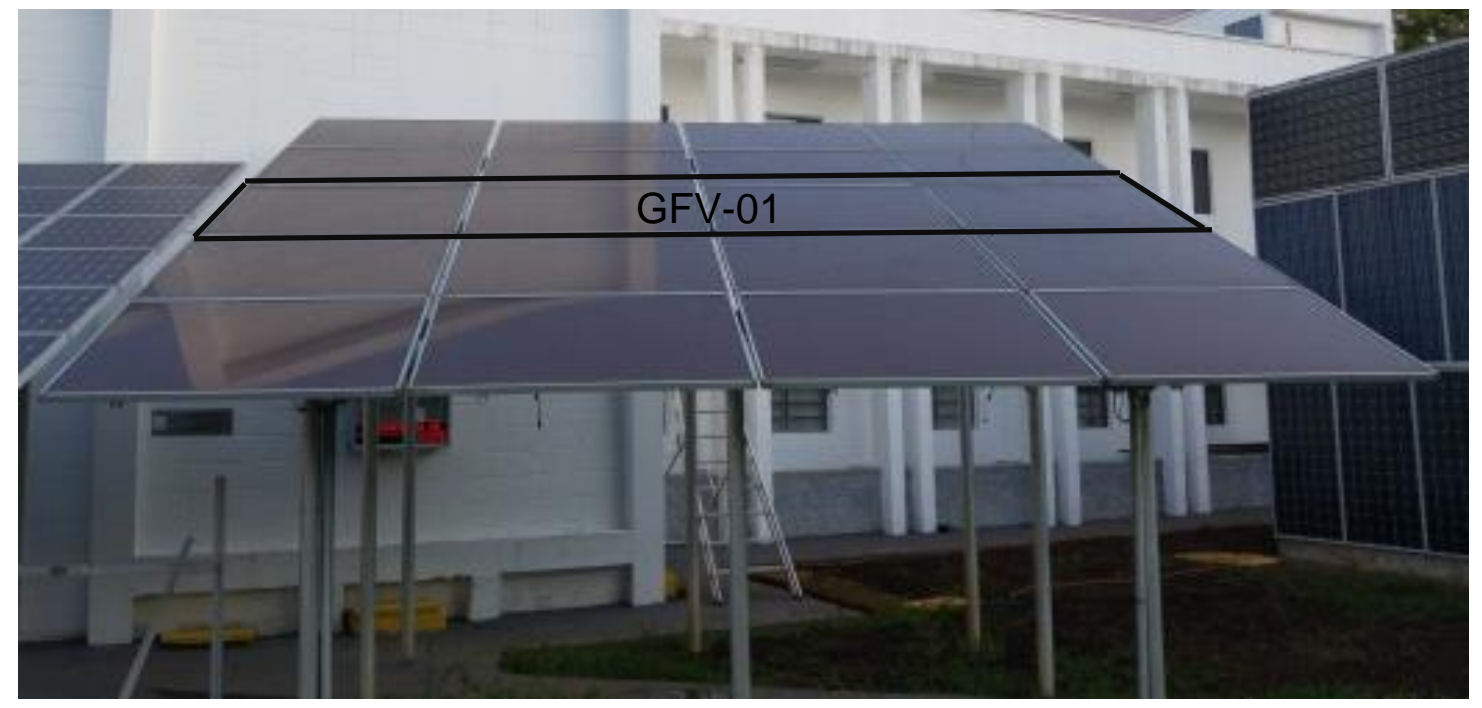

Figura 2.47 - Gerador fotovoltaico do SM2.

Os módulos fotovoltaicos que não estão destacados na Figura 2.47 são utilizados para outros sistemas ou atividades do laboratório. Os módulos fotovoltaicos que compõem o gerador fotovoltaico são do fabricante Dupont, cuja foto e especificações técnicas estão apresentadas respectivamente na Figura 2.48 e na Tabela 2.19. 


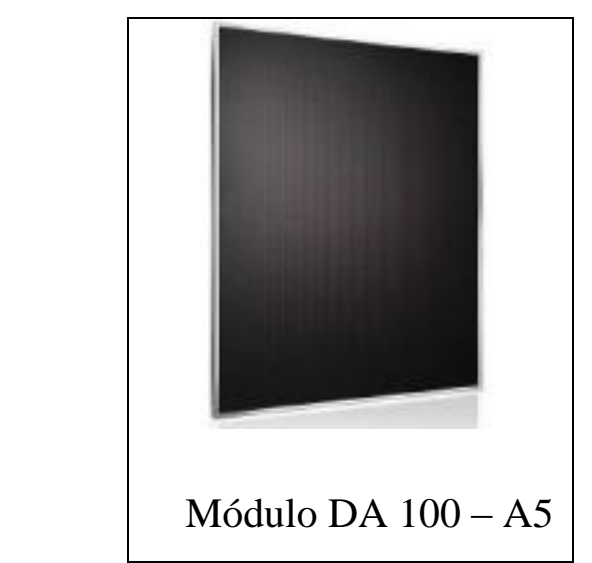

Figura 2.48 - Módulo fotovoltaico do SM2.

Fonte: INMETRO (2013).

\begin{tabular}{|c|c|}
\hline Fabricante & DuPont \\
\hline Modelo & DA $100-$ A5 \\
\hline Potência & $100 \mathrm{~W}$ \\
\hline Tensão de máxima potência (Vmp) & $75 \mathrm{~V}$ \\
\hline Corrente de máxima potência (Imp) & $1,34 \mathrm{~A}$ \\
\hline Corrente de curto-circuito & $1,66 \mathrm{~A}$ \\
\hline Tensão de circuito aberto & $100 \mathrm{~V}$ \\
\hline Máxima tensão do sistema & $1.000 \mathrm{~V}$ \\
\hline Tipo de célula & Filme fino \\
\hline Número de células & -- \\
\hline
\end{tabular}

A composição do gerador fotovoltaico é descrita a seguir:

- $\quad$ GFV-01/SM2: 4 módulos em série (string) (400 Voc / 300 Vmp) e (1,34 Imp), totalizando 4 módulos (0,4 kWp).

\subsubsection{Grupo Gerador a Diesel}

O GGD é o elemento comum entre todos os sistemas híbridos e suas imagens e especificações técnicas estão apresentadas na Figura 2.6, na Figura 2.7, na Figura 2.8, na Tabela 2.3 e na Tabela 2.4. 


\subsubsection{Rede Elétrica Externa}

Assim como mencionado anteriormente, a rede elétrica pode fornecer energia para todos os sistemas híbridos $(\mathrm{SH})$ simultaneamente ou individualmente. A rede elétrica pode fornecer energia pela chave de transferência presente no GGD ou direto no sistema de interconexão entre todos os SH.

\subsubsection{Sistema de Condicionamento de Potência}

O sistema de condicionamento de potência realiza a conversão de energia para padrões aceitáveis para o sistema, sejam essas conversões c.c./c.a ou o inverso, e conversão c.c/c.c. O sistema de condicionamento de potência do SM2 possui um inversor bidirecional e um controlador de carga.

\subsubsection{Inversor Bidirecional}

O INVB-01/SM2 (Figura 2.49) é um inversor/retificador, podendo ser instalado em sistemas monofásicos ou trifásicos, com dupla entrada de alimentação c.a. (entradas para rede elétrica ou GGD). O inversor está instalado em um sistema monofásico e suas especificações técnicas estão apresentadas na Tabela 2.20.

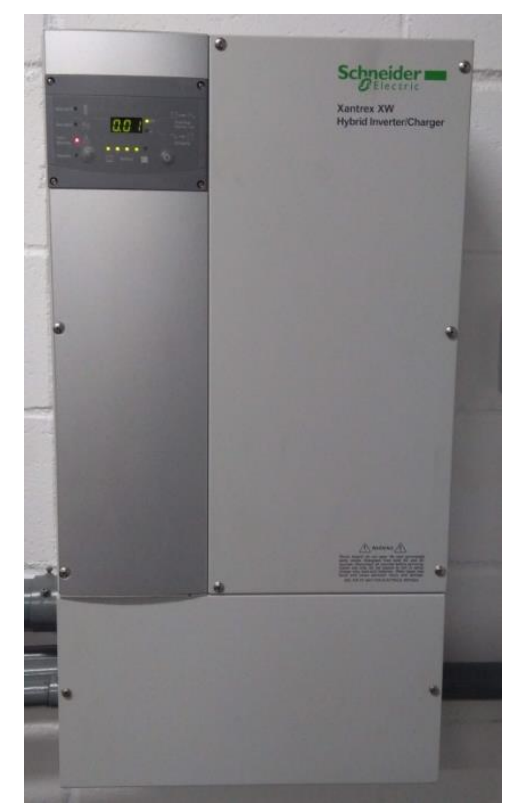

Figura 2.49 - Inversor do INVB-01 do SM2. 
Tabela 2.20 - Especificações técnicas do INVB-01 do SM2.

\begin{tabular}{|c|c|c|}
\hline Fabricante & \multicolumn{2}{|c|}{ Schneider } \\
\hline Modelo & \multicolumn{2}{|c|}{ XW4024 } \\
\hline Inversor & \multicolumn{2}{|l|}{-} \\
\hline Tensão nominal de entrada & \multicolumn{2}{|c|}{$24 \mathrm{~V}$} \\
\hline Faixa de tensão de entrada & \multicolumn{2}{|c|}{$20-38 V$} \\
\hline Faixa de frequência de saída & \multicolumn{2}{|c|}{$60+/-0,1 \mathrm{~Hz}$} \\
\hline Potência contínua de saída a $25^{\circ} \mathrm{C}$ & \multicolumn{2}{|c|}{$4.000 \mathrm{VA}$} \\
\hline Potência de saída por 20 segundos a $40^{\circ} \mathrm{C}$ & \multicolumn{2}{|c|}{$8.000 \mathrm{VA}$} \\
\hline Forma de onda & \multicolumn{2}{|c|}{ Senoidal pura } \\
\hline Carregador de Bateria & \multicolumn{2}{|l|}{ - } \\
\hline Corrente de entrada na potência nominal & \multicolumn{2}{|c|}{$178 \mathrm{~A}$} \\
\hline Corrente de carga & \multicolumn{2}{|c|}{$150 \mathrm{~A}$} \\
\hline Método de regulagem do carregamento & \multicolumn{2}{|c|}{$\begin{array}{c}\text { PWM em } 3 \text { etapas (carga, absorção e } \\
\text { flutuação) }\end{array}$} \\
\hline Dados Gerais & \multicolumn{2}{|c|}{-} \\
\hline Faixa de tensão de entrada & \multicolumn{2}{|c|}{ F_N: $120 \mathrm{~V}+/-3 \% ; \mathrm{F}-\mathrm{F}: 240 \mathrm{~V}+/-3 \%$} \\
\hline Faixa de frequência de entrada & \multicolumn{2}{|c|}{$45 \mathrm{a} 65 \mathrm{~Hz}$} \\
\hline Corrente máxima de carregamento & \multicolumn{2}{|c|}{$30+30 A$} \\
\hline \multirow{3}{*}{ Dimensões (mm) } & Comprimento & 230 \\
\hline & Largura & 410 \\
\hline & Altura & 580 \\
\hline Peso (kg) & \multicolumn{2}{|c|}{52,5} \\
\hline
\end{tabular}

Fonte: Adaptado de SCHNEIDER ELECTRIC (2014).

\subsubsection{Controlador de Carga}

O CDC-01/SM2 (Figura 2.50) instalado no sistema realiza o condicionamento de potência da energia proveniente dos módulos para uma faixa aceitável para o banco de baterias. O controlador CDC-01/SM2 está instalado entre o gerador fotovoltaico e o barramento em corrente contínua no XW Power Distribution Painel. Suas especificações técnicas estão apresentadas na Tabela 2.21 . 


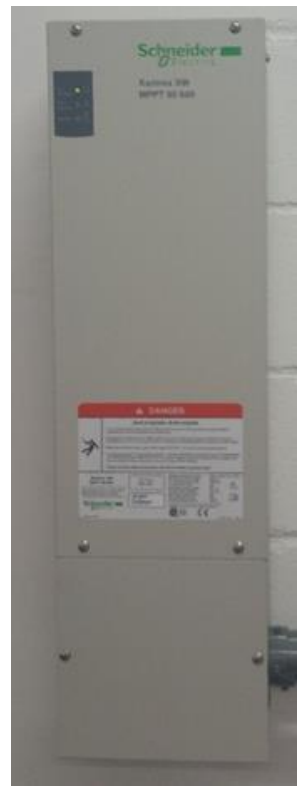

Figura 2.50 - CDC-01 do SM2.

Tabela 2.21 - Especificações Técnicas do CDC-01 do SM2.

\begin{tabular}{|c|c|c|}
\hline Modelo & \multicolumn{2}{|c|}{ Conext MPPT 80 600 } \\
\hline Configuração de tensão de saída & \multicolumn{2}{|c|}{24 ou 48 V } \\
\hline Faixa de tensão de entrada & \multicolumn{2}{|c|}{195 a 550 V } \\
\hline Máxima tensão de entrada & \multicolumn{2}{|c|}{$80 \mathrm{~A}$} \\
\hline Máxima corrente de carregamento & $94 \%$ (nominal 24 V), 96 \% (nominal 48 V) \\
\hline Eficiência & \multicolumn{2}{|c|}{$<10 \mathrm{~mA}$} \\
\hline Corrente de autoconsumo & Comprimento & 220 \\
\hline \multirow{2}{*}{ Dimensões (mm) } & Largura & 760 \\
\cline { 2 - 3 } & Altura \\
\cline { 2 - 3 } & \multicolumn{2}{|c|}{13,5} \\
\hline Peso (kg)
\end{tabular}

Fonte: Adaptado de SCHNEIDER ELECTRIC (2015).

\subsubsection{Sistema de Armazenamento}

O sistema de armazenamento é composto por um banco de baterias constituído por dois elementos associados em série. As baterias Actopower utilizadas possuem tensão de $12 \mathrm{~V}$ e capacidade nominal de $200 \mathrm{Ah}$ (regime C10), totalizando um banco de 4,8 kWh. A Figura 2.51 ilustra o banco de baterias e a Tabela 2.15 apresenta as especificações técnicas das baterias. 


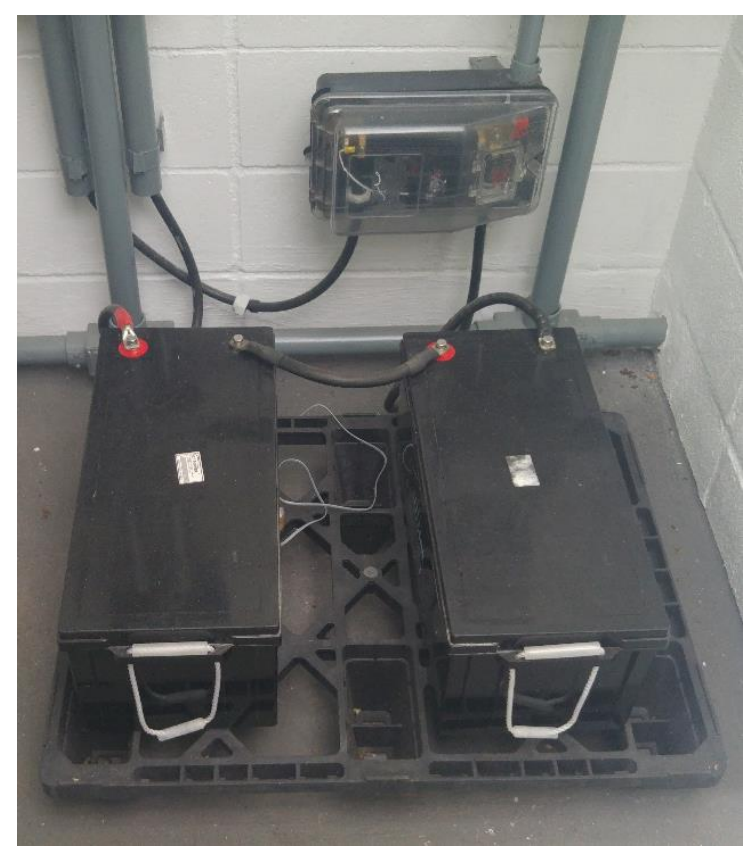

Figura 2.51 - Banco de Baterias do SM2.

\subsubsection{Sistema de Distribuição}

O Power Distribution panel (PDP) é o quadro que integra toda a distribuição de energia do sistema, realizando o seccionamento e a proteção, em corrente contínua e em corrente alternada.

A Figura 2.52 apresenta o PDP, onde está localizado o barramento c.c., que realiza a conexão do banco de baterias, controlador de carga, entrada c.c. do INVB01/SM2 e as cargas c.c. O barramento c.a. realiza a conexão entre as fontes externas de energia, a saída c.a. do INVB-01/SM2 e o fornecimento de energia para as cargas em corrente alternada (SCHNEIDER ELECTRIC, 2015). 


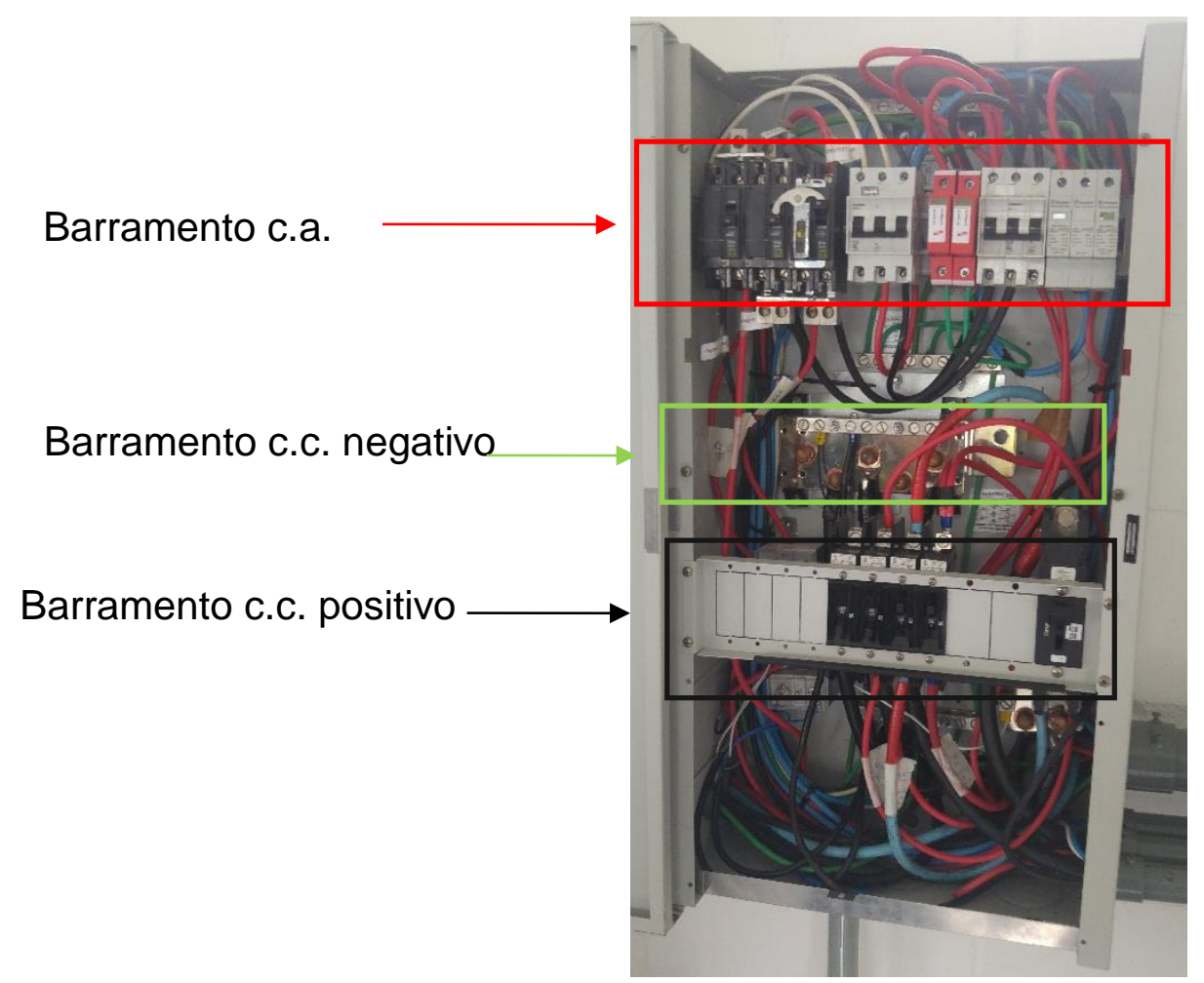

Figura 2.52 - Vista interna do - XW Power Distribution Panel.

\subsubsection{Sistema de Proteção}

O sistema de proteção é composto por dois quadros de proteção e seccionamento, duas chaves seccionadoras porta-fusível, e os dispositivos presentes no PDP. Desta forma, as proteções ocorrem tanto no âmbito de corrente contínua quanto no de corrente alternada, além da possibilidade de seccionamento do sistema em pontos distintos.

\subsubsection{Sistema de Medição}

O SM2 possui um shunt para medição da corrente total que flui no banco de baterias, um shunt para medir a corrente do GFV-01/SM2 e um shunt para medir a corrente do CDC-01/SM2, os outros parâmetros elétricos pelos equipamentos de condicionamento de potência do fabricante.

O INVB-01/SM2 realiza a medição dos parâmetros de corrente, tensão e potência entrada e saída do banco de baterias. Estas medições ocorrem no processo de carga e descarga do banco de baterias. 


\subsubsection{Sistema de Monitoramento}

A Figura 2.53 apresenta o sistema de monitoramento, que é composto por um Conext System Control Panel (SCP), um Conext Automatic Generator Start (AGS), e um computador, para exibir os dados e realizar a interface gráfica.

O CSP é um dispositivo que permite a realização das configurações dos dispositivos da linha $X W$ do fabricante Schnneider, além de realizar o monitoramento do sistema e a apresentação da interface dos valores medidos no sistema.

O AGS é um dispositivo de auxílio para o sistema, sendo instalado em sistemas híbridos isolados da rede elétrica ou servindo como backup da rede, enviando o comando de partir ou parar um GGD.

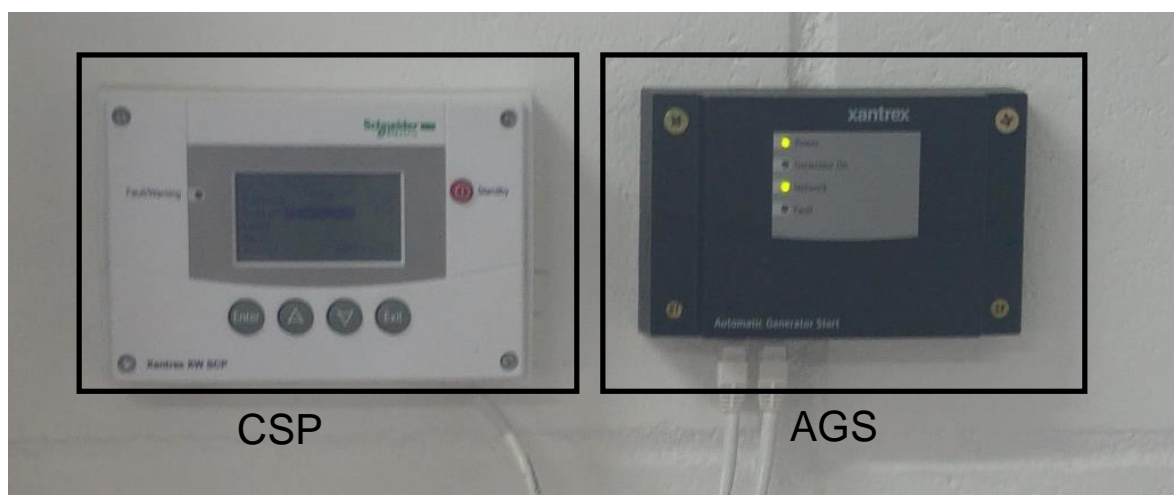

Figura 2.53 - Sistema de monitoramento SM2.

\subsubsection{Sistema de Consumo de Energia}

Este sistema tem a possibilidade da função Grid suport, que permite retirar energia do banco de baterias ou geração e injetar na rede elétrica, realizando o fluxo bidirecional de energia. Além deste modo de demandar a energia, o sistema também possui uma carga resistiva de $500 \mathrm{~W}$ e um quadro para distribuição de energia para suas cargas. 


\subsection{Sistema de Interconexão entre os Sistemas Híbridos}

O sistema de interconexão entre as diferentes topologias de sistemas híbridos é composto por dispositivos de proteção e seccionamento, controle, monitoramento e medição, conforme descrito a seguir.

- Sistema de Controle:

$>1$ CompactRio;

> 3 Módulos de controle.

- Sistema de Medição:

> 3 Transformadores de corrente;

> 4 Módulos de medição de corrente;

> 1 Módulo de medição de tensão.

- Sistema de Monitoramento:

> 1 Computador.

- Sistema de Proteção:

$>7$ Chaves contatoras;

$>11$ Disjuntores;

> 4 Dispositivos de proteção contra surtos.

A Figura 2.54 ilustra o diagrama esquemático do sistema de interconexão dos sistemas híbridos. 


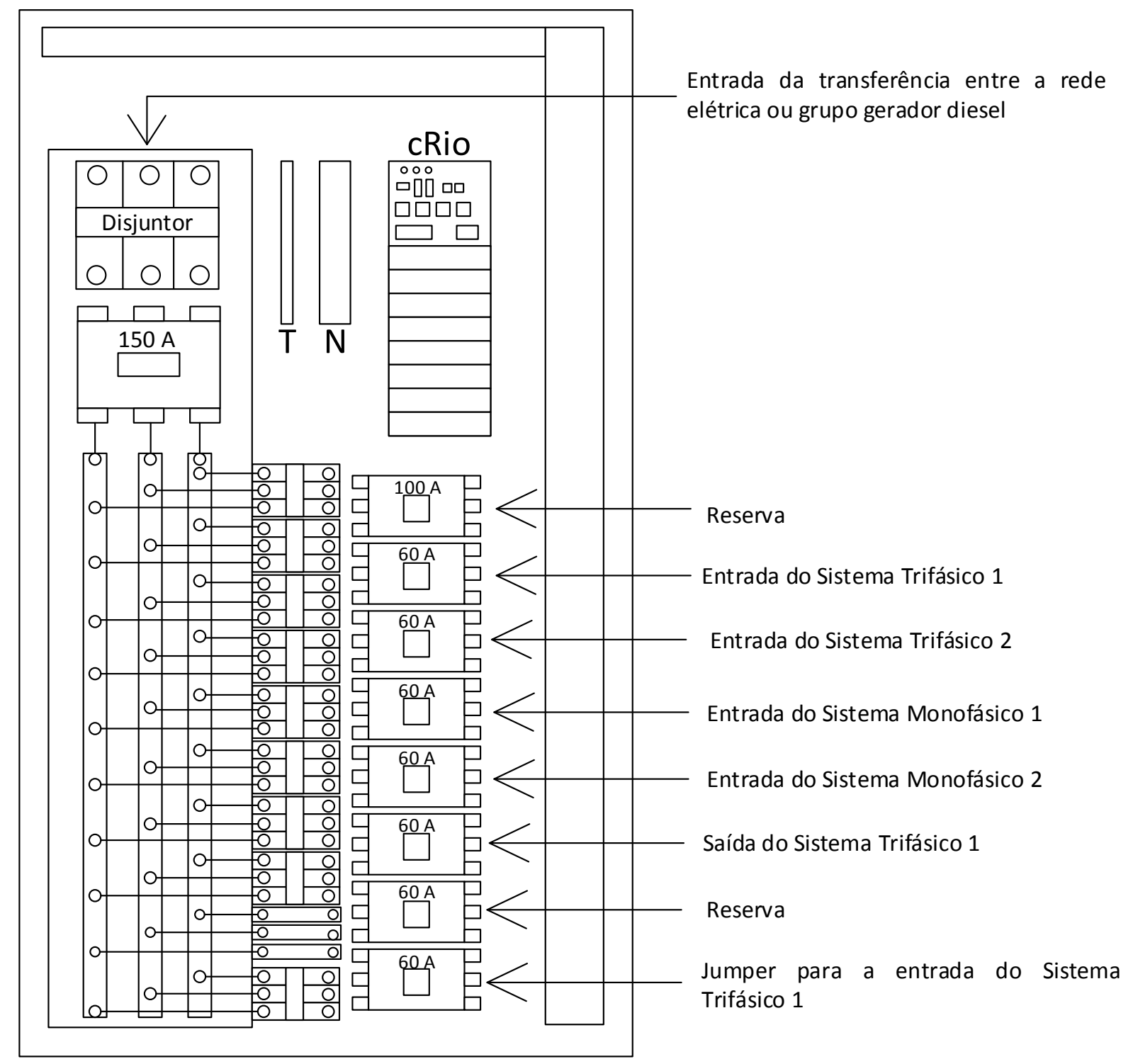

Figura 2.54 - Sistema de interconexão dos sistemas híbridos.

\subsubsection{Sistema de Controle}

A interconexão entre diferentes sistemas híbridos com especificações técnicas distintas requer uma complexidade maior para o sistema de controle, devendo, neste caso, o controle, a medição e a proteção atuar de forma conjunta e eficiente. O sistema de controle é composto pelo CompactRio (cRio) e por três módulos de controle para acionar as chaves contatoras. A conexão com as fontes externas pode ocorrer de modo individual ou simultâneo entre os SH. O ST1 pode exercer a função de rede principal, fornecendo energia para os outros $\mathrm{SH}$ ou permitindo fluxo reverso de potência pelo próprio ST1 e pelos SM1 e SM2. 


\subsubsection{CompactRio}

O cRio é uma plataforma de controlador industrial que possui controladores embarcados, com sistema de processamento, sistema de aquisição de sinais, além do sistema de comunicação. A Figura 2.55 apresenta o dispositivo, cujas especificações técnicas estão descritas na Tabela 2.22. O cRio está sendo utilizado para comandar as chaves contatoras, medir os parâmetros de tensão, corrente, e potência dos $\mathrm{SH}$ e das fontes externas, adquirir os dados dos medidores bidirecionais, e dos dataloggers. O cRio exerce a função de Micro Grid Central Controller. (MGCC), controlando os $\mathrm{SH}$ e medindo os parâmetros elétricos.
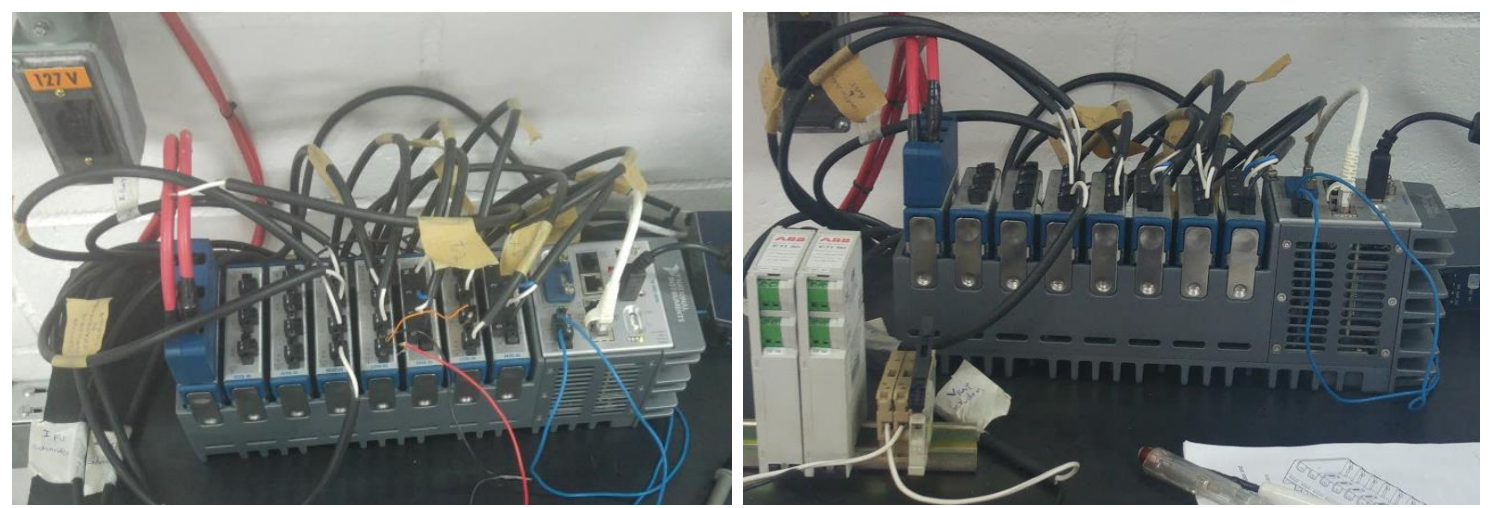

Figura 2.55 - CompactRio.

Tabela 2.22 - Especificações Técnicas do CompactRio.

\begin{tabular}{|c|c|}
\hline Fabricante & National Instruments \\
\hline Modelo & cRio 9036 \\
\hline \multicolumn{2}{|c|}{ Especificações gerais } \\
\hline Tipo de controladora & Alto desempenho \\
\hline Tipo de processador & $1.33 \mathrm{GHz}$ Dual Core Intel Atom Processor E3825 \\
\hline Frequência de clock da CPU & $1.33 \mathrm{GHz}$ \\
\hline Quantidade de núcleos & Dual-core \\
\hline Sistema operacional / target & Linux \\
\hline Memória não volátil & $1 \mathrm{~GB}$ \\
\hline Memória do sistema & 2 \\
\hline \multicolumn{2}{|c|}{ Portas para periféricos } \\
\hline Quantidade de portas Ethernet & \\
\hline
\end{tabular}




\begin{tabular}{|c|c|c|}
\hline \multirow{3}{*}{ Ethernet } & \multicolumn{2}{|c|}{ 10BaseT } \\
\hline & \multicolumn{2}{|c|}{ 100BaseTX } \\
\hline & \multicolumn{2}{|c|}{ 1000BaseT } \\
\hline Serial Ports (RS232) & \multicolumn{2}{|c|}{ Sim } \\
\hline Portas seriais (RS485) & \multicolumn{2}{|c|}{1} \\
\hline \multicolumn{3}{|c|}{ Alimentação } \\
\hline Faixa de tensão de entrada & \multicolumn{2}{|c|}{$9 \mathrm{~V}-30 \mathrm{~V}$} \\
\hline \multicolumn{3}{|c|}{ FPGA reconfigurável } \\
\hline FPGA & \multicolumn{2}{|c|}{ Kintex-7 } \\
\hline \multicolumn{3}{|c|}{ Chassi } \\
\hline Quantidade de slots & \multicolumn{2}{|c|}{8} \\
\hline \multicolumn{3}{|c|}{ Especificações físicas } \\
\hline Temperatura de operação & \multicolumn{2}{|c|}{$-40^{\circ} \mathrm{C}-70^{\circ} \mathrm{C}$} \\
\hline Temperatura de armazenamento & \multicolumn{2}{|c|}{$-40^{\circ} \mathrm{C}-85^{\circ} \mathrm{C}$} \\
\hline Umidade relativa de operação & \multicolumn{2}{|c|}{$10 \%-90 \%$} \\
\hline Umidade relativa de armazenamento & \multicolumn{2}{|c|}{$5 \%-95 \%$} \\
\hline Altitude máxima & \multicolumn{2}{|c|}{$5.000 \mathrm{~m}$} \\
\hline Temperatura de armazenamento & \multicolumn{2}{|c|}{$-40^{\circ} \mathrm{C}-85^{\circ} \mathrm{C}$} \\
\hline \multirow{3}{*}{ Dimensões (mm) } & Comprimento & 328,8 \\
\hline & Largura & 88,1 \\
\hline & Altura & 109,2 \\
\hline Peso (g) & \multicolumn{2}{|c|}{2.250} \\
\hline
\end{tabular}

Fonte: Adaptado de NATIONAL INSTRUMENTS (2015).

\subsubsection{Controle das Chaves Contatoras}

O controle das chaves contatoras é realizado pelos módulos da National Instruments, (NI). Utilizam-se três módulos N19482 para comandar os contatos, executando a ação coordenados pelo cRio.

\subsubsection{Sistema de Medição}

Os módulos realizam as medições dentro do MGCC, sendo quatro módulos destinados à medição de corrente e um módulo destinado à medição de tensão. 
As medições de corrente direta são realizadas por três módulos NI 9247. Os mesmos podem medir corrente direta até $50 \mathrm{~A}$. Estes módulos medem as correntes fornecidas ou recebidas dos ST1, SM1 e SM2.

As medições de corrente de forma indireta são realizadas pelo módulo $\mathrm{NI}$ 9227, com o auxílio de três TC. Este módulo mede a corrente fornecida ou recebida pelas fontes externas do sistema.

As medições de tensão são realizadas pelo módulo NI 9244. O referencial de tensão retirado para análise é do barramento presente no MGCC.

\subsubsection{Sistema de Monitoramento}

O sistema de monitoramento é realizado por um computador, que realiza a interface gráfica dos sistemas. O programa de monitoração e controle, feito na plataforma Labview, apresenta os dados processados pelo MGCC, permitindo alterar o comando para acionamento das chaves contatoras, visualizar os parâmetros de tensão e corrente de cada sistema além de outras variáveis dos $\mathrm{SH}$ (Figura 2.56).

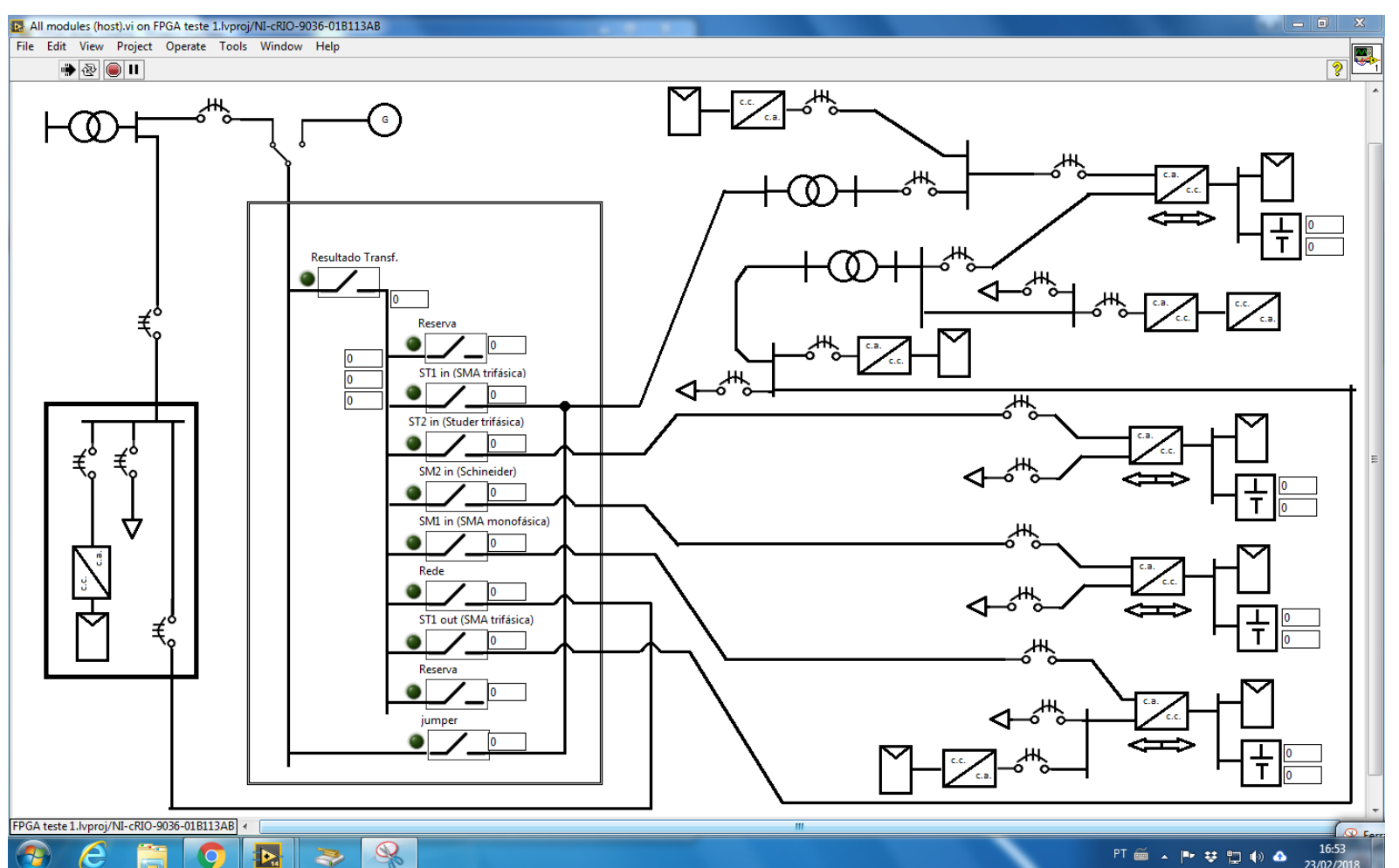

Figura 2.56 - Tela apresentando o diagrama do sistema completo de minirredes, com destaque para o MGCC. 
Na Figura 2.56 é destacada uma carga, que representa o LSF, e uma geração distribuída, que são quatro módulos fotovoltaicos conectados a dois microinversores que estão instalados no terraço do laboratório.

\subsubsection{Sistema de Proteção}

O sistema de proteção no MGCC ocorre apenas em corrente alternada, com os dispositivos nele presentes realizando as funções de proteção e seccionamento. As chaves contatoras realizam seccionamentos controlados pelo cRio e os disjuntores e DPS realizam a proteção contra sobrecorrente e sobretensão, respectivamente.

Neste capitulo foram apresentadas as topologias de sistemas híbridos instalados no LSF de forma simplificada. Informações mais detalhadas sobre os outros componentes dos sistemas e seus respectivos datasheets e diagramas unifilares estão presentes na Descrição da Minirrede com Sistemas Híbridos do LSF, relatório técnico, (Novaes et al., 2018b). 


\section{Capítulo 3 - Comissionamento e Ensaios Operacionais com os Sistemas Híbridos do LSF}

Este capítulo descreve o comissionamento dos sistemas híbridos e a realização de ensaios operacionais, incluindo as análises de fluxo de potência, gestão de geração e carga, e despacho de energia.

O comissionamento consiste no processo de avaliação para assegurar que os componentes, geradores, e os sistemas fotovoltaicos estejam projetados, instalados, testados, e operando de acordo com as necessidades e requisitos operacionais. No Brasil, a norma brasileira NBR 16274 regulamenta os processos de comissionamento para sistemas fotovoltaicos conectados à rede elétrica.

\subsection{Comissionamento}

$\mathrm{O}$ processo de comissionamento realizado nos $\mathrm{SH}$ do laboratório foi executado antes do procedimento de inicialização e operação dos sistemas. As inspeções visuais, procedimentos de configuração e testes operacionais foram realizados individualmente para cada $\mathrm{SH}$. Inicialmente foram comissionadas as fontes externas e, posteriormente, os sistemas híbridos, na seguinte ordem: ST1, SM1, ST2 e SM2.

\subsubsection{Comissionamento do GGD}

$\mathrm{O}$ GGD é uma fonte externa de energia para os $\mathrm{SH}$. Os procedimentos de comissionamento para conexão do GGD com os $\mathrm{SH}$ foram realizados obedecendo as seguintes etapas.

Verificação do nível de tensão do banco de baterias do GGD - A verificação do nível de tensão do banco de baterias consistiu na inspeção da tensão utilizando um multímetro, e comparando esse valor com o fornecido pelo fabricante do GGD.

Verificação do processo de partida do GGD - A verificação do processo de partida do GGD consistiu na análise da sua partida, verificando o tempo para o 
começo de operação, nível de fumaça liberada pelo escapamento, e tempo de resposta ao comando de partida.

Verificação do cabeamento, desde o GGD até o sistema de interconexão dos SH, passando pelos sistemas de proteção - A verificação do cabeamento consistiu na averiguação de todos os parafusos e elementos de contato que conduzem tensão desde o GGD até o quadro de interconexão dos SH.

Verificação da sequência de fases, no sentido horário - A verificação da sequência de fases consistiu em verificar o sentido horário da tensão, utilizando um fasímetro.

Verificação dos níveis de tensão - A verificação dos níveis de tensão consistiu na medição da tensão com a utilização de um multímetro. Os casos analisados são: os valores das tensões em circuito aberto, e os seus valores no momento de fornecimento de potência para as cargas e/ou os $\mathrm{SH}$.

Verificação do nível de frequência - O mesmo procedimento ocorre para a frequência, onde a verificação consistiu na medição da frequência com a utilização de um multímetro. Os casos analisados são: o valor da frequência em circuito aberto, e o valor da frequência no momento de fornecimento de potência para as cargas e/ou os $\mathrm{SH}$.

Verificação da corrente no fornecimento de potência para os $\mathrm{SH}-\mathrm{A}$ verificação da corrente no fornecimento de potência para os SH consistiu na medição com alicate amperímetro dos valores das correntes no momento de fornecimento de potência para as cargas e/ou os $\mathrm{SH}$.

\subsubsection{Comissionamento da Rede Elétrica}

$\mathrm{O}$ comissionamento da conexão da rede elétrica com os $\mathrm{SH}$ foi realizado seguindo os mesmos procedimentos do comissionamento do GGD, apenas eliminando as etapas de inspeção do maquinário. Desta forma foram verificados a conexão elétrica, a sequência de fases, os níveis de tensão, o nível de frequência, e a corrente no fornecimento de potência para os $\mathrm{SH}$. 


\subsubsection{Comissionamento dos Sistemas Híbridos}

Após a realização do comissionamento das fontes externas, foram realizadas as avaliações dos sistemas de modo individual, sendo comissionados na seguinte ordem: ST1, SM1, ST2 e SM1.

\subsubsection{Comissionamento do ST1}

O ST1 foi o primeiro SH instalado no LSF e seu comissionamento já havia sido realizado. Contudo, foram realizadas modificações, com a interconexão dos SH. Desta forma, realizaram-se verificações que abrangeram as conexões elétricas, parametrizações e ampliação das funcionalidades do ST1.

A interconexão dos $\mathrm{SH}$ alterou a disposição dos equipamentos do LSF e o fornecimento e a demanda de energia do ST1 foram modificados, e os cabeamentos foram refeitos. As conexões de entrada (fornecimento de energia) e saída (demanda de energia) foram conectadas no MGCC. As modificações nas conexões do ST1 possibilitaram ao mesmo demandar energia das fontes externas ou dos outros $\mathrm{SH}$, e fornecer energia para suas cargas, para os outros $\mathrm{SH}$ ou para a rede elétrica.

Inicialmente foram realizadas inspeções visuais e manuais, que tinham por objetivo a constatação do aperto dos parafusos e elementos de conexão elétrica. As verificações abrangeram: banco de baterias, os GFV, as conexões nos CDC, INVB, INVG, quadros de conexão, medição, e nas conexões com as cargas.

A verificação no banco de baterias foi realizada com o auxílio de um torquímetro, para constatar o aperto dos parafusos das conexões. Além disso, foi verificada a densidade do eletrólito de cada vaso com um densímetro.

As verificações nos GFV foram realizadas analisando as conexões nos conectores MC4 e, posteriormente, as conexões com os disjuntores e nos dispositivos de proteção contra surto (DPS) presentes nas caixas de proteção e seccionamento.

Foram realizadas inspeções visuais e manuais com o auxílio de chaves de fenda, chaves philips, chaves sextavadas, e chaves de catraca nas conexões dos CDC, INVB e INVG. Estas inspeções também foram realizadas nos quadros de 
medição e seccionamento e nos quadros de conexão das cargas do ST1; porém, nestes foram utilizadas somente as chaves de fenda, philips e sextavadas.

Ao término das inspeções visuais e manuais dos equipamentos do ST1, foram realizas algumas modificações nas parametrizações do sistema. As principais funcionalidades mantiveram-se iguais, como o sistema "master e slaves" dos INVB/ST1, os limites de tensão, corrente, frequência, fornecimento de potência, níveis de conexão e desconexão pelo estado de carga do banco de baterias, dentre outros parâmetros. A modificação mais relevante foi a habilitação do fluxo reverso de potência, onde o excedente de geração passou a poder ser injetado na rede elétrica.

Os limites de tempo e quantidade de potência que podem ser injetados na rede elétrica pelo fluxo reverso de potência foram ajustados no INVB-01, que realiza a função de inversor bidirecional master.

A ampliação das funcionalidades de ST1 consistiu na operacionalização de algumas funções que ocorriam de modo parcial. O prédio do LSF tinha a opção de ser abastecido pelo ST1, porém esta ação era muito complexa e necessitava de um conhecimento detalhado do sistema. Esta operação foi simplificada, mantendo o mesmo grau de proteção. O sistema de geração também passou por atualizações; os GFV-04, GFV-05, GFV-06, GFV-07 e GFV-8, estavam instalados, porém não estavam conectados aos seus respectivos equipamentos de condicionamento de potência. As conexões foram realizadas e os equipamentos de condicionamento de potência foram parametrizados. Os GFV-04, GFV-05 e GFV-06 realizam a geração distribuída e os GFV-07 e GFV-08 realizam a geração no acoplamento c.c. A fonte em corrente contínua foi adicionada ao sistema de geração, para permitir a emulação de um aerogerador, utilizando series temporais para a velocidade de vento. As modificações realizadas no laboratório foram inspecionadas visualmente e manualmente. Foram realizados testes individuais e, posteriormente, com todos os geradores conectados ao ST1.

\subsubsection{Comissionamento do SM1}

O SM1 também já estava em operação e seu comissionamento já havia sido realizado. Entretanto foram realizadas algumas modificações, sendo a principal a 
conexão do sistema com o MGCC. Desta forma, o SM1 começou a demandar potência das fontes externas e/ou da dos outros $\mathrm{SH}$ e fornecer potência para suas cargas, e pelo fluxo reverso de potência fornecer potência para a rede elétrica e/ou outros SH.

As inspeções visuais e manuais abrangeram todos os componentes presentes no SM1, principalmente por conta da desconexão e reconexão da entrada de energia do mesmo. As parametrizações mantiveram-se sem alterações.

\subsubsection{Comissionamento do ST2}

O ST2 foi instalado no decorrer desta dissertação. Deste modo foi necessário realizar os processos de instalação, inicialização e comissionamento deste sistema, da forma descrita a seguir.

Inspeções visuais e manuais do cabeamento e conexões presentes no sistema - as inspeções abrangeram todo o ST2 e foram analisados desde os geradores fotovoltaicos, sistema de condicionamento de potência, cargas e os bancos de baterias. Após a inspeção visual foi realizada uma inspeção manual das conexões, utilizando chaves de fendas, philips e sextavadas. O objetivo desta inspeção foi averiguar se todas as conexões estavam bem fixadas.

Medição da polaridade do arranjo fotovoltaico - foi realizada a medição da polaridade do arranjo fotovoltaico com o auxílio de um multímetro.

Medições das tensões do arranjo fotovoltaico - foram medidas as tensões em circuito aberto e no momento de fornecimento de potência, ambas utilizando um multímetro. As medições ocorreram no ponto de interconexão do GFV-01/ST2 com o CDC-01/ST2 e do CDC-01/ST2 com X-connect.

Medições de corrente no banco de baterias - foram realizadas medições utilizando um alicate amperímetro para medir a corrente que flui no banco de baterias. As medições foram realizadas no processo de carga e descarga do banco de baterias.

Após as inspeções e medições dos componentes em corrente contínua do sistema, foi realizada a inicialização dos INVB. A inicialização teve por objetivo 
configurar alguns parâmetros para o ST2, os ciclos do banco de baterias para flutuação, equalização, tensões de conexão e desconexão com a rede, limites de corrente, entre outros parâmetros. A inicialização também teve como objetivo verificar se todas as funcionalidades do INVB estavam operando. Após a parametrização e verificação de algumas funcionalidades específicas, foram realizados os testes de comissionamento no âmbito de corrente alternada.

Verificação dos níveis de tensão para as cargas - as tensões de saída para as cargas foram medidas utilizando um multímetro. As condições de teste foram com o inversor fornecendo energia para as cargas, com as fontes externas fornecendo energia para o ST2 e este fornecendo para as cargas. Quando as fontes externas estavam fornecendo energia para o sistema, a tensão na entrada também foi verificada.

Verificação da corrente para as cargas - a corrente para fornecimento de potência para as cargas foi medida utilizando um alicate amperímetro. As condições de teste foram com o inversor fornecendo energia para as cargas, com as fontes externas fornecendo energia para o ST2 e este fornecendo para as cargas. Quando as fontes externas estavam fornecendo energia para o sistema, a corrente de entrada também foi verificada.

\subsubsection{Comissionamento do SM2}

O SM2 foi o último SH instalado no LSF, contudo este sistema possui funcionalidades que não estão presentes nos outros sistemas. Assim como o ST2, foi necessário realizar os procedimentos de instalação, inicialização e comissionamento.

O comissionamento deste sistema seguiu a mesma sequência empregada no ST2, com inspeções visuais e manuais, inicialização e parametrizações, e posteriormente medições.

Inspeções visuais e manuais do cabeamento e conexões presentes no sistema - as inspeções abrangeram todo o SM2, e foram analisados desde os geradores fotovoltaicos, sistema de condicionamento de potência, cargas e o banco de baterias. Após a inspeção visual foi realizada uma inspeção manual das 
conexões utilizando chaves de fendas, philips e sextavadas. $O$ objetivo desta inspeção foi averiguar se todas as conexões estavam bem fixadas.

Medição da polaridade do arranjo fotovoltaico - foi realizada a medição da polaridade do arranjo fotovoltaico com o auxílio de um multímetro.

Medições das tensões do arranjo fotovoltaico - foram medidas as tensões em circuito aberto e no momento de fornecimento de potência, ambas utilizando um multímetro. As medições ocorreram no ponto de interconexão do GFV-01/SM2 com o CDC-01/SM2, e do CDC-01/SM2 com PDP.

Medições de corrente no banco de baterias - foram realizadas medições utilizando um alicate amperímetro para medir a corrente que flui no banco de baterias. As medições foram realizadas no processo de carga e descarga do banco de baterias.

Após as inspeções e medições dos componentes em corrente contínua do sistema, foi realizada a inicialização dos INVB. A inicialização tinha por objetivo configurar alguns parâmetros para o SM2, os ciclos do banco de baterias para flutuação, equalização, tensões de conexão e desconexão com a rede, limites de corrente, entre outros parâmetros.

A inicialização também tinha como objetivo verificar se todas as funcionalidades do INVB estavam operando. Após a parametrização e verificação de algumas funcionalidades especificas foram realizados os testes de comissionamento no âmbito de corrente alternada.

Verificação da conexão com uma fonte externa - um GGD de 6 kVA foi utilizado para realização da conexão com uma fonte externa. Foram necessários ajustes na parametrização para o acoplamento do SM2 com essa fonte externa. Os ajustes realizados foram nos valores máximos e mínimos de corrente, frequência e tensão.

Verificação dos níveis de tensão para as cargas - as tensões de saída para as cargas foram medidas utilizando um multímetro. As condições de teste foram com o inversor fornecendo energia para as cargas, com as fontes externas fornecendo energia para o SM2 e este fornecendo para as cargas. Quando as fontes externas 
estavam fornecendo energia para o sistema, a tensão na entrada também foi verificada.

Verificação da corrente para as cargas - a corrente para fornecimento de potência para as cargas foi medida utilizando um alicate amperímetro. As condições de teste foram com o inversor fornecendo energia para as cargas, com as fontes externas fornecendo energia para o SM2 e este fornecendo para as cargas. Quando as fontes externas estavam fornecendo energia para o sistema, a corrente de entrada também foi verificada.

Verificação do fluxo reverso de potência - o SM2 tem a possibilidade de utilização da função grid support, que permite a injeção de potência para as fontes externas, com a energia retirada do banco de baterias. Esta função foi analisada com a utilização de um alicate amperímetro. $O$ mesmo foi conectado em pontos do sistema para medição e verificação da corrente que fluía do banco de baterias para a rede elétrica ou para os outros $\mathrm{SH}$.

\subsubsection{Comissionamento do MGCC}

O MGCC realiza a interconexão das fontes externas com o $\mathrm{SH}$, que atua como operador do sistema de distribuição, devendo ter a capacidade de trocar informações e controlar cada $\mathrm{SH}$ conectado ao ponto de acoplamento comum (PAC). O quadro de interconexão foi idealizado, montado e comissionado pelos colaboradores do LSF.

Para a interconexão dos SH foi necessário realizar alterações na infraestrutura do LSF. As modificações realizadas nos SH foram mencionadas anteriormente, contudo também foram realizadas alterações no fornecimento de energia da rede elétrica. Inicialmente o prédio do LSF era alimentado por dois transformadores presentes na cabine primária, que está localizada próximo ao prédio do LSF. Contudo, era necessário que o prédio fosse alimentado pelo mesmo transformador, para não ter diferença de potencial entre os neutros. Com a alteração, o prédio do LSF passou a ser alimentado apenas por um transformador, em dois pontos distintos, sendo um pela transferência com o GGD e o outro 
conectado direto no MGCC. Após as modificações foi realizado o processo de comissionamento.

A primeira etapa do comissionamento do MGCC foi a inspeção visual, onde todas as conexões nele presentes foram verificadas. Após a inspeção visual foi realizada uma inspeção manual, quando todos os parafusos foram conferidos utilizando chaves de fenda, philips e sextavadas. Neste momento o quadro estava totalmente desenergizado.

Ao término das inspeções, começaram as medições individuais. Inicialmente foram medidas as fontes externas. Estas medições objetivaram a confirmação das informações obtidas no comissionamento prévio das fontes externas. Os SH foram energizados individualmente com a energia sendo suprida por uma fonte externa. Os sistemas trifásicos foram testados primeiramente, e posteriormente os sistemas monofásicos.

Durante o processo de energizar os $\mathrm{SH}$, ocorreram de modo concomitante medições de tensão e corrente do sistema energizado. Este procedimento teve por objetivo verificar se o sistema operava de maneira estável.

Os comissionamentos do MGCC e todos os sistemas híbridos serviram para constatar que os sistemas estão operando normalmente, após o que foi possível iniciar as etapas de testes operacionais.

Simultaneamente aos testes operacionais foi realizada a termografia do MGCC, quando ele estava operando com os três SH demandando ou injetando energia na rede elétrica, não tendo sido verificados pontos quentes (Figura 3.1). 

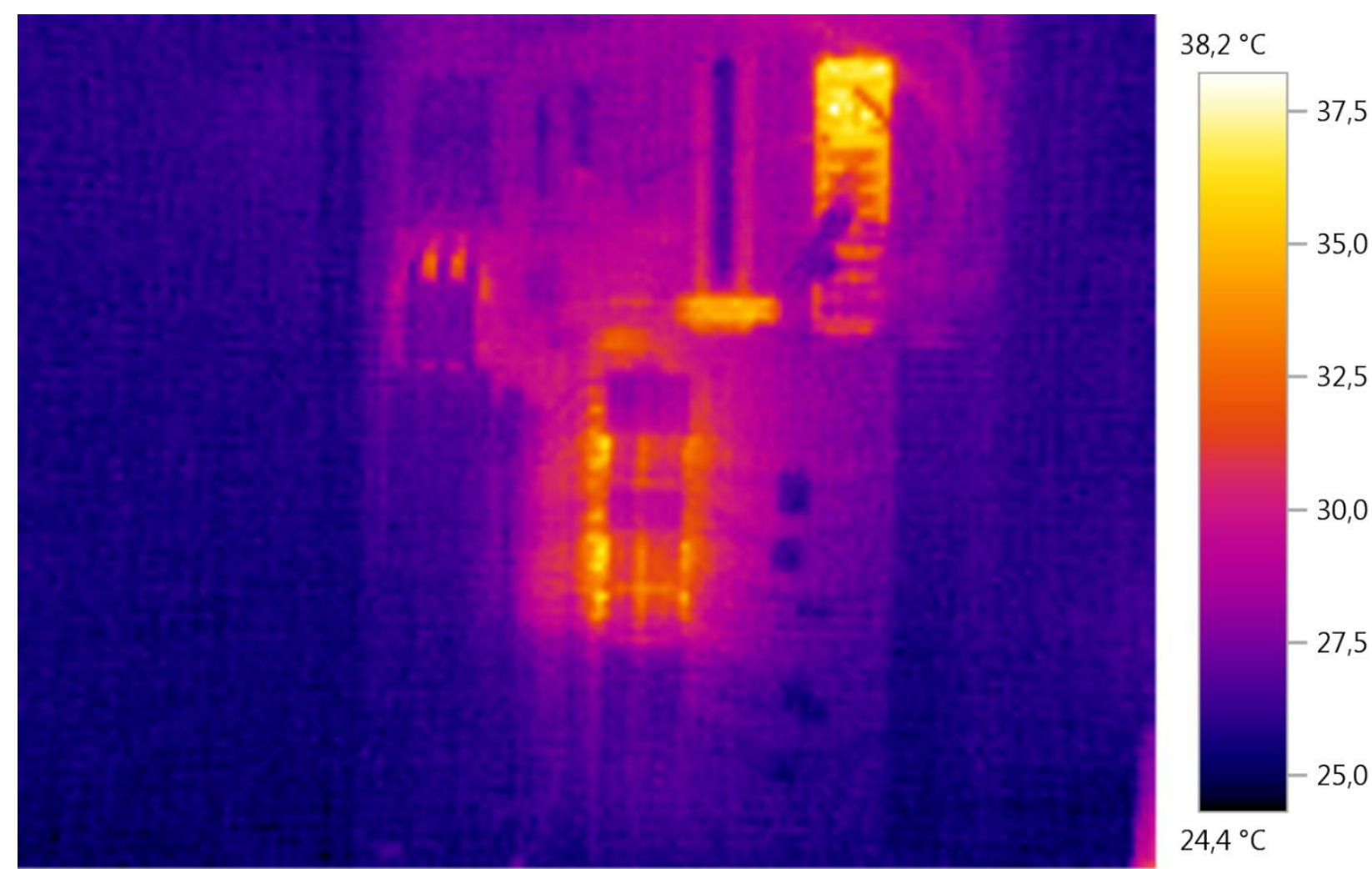

Figura 3.1 - Termografia do MGCC.

\subsection{Testes Operacionais}

Os testes operacionais têm por objetivo a compreensão do comportamento do sistema nos aspectos técnicos. Para isso são realizados testes emulando uma minirrede inteligente, com o intercâmbio de energia entre os $\mathrm{SH}$, como se fossem vários produtores, consumidores e produtores/consumidores (prosumidores) conectados à minirrede.

A infraestrutura do LSF é composta por quatro $\mathrm{SH}$, cada um com suas respectivas cargas, armazenamento, geração distribuída e sistemas de condicionamento de potência. Os quatro SH estão conectados a um PAC, onde um GGD e a rede elétrica também estão conectados. Além disso, dois circuitos de espera foram introduzidos, para permitir a conexão de componentes temporários, como cargas ou geração distribuída, conforme mostrado na Figura 3.2. 


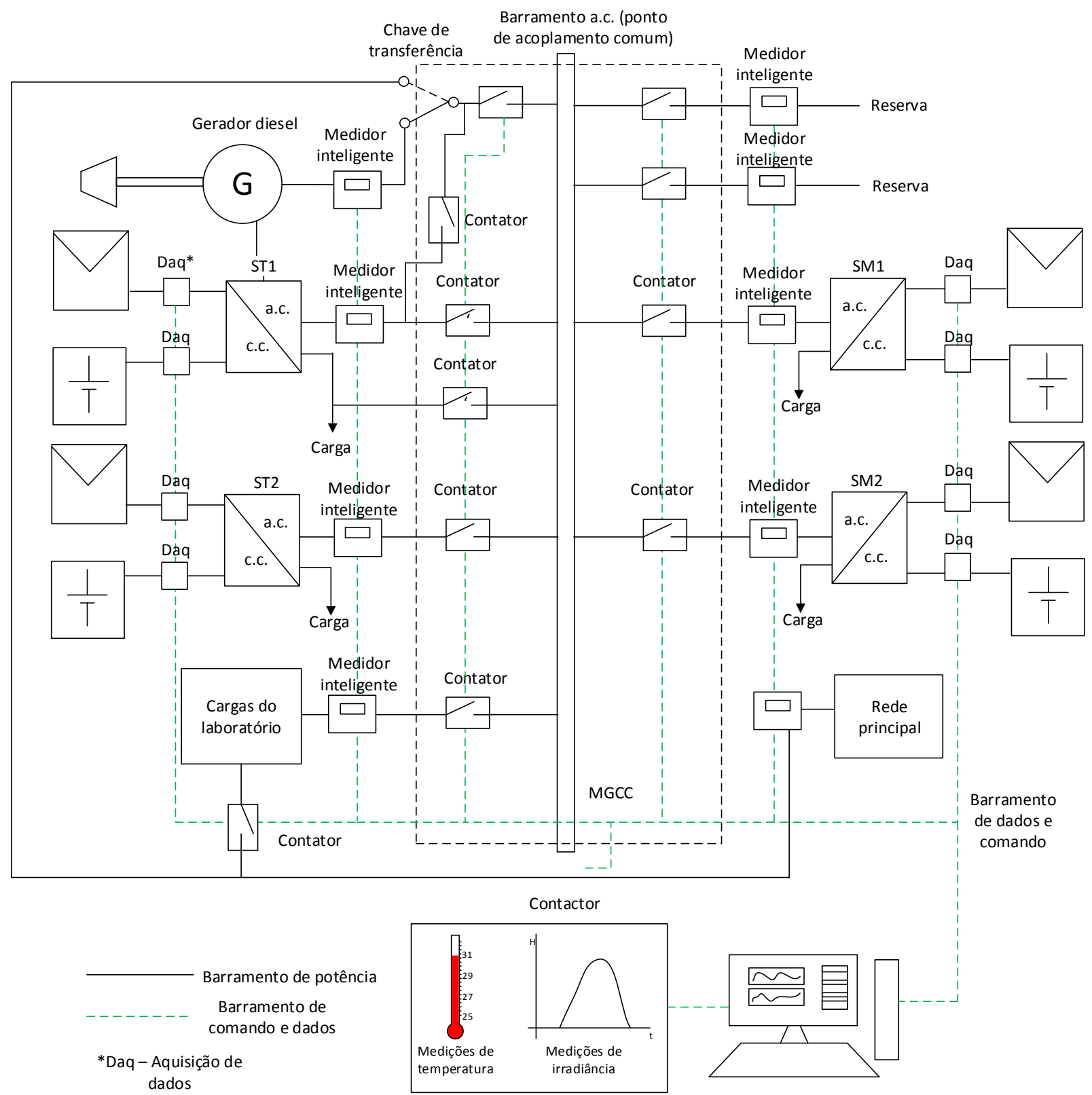

Figura 3.2 - Infraestrutura e integração dos SH.

Fonte: (MANITO et al. 2017).

O MGCC é responsável pela coordenação da operação de todos os elementos conectados ao PAC, de acordo com características operacionais prédefinidas e restrições, que podem ser programadas no MGCC. A flexibilidade e escalabilidade permitem reproduzir muitos casos reais no funcionamento de todo o sistema e analisar as vantagens e desvantagens das diferentes topologias.

A Tabela 3.1 apresenta as possíveis estratégias operacionais, sendo apresentados dois eixos, que são fontes e cargas. Os $\mathrm{SH}$ podem executar a função 
de carga (demandando energia) ou de fonte (injetando energia); a rede elétrica também pode executar as mesmas funções. Somente o ST1 pode realizar a função de fonte de tensão, e os outros sistemas operam como fontes de corrente ou cargas, que irão demandar ou injetar energia do PAC.

Tabela 3.1 - Estratégias operacionais.

\begin{tabular}{|c|c|c|c|c|c|}
\hline $\begin{array}{ll}\text { Fonte } & \text { Cargas } \\
\end{array}$ & $\mathrm{RP}$ & ST1 & ST2 & SM1 & SM2 \\
\hline $\mathrm{RP}$ & & $x$ & $\mathrm{X}$ & $x$ & $x$ \\
\hline GGD & $x$ & $x$ & $\mathrm{X}$ & $x$ & $x$ \\
\hline ST1 & $x$ & & $x$ & $x$ & $x$ \\
\hline$R P+S T 1$ & & & $x$ & $\mathrm{x}$ & $\mathrm{x}$ \\
\hline $\mathrm{RP}+\mathrm{SM} 1$ & & $x$ & $\mathrm{x}$ & & $x$ \\
\hline $\mathrm{RP}+\mathrm{SM} 2$ & & $x$ & $x$ & $x$ & \\
\hline $\mathrm{RP}+\mathrm{ST} 1+\mathrm{SM} 1$ & & & $x$ & & $x$ \\
\hline $\mathrm{RP}+\mathrm{ST} 1+\mathrm{SM} 2$ & & & $x$ & $x$ & \\
\hline $\mathrm{RP}+\mathrm{SM} 1+\mathrm{SM} 2$ & & $x$ & $x$ & & \\
\hline $\mathrm{RP}+\mathrm{ST} 1+\mathrm{SM} 1+\mathrm{SM} 2$ & & & $\mathrm{x}$ & & \\
\hline GGD + ST1 & $x$ & & $x$ & $x$ & $\mathrm{x}$ \\
\hline GGD + SM1 & $x$ & $x$ & $x$ & & $x$ \\
\hline GGD + SM2 & $x$ & $x$ & $x$ & $x$ & \\
\hline GGD + ST1 +SM1 & $x$ & & $x$ & & $x$ \\
\hline GGD + ST1 +SM2 & $\mathrm{x}$ & & $\mathrm{x}$ & $\mathrm{x}$ & \\
\hline GGD + SM1+ SM2 & $x$ & $\mathrm{x}$ & $x$ & & \\
\hline GGD+ ST1 +SM1 + SM2 & $x$ & & $x$ & & \\
\hline ST1 + SM1 & $x$ & & $\mathrm{x}$ & $x$ & \\
\hline ST1 + SM2 & $x$ & & $x$ & & \\
\hline $\mathrm{ST} 1+\mathrm{SM} 1+\mathrm{SM} 2$ & $x$ & & $x$ & & \\
\hline
\end{tabular}

A Tabela 3.1 apresenta as possibilidades de estratégias operacionais com a formação de uma minirrede controlada pelo MGCC. As premissas utilizadas para formação das estratégias operacionais levaram em consideração as limitações técnicas dos equipamentos presentes no LSF. Os sistemas monofásicos não poderiam abastecer o PAC sem a complementação de uma fonte trifásica. Outra 
premissa é que o ST2 não possui sua saída conectada ao MGCC, e também não realiza fluxo reverso de potência e, portanto, ele estaria no sistema apenas como um consumidor e não como um prosumidor. $O$ prédio do LSF também pode ser alimentado pelo PAC.

A Figura 3.3 apresenta a plataforma de controle do MGCC para realização de modificação das estratégias operacionais. Esta executa a função de sistema de supervisão e aquisição de dados (SCADA), sendo desta forma possível realizar alterações da estratégia utilizada. Ao tocar no interruptor presente na tela, o SH selecionado pode entrar ou sair de operação junto à minirrede, como se a concessionária estivesse conectando ou desconectando o consumidor, produtor ou prosumidor de sua rede de distribuição.

A Tabela 3.2 apresenta a lógica do processo de intertravamento do sistema, sendo: $V$, verdadeiro, o sistema pode ser ligado; $F$, falso, o sistema não pode ser ligado; $T$, talvez, o sistema pode ser ligado, porém é necessário realizar ações que não competem ao MGCC efetuar.

Tabela 3.2 - Intertravamento no MGCC.

\begin{tabular}{|c|c|c|c|c|c|c|c|c|c|c|}
\hline & $\begin{array}{c}\text { Res. } \\
\text { Trans. }\end{array}$ & Jumper & Reserva & $\begin{array}{c}\text { ST1 } \\
\text { out }\end{array}$ & Prédio & SM1 & SM2 & ST2 & $\begin{array}{c}\text { ST1 } \\
\text { in }\end{array}$ & Reserva \\
\hline $\begin{array}{c}\text { Resultado } \\
\text { Trans. }\end{array}$ & $\mathrm{V}$ & $\mathrm{F}$ & $\mathrm{V}$ & $\mathrm{F}$ & $\mathrm{T}$ & $\mathrm{V}$ & $\mathrm{V}$ & $\mathrm{V}$ & $\mathrm{V}$ & $\mathrm{V}$ \\
\hline Jumper & $\mathrm{F}$ & $\mathrm{V}$ & $\mathrm{V}$ & $\mathrm{V}$ & $\mathrm{T}$ & $\mathrm{V}$ & $\mathrm{V}$ & $\mathrm{V}$ & $\mathrm{F}$ & $\mathrm{V}$ \\
\hline Reserva & $\mathrm{V}$ & $\mathrm{V}$ & $\mathrm{V}$ & $\mathrm{V}$ & $\mathrm{T}$ & $\mathrm{V}$ & $\mathrm{V}$ & $\mathrm{V}$ & $\mathrm{V}$ & $\mathrm{V}$ \\
\hline ST1 out & $\mathrm{F}$ & $\mathrm{V}$ & $\mathrm{V}$ & $\mathrm{V}$ & $\mathrm{T}$ & $\mathrm{V}$ & $\mathrm{V}$ & $\mathrm{V}$ & $\mathrm{F}$ & $\mathrm{V}$ \\
\hline Prédio & $\mathrm{T}$ & $\mathrm{T}$ & $\mathrm{T}$ & $\mathrm{T}$ & $\mathrm{T}$ & $\mathrm{T}$ & $\mathrm{T}$ & $\mathrm{T}$ & $\mathrm{T}$ & $\mathrm{T}$ \\
\hline SM1 & $\mathrm{V}$ & $\mathrm{V}$ & $\mathrm{V}$ & $\mathrm{V}$ & $\mathrm{T}$ & $\mathrm{V}$ & $\mathrm{V}$ & $\mathrm{V}$ & $\mathrm{V}$ & $\mathrm{V}$ \\
\hline SM2 & $\mathrm{V}$ & $\mathrm{V}$ & $\mathrm{V}$ & $\mathrm{V}$ & $\mathrm{T}$ & $\mathrm{V}$ & $\mathrm{V}$ & $\mathrm{V}$ & $\mathrm{V}$ & $\mathrm{V}$ \\
\hline ST2 & $\mathrm{V}$ & $\mathrm{V}$ & $\mathrm{V}$ & $\mathrm{V}$ & $\mathrm{T}$ & $\mathrm{V}$ & $\mathrm{V}$ & $\mathrm{V}$ & $\mathrm{V}$ & $\mathrm{V}$ \\
\hline ST1 in & $\mathrm{V}$ & $\mathrm{F}$ & $\mathrm{V}$ & $\mathrm{F}$ & $\mathrm{T}$ & $\mathrm{V}$ & $\mathrm{V}$ & $\mathrm{V}$ & $\mathrm{V}$ & $\mathrm{V}$ \\
\hline Reserva & $\mathrm{V}$ & $\mathrm{V}$ & $\mathrm{V}$ & $\mathrm{V}$ & $\mathrm{T}$ & $\mathrm{V}$ & $\mathrm{V}$ & $\mathrm{V}$ & $\mathrm{V}$ & $\mathrm{V}$ \\
\hline
\end{tabular}




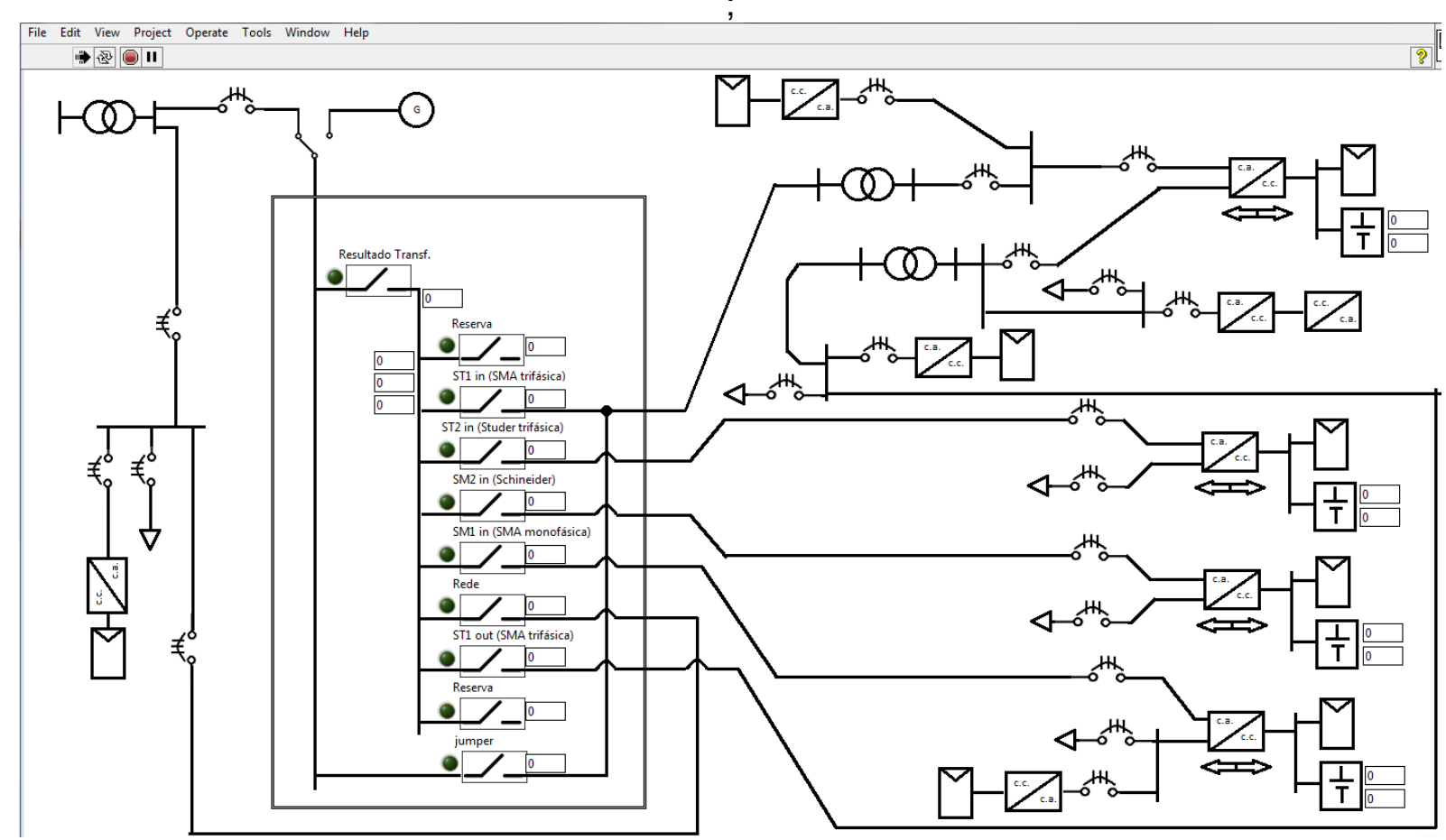

Figura 3.3 - Sistemas de supervisão e aquisição de dados do MGCC.

A integração entre os SH possibilita diferentes estratégias, assim como apresentado na Tabela 3.1, podendo-se destacar duas topologias distintas, que possibilitam usar diferentes níveis de hierarquia. Em uma topologia todos os sistemas têm o mesmo nível de hierarquia. A fonte externa alimenta o PAC e os quatros sistemas estão conectados a ele de forma independente, podendo demandar ou injetar energia, como indicado na Figura 3.4. 


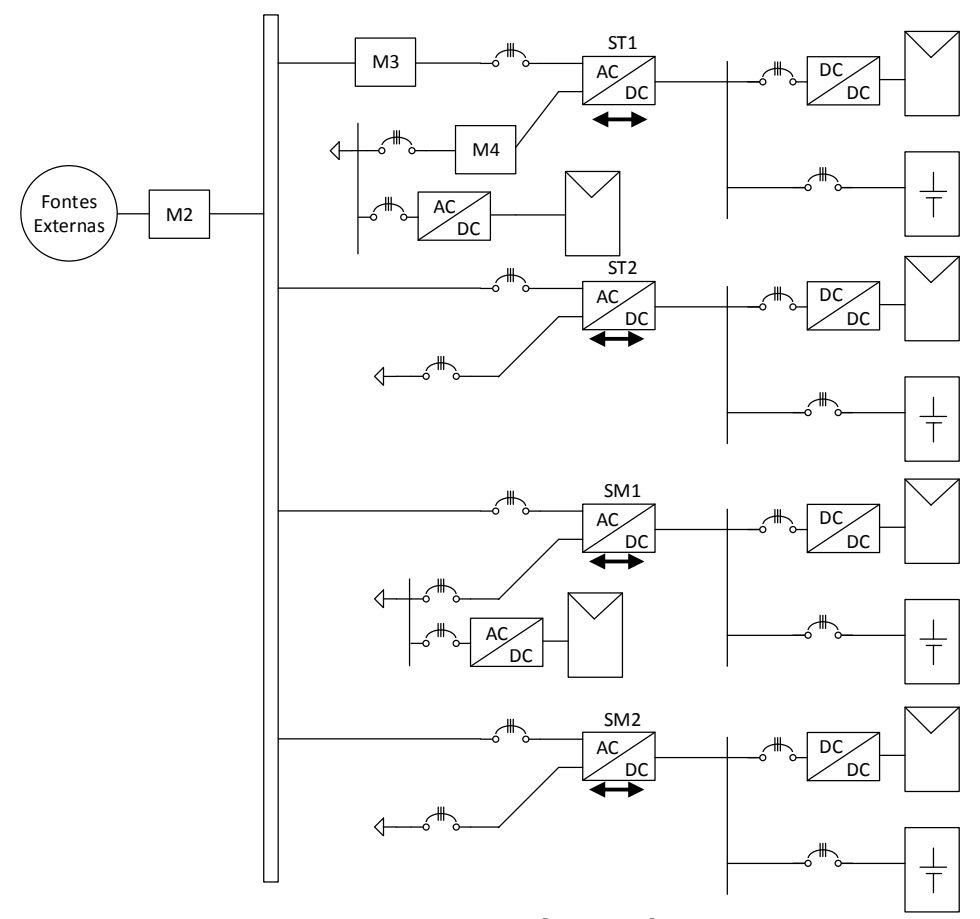

Figura 3.4 - Topologia com um único nível de hierarquia.

$\mathrm{Na}$ segunda topologia o ST1 está inserido na primeira hierarquia entre as fontes externas e os outros três sistemas. Os SM1, SM2 e ST2 estão conectados no PAC e este na saída do ST1, assim como apresentado na Figura 3.5. Nesta topologia o ST1 possui nível hierárquico superior aos outros sistemas, pois ele é o formador da rede e o sistema que alimenta o PAC.

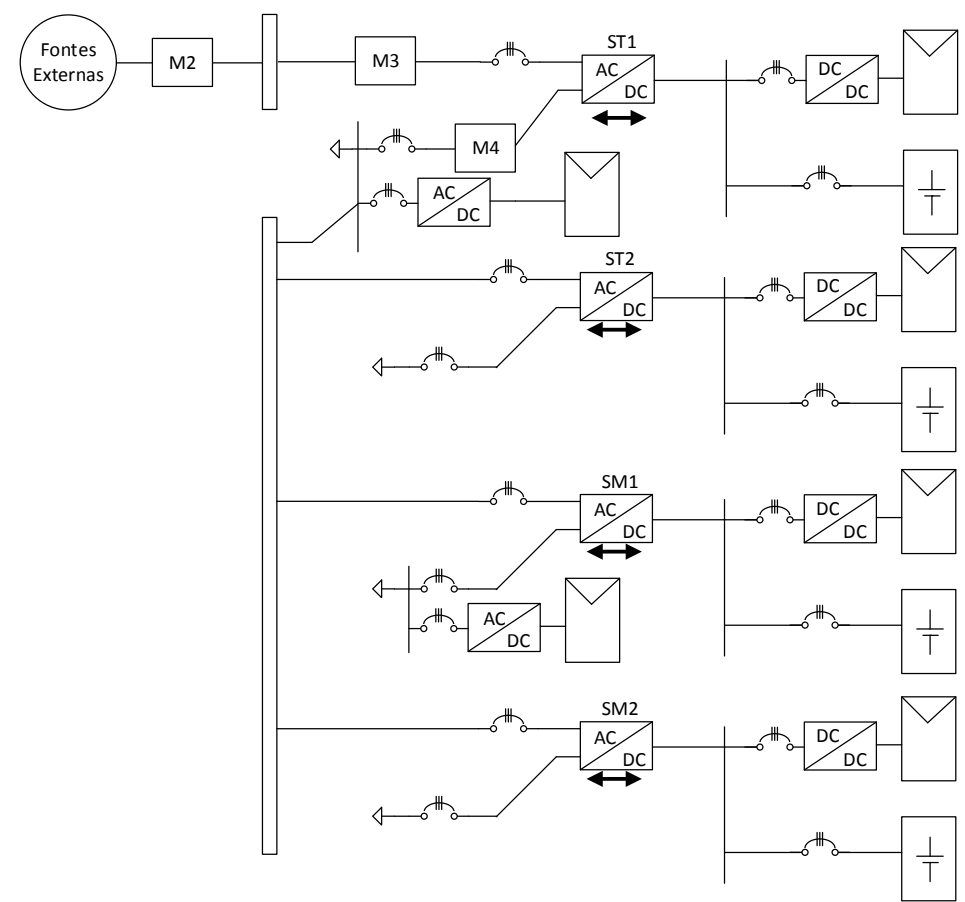

Figura 3.5 - Topologia com dois níveis de hierarquia. 
Os medidores instalados ao longo do sistema mensuram dados distintos de acordo com o nível de hierarquias que o sistema apresenta. A Figura 3.4 apresenta uma topologia no mesmo nível hierárquico, onde o medidor 2 monitora a energia demandada ou injetada de todos os SH para as fontes externas; o medidor 3 monitora a energia demandada ou injetada das fontes externas para o ST1; e o medidor 4 realiza a medição da energia demandada ou injetada das cargas do ST1.

Na Figura 3.5 é representado o sistema com dois níveis de hierarquias, onde os medidores mensuram os seguinte dados: o medidor 2 monitora a energia demandada ou injetada de todos os SH para as fontes externas; o medidor 3 mensura o resultado da energia demandada ou injetada de todos os $\mathrm{SH}$ para as fontes externas; e o medidor 4 mensura a energia demandada ou injetada pelas cargas do ST1 e também dos sistemas presentes no MGCC.

As topologias apresentam pontos positivos e negativos, dependendo da aplicação. A primeira topologia se apresenta mais apropriada para a interconexão com a rede elétrica. Os sistemas são independentes, podendo realizar intercâmbio de energia com a rede, sem um sistema interferir no outro. Nesta topologia cada SH pode gerenciar sua geração e demanda, além de poder prestar serviços ancilares.

Os ST1 e SM1 controlam sua geração pela frequência, devido à maior penetração de geração fotovoltaica no acoplamento em corrente alternada. Contudo, quando a frequência é elevada, os INVG deslocam o MPPT, desta forma diminuindo ou deixando de gerar energia. A possibilidade de interconexão com a rede ou outros $\mathrm{SH}$ representa uma nova estratégia de otimização do sistema, pois a frequência permanece constante e o excesso da geração é injetado na rede, ou fornecido para outro sistema que demande energia. A ausência da interconexão com outros $\mathrm{SH}$ ou com a rede elétrica pode ocasionar perda do potencial de geração, assim como apresentado na Figura 3.6. Esta figura representa a perda da geração do ST1. Neste dia a geração estava maior que a demanda de energia e o banco de baterias estava totalmente carregado. Neste caso, a frequência foi elevada, para retirada da geração c.a., diminuindo o fornecimento de potência, e o despacho do excedente de energia para a rede elétrica ou outros SH não foi liberado. 


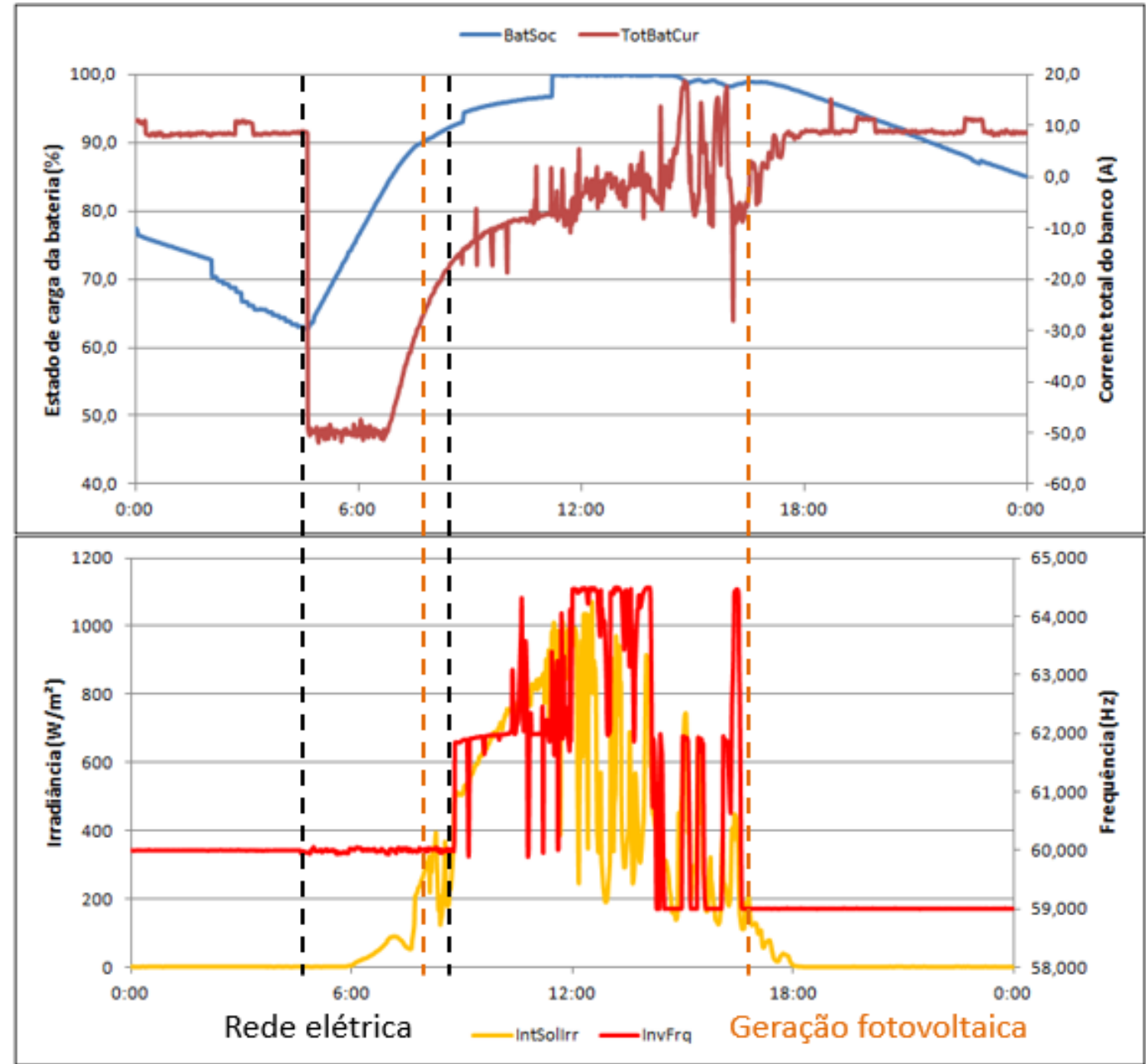

Figura 3.6 - Exemplo de controle da geração.

A interconexão entre os $\mathrm{SH}$ e a rede elétrica representa uma forma de gestão de energia para os sistemas. A conexão possibilita a interação entre os $\mathrm{SH}$, e a otimização da geração, quando a mesma está maior que a demanda. A Figura 37 representa este evento, quando os sistemas estão conectados na mesma hierarquia no PAC, e injetam energia na rede elétrica da concessionária (Figura 3.8). Durante uma parcela do dia, os sistemas demandam energia da rede, ao mesmo tempo em que estão carregando seus bancos de baterias com as suas respectivas gerações fotovoltaicas. Posteriormente, ao atingirem um nível determinado do estado de carga e a geração permanecendo maior do que a demanda, eles conseguem injetar energia na rede da concessionária. 


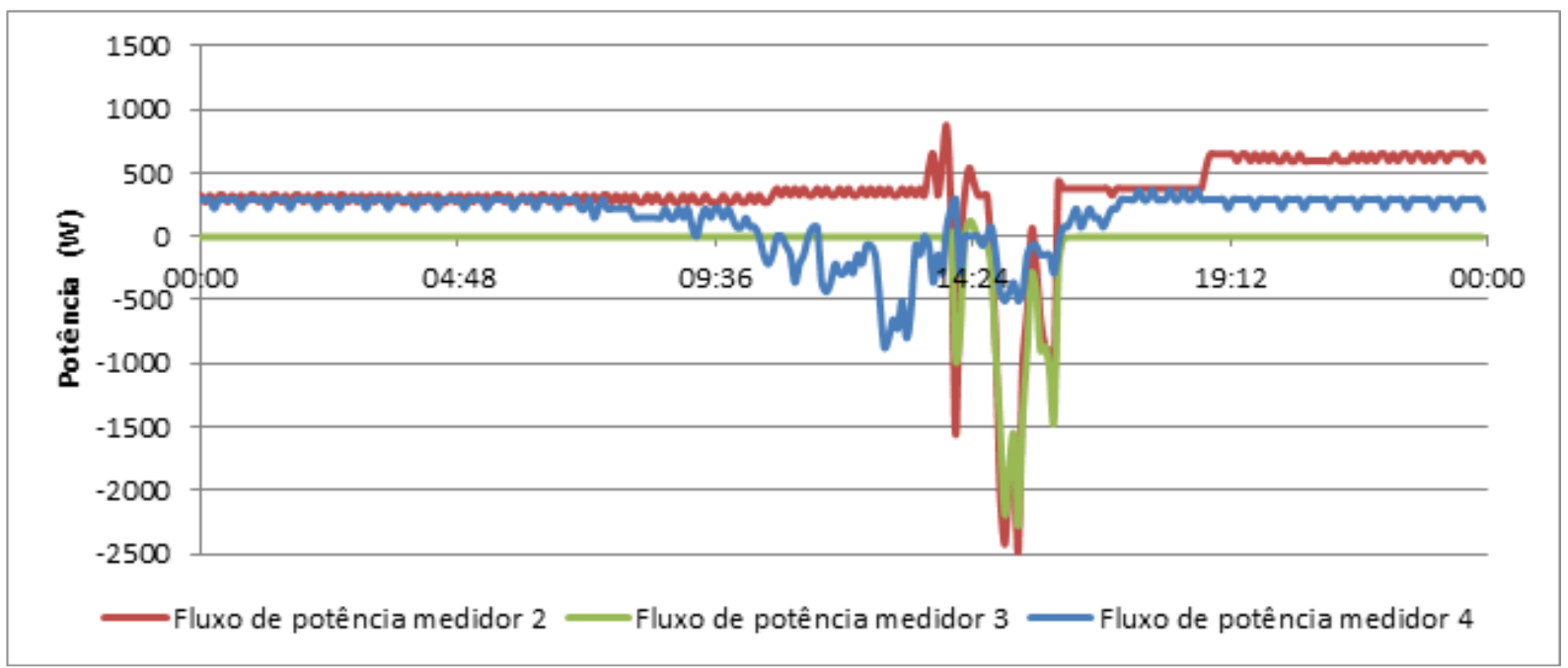

Figura 37 - Interação com a rede elétrica.

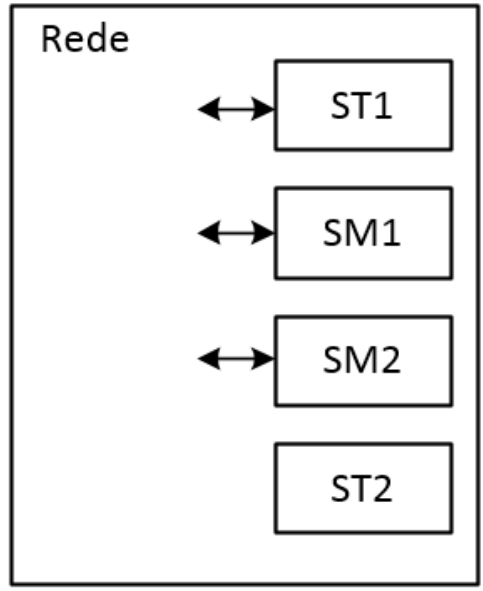

Figura 3.8 - Topologia com um nível de hierarquia e três SH injetando potência.

A Figura 37 apresenta o perfil de injeção e demanda de potência ativa do prosumidor visto pela rede. A injeção de energia dos SH pode não iniciar ao mesmo momento; porém, durante parte do dia esta ocorre de modo simultâneo. A injeção de potência na rede ocorre quando os medidores apresentam potência negativa, e a demanda de potência da rede ocorre quando a potência está positiva. $O$ início da injeção de energia ocorre quando a conexão dos $\mathrm{SH}$ com a rede elétrica é liberada pelo MGCC.

Outro ponto a ser destacado na Figura 37 é a diferença entre as medições dos medidores. No ST1, existem dois transformadores de 50 kVA, que estão alocados após os medidores 2 e 4, ocorrendo, desta forma, perdas nos 
transformadores, o que causa a diferença nas medições. Nos períodos de conexão do MGCC com o ST1, mesmo que não haja carga, os transformadores demandam energia.

A Figura 3.9 apresenta a análise dos dados dos sistemas de monitoramento do ST1 e do SM1 (Figura 3.10) para um dia com injeção de potência na rede elétrica. Inicialmente o fluxo não é liberado, e as frequências dos sistemas estão elevadas. Contudo, quando o fluxo é liberado a frequência permanece constante em $60 \mathrm{~Hz}$ e, com a irradiância elevada, o excedente da geração é injetado na rede elétrica.

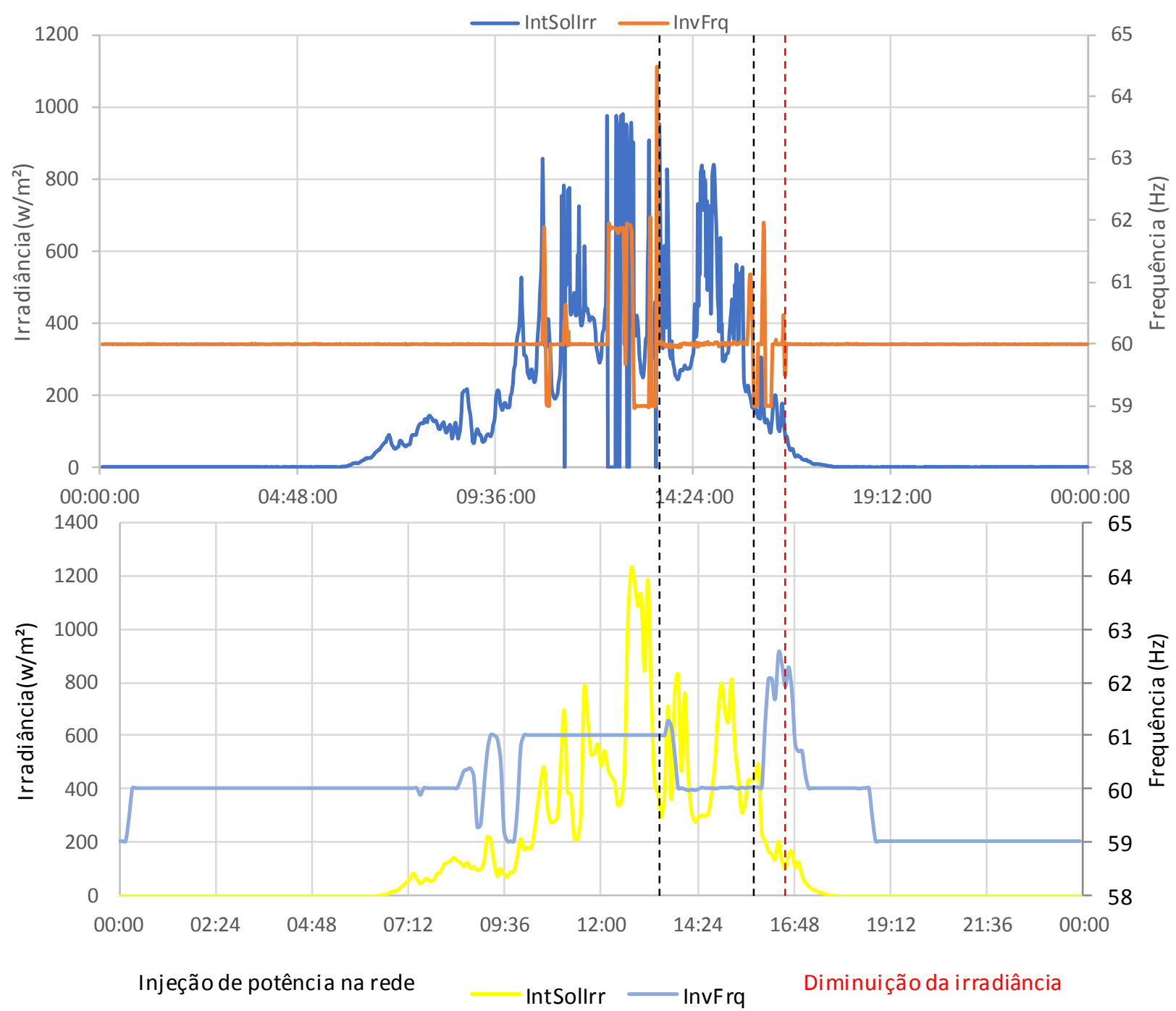

Figura 3.9 - Irradiância e frequência dos ST1 e SM1. 


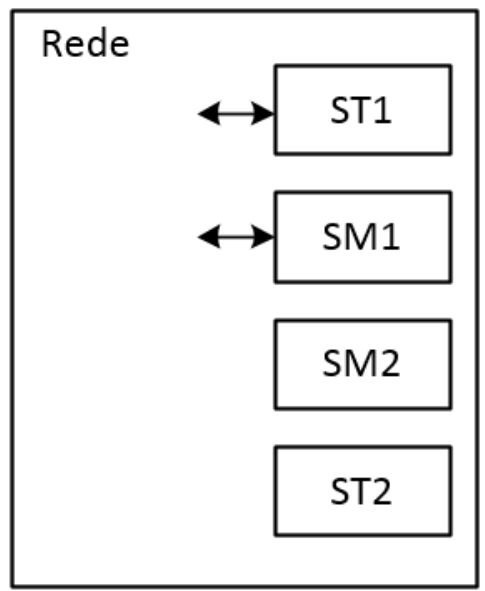

Figura 3.10 - Topologia com um nível de hierarquia e com o ST1e SM1 injetando potência.

Ao término da injeção de potência na rede elétrica, a frequência dos sistemas ainda permanece elevada. Isso ocorre porque após a desconexão ainda há recurso solar para carregar o banco, porém não há recurso solar suficiente para injeção de potência na rede, e a demanda de energia é menor do que a geração. $\mathrm{Na}$ Figura 3.9 está destacada, pela linha pontilhada vertical vermelha, o momento em que a irradiância diminui e a frequência volta a estabilizar em $60 \mathrm{~Hz}$.

A injeção de potência dos SH para a rede elétrica pode ser mensurada e analisada em pontos distintos na infraestrutura presente no LSF. A Figura 3.11 apresenta os dados coletados pelo MGCC, medidos no PAC, onde são apresentadas as formas de ondas das correntes dos três $\mathrm{SH}$ que realizam a função de prosumidor. As ondas com menor amplitude são as dos sistemas monofásicos, que injetam uma corrente menor na rede elétrica.

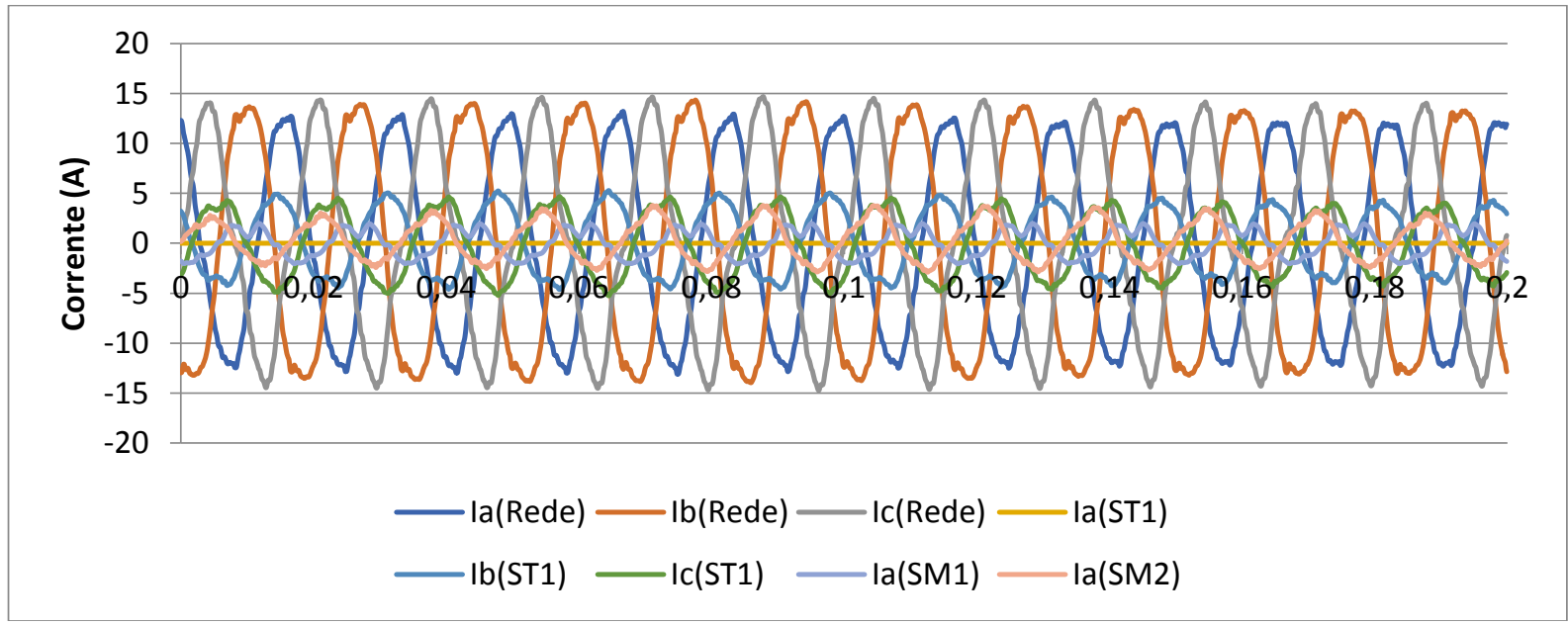

Figura 3.11 - Forma de onda da corrente no MGCC. 
A injeção de potência dos $\mathrm{SH}$ na rede elétrica não representou um impacto relevante. A Figura 3.12 apresenta as medições de tensão antes e durante a injeção de potência na rede elétrica. $O$ formato de onda permanece com a mesma amplitude, não ocorrendo elevação da tensão.

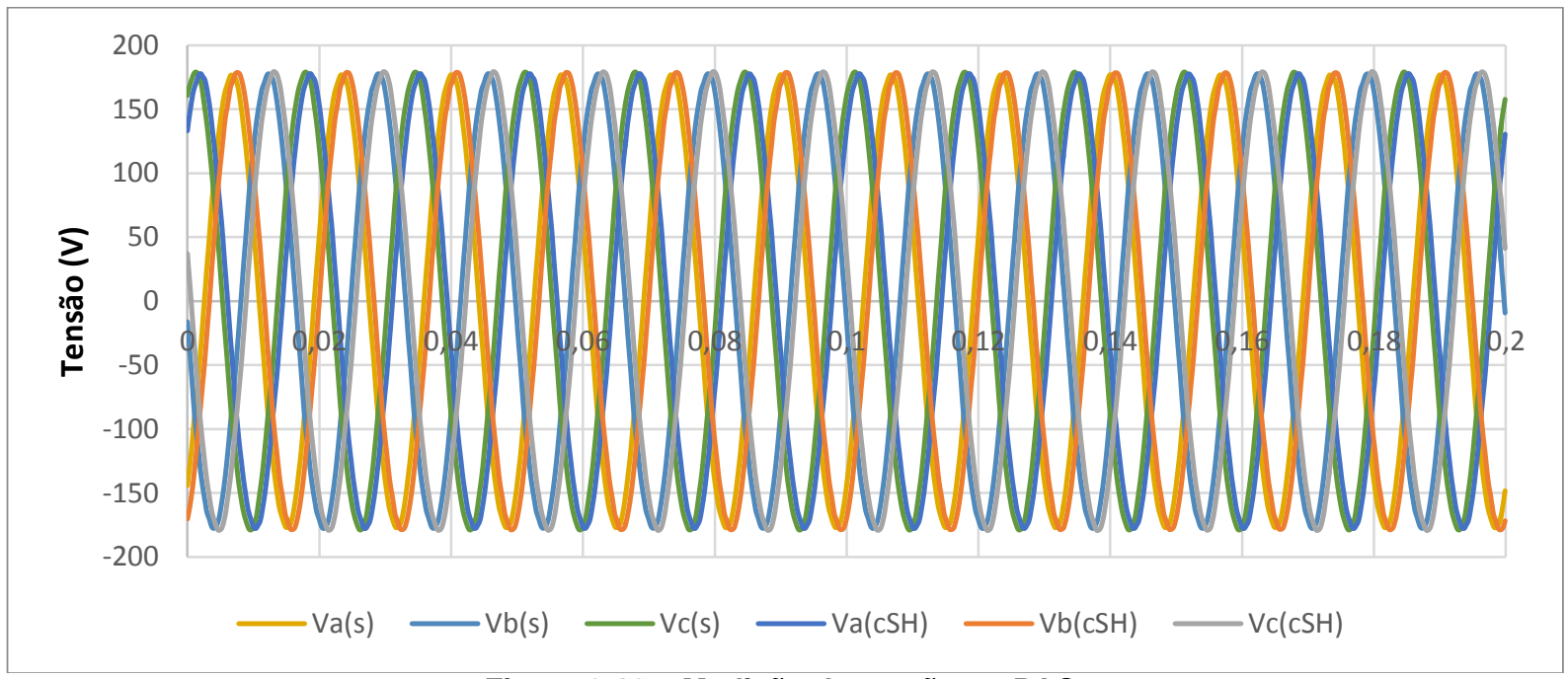

Figura 3.12 - Medição de tensão no PAC.

A emulação do aerogerador utilizando a fonte c.c. na topologia com um nível de hierarquia foi realizada (Figura 3.13). Neste teste, o prédio do LSF não estava sendo abastecido pelos SH e o excedente da geração era injetado na rede elétrica, como mostrado na Figura 3.14. A diferença apresentada entre os valores dos medidores é devida às suas posições no ST1 e as perdas nos transformadores e nos cabos. O medidor mais próximo da rede elétrica e mais distante da fonte indicou uma injeção de potência menor.

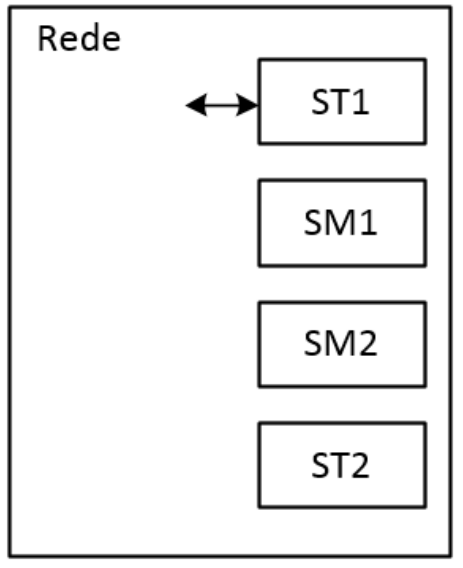

Figura 3.13 - Topologia com um nível de hierarquia e com o ST1 injetando potência. 


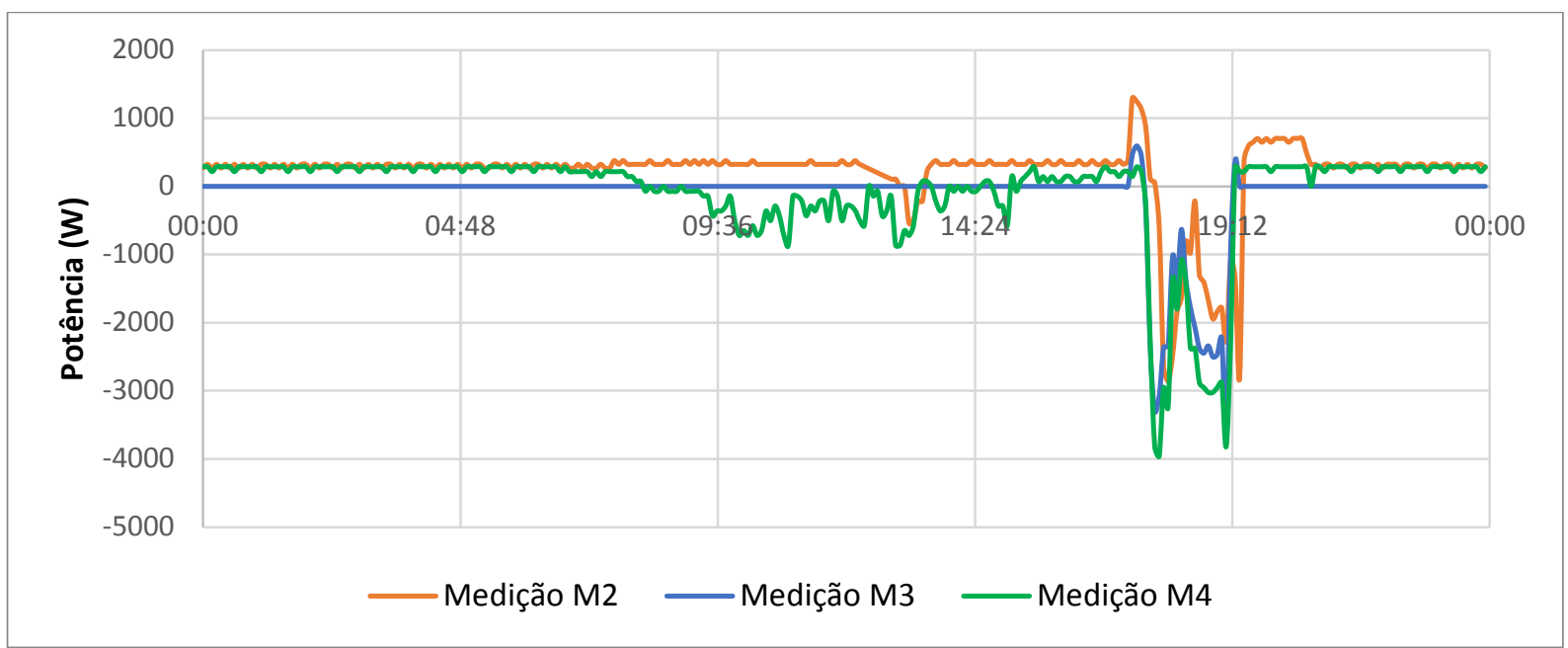

Figura 3.14 - Injeção de potência com o aerogerador emulado.

A realização dos testes operacionais com um nível de hierarquia permite modularidade e independência para os $\mathrm{SH}$, pois cada sistema demanda ou injeta potência da rede, e um SH não interfere no outro. Desta forma, a interação dos SH é com a rede elétrica.

A individualidade de cada $\mathrm{SH}$ permite que em casos de defasagem entre $\mathrm{o}$ ápice de geração e de demanda, a rede elétrica seja um elemento de apoio. Quando a geração for maior que a demanda e o estado de carga do banco de baterias estiver elevado, a rede elétrica demanda energia. Quando a demanda for maior que a geração e o estado de carga do banco estiver baixo, a rede elétrica pode auxiliar, fornecendo energia.

A segunda topologia introduz o conceito de dois níveis de hierarquia entre os SH (Figura 3.15). Nesta topologia, o ST1 realiza a função de rede principal para os outros $\mathrm{SH}$, e estes demandam ou injetam energia através dele. A Figura 3.16 apresenta na curva azul a relação de demanda da fonte externa para o ST1, e em laranja a relação do ST1 com os outros $\mathrm{SH}$, e a suas cargas. 


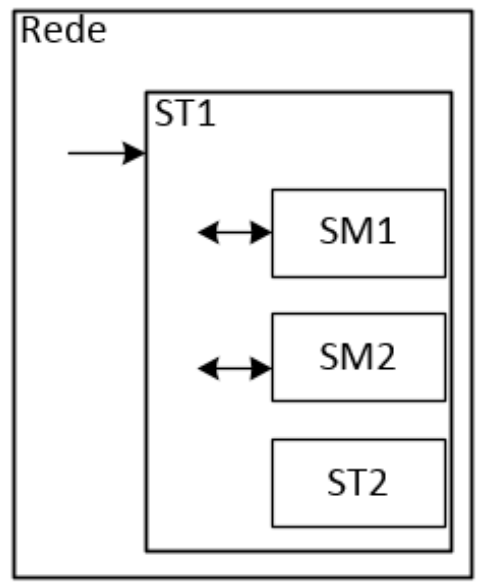

Figura 3.15 - Topologia com dois níveis hierarquias e com intercâmbio de energia.

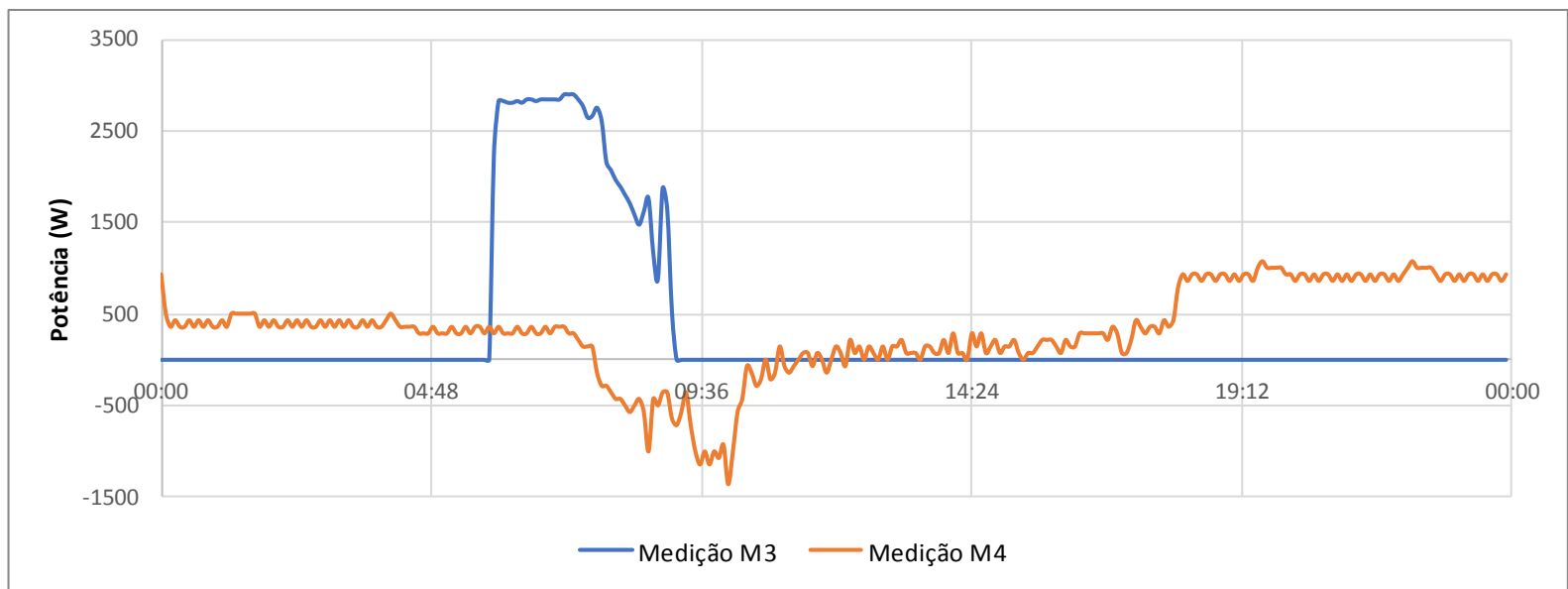

Figura 3.16 - Relação entre demanda e injeção de potência no segundo nível de hierarquia.

No período em que a linha azul está na parte positiva, o ST1 está demandando potência da fonte externa, e nos momentos em que a linha azul está no zero, o sistema está desconectado. Como a linha azul não foi para a parte negativa neste dia, não houve injeção de potência para a fonte externa. Quando a linha laranja está na parte negativa, os outros SH estão injetando potência para o ST1, e quando ela está na parte positiva o banco de baterias está fornecendo energia para as cargas. Durante o período em que a linha laranja está na parte negativa e a linha azul na positiva, o ST1 está carregando o banco de baterias por ambos os sentidos.

No decorrer desta análise operacional o prédio do LSF estava conectado na minirrede e desconectado da rede elétrica. A demanda elétrica era suprida pela 
energia armazenada no banco de baterias, ou pelas gerações fotovoltaicas. Esta topologia possibilita maior interação entre os $\mathrm{SH}$, fomentando o intercâmbio de energia e a diminuição da dependência da rede, assim como apresentado na Figura 3.16. Quando as curvas de demanda e geração não estavam coincidentes, o excedente de energia era enviado para outro $\mathrm{SH}$.

A Figura 3.17 apresenta como esta topologia é coordenada pelo MGCC em seu software de comando. O barramento é alimentado pela saída do ST1, e os SM1 e SM2 estão conectados no PAC, realizando a topologia com dois níveis de hierarquia.

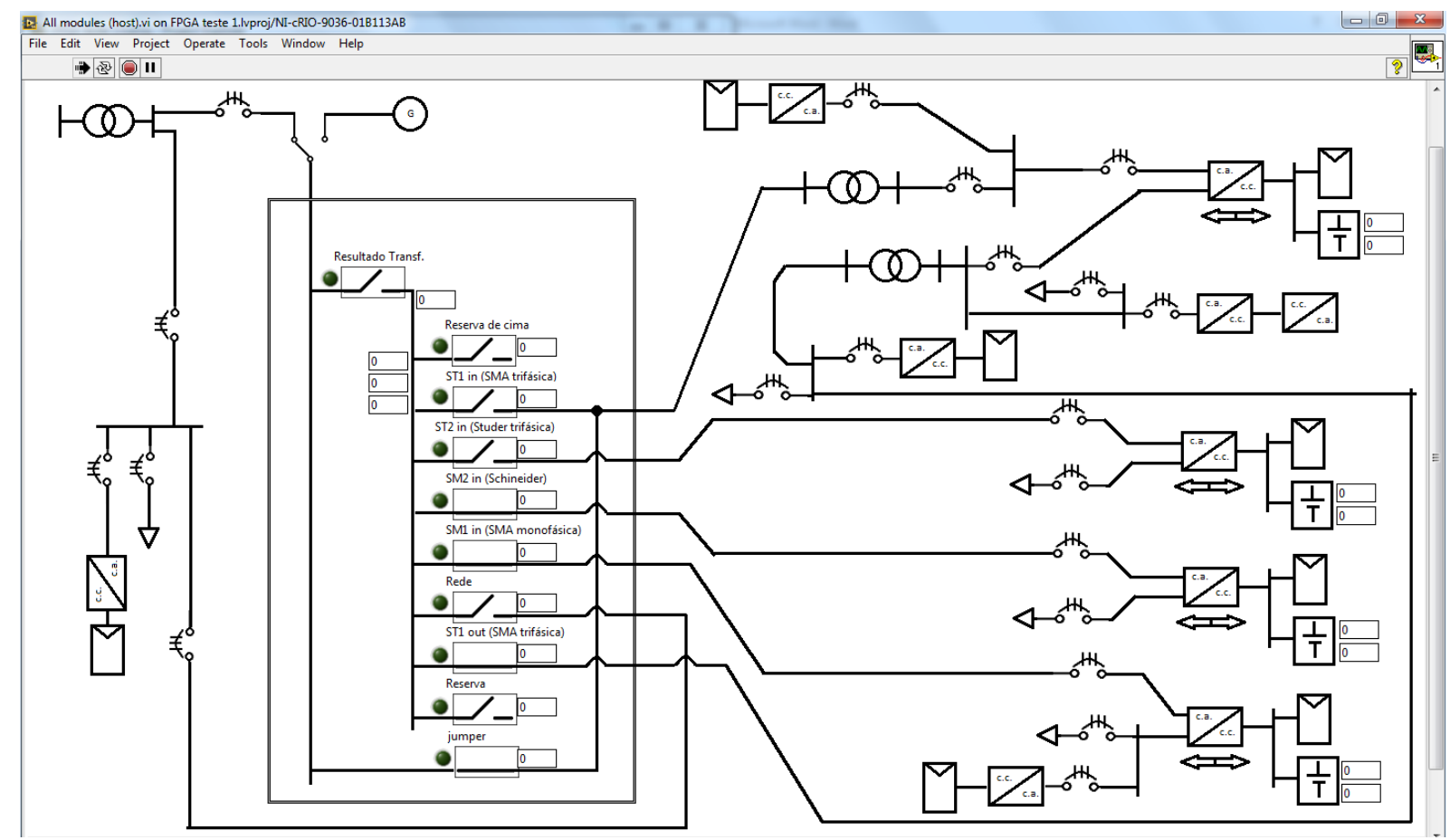

Figura 3.17 - Topologia com dois níveis de hierarquia no MGCC.

A Figura 3.18 apresenta as medições de corrente realizadas no MGCC. As formas de onda das fases a e $c$ estavam recebendo corrente dos dois SM, e a fase $b$ não estava recebendo. Esta constatação é baseada na diferença de amplitude e formato das formas de onda das correntes do ST1. A oposição do sentido da corrente mostra que um sistema está demandando energia e outro está injetando energia. 


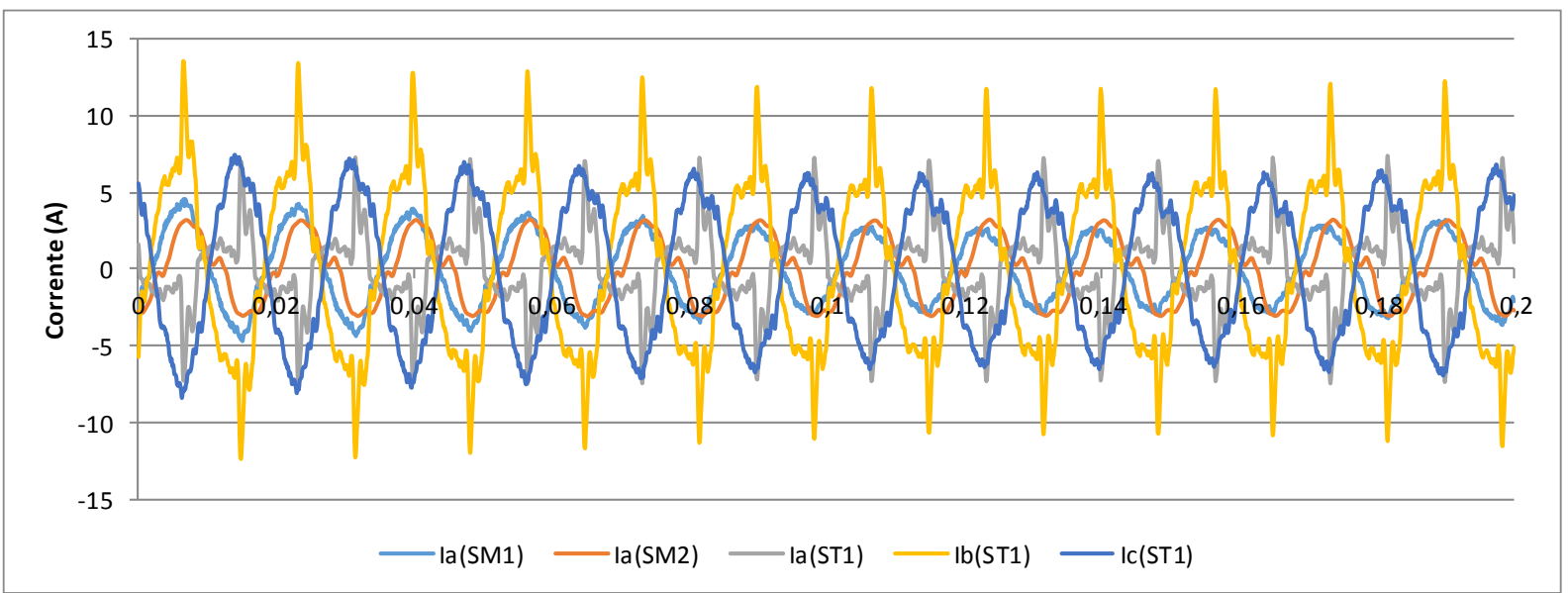

Figura 3.18 - Correntes medidas com dois níveis de hierarquia.

A topologia com dois níveis de hierarquia apresenta-se como uma melhor estratégia operacional para sistemas isolados, pois esta permite elevação da interação entre os $\mathrm{SH}$, assim como apresentado na Figura 3.16, pois quando os SM1 e SM2 estão injetando potência no ST1, este pode suprir parte de sua demanda pela injeção dos outros sistemas.

A segunda topologia apresenta maiores benefícios quando a fonte externa é o GGD, pois a interação dele será somente com o ST1. Desta forma, é possível configurar apenas um sistema para não realizar o fluxo reverso de potência, e os outros $\mathrm{SH}$ permanecem com a mesma configuração para o intercâmbio de energia. Quando o GGD entra em operação, a demanda de energia é maior e, logo, o mesmo pode trabalhar com um carregamento maior, otimizando sua utilização.

Entretanto, esta topologia não apresenta somente pontos positivos. A parametrização dos SH deve ser realizada com muita atenção, porque o ST1 regula a relação geração e demanda pela frequência, e pode chegar ao ponto de nos sistemas monofásicos a frequência estar elevada, pois há excesso de geração e não ocorre a conexão entre os SH (Figura 3.19). 


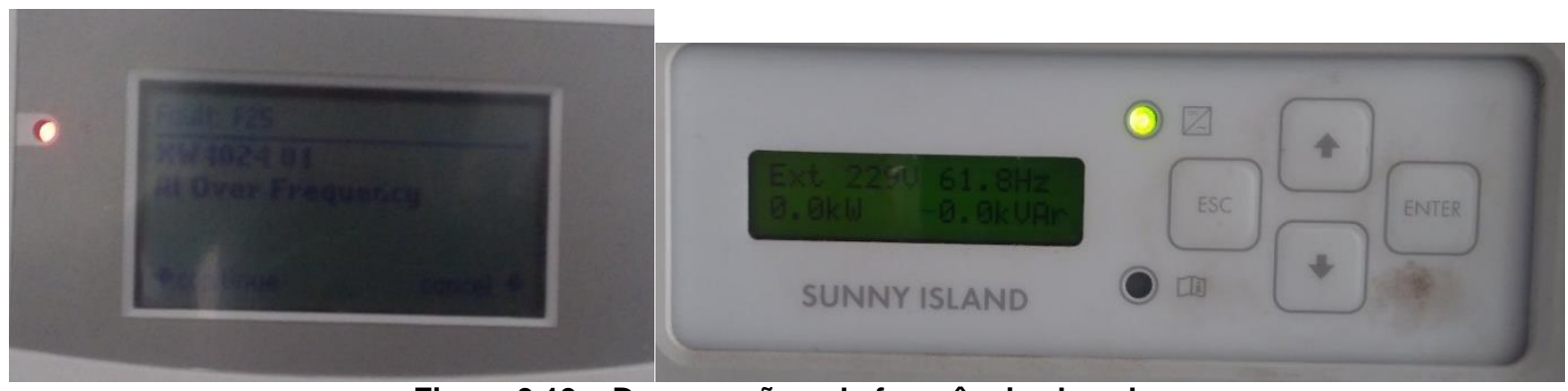

Figura 3.19 - Desconexão pela frequência elevada.

A Figura 3.20 apresenta a relação de demanda e injeção de potência com as fontes externas no medidor 2. Na maior parte do período analisado o fluxo reverso de potência não foi liberado; então, os SH, na maior parte do período, apenas demandaram energia.

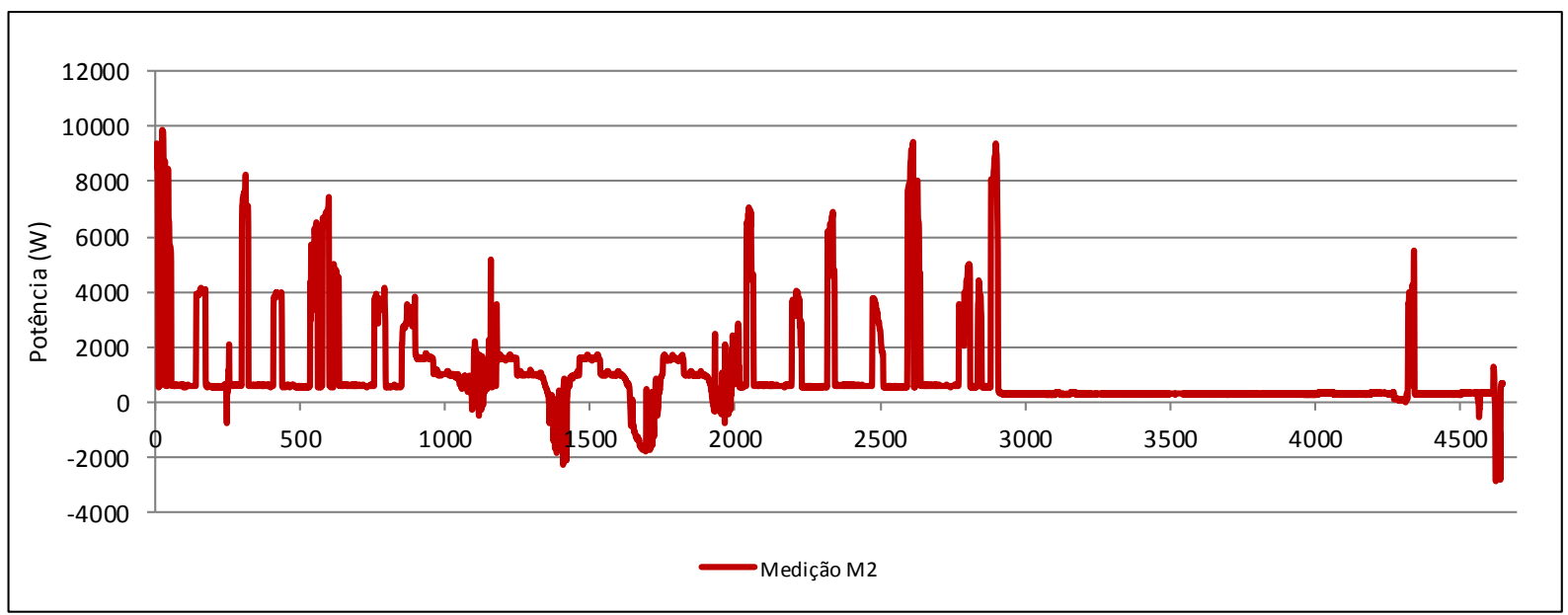

Figura 3.20 - Resultado de demanda e injeção de energia com as fontes externas.

Os testes operacionais realizados serviram para compreender a interação entre os SH. Nos testes operacionais a possibilidade de realizar duas hierarquias distintas permite maior ou menor interação com a rede, modularidade e flexibilidade. A conexão entre os SH e o PAC foi comandada ativamente pelo MGCC, mas a gestão da geração e da demanda foi controlada nos $\mathrm{SH}$.

A topologia com um nível de hierarquia apresentou maior potencial para a conexão dos SH com a rede elétrica. Isso pela modularidade e possibilidade de uma gestão individual para cada sistema. A conexão com a rede elétrica também auxilia na gestão da geração e da demanda, pois quando há excesso de geração ou aumento de demanda, o sistema interage com a rede. Contudo, esta modularidade e 
maior interação com a fonte externa, quando esta for o GGD, necessita de proteção para evitar a motorização do mesmo.

A topologia com dois níveis de hierarquia apresentou maior potencial para conexão com o GGD, e em sistemas isolados, pois há uma diminuição da dependência com a fonte externa, e maior possibilidade de intercâmbio de energia entre os SH. Também há uma otimização da utilização do GGD, pois quando ele entra em operação para fornecer potência para os SH, eles estão com uma demanda maior. Entretanto, há uma dependência do ST1, e este deve ser bem gerenciado, pois pode haver casos de excesso de geração e de necessidade de energia por outros sistemas, mas não haver a conexão, por conta da elevação da frequência.

Ambas as topologias atuaram de modo estável, com os sistemas ora demandando e ora injetando potência, seguindo os padrões de tensão da rede principal. 


\section{Capítulo 4 - Proposta de Curso de Aperfeiçoamento em Minirredes e Sistemas Híbridos}

Este capítulo apresenta uma proposta de curso de aperfeiçoamento em minirredes e sistemas híbridos utilizando a infraestrutura existente no LSF.

\subsection{Capacitação}

A capacitação hoje representa uma das barreiras para a disseminação e maior penetração dos sistemas fotovoltaicos, tanto em sistemas isolados, quanto em sistemas conectados à rede elétrica. Os sistemas híbridos possuem maior complexidade em sua instalação, manutenção e operação.

Alguns autores já apontam possíveis soluções para diminuição das lacunas educacionais, propondo métodos para a maior inserção de sistemas fotovoltaicos com profissionais qualificados. SILVA (2017) apresenta uma proposta de curso póstécnico e potencial de aplicação nas ETEC, dada a abrangência das escolas técnicas no estado de São Paulo. MOCELIN (2014) apresenta a experiência do LSF, para propor meios efetivos para qualificação de recursos humanos. Ambos os trabalhos buscam vincular conteúdos teóricos e práticos, utilizando a infraestrutura do LSF.

Algumas instituições de ensino já oferecem cursos sobre energia solar fotovoltaica para profissionais que estão ou queiram ingressar no mercado fotovoltaico, como por exemplo: O Serviço Nacional de Aprendizagem Industrial (SENAI), em conjunto com o instituto a agência de cooperação alemã GIZ, que oferta cursos profissionalizantes nas áreas correlatas à energia solar; o Grupo de Estudos e Desenvolvimento de Alternativas Energéticas (GEDAE), da Universidade Federal do Pará (UFPA) oferta regularmente um curso sobre sistemas fotovoltaicos conectados à rede elétrica (SFCR) e, mais recentemente também sobre sistemas fotovoltaicos isolados; e a Universidade Estadual de Campinas (UNICAMP) oferta três modalidades de curso sobre energia solar, a saber: Curso 1 - Básico - Sistemas Fotovoltaicos, Curso 2 - Avançado: Projeto e Dimensionamento, Curso 3 - Instalador Profissional. 
Nesta perspectiva, este capítulo visa propor um curso de aperfeiçoamento em minirredes e sistemas híbridos, utilizando a infraestrutura do LSF, para profissionais que já atuam no mercado fotovoltaico, ou pessoas que tenham conhecimentos teóricos e práticos sobre sistemas fotovoltaicos, porém ainda não atuem na área. $O$ foco em pessoas que já tenham conhecimento é justificado pela quantidade de informação a ser transmitida no período estipulado para o curso.

A proposta de curso visa mesclar conhecimentos práticos e teóricos sobre sistemas híbridos e minirredes, utilizando toda a infraestrutura presente no LSF, além de publicações (artigos e livros), bem difundidos sobre sistemas fotovoltaicos, como: Manual de Engenharia para Sistemas Fotovoltaicos, (Pinho, J; Galdino, M.(Org), 2014); Manual de Implantação de Sistemas Híbridos Fotovoltaico-EólicoDiesel para Geração de Energia Elétrica, (Pinho et al.,2008a) e Sistemas Híbridos: Soluções Energéticas para a Amazônia, (Pinho et al.,2008b). O foco em sistemas híbridos é embasado na potencial aplicação em sistemas conectados e sistemas isolados e na ausência de cursos que busquem explanar esta temática tão pertinente no presente e com elevado potencial de aplicação no futuro.

\subsubsection{Objetivo}

Aperfeiçoar os conceitos relacionados a sistemas híbridos e minirredes e desenvolver competências em todas as fases de projeto, instalação, operação e manutenção desse tipo de sistema.

\subsubsection{Pré-requisito}

O aluno deve ter concluído o ensino técnico em eletrotécnica ou concluído um curso técnico correlato ao curso técnico de eletrotécnica, ou ter concluído graduação em engenharia elétrica ou uma graduação correlata a engenharia elétrica. 


\subsection{Estrutura do Curso}

A proposta de curso de aperfeiçoamento em sistemas híbridos é dividida em aulas teóricas e práticas. Sugere-se um máximo de oito alunos para melhor acomodação e maior assimilação por parte do público alvo.

\subsubsection{Ementa}

Conceitos Básicos sobre Energia Elétrica; Energia Solar; Grupos Geradores; Sistema de Armazenamento; Sistema de Condicionamento de Potência; Sistemas Híbridos; Minirredes; Projeto de Sistemas Híbridos e Minirredes; Operação e Manutenção de Sistemas Híbridos e Minirredes.

\subsubsection{Conteúdo Programático Teórico}

Aula Teórica 1 - Conceitos Básicos sobre Energia Elétrica: A importância da energia, Energia e potência; Unidades de energia e potência; Tipos e fontes de energia.

Aula Teórica 2 - Energia Solar: Breve histórico da energia solar fotovoltaica; Conversão solar fotovoltaica; Características dos módulos fotovoltaicos; Curva I-V; Associação de módulos; Aplicações de sistemas fotovoltaicos.

Aula Teórica 3 - Grupos Geradores: Motores a combustão; Geradores elétricos; Grupos geradores; Consumo de combustível dos grupos geradores; Vantagens e desvantagens dos grupos geradores a diesel; Impactos ambientais de grupos geradores.

Aula Teórica 4 - Sistema de Armazenamento: Conceitos básicos; Acumuladores de energia elétrica; Processos de carga e descarga; Composição do banco de baterias.

Aula Teórica 5 - Sistema de Condicionamento de Potência: Conceitos básicos; Controladores de carga; Inversores bidirecionais; Inversores de conexão à rede; Retificadores. 
Aula Teórica 6- Sistemas Híbridos e Minirredes: Conceitos básicos; Principais tipos de sistemas; Classificações de sistemas híbridos; Vantagens e desvantagens; Estratégias de operação; Sistemas de medição; Tipos de minirredes; Normas técnicas e formas de avaliação de conformidade.

Aula Teórica 7- Projeto de Sistemas Híbridos: Cálculo do consumo a ser atendido; Dimensionamento do sistema de armazenamento; Dimensionamento do sistema de geração; Dimensionamento do sistema de condicionamento de potência; Dimensionamento da minirrede de distribuição de energia; Utilização de softwares de simulação.

Aula Teórica 8- Operação e Manutenção: Sistema fotovoltaico; Grupo gerador a diesel; Sistema de armazenamento de energia; Sistema de condicionamento de potência; Minirrede de distribuição.

\subsubsection{Conteúdo Programático Prático}

Aula Prática 1 - Apresentação do Laboratório de Minirredes: Sistemas híbridos; cargas compartilhadas; grupo gerador a diesel; conexão com a rede elétrica.

Aula Prática 2 - Sistema Monofásico 2: Sistema de geração; Sistema de condicionamento de potência; Sistema de armazenamento; Sistema de medição; Sistema de monitoramento; Sistema de proteção e seccionamento; Cargas.

Aula Prática 3 - Sistema Monofásico 1: Sistema de geração; Sistema de condicionamento de potência; Sistema de armazenamento; Sistema de medição; Sistema de monitoramento; Sistema de proteção e seccionamento; Cargas.

Aula Prática 4 - Sistema Trifásico 2: Sistema de geração; Sistema de condicionamento de potência; Sistema de armazenamento; Sistema de medição; Sistema de monitoramento; Sistema de proteção e seccionamento; Cargas.

Aula Prática 5 - Sistema Trifásico 1: Sistema de geração; Sistema de condicionamento de potência; Sistema de armazenamento; Sistema de medição; Sistema de monitoramento; Sistema de proteção e seccionamento; Cargas. 
Aula Prática 6 - Sistema de Interconexão entre os Sistemas Híbridos: Conceitos básicos; Sistema de controle; Sistema de medição; Sistema de aquisição de dados.

\section{Aula Prática 7 - Instalação, Operação e Manutenção de Sistemas} Híbridos: Sistema fotovoltaico; Grupo gerador a diesel; Sistema de armazenamento de energia; Sistema de condicionamento de potência; Utilização do SH móvel.

\subsection{Plano de Ensino}

A proposta deste curso é aprimorar e reforçar os conhecimentos teóricos e práticos sobre os sistemas híbridos e minirredes. Desta forma, foram planejadas aulas que abrangem os principais elementos presentes nesta aplicação. A seguir são apresentadas as cargas horárias das aulas teóricas e práticas, bem como o local onde as mesmas poderão ser ministradas.

\subsubsection{Plano de Ensino das Aulas Teóricas}

A proposta é que as aulas teóricas sejam ministradas nas instalações do LSF ou nas salas de aula do IEE-USP, com uma carga horária de 20 horas, divididas da seguinte forma: Aula Teórica $1-2 \mathrm{~h}$; Aula Teórica 2 - 2 h; Aula Teórica 3-2 h; Aula Teórica 4-2 h; Aula Teórica 5-2 h; Aula Teórica 6 - 2 h; Aula Teórica 7 - 4 h; Aula Teórica 8 - $4 \mathrm{~h}$.

\subsubsection{Plano de Ensino das Aulas Práticas}

A proposta é que as aulas práticas sejam ministradas nas instalações do LSF, com uma carga horária de 16 horas, utilizando os conceitos teóricos já transmitidos aos alunos nas aulas teóricas. Para tanto, sugere-se que os mesmos realizem as atividades propostas no laboratório, executando tarefas referentes a instalação, operação e manutenção de sistemas híbridos e minirredes. Sugere-se a seguinte distribuição da carga horária: Aula Prática 1 - $1 \mathrm{~h}$; Aula Prática 2 - $1 \mathrm{~h}$; Aula Prática 3 - 1 h; Aula Prática 4 - 1 h; Aula Prática 5 - 2 h; Aula Prática 6 - 2 h; Aula Prática $7-8 \mathrm{~h}$. 
Assim como descrito anteriormente, O LSF possui quatro topologias de $\mathrm{SH}$. Contudo, para realização do curso de aperfeiçoamento com maior assimilação por parte dos alunos, pretende-se utilizar outro SH que está instalado em uma bancada móvel (Figura 4.1).

A possibilidade de locomoção da bancada é um fator importante para realização de medições dos parâmetros elétricos. Os geradores fotovoltaicos utilizados neste sistema já estão fixados em uma instalação; porém, para maior dinamismo da aula espera-se que os alunos realizem as conexões, montagem das configurações, e realizem medições, para compreenderem os problemas reais da instalação.

Outra possibilidade de atividade utilizando este sistema híbrido é a realização da conexão com uma fonte externa utilizando a rede elétrica ou o GGD de 5,5 kVA (Figura 4.2). Desta forma, será ampliado o conhecimento prático dos alunos sobre as diversas formas de acoplamento das gerações nos sistemas híbridos. Este sistema móvel não está conectado ao MGCC e, então, os dados de geração e demanda deverão ser mensurados.

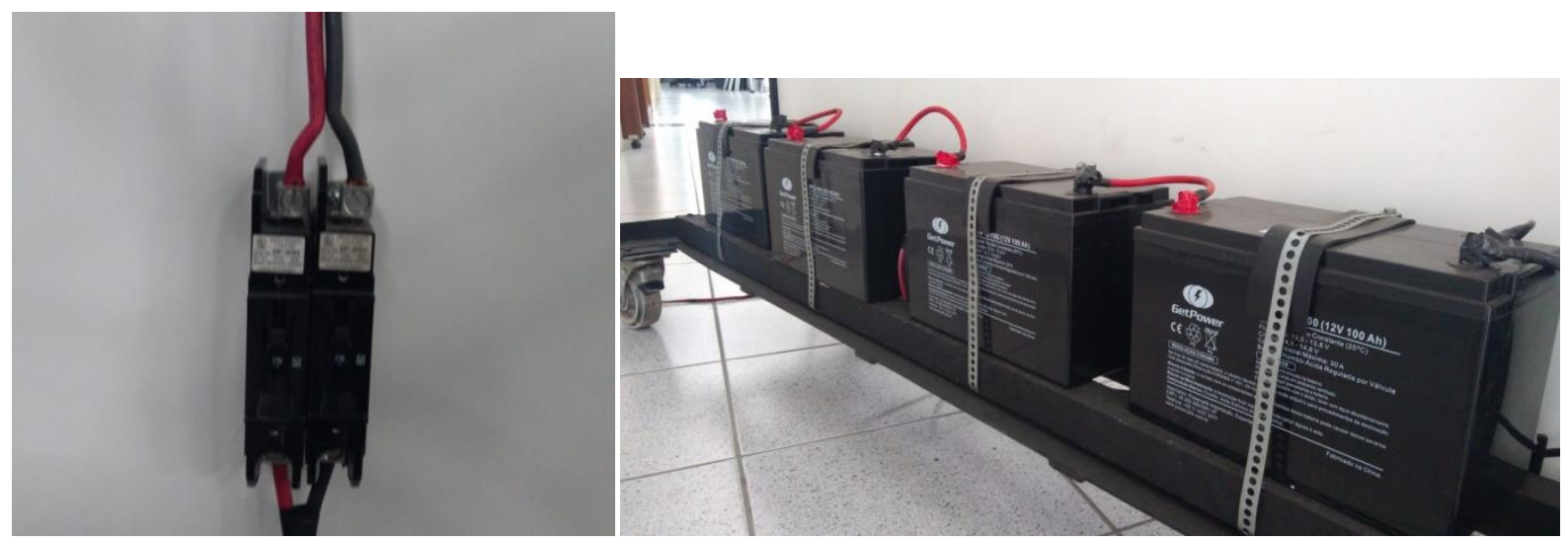




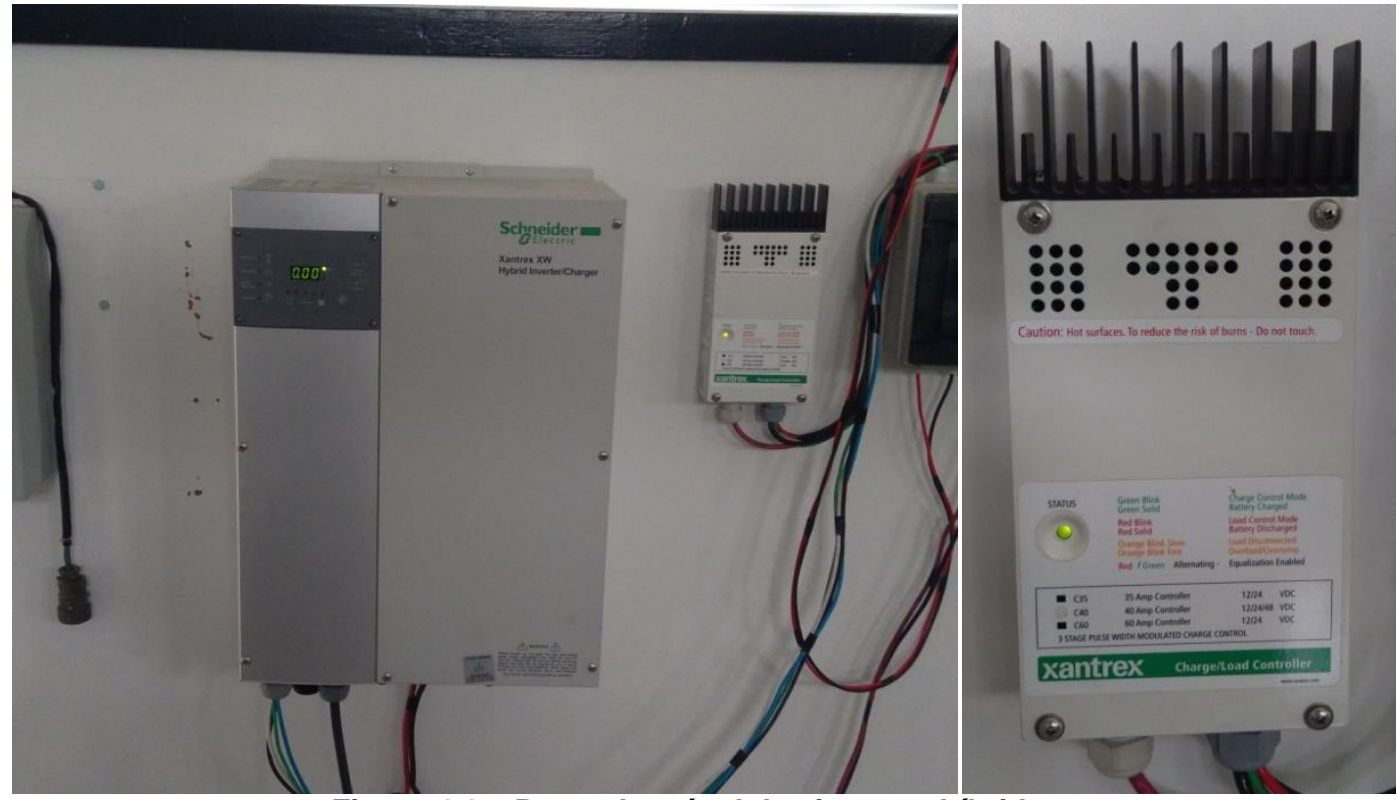

Figura 4.1 - Bancada móvel de sistemas híbridos.

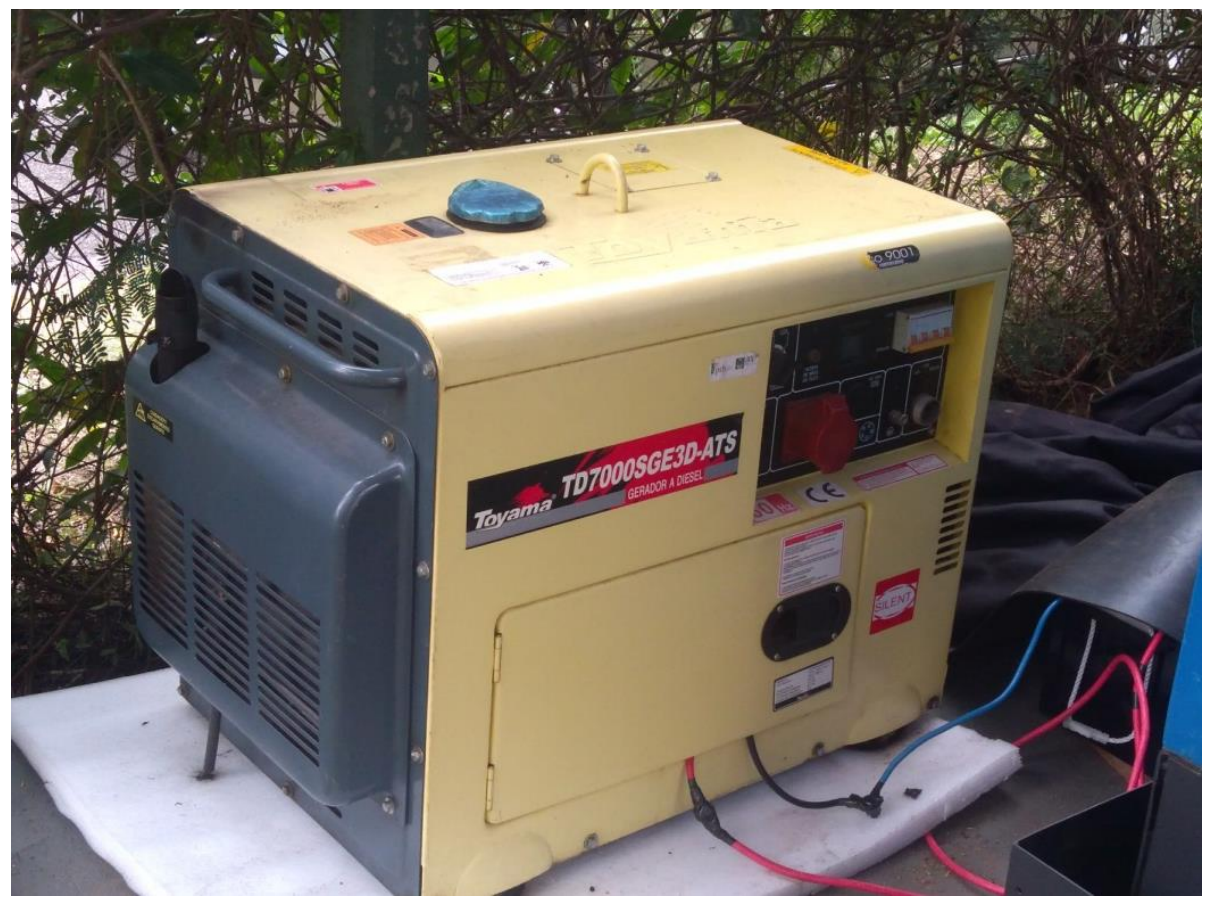

Figura 4.2 - Grupo gerador a diesel de 5,5 kVA.

\subsubsection{Avaliação}

Como metodologia de avaliação dos alunos, propõe-se realizar uma prova teórica e uma prova prática ao final do curso. Sugere-se que os dois processos utilizem uma carga horária de 4 horas, sendo 2 horas para cada uma das avaliações. 


\subsection{Material Didático Necessário}

\subsubsection{Material para as Aulas Teóricas}

A proposta para as aulas teóricas é elucidar as principais características dos sistemas híbridos e minirredes. Desta forma, para realização das mesmas será necessário utilizar computador, projetor multimídia e quadro branco, com seus respectivos acessórios.

\subsubsection{Material para as Aulas Práticas}

O curso está sendo projetado para ser ministrado nas instalações do LSF. O laboratório já possui infraestrutura para a realização do curso de aperfeiçoamento utilizando os materiais descritos no Capítulo 2 desta dissertação e também na Descrição da Minirrede com Sistemas Híbridos do LSF, relatório técnico, (Novaes et al., 2018b).

Para realização do curso em outro local que não disponha da mesma infraestrutura, sugere-se uma lista mínima de materiais para as aulas práticas, apresentada na Tabela 4.1 .

Tabela 4.1 - Lista de materiais para as aulas práticas.

\begin{tabular}{|c|c|}
\hline Material & Quantidade \\
\hline Grupo gerador a diesel & 1 \\
\hline Módulos fotovoltaicos & 6 \\
\hline Controlador de carga & 1 \\
\hline Inversor de conexão à rede & 1 \\
\hline Inversor bidirecional & 1 \\
\hline Disjuntor de curva c & 2 \\
\hline DPS c.a. & 4 \\
\hline DPS PV & 4 \\
\hline Disjuntor c.c. & 4 \\
\hline Chave seccionadora c.c. & 2 \\
\hline Fusível cartucho porcelana GPV Solar 1.000 Vcc & 4 \\
\hline
\end{tabular}




\begin{tabular}{|c|c|}
\hline Medidor de energia bidirecional & 1 \\
\hline Multímetro & 1 \\
\hline Alicate amperímetro c.c. e c.a. & 1 \\
\hline Alicate universal & 1 \\
\hline Alicate de bico & 1 \\
\hline Alicate de corte & 1 \\
\hline Alicate desencapador & 1 \\
\hline Kit de ferramentas Solar Alicate Crimpador Mc4 & 1 \\
\hline Jogo de chaves allen & 1 \\
\hline Jogo de chaves de fendas e phillips isoladas & 1 \\
\hline Jogo de chaves combinadas & 1 \\
\hline Caixa de ferramentas sanfonada & 1 \\
\hline Fasímetro & 1 \\
\hline
\end{tabular}

\subsection{Conclusão do Curso}

Ao término das 40 horas do curso de aperfeiçoamento em minirredes e sistemas híbridos, com aulas teóricas e práticas, espera-se que os alunos tenham obtido os conceitos básicos relacionados a minirredes e sistemas híbridos e tenham desenvolvido competências básicas em todas as fases de projeto, instalação, operação e manutenção desses tipos de sistemas. 


\section{CONCLUSÃO}

Este trabalho tratou do processo de ampliação da infraestrutura laboratorial de minirredes e sistemas híbridos do LSF. Com isto, foi possível realizar a documentação dos SH do laboratório, a realização do comissionamento e testes operacionais e, com a infraestrutura disponível e a experiência adquirida nesses processos, propor um curso de aperfeiçoamento em minirredes e sistemas híbridos.

Com a revisão do estado da arte foi possível apresentar aspectos técnicos, como formas de acoplamento, interações com a rede elétrica de distribuição, classificação e a distinção entre sistemas híbridos e minirredes, bem como apontar os principais benefícios de sua utilização e os fatores que entravam sua utilização.

Com a elaboração da documentação dos SH do LSF foi possível apresentar os principais componentes dos dois sistemas híbridos pré-existentes e dos dois sistemas instalados no decorrer deste trabalho, além de apresentar a integração dos quatro sistemas híbridos.

O comissionamento foi realizado para assegurar que os componentes, geradores, e todo sistema estavam projetados, instalados, testados, e operando de acordo com os requisitos operacionais. A realização dos testes operacionais da conexão dos sistemas híbridos e com a rede elétrica possibilitou analisar as formas de interação dos sistemas em diferentes níveis de hierarquia, maximizando a utilização das fontes renováveis, diminuindo a dependência da rede elétrica e possibilitando diferentes estratégias operacionais. Com isso, foi possível verificar qual forma de interação apresentava mais benefícios para sistemas isolados e qual apresentava mais benefícios para sistemas conectados à rede elétrica.

Com a ampliação do laboratório de minirredes e sistemas híbridos do LSF, e utilizando a experiência adquirida na revisão do estado da arte, documentação, comissionamento, e realização testes operacionais, foi possível propor um curso que utilizasse a infraestrutura do LSF e que abrangesse conceitos teóricos e práticos, de forma a servir de suporte para mitigar os problemas de escassez de mão de obra qualificada em diversos setores da aplicação de minirredes e sistemas híbridos. 


\section{Sugestão para Trabalhos Futuros}

Utilizando como base a experiência acumulada, propõem-se os seguintes temas para trabalhos futuros:

- Continuação da automatização do sistema de interconexão dos sistemas híbridos;

- Análise econômica da interconexão de sistemas híbridos com a rede elétrica, aplicando postos tarifários horários;

- Expansão das minirredes de distribuição, adicionando uma minirrede em corrente contínua e analisando seu impacto;

- Avaliação mais detalhada das estratégias operacionais propostas. 
Referências Bibliográficas

Acumuladores Moura, Clean Max Fotovoltaica - MFV- 490, manual e certificado de garantia. 2015.

Actpower, Datasheet, VRLA AP12200. 2015.

Alex R. A. Manito, Novaes, K., André R. Mocelin, Teddy A. F. Melendez, João Tavares Pinho, Roberto Zilles.,. Laboratory infraestructure for research and capacity building on isolated and grid-connected smart micro-grids. European PV Solar Energy Conference and Exhibition (PVSEC 2017).

Astro Power, Datasheet - AP-50 Data sheet MKTG-2002-003-020607-10M. s.l.:s.n, 2002.

Atersa, Datasheet - Am 100 - MU-5M. 2012.

Barbosa, C., Montagem, Comissionamento e Telesupervisão de um Sistema Híbrido Solar-Eólico-Diesel para Geração de Eletricidade. Bélem: Trabalho de Conclusão de Curso, UFPA . 2004.

Barbosa, C., Avaliação Tecnológica, Operacional e de Gestão de Sistemas Híbridos para Geração de Eletricidade na Região Amazônica. Belém: Universidade Federal do Pará, Centro Tecnológico, Programa de Pós-Graduação em Engenharia Elétrica. 2006

Barbosa, C.; Pinho, J.; Galhardo, M.; Pereira, E. Sistemas Híbridos de Energia: Aplicações e Estudos no Brasil. In: VI Congresso Brasileiro de Energia Solar - VI CBENS, 2016, Belo Horizonte. VI CBENS, 2016a.

Barbosa, C.; Pinho, J.; Galhardo, M.; Pereira, E. Conceito sobre Sistemas Híbridos de Energia para Produção de Eletricidade. In: VI Congresso Brasileiro de Energia Solar - VI CBENS, 2016, Belo Horizonte. VI CBENS, 2016b.

Barbosa, C Verissimo, P.; Pinho, J.; Correa, J; Galhardo, M. Laboratório de Sistemas Híbridos de Energia e Minirredes (Implementação e Ensaios Operacionais). In: VI Congresso Brasileiro de Energia Solar - VI CBENS, 2016, Belo Horizonte. VI CBENS, 2016c. 
Berry, A.; Platt, G.; Cornforth, D., Minigrids: Analysing the state-of-play Power Electronics Conference (IPEC), 2010 International, pp.710,716, 21- 24 June 2010.

Blasques, L., Otimização de Sistemas Híbridos para a Eletrificação de Minirredes com Fontes Renováveis: Aspectos de Projeto, Operação e Gestão. Bélem: Tese (Engenharia Elétrica) - Universidade Federal do Pará. 2014.

Blasques, L. \& Pinho, J., Metering systems and demand-side management models applied to hybrid renewable energy systems in micro-grid configuration. v.45, p.721 - 729 ed. s.I.:Energy Policy. 2012.

BP Solar, Datasheet - MST45MVHS. s.I.:S.n, 2009.

Dali, M., Belhadj, J. \& Roboam, X., Hybrid solarewind system with battery storage operating in grid-connected and standalone mode: Control and energy management e Experimental investigation. Energy Elsevier, 8 April, pp. 2587 2595. 2010.

Divya, K. C. \& Østergaard, J., Battery energy storage technology for power systems-An overview. Electric Power Systems Research, IEEE, 4 April, pp. 511520. 2009.

Goldemberg, J. \& Lucon, O., Energia, Meio Ambiente e Desenvolvimento. 3aㅗ ed. São Paulo: EDUSP. 2012

Hauschild, L., Avaliação de Estratégias de Operação de Sistemas Híbridos Fotovoltaico-Eólico-Diesel. São Paulo: Dissertação de Mestrado do programa de pós graduação em energia. 2006.

Hauschild, L. \& Zilles, R., Photovoltaic individual solar home systems versus photovoltaic centralized mini-grid systems. 20th ed. München: European Photovoltaic Solar Energy Conference. 2005.

Hauschild, L. \& Zilles, R., Avaliação de Estratégias de Operação de Sistemas Híbridos. Rio de Janeiro: Congresso Brasileiro de Energia. 2006.

IBGE, Censo 2010.[Online] Available at:www.censo2010.ibge.gov.br [Acesso em 3003 2017]. 2010. 
INMETRO - Instituto Nacional de Metrologia, Qualidade e Tecnologia, Datasheet - PBE - Fotovoltaico - Módulo. 2013.

Isofoton, Datasheet - Photovoltaic Module -60-12. 2007.

Jiang, Q., Xue, M. \& Geng, G., Energy Management Systems in GridConnected and Stand-Alone Modes. IEEE, 3 August, pp. 3380-3389. 2013.

Lasseter, B., Microgrids [distributed power generation]. Power Engineering Socity Winter Meeting, Volume 1, pp. 146-149. 2001.

Manwell, J. F., Hybrid Energy Systems. Encyclopedia of Energy, Volume 3. Massachusetts, United States: s.n. 2004.

Marzband, M., Parhizi, N., Savaghebi, M. \& Guerrero, J. M., Distributed Smart Decision-Making for a Multimicrogrid System Based on a Hierarchical Interactive Architecture. IEEE, 2 June, pp. 637 - 648. 2016.

MME, Resenha Energética Brasileira. Brasília : MINISTÉRIO DE MINAS E ENERGIA. 2017.

Mocelin, A. Qualificação profissional e capacitação laboratorial em sistemas fotovoltaicos. São Paulo: Tese (Doutorado em Ciência) - Programa de Pós-Graduação em Energia - Instituto de Energia e Ambiente da Universidade de São Paulo. 2014

Mocelin, A. \& Zilles, R., Unidade de capacitação e difusão de minirrede fotovoltaica-bateria-diesel-rede elétrica. São Paulo: IV Congresso Brasileiro de Energia Solar. 2012.

National Instruments, Specifications NI cRIO-9036. 2015.

Ningbo Komaes Solar Technology Co.,Ltd., Datasheet, Polycrystalline Solar Modules $\mathrm{KM}(\mathrm{P})$ 130,KM(P) 135, KM(P) 140, KM(P) 145, KM(P) 150.. s.l.:s.n, 2009.

Novaes, K., Alex R. A. Manito, André R. Mocelin, Teddy A. F. Melendez, João Tavares Pinho, Roberto Zilles., Geração Distribuida com Armazenamento 
Conectada à Rede Elétrica. VII Congresso Brasileiro de Energia Solar, 17 a 20 Abril, 2018a.

Novaes, K; Manito, A; Mocelin; A; Melendez; T; Zilles, R; Pinho, J. Descrição da Minirrede com Sistemas Híbridos do LSF, relatório técnico. 2018b.

Palizban, O., Kauhaniemi, K. \& Guerrero, J. M., Microgrids in active network management-Partl:Hierarchical control, energy storage, virtual power plants, and market participation. Renewable and Sustainable Energy Reviews, 4 January, p. 428 - 439, 2014.

Peças Lopes, J. A.; Hatziargyriou, N.; Mutale, J.; Djapic, P.; Jenkins, N., Integrating distributed generation into electric power systems: A review of drivers, challenges and opportunities. Electric Power Systems Research, IEEE, 9 July, pp. 1189-1203. 2007.

Peças Lopes, J. A., Moreira, C. L. \& Madureira, A. G., Defining Control Strategies for MicroGrids Islanded Operation. Electric Power Systems Research, IEEE, 2 May, pp. 916 - 924, 2006.

Phocos AG, Datasheet_MPS series_1/1; MPS series (45 - 80 A). s.I.:s.n., 2015.

Pinho, J; Barbosa, C; Pereira, E; Souza, H; Blasques, L; Galhardo, M; Macêdo, W., Manual de Implantação de Sistemas Híbridos Fotovoltaico-EólicoDiesel para Geração de Energia Elétrica. Bélem: Ministério de Minas e Energia. 2008a.

Pinho, J.; Barbosa, C.; Barreto, Eduardo., Pereira, E; Souza, H; Blasques, L; Galhardo, M; Macêdo, W.,. Sistemas Híbridos: soluções energeticas para a Amazônia. 1ํㅡㄹ Edição ed. Bélem: Ministério de Minas e Energia. 2008b.

Pinho, J; \& Galdino, M.(Org) Manual de Engenharia para Sistemas Fotovoltaicos. Rio de Janeiro: CEPEL-CRESESB. 2014. 
Rahimi, F. \& Ipakchi, A., Demand Response as a Market Resource Under the Smart Grid Paradigm. IEEE TRANSACTIONS ON SMART GRID, 1 JUNE , pp. 82-88. 2010.

Ramos, V., 2014. Laboratório Virtual de Minirredes de Energia Elétrica com Geração Distribuída. Bélem: Trabalho de Conclusão de Curso. (Graduação em Engenharia Elétrica) - Universidade Federal do Pará.

Schneider Electric, Conext ${ }^{\mathrm{TM}} \mathbf{X W}$ Inversor/Carregador: Guia do proprietário 865-5548-01 - Conext XW+5548 NA. s.I.:s.n, 2014.

Schneider Electric, Conext XW Power Distribution Panels: Technical data DS20150605_ConextXW+PDP. s.I.:s.n, 2015.

Schneider Electric, Controlador de carregamento solar Conext ${ }^{\mathrm{TM}}$ MPPT 80 600: Guia do proprietário 975-560-08-01 Revisão. 2015.

Silva, C. C. d., Geração Distribuida com Sistemas Fotovoltaicos e a Qualificação Profissional: uma Proposta de Curso Pós-Técnico e Potencial de Aplicação nas Etecs. São Paulo: Dissertação de Mestrado apresentada ao Programa de Pós-Graduação em Energia do Instituto de Energia e Ambiente da Universidade de São Paulo para a obtenção do título de Mestre em Ciências. 2017.

Sinha, Arup; Basu, A. K.; Lahiri, R. N.; Chowdhury, S.; Chowdhury, S. P.; Crossley, Peter A.,. Setting of Market Clearing Price (MCP) in Microgrid Power Scenario. Power and energy Society General Meeting-Conversion and Delivery of Electrical Energy in the 21 st Century,IEEE, August, pp. 1 - 8. 2008.

SMA America, Sunny Boy 1100 E: Technical Description SB1100E11:EE5000, Issue 1.0. 2004.

SMA America, Sunny Boy 1200: Installation Guide SB11_12_17-IEN100132 IMEN-SB11_17 Version 3.2. 2010.

SMA America, Sunny Island 5048: Technical Description SI5048-TBTEN110340, I5048-TB-TEN110340, TBE-SI5048, Version 4.0. 2011.

SMA Australia, Multicluster Boxes for Sunny Island 5048: Datasheet, Clustbox-Dau102020W. 2010. 
Sooriyaarachchi, M.; Tsai, I El Khatib, S; Farid, M.; Mezher, T., Job creation potentials and skill requirements in, PV, CSP, wind, water-to-energy and energy efficiency value chains. Renewable and Sustainable Energy Reviews, Volume 52, Pages 653-668, December 2015.

Strauss, A. E., Ac coupled pv hybrid systems and micro grids - state of the art and future trends. 3rd World Conference on Photovoltaic Energy Conversion, 1811.2003.

Studer Innotec SA, Remote control and programming unit RCC-02 and RCC-03 for the Xtender: User manual V4.5.1. Switzerland: s.n. 2016.

Studer Innotec SA, Xtender, Unit combining inverter, battery charger and transfer system: User manual V4.6.0. Switzerland: s.n. 2016.

Studer Innotec, Manual montaje para X-Connect. Sion: s.n. 2008.

Vasiljevska, J., Peças Lopes, J. A. \& Matos, M. A., Evaluating the impacts of the multi-microgrid concept using multicriteria decision aid. Electric Power Systems Research, p. 44-51. 2012.

Veríssimo, P., Laboratório de sistemas híbridos e minirredes: processo de montagem, instalação, comissionamento e ensaios operacionais. Bélem: Curso (Engenharia Elétrica) - Universidade Federal do Pará. 2014.

Tsoutsos, T; Tournaki, S; Gkouskos, Z; Masson, G; Holden, J; Huidobro, A; Stoykova, E; Rata, C; Bacan, A; Maxoulis, C; Charalambous, A., Training and certification of PV installers in Europe: A transnational need for PV industry's competitive growth. Energy Policy, April 2013. Pages 593-601.

Technology Internacional, Xantrex C40, 970-0026-01-02 Rev A - C Series Datasheet.indd. 2001.

Xantrex Technology Internacional, Trace C40, Manual de usuário da serie C, Xantrex Technology Inc. 2002. 


\section{Trabalhos Publicados}

Manito, A; Novaes, K; Mocelin, A; Melendez, T; Pinho, J; Zilles, R. Laboratory Infrastructure for Research and Capacity Building on Isolated and Grid-Connected Smart Micro-Grids. European Photovoltaic Solar Energy Conference and Exhibition 2017.

Manito, A; Novaes, K; Mocelin, A; Melendez, T; Pinho, J; Zilles, R. Integration of autonomous renewable energy generation systems with different topologies in a smart grid cluster to enhance performace in usual operational situations. Solar World Congress 2017.

Novaes, K; Manito, A; Mocelin, A; Melendez, T; Pinho, J; Zilles, R. Geração distribuída com armazenamento conectada à rede elétrica. VII Congresso Brasileiro de Energia Solar 2018.

Valer, L.R; Novaes, K; Melendez, T; Mocelin, A; Fedrizzi, M.C; Zilles, R; Martins, M. Processo de implantação de sistemas fotovoltaicos para uso comunitário no parque indígena do Xingu. VII Congresso Brasileiro de Energia Solar 2018.

Novaes, K; Valer, L.R; Melendez, T; Mocelin, A;. Zilles, R; Martins, M. Análise da demanda de energia elétrica no Polo Indígena de Diauarum. Resumo aprovado no Congresso Brasileiro de Planejamento Energético (CBPE-2018).

Novaes, K; Manito, A; Almeida, M; Figueiredo, G; Mocelin, A; Melendez, T; Pinho, J; Zilles, R. Evaluation and Comparison of the Operational Aspects of Two Topologies for the Integration of Several Hybrid Renewable Energy Systems for Grid-Connected and Stand-Alone Applications. Abstract aceito no European PV Solar Energy Conference and Exhibition (PVSEC 2018).

Manito, A; Novaes, K; Almeida, M; Figueiredo, G; T; Pinho, J; Zilles, R. PV Battery Systems Sizing to Account for the Provision of Ancillary Services under Different Scenarios for Energy Policies and Tariffs. Abstract aceito no European PV Solar Energy Conference and Exhibition (PVSEC 2018). 